\title{
THERMO-PHYSICAL CHARACTERISTICS OF BUILDING \\ INTEGRATED PHASE CHANGE MATERIALS (PCM) AND \\ THEIR APPLICABILITY TO ENERGY EFFICIENT HOMES
}

\author{
by \\ Omar Siddiqui \\ B.Eng. (Mechanical Engineering) \\ Ryerson University, Toronto, 2007
}

\author{
A thesis \\ presented to Ryerson University \\ in partial fulfillment of the \\ requirements for the degree of \\ Master of Applied Science \\ in the Program of \\ Mechanical Engineering
}

Toronto, Ontario, Canada, 2009

(C) Omar Siddiqui, 2009 


\section{AUTHOR'S DECLARATION}

I hereby declare that I am the sole author of this thesis.

I authorize Ryerson University to lend this thesis to other institutions or individuals for the purpose of scholarly research.

I further authorize Ryerson University to reproduce this thesis by photocopying or by other means, at the request of other institutions or individuals for the purpose of scholarly research. 


\section{BORROWER'S PAGE}

Ryerson University requires the signatures of all persons using or photocopying this thesis.

Please sign below, and give address and date. 


\title{
THERMO-PHYSICAL CHARACTERISTICS OF BUILDING INTEGRATED PHASE CHANGE MATERIALS (PCM) AND THEIR APPLICABILITY TO ENERGY EFFICIENT HOMES.
}

\author{
Omar Siddiqui \\ Masters of Applied Science \\ Department of Mechanical \& Industrial Engineering \\ Ryerson University, Toronto, Ontario, Canada, 2009
}

\begin{abstract}
The applicability of utilizing a variety of thermal mass including phase change materials with commonly used building materials is investigated through the use of simulations and physical testing. The thermal performance and occupant comfort potential of a novel solid-solid phase change material, known as Dal HSM, is compared and contrasted to commonly available forms of thermal mass. Detailed experimentation is conducted to successfully integrate Dal HSM with gypsum and concrete. The measurement of physical characteristics such as compressive strength and modulus of rupture is conducted to ensure that the PCM-composite compound retains the structural integrity to be utilized in a typical building.

The use of thermal mass in the Toronto Net Zero house was found to contribute to energy savings of $10-15 \%$ when different types of thermal mass were used. The comfort level of the indoor occupants was also found to increase. The performance of Dal HSM was found to be comparable to a commercially available PCM known as Micronal in the heating mode. The cooling mode revealed that Dal HSM provided slightly lower energy savings when compared to Micronal due to a lower phase transition temperature and latent heat.

The performance of physical tests revealed a decrease in the compressive strength as the concentration of Dal HSM was increased in the PCM-gypsum specimens. Tests were also performed to analyze the impact of increasing the PCM concentration on the flexural strength of PCM-gypsum composite.
\end{abstract}




\section{ACKNOWLEDGEMENTS}

I would like to express my thanks to Dr. Alan Fung for his guidance and invaluable advice throughout this project. Without his direction and assistance, it would have been impossible to finish this thesis successfully.

I would also like to thank Dr. Mary Anne White from Dalhousie University for all the assistance that was received during the collaboration with her. Her ideas were instrumental in the timely completion of this project. Special thanks also go to Mr. Dahai Zhang, for his participation and help in the various aspects of this project.

I would also like to thank the Solar Buildings Research Network under the Strategic Network Grants Program of the Natural Sciences and Engineering Research Council of Canada for funding this project. 


\section{TABLE OF CONTENTS}

AUTHOR'S DECLARATION ............................................................................... ii

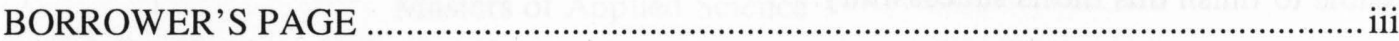

ABSTRACT

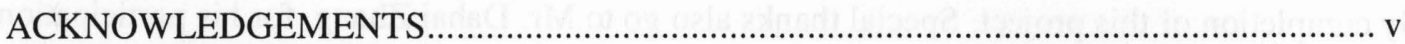

TABLE OF CONTENTS ........................................................................................... vi

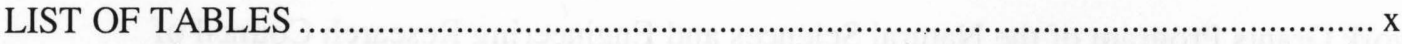

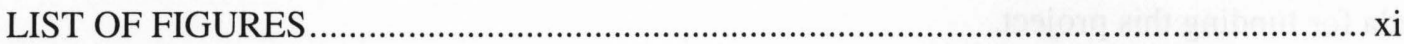

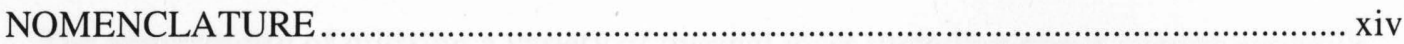

\section{CHAPTER 1: LITERATURE REVIEW}

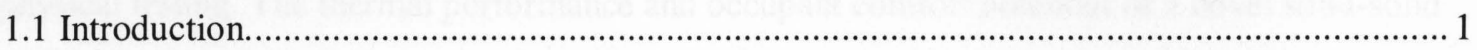

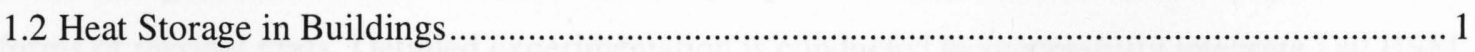

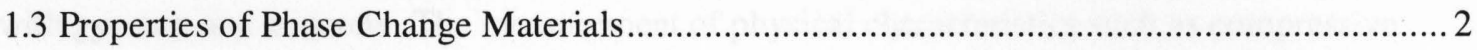

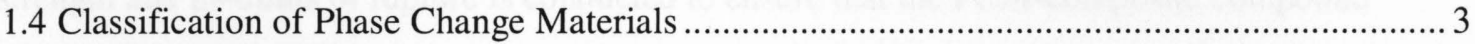

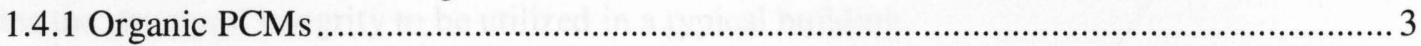

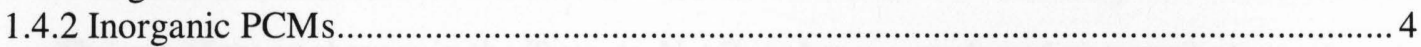

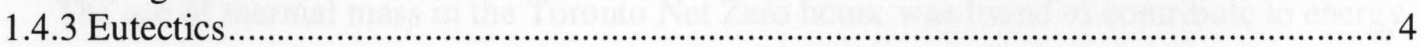

1.5 Types of Phase Change Materials ........................................................................................... 5

1.5.1 Solid-Solid Phase Change Materials ...................................................................... 5

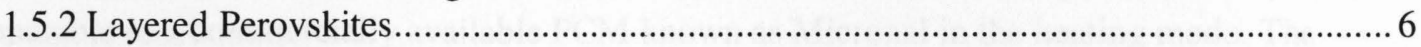

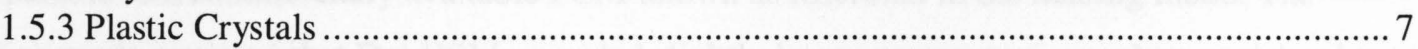

1.6 Solid-Liquid Phase Change Materials ......................................................................... 7

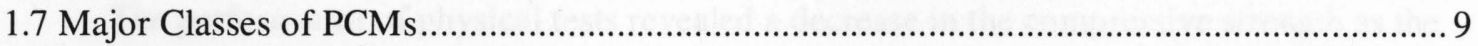

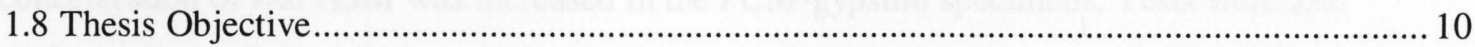

CHAPTER 2: NUMERICAL AND ANALYTICAL TREATMENT OF PHASE CHANGE HEAT TRANSFER

2.1 Introduction. 
2.3 Heat Transfer Mechanism ............................................................................................ 14

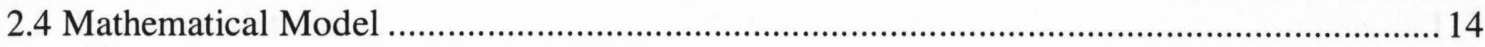

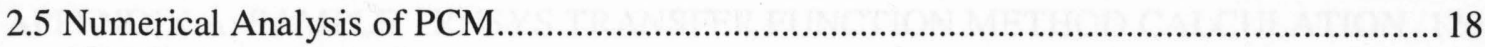

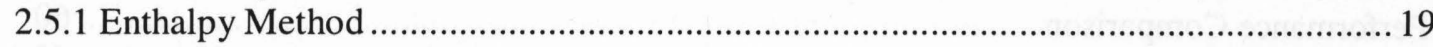

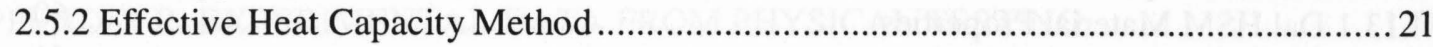

\section{CHAPTER 3: APPLICATION OF PHASE CHANGE MATERIAL TO BUILDING MATERIALS}

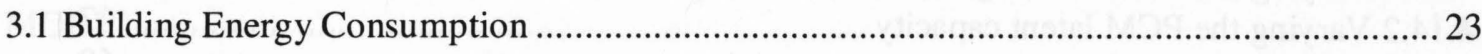

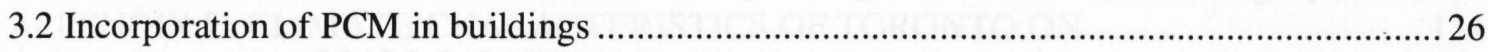

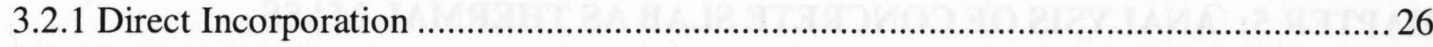

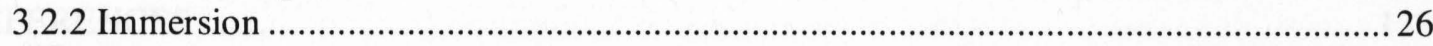

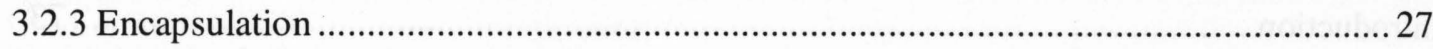

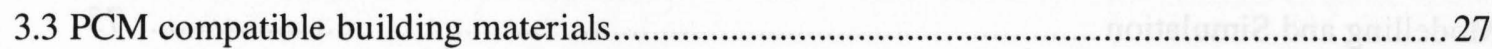

3.3.1 PCM integrated gypsum and manufacturing methods .............................................. 27

3.3.2 Experimental simulation of PCM/Gypsum wall board .......................................... 30

3.3.3 Numerical Analysis of Composite of PCM/Gypsum .............................................. 31

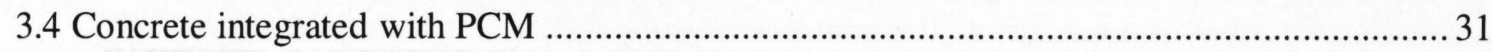

CHAPTER 4: ENERGY MODELLING AND ANALYSIS OF PCM

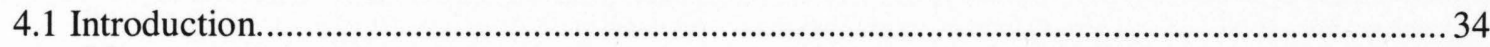

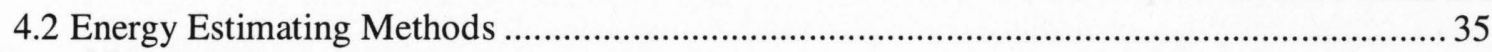

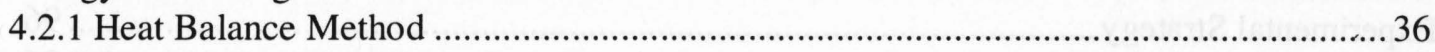

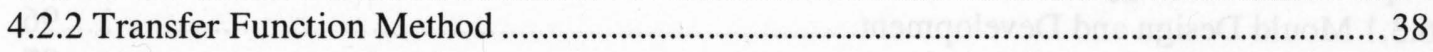

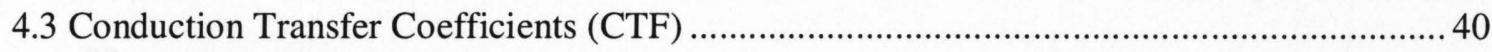

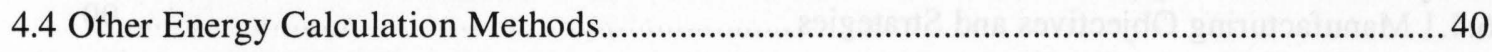

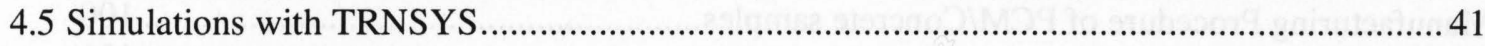

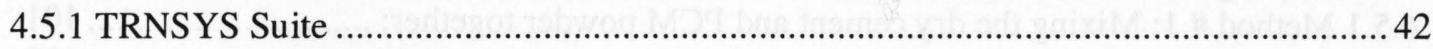

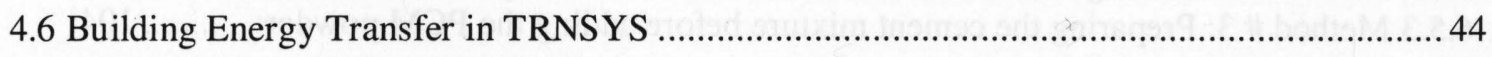

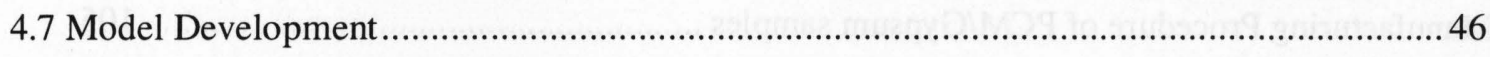

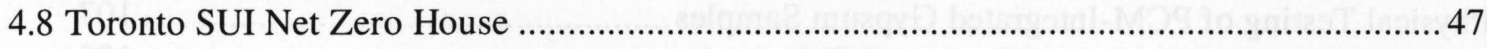

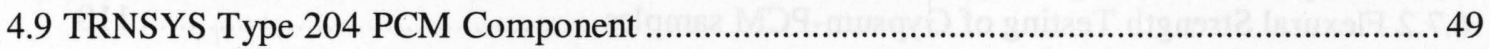


4.10 Simulation Parameters............................................................................................... 51

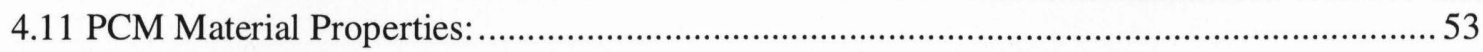

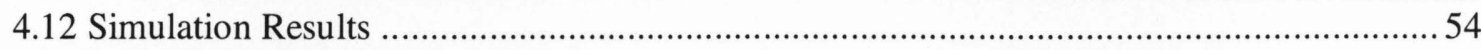

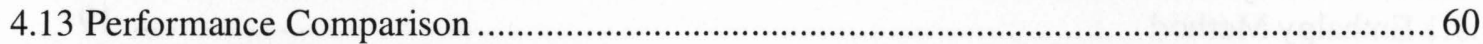

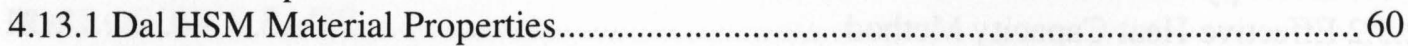

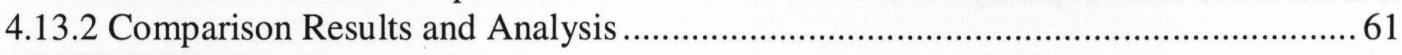

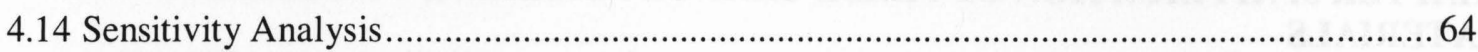

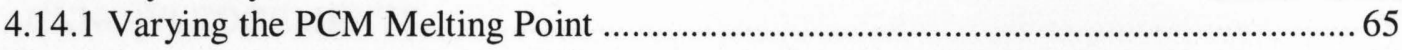

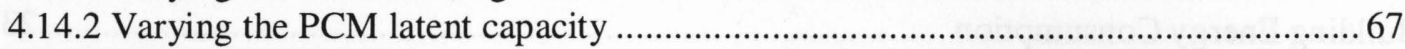

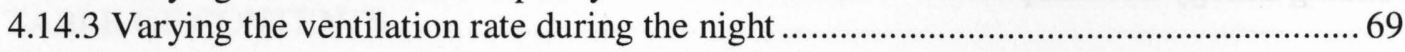

\section{CHAPTER 5: ANALYSIS OF CONCRETE SLAB AS THERMAL MASS}

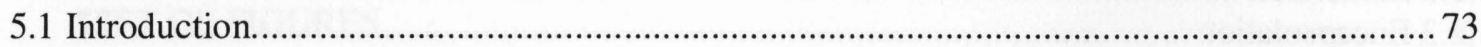

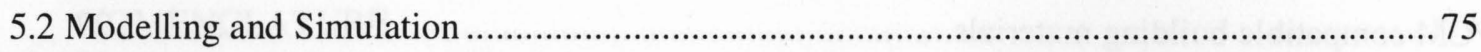

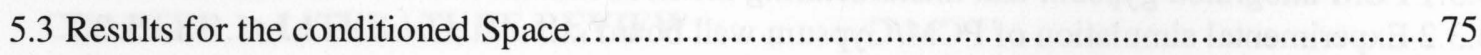

5.4 Results for the Un-Conditioned Space ...................................................................... 84

\section{CHAPTER 6: SAMPLE MANUFACTURING METHODS AND PHYSICAL TESTING}

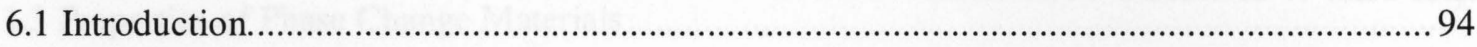

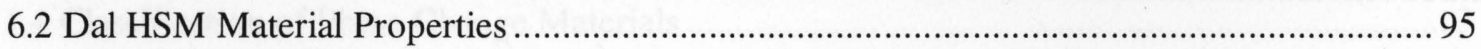

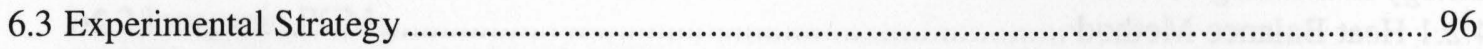

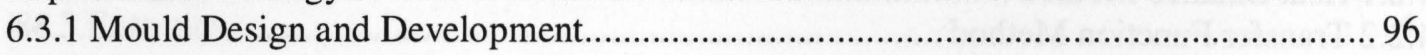

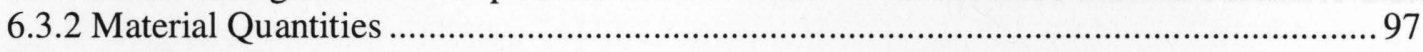

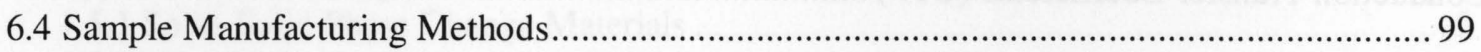

6.4.1 Manufacturing Objectives and Strategies ............................................................ 99

6.5 Manufacturing Procedure of PCM/Concrete samples......................................................... 100

6.5.1 Method \# 1: Mixing the dry cement and PCM powder together: ............................. 101

6.5.2 Method \# 2: Mixing the PCM with water before combining with cement:............... 102

6.5.3 Method \# 3: Preparing the cement mixture before adding the PCM powder: ............ 104

6.6 Manufacturing Procedure of PCM/Gypsum samples ................................................. 105

6.7 Physical Testing of PCM-Integrated Gypsum Samples ..................................................... 107

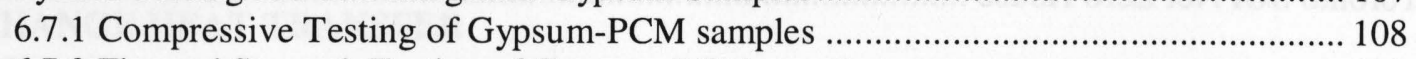

6.7.2 Flexural Strength Testing of Gypsum-PCM samples........................................... 110 


\section{CHAPTER 7: CONCLUSIONS AND RECOMMENDATIONS}

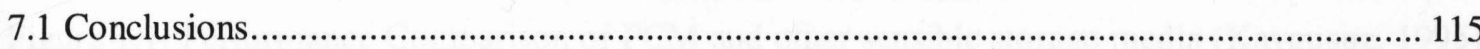

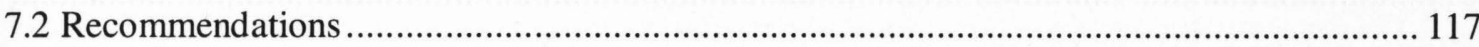
APPENDIX A: SAMPLE TRNSYS TRANSFER FUNCTION METHOD CALCULATION. 120 APPENDIX B: EXPERIMENTAL DATA FROM PHYSICAL TESTING ........................... 123 APPENDIX C: COMPRESSIVE TESTING MACHINE PROCEDURE................................ 125 APPENDIX D: INPUT CHARACTERISTICS OF THE SUI TORONTO NET ZERO ENERGY MODEL

APPENDIX E: CLIMATE CHARACTERISTICS OF TORONTO,ON 134 REFERENCES 138 


\section{LIST OF TABLES}

Table 1.1: Major Classes of Phase Change Materials (Wirtz et al., 1999) .................................. 9

Table 3.1: Time of Use Price in Ontario as of Nov 2008 (Ontario Energy Board, 2008) ............ 24

Table 4.1: Commonly used energy estimating methods (ASHARE Fundamentals Handbook, 2005).

Table 4.2: Wall layers used in the Net Zero Energy House ............................................... 48

Table 4.3: Material Properties of Micronal DS 5001(BASF, 2008) ......................................... 54

Table 4.4: Selected Material properties of the Dal HSM ....................................................... 61

Table 4.5: Annual heating and cooling loads for the Toronto SUI Net Zero Energy house using different types of thermal mass

Table 4.6: Peak heating and cooling loads for the Toronto SUI Net Zero Energy house using different types of thermal mass

Table 4.7: Total number of hours during the winter season, the indoor temperature exceeds the heating set point, $21^{\circ} \mathrm{C}$

Table 4.8: Total number of hours during the winter season, the indoor temperature exceeds the heating set point, $25^{\circ} \mathrm{C}$

Table 5.1: Yearly heating and cooling loads as a result of varying thermal mass.

Table 5.2: Total number of hours during the winter season, the indoor temperature overheats to the cooling set point, $25^{\circ} \mathrm{C}$

Table 5.3: Total number of hours during the winter season, the indoor temperature exceeds the heating set point, $21^{\circ} \mathrm{C}$.

Table 6.1: Selected Material properties of the Dal HSM .................................................. 96

Table 6.2: Relative materials quantities for the PCM-gypsum combination ........................... 98

Table 6.3: Relative materials quantities for the PCM-cement combination ............................. 98

Table 6.4: Different PCM-Cement composite manufacturing methods .................................. 105 


\section{LIST OF FIGURES}

Figure 1.1: Performance Comparison of PCM and other sensible storage media (Kaygusuz, 1995)

Figure 1.2: Classification of Heat Storage Materials (Khudhair and Farid, 2004) .....................5

Figure 1.3: Heating curve of a typical solid-liquid PCM (Abhat, 1981) .................................. 8

Figure 2.1: Differential Scanning Curve showing the range of melting and solidification of

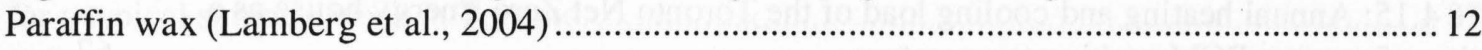

Figure 2.2: Physical model of a PCM undergoing close contact melting (Groulx et al., 2006) ... 15

Figure 2.3: Temperature distribution in the melted liquid layer (Groulx et al., 2006) 18

Figure 3.1: Solar radiation in Toronto on a typical summer day (TRNSYS Simulation performed).

Figure 3.2: Comparison of PCM wall with conventional wall board (Schossig et al., 2005)....... 30

Figure 4.1: Graphical representation of the energy balance at the interior and exterior surfaces

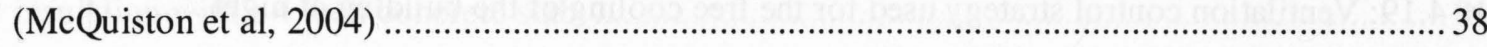

Figure 4.2: TRNSYS Simulation Studio (TRNSYS, 2006) .............................................. 43

Figure 4.3: Graphical representation of TRNBuild (TRNSYS, 2006). ................................. 44

Figure 4.4: Zone-Air Heat balance in TRNBUILD (TRNSYS, 2006).................................. 45

Figure 4.5: 3-D computer representation of one of the three identical Toronto Net Zero Energy

Homes (Sustainable Urbanism Initiative Toronto, http://www.sui-toronto.com, 2008) ............. 48

Figure 4.6: TRNSYS Model of the Toronto Net Zero Energy House …................................. 52

Figure 4.7: Temperature profile of the 3rd floor of the Net Zero Energy house on a typical winter day with varying PCM concentration.

Figure 4.8: Temperatures profile of the 3rd floor of the Net Zero Energy house on a typical summer day when PCM and concrete slab is used

Figure 4.9: Temperatures profile of the 3rd floor of the Net Zero Energy house on a typical summer day when $5 \% \mathrm{PCM}$ is contrasted with the 2 inch concrete slab....

Figure 4.10: Yearly heating/cooling load requirements of the Net Zero Energy house for a variety of thermal mass used.

Figure 4.11: Yearly temperature profile of the 3rd floor of the Net Zero energy house, illustrating the impact of using PCM. .59 
Figure 4.12: Yearly Heating/Cooling Load of the Net Zero Energy House as the concentration of PCM is varied.

Figure 4.13: Temperature profile of the $3^{\text {rd }}$ floor of the Toronto Net Zero Energy house for a typical winter week

Figure 4.14: Temperature profile of the $3^{\text {rd }}$ floor of the Toronto Net Zero Energy house for a typical summer week

Figure 4.15: Annual heating and cooling load of the Toronto Net Zero Energy house as a function of varying PCM melting temperature.

Figure 4.16: Peak heating and cooling load of the Toronto Net Zero Energy house as a function of varying PCM melting temperature

Figure 4.17: Annual heating and cooling load of the Toronto Net Zero Energy house as a function of varying PCM latent heat capacity.

Figure 4.18: Peak heating and cooling load of the Toronto Net Zero Energy house as a function of varying PCM latent heat capacity

Figure 4.19: Ventilation control strategy used for the free cooling of the building at night

Figure 4.20: Temperature profile of the $3^{\text {rd }}$ floor of the Toronto Net Zero Energy house during a typical summer week showing the effect of increasing the ventilation rate at night.....

Figure 4.21: Monthly cooling load comparison of the $3^{\text {rd }}$ floor of the Toronto Net Zero Energy house as a result of increasing the ventilation at night

Figure 5.1: Temperature profile of the Mezzanine floor of the Net Zero Energy house during a typical winter week with varying thermal mass.

Figure 5.2: Temperature profile of the 3rd floor of the Net Zero Energy house during a typical winter week with varying thermal mass.

Figure 5.3: Temperature profile of the Mezzanine floor of the Net Zero Energy house during a typical summer week with varying thermal mass.

Figure 5.4: Temperature profile of the 3rd floor of the Net Zero Energy house during a typical summer week with varying thermal mass.

Figure 5.5: Temperature profile comparing the thermal mass effect of 20\% Micronal PCM and 4Inch Concrete Slab for the 3rd floor of the Net Zero Energy house during a typical winter week.

Figure 5.6: Comparison of the impact on the heating and cooling loads as insulation levels are varied when thermal mass is used versus no thermal mass.

Figure 5.7: Yearly temperature profile of the Mezzanine Floor of the house comparing the impact of using a 4 -inch thick concrete slab. 
Figure 5.8: Temperature profile of the 3rd Floor of the house for a 48-hour duration for the winter season, comparing the impact of using a 4-inch thick concrete slab.

Figure 5.9: Yearly unconditioned temperature profile of the 3rd floor of the Net Zero Energy House.

Figure 5.10: Unconditioned Temperature profile of the 3rd floor of the Net Zero Energy House for a typical winter week in Toronto.

Figure 5.11: Unconditioned Temperature profile of the 3rd floor of the Net Zero Energy Housefor a typical summer week in Toronto.

Figure 5.12: Possible Locations of thermal mass within the building envelope (Al-Homoud, 2005)

Figure 5.13: Thermal mass placed at different locations within the building envelope for a typical winter week in Toronto.

Figure 5.14: Thermal mass placed at different locations within the building envelope for a typical summer week in Toronto.

Figure 5.15: Yearly temperature profile showing the impact of replacing the Polyisocyanurate insulation with a 4 inch concrete slab.

Figure 5.16: Effect of varying the thermal mass of the Net Zero Energy house for a typical winter week in Toronto.

Figure 5.17: Effect of varying the thermal mass of the Net Zero Energy house for a typical summer week in Toronto.

Figure 5.18: Peak heating and cooling load of the Net Zero Energy house using a variety of thermal mass.

Figure 6.1: Dal HSM in powdered form

Figure 6.2: A 4 x 4 inch plastic mould for casting samples.

Figure 6.3: Cast PCM-Gypsum sample removed from the mould

Figure 6.4: Compressive strength testing apparatus at Ryerson University

Figure 6.5: Compressive strength of PCM-gypsum composite specimens as a result of varying the PCM concentration.

Figure 6.6: Typical 3-point bending test apparatus (ASTM, 2008)

Figure 6.7: Modulus of rupture of PCM-gypsum composite specimens as a function of PCM concentration 


\section{NOMENCLATURE}

\section{Dimensional variables}

$\mathrm{A}_{\mathrm{o}}$

$a$

$b$

B

C

$d$

E

F

$F_{m}$

$F_{a p p}$

$h_{c}$

H

$\mathrm{H}_{\text {tot }}$

k

$L$

$L_{H}$

$m$

M

$n$

$P$

$q^{\prime \prime}$

$\dot{Q}$

$\mathrm{R}$

$R_{h}$

$S$

$T$

$t$

$u$

v

w

$x$

$X$

$Y$

Z

$u$

$v$

V original area of the specimen

distance between the line of fracture and support

width of the specimen

molten height of the block

heat capacity

depth of the specimen

enthalpy

forces, other than pressure

flux history coefficients

applied axial force

heat transfer coefficient

initial height of the block

total enthalpy

thermal conductivity

length of the block

latent heat of fusion

time index variable

mass

summation index

pressure

heat flux

rate of heat flow

modulus of rupture

heating rate

solid-liquid phase change interface

temperature

time

$x$ velocity component

$y$ velocity component

$z$ velocity component

slab thickness

exterior $\mathrm{CTF}$ value

cross CTF value

interior $\mathrm{CTF}$ value

velocity of liquid phase

volume of the solid portion of the PCM

melting speed $\left[\mathrm{m}^{2}\right]$

[m]

[m]

[m]

$\left[\mathrm{J} \mathrm{kg}^{-1} \mathrm{~K}^{-1}\right]$

[m]

[J]

$[\mathrm{N}]$

$[\mathrm{N}]$

$\left[\mathrm{Jm}^{-2} \mathrm{~s}^{-1} \mathrm{~K}^{-1}\right.$ ]

[m]

[J]

$\left[\mathrm{Wm}^{-1} \mathrm{~K}^{-1}\right]$

[m]

$\left[\mathrm{J} \mathrm{kg}^{-1}\right]$

[kg]

[Pa]

$\left[\mathrm{Js}^{-1} \mathrm{~m}^{-2}\right]$

$\left[\mathrm{Js}^{-1}\right]$

$\left[\mathrm{Nm}^{-2}\right]$

$\left[\mathrm{Js}^{-1} \mathrm{~kg}^{-1}\right]$

$\left[\mathrm{m}^{2}\right]$

[K]

[s]

$\left[\mathrm{ms}^{-1}\right]$

$\left[\mathrm{ms}^{-1}\right]$

$\left[\mathrm{ms}^{-1}\right]$

[m]

$\left[\mathrm{ms}^{-1}\right]$

$\left[\mathrm{m}^{3}\right]$

$\left[\mathrm{ms}^{-1}\right]$

\section{Greek symbols}

$\alpha$

$\delta$

$\Delta T$

$\Phi$

$\mu$

$v$ thermal diffusivity of melt

molten layer thickness

temperature difference $\left(T_{\mathrm{p}}-T_{\mathrm{m}}\right)$

viscous dissipation

dynamic viscosity

kinematic viscosity $\left[\mathrm{m}^{2} \mathrm{~s}^{-1}\right]$

[m]

[K]

$\left[\mathrm{m}^{2} \mathrm{~s}^{-2}\right]$

$\left[\mathrm{Nsm}^{-2}\right.$ ]

$\left[\mathrm{m}^{2} \mathrm{~s}^{-1}\right]$ 


\begin{tabular}{|c|c|}
\hline $\begin{array}{l}\text { density } \\
\text { surface tension }\end{array}$ & $\begin{array}{l}{\left[\mathrm{kgm}^{-3}\right]} \\
{\left[\mathrm{Nm}^{-1}\right]}\end{array}$ \\
\hline \multicolumn{2}{|l|}{ Subscripts } \\
\hline app & applied(force) \\
\hline$A$ & starting \\
\hline$B$ & ending \\
\hline$e$ & end of phase transition \\
\hline conduction, ext,j, $t$ & external conduction heat flux for $\mathrm{j}$ surface at time $\mathrm{t}$ \\
\hline cplg, $i$ & gains due to airflow from other zones \\
\hline solar, ext,j,t & external solar radiation for $\mathrm{j}$ surface at time $\mathrm{t}$ \\
\hline convection, ext,j,t & external convection heat flux for $\mathrm{j}$ surface at time $\mathrm{t}$ \\
\hline radiation, $j, t$ & external thermal radiation flux for $\mathrm{j}$ surface at time $\mathrm{t}$ \\
\hline conduction, in, $j, t$ & internal conduction heat flux for $\mathrm{j}$ surface at time $\mathrm{t}$ \\
\hline solar, in, j,t & internal solar radiation for $\mathrm{j}$ surface at time $\mathrm{t}$ \\
\hline convection, in, $j, t$ & internal convection heat flux for $\mathrm{j}$ surface at time $\mathrm{t}$ \\
\hline radiation,in, j,t & internal thermal radiation flux for $\mathrm{j}$ surface at time $\mathrm{t}$ \\
\hline$e, t-n \delta$ & sol-air temperature at time $\mathrm{t}$ \\
\hline eff & effective \\
\hline$f$ & liquid \\
\hline fs & solid liquid interface \\
\hline$g, c, i$ & gains from people, equipment and lighting \\
\hline$H, v$ & heat of fusion from the liquid to gas phase \\
\hline in & inside surface subscript \\
\hline infiltration, $t$ & infiltration at time $\mathrm{t}$ \\
\hline inf & infiltration \\
\hline inf,I & total infiltration gains \\
\hline internal, conv, $t$ & convective portion of internal heat gains \\
\hline in,t & internal at time $\mathrm{t}$ \\
\hline$j$ & nodal point \\
\hline$k, m$ & order of CTF at time index variable \\
\hline$m$ & melting phase \\
\hline$n$ & outward unit normal \\
\hline$o$ & onset of phase transition \\
\hline$o, t-m+1$ & outside surface at time $t$ \\
\hline$p$ & plate \\
\hline$p, l$ & specific heat in liquid phase \\
\hline $\mathrm{r}, \mathrm{c}$ & constant room temperature \\
\hline$s$ & solid \\
\hline system, $t$ & heat gain due to heating/cooling system \\
\hline$s c$ & sub cooled \\
\hline surf, $i$ & all inside surfaces \\
\hline vent & ventilation \\
\hline Definitions of non & \\
\hline $\mathrm{Pr} \quad$ Prandtl number & $v / \alpha$ \\
\hline Stefan number & $C \Delta T / h_{\mathrm{fs}}$ \\
\hline
\end{tabular}




\section{CHAPTER 1: LITERATURE REVIEW}

\subsection{Introduction}

The rising price of fossil fuel energy along with a concern for the environment over the last few years has generated significant interest in the use of renewable energy sources. Previously many of these newer technologies could not compete on an economic basis with the conventional sources of energy such as coal fired power plants and natural gas. Technologies such as solar PV and wind for the purpose of generating electricity have only become competitive recently with the dramatic rise in the price of electricity and oil (Sharma et al., 2009).

Solar energy is versatile, in that it could be used for a variety of purposes; whether it is the generation of electricity through the use of photovoltaic solar panels or the utilization of solar collectors for the heating of water. Passive storage of solar energy has become popular as a means to utilize the excess heat available in form of solar radiation during the day and utilizing it during the night time and other periods. Traditionally there are two different methods in which heat can be stored; sensible and latent heat. Sensible heat involves the storing of heat by raising the temperature of the material such as water or rock (Hasnain, 1998). A much more innovative technology is the use of latent energy to store heat. This involves a change in phase that a material experiences when sufficient heat is added to reach the melting point. The melting of ice at $0^{\circ} \mathrm{C}$ to liquid water also at $0^{\circ} \mathrm{C}$ is one example where sufficient quantity of heat is added to the ice to effect a change in phase from solid to liquid. One of the advantages of latent heat storage is the relatively smaller temperature fluctuation and lower weight per unit of storage capacity (Hasnain, 1998).

\subsection{Heat Storage in Buildings}

One of the applications of heat storage that has gained prominence is the latent storage of heat in building materials such as concrete and gypsum. Materials that can change phase such as solid to liquid, upon application of heat are referred to as phase change materials or PCMs. Considerable research has been conducted investigating the incorporation of phase change materials into building fabrics. In terms of using PCMs for building applications, most of the 
currently available materials have melting temperatures ranging between $20^{\circ} \mathrm{C}$ and $32^{\circ} \mathrm{C}$ (Tyagi and Buddhi, 2005).

\subsection{Properties of Phase Change Materials}

Phase change material can be defined as any material which possesses a high latent heat of fusion and is capable of releasing/storing a large amount of energy upon a change in physical phase. Normally materials can undergo three different types of changes in phase; Solid-Liquid, Liquid-Gas and Solid-Solid. Extensive research has been conducted on the use of Solid-Liquid PCM for a variety of applications. Some of the examples of Solid-Liquid PCM include paraffin wax which melts to a liquid state at a temperature range of $20^{\circ} \mathrm{C}-22^{\circ} \mathrm{C}$ (Tyagi and Buddhi, 2005).

As research continues, Solid-Solid PCM have generated considerable interest mainly due to the ease with which they can be integrated into building materials without any of the difficulties of "wetness" encountered with Solid-Liquid PCM upon melting.

In order for a material to be classified as a PCM, it must possess certain characteristics which are desirable such as thermal, physical, chemical and kinetic. The most critical property as mentioned previously is the phase change temperature, which should not exceed $32^{\circ} \mathrm{C}$, in order to ensure the comfort of the occupant. High Latent heat of fusion per unit volume and high sensible heat storage are also desirable since they allow a large amount of energy to be stored in a small volume, which is particularly appealing for thermal energy storage in buildings where space is always a constraint (Tyagi and Buddhi, 2005).

Other properties that are useful are high thermal conductivity of the solid and liquid phases, relatively small change in volume upon phase change and a constant storage capacity of the material with each cycle of phase change.

The material should also possess reasonable physical and chemical properties. These include a high nucleation rate to prevent super cooling, reversible phase change cycle ensuring that there is no degradation in the properties of the PCM after a large number of cycles and very little reactivity with the materials being integrated with. For the purposes of safety it should also be non-toxic, non-corrosive and non-flammable (Tyagi and Buddhi, 2005). Figure 1.1 compares the energy storage capacity of a theoretical phase change material with water. While the PCM has considerably less sensible storage capacity below its melting point when compared to water, there is a dramatic increase in this storage capacity when the temperature reaches $27^{\circ} \mathrm{C}$. The PCM, at the conclusion of the phase change process, would be able to absorb more than five 
times the energy stored by water at $27^{\circ} \mathrm{C}$. Water, on the other hand would not be able to utilize its latent storage capacity until it reaches the melting point of $0^{\circ} \mathrm{C}$, which is not the most convenient temperature to store and release energy. The ability of phase change materials to absorb thermal energy close to the normal ambient temperatures makes them ideally suited for energy storage in a wide variety of applications such as buildings, storage tanks and clothing.

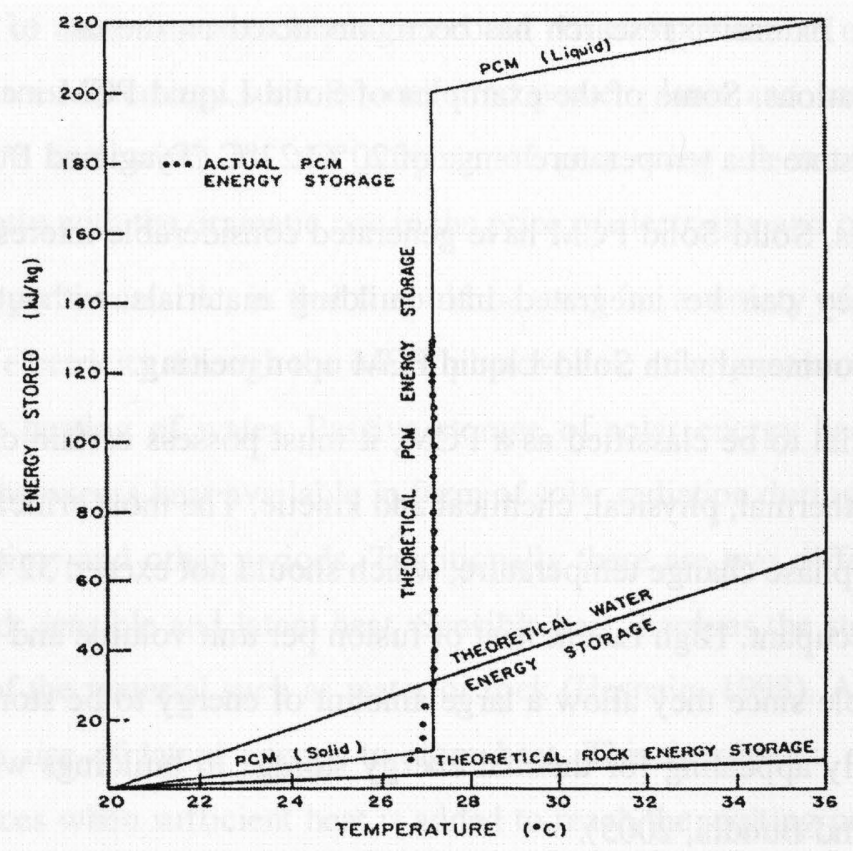

Figure 1.1: Performance Comparison of PCM and other sensible storage media (Kaygusuz, 1995)

\subsection{Classification of Phase Change Materials}

Phase Change materials can be classified into three distinct categories namely Organic, Inorganic and Eutectic materials.

\subsubsection{Organic PCMs}

Organic PCMs are derived from carbon and its molecules. They can be further divided into paraffin and non-paraffin (Tyagi and Buddhi., 2005). Some of the advantages of Organic PCMs include stability at phase change, non-corrosive, excellent resistance to super cooling and 
self nucleation. Some of the disadvantages include low thermal conductivity and phase change enthalpy and flammability (Hasan and Sayigh, 1994)

\subsubsection{Inorganic PCMs}

Inorganic materials encompass a large category that is further divided into salt hydrate and metallics (Hasnain, 1998). Compared to organic PCMs, these materials have a high latent heat per unit mass and are non-flammable. In terms of cost, these materials are also cheaper when compared to organic PCMs and are therefore quite attractive in applications involving buildings (Tyagi and Buddhi., 2005). One of the disadvantages is the tendency of these materials to super cool, which can caused unexpected changes in the thermal properties. The tendency to corrode easily is also a major drawback when using inorganic PCMs in any application.

\subsubsection{Eutectics}

"Eutectic materials are mixtures of two or more components, each of which melt and freeze congruently forming a mixture of component crystals during crystallization" (Tyagi and Buddhi., 2005). These can be divided into three different categories; Organic-Organic, OrganicInorganic and Inorganic-Inorganic (Sharma et al., 2009).

Even though there is a wide variety of different materials available that can be used as PCMs, the most commonly studied materials include Glauber's salt which melts at $32.2^{\circ} \mathrm{C}$, sodium thiosulfate pentahydrate, which melts at $56^{\circ} \mathrm{C}$ and calcium chloride hexahydrate, which melts at $28.4^{\circ} \mathrm{C}$. Calcium chloride hexahydrate has received particular attention and currently is available as a commercial product from Dow Chemical Company (Kaygusuz, 2005). One of the difficulties with salt based PCMs is the incongruent melting, which results in the material melting into an aqueous solution and a solid phase (He and Setterwall, 2002).

Figure 1.2 presents a detailed classification of commonly used heat storage materials. Phase change materials typically fall within the solid-liquid variety but advances in chemistry have enabled the development of materials that remain in the solid state upon a change in phase.

It is the significant increase in the heat storage at the phase change temperature that signifies whether the material has made a phase transition. These materials are referred to as solid-solid phase change materials. 


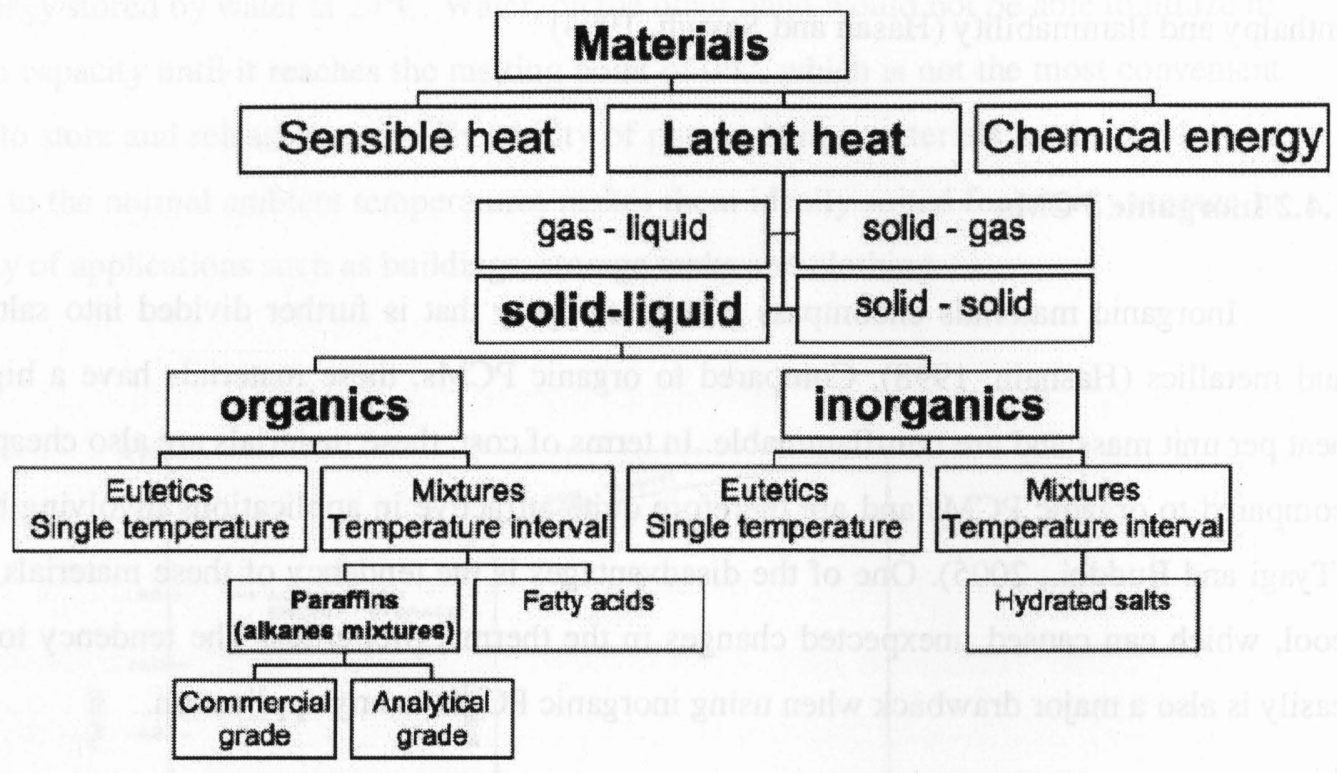

Figure 1.2: Classification of Heat Storage Materials (Khudhair and Farid, 2004)

\subsection{Types of Phase Change Materials}

Most of the research conducted has focused primarily on the use of solid-liquid phase change materials. The reason for this has been the relatively inexpensive cost to prepare the heat storage material and a mainly generalized use of the PCM for the purposes of heat storage without regard for any specific applications such as in buildings. With the increasing interest in the use of PCM for buildings and other specialized applications, a new category of phase change materials known as solid-solid phase change materials was discovered. These materials possessed several distinct advantages when compared to the conventional solid-liquid PCM, chief among them, being the ease with which these could be incorporated into the building materials. Furthermore, at phase change, the generation of the melted liquid layer, through the use of solidliquid PCM was avoided by the use of these materials. Thus these materials were found to be ideally suited for use in porous building materials such as concrete and gypsum.

\subsubsection{Solid-Solid Phase Change Materials}

Solid-Solid phase change is a process whereby a material in the solid state absorbs thermal energy at a fixed temperature referred to as the phase change temperature and unlike a 
solid-liquid which either changes from the solid state to the liquid state or vise versa, remains a solid upon phase change (Gao et al., 2007). This process results in a molecular change, which causes the transformation of the low-symmetry crystal structure into a high-symmetry one as thermal energy is absorbed.

When compared to Solid-Liquid PCM, these materials exhibit superior characteristics such as a relatively small volume change upon phase change, no leakage, smaller erosion and a longer life span (Gao et al., 2007). Also some crystal-type solids containing carbon and hydrogen can absorb and discharge a lot of energy, when they change from one crystal structure to another (Gao et al., 2007).Some of the disadvantages of these materials include a smaller latent heat and high temperatures at phase change.

There are two categories of solid-solid phase change materials, layered perovskites and plastic crystals.

\subsubsection{Layered Perovskites}

Layered perovskites are chemical compounds that have the general chemical formula $\left(\mathrm{n}-\mathrm{C}_{\mathrm{n}}-\mathrm{H}_{2 \mathrm{n}+1}-\mathrm{NH}_{3}\right)_{2} \mathrm{MCL}_{4}$, where $\mathrm{M}$ is a divalent metal atom such as $\mathrm{Mn}, \mathrm{Cu}, \mathrm{Hg}$ or $\mathrm{Fe}$ and the variable $\mathrm{n}$ is an integer between 8 and 18. The structure of these materials is composed of an inorganic layer that is sandwiched between two hydrocarbon layers. The hydrocarbon regions are made up of long chain alkylammonium groups and are bonded to the inorganic group. It is the presence of the alkyl group that contributes to the thermal properties of the material (Hittle, 2002). The alkyl chains are ordered in a zigzag alternating manner at low temperatures. These chains become disordered at higher temperatures and exhibit a liquid like behaviour but the liquid phase is not obtained because the alkyl chains are bonded to the inorganic layers, which helps in maintaining the lattice structure. One advantage is that transition temperatures are dependent on alkyl chain length which enables the transition temperatures to be controlled. Other advantages include a relatively high thermal conductivity and chemical stability at high temperatures. Disadvantages include the possibility of toxicity, lower value of enthalpy per unit weight and the reduced latent heat due to the inorganic regions of the molecules that are inert (Hittle, 2002). 


\subsubsection{Plastic Crystals}

Plastic crystals have been studied extensively by NASA during the 1970 s for the passive control of temperature of earth satellites. 'These materials belong to a class of compounds called polyalcohols or polyols. Each molecule has a central carbon atom with four attached carbon atoms forming a tetrahedron. The number of hydroxyl groups attached to the four carbon atoms distinguished the three compounds from each other. Pentaerythritol is the largest molecule, the smallest is neopentyl glycol' (Hittle, 2002).

Some of the most promising Solid-Solid PCMs for a variety of applications include, polyalcohols, polyethylenes and layered perovskites. Solid-Solid phase change characteristics of a variety of polyalcohols have been evaluated. These include neopentyl glycol (NPG, $\mathrm{C}_{5} \mathrm{H}_{12} \mathrm{O}_{2}$ ), pentaerythritol ( $\mathrm{PE}, \mathrm{C}_{5} \mathrm{H}_{12} \mathrm{O}_{4}$ ), trihydroxy methyl-aminomethane (TAM, $\mathrm{C}_{4} \mathrm{H}_{11} \mathrm{O}_{3} \mathrm{~N}$ ) and pentaglycerol (PG, $\mathrm{C}_{5} \mathrm{H}_{12} \mathrm{O}_{3}$ ) (Gao et al., 2007). Murrill and Breed (1970) have determined the solid-solid phase transitions of NPG, PE and PG using differential scanning calorimetry techniques while Nakano et al. (1969) have determined the crystal properties of PG and NPG. The formation of the plastic crystal phase of PE has also been investigated by Doshi et al. (1973) using a variety of different methods such as DSC, observations through a polarizing microscope and the use of X-ray diffraction to obtain flat plate powder photographs. These investigations concluded that PE and its derivatives form a highly disordered crystalline phase just below the melting point. Further investigations into the phase change transition characteristics of polyalcohols concluded that these materials are suitable for heat storage over a range of temperatures encountered in building applications. It was also determined that the mechanism for solid-solid phase transition involves the reversible breaking of nearest hydrogen resonance bonds in the molecular crystals at the transformation temperatures (Gao et al., 2007). The use of mixtures of a variety of different polyalcohols was also found to be one way in which the phase transition temperature could be controlled. The thermal properties of mixtures of PE/NPG and PG/NPG were investigated with a heat flux scanning calorimeter and found that polyalcohols experienced a first-order phase transition with no changes in Gibbs energy (Gao et al., 2007).

\subsection{Solid-Liquid Phase Change Materials}

By far the most common type of phase change materials used for the purpose of thermal energy storage falls into the solid-liquid category. These materials exist in the solid phase at temperatures below the transition temperature. With the addition of thermal energy, the 
temperature of the material increases, until the transition temperature is reached. It is at this stage that the phase of the materials starts to change from liquid to solid. Any subsequent thermal energy that is absorbed contributes to the change in phase, without any increase in temperature. This is referred to as the latent heat. After the completion of the transformation from solid to liquid, any further addition of heat translates into a temperature rise which is referred to as sensible energy. Figure 1.3 illustrates the entire phase change process temporally for a typical solid-liquid material undergoing thermal energy addition.

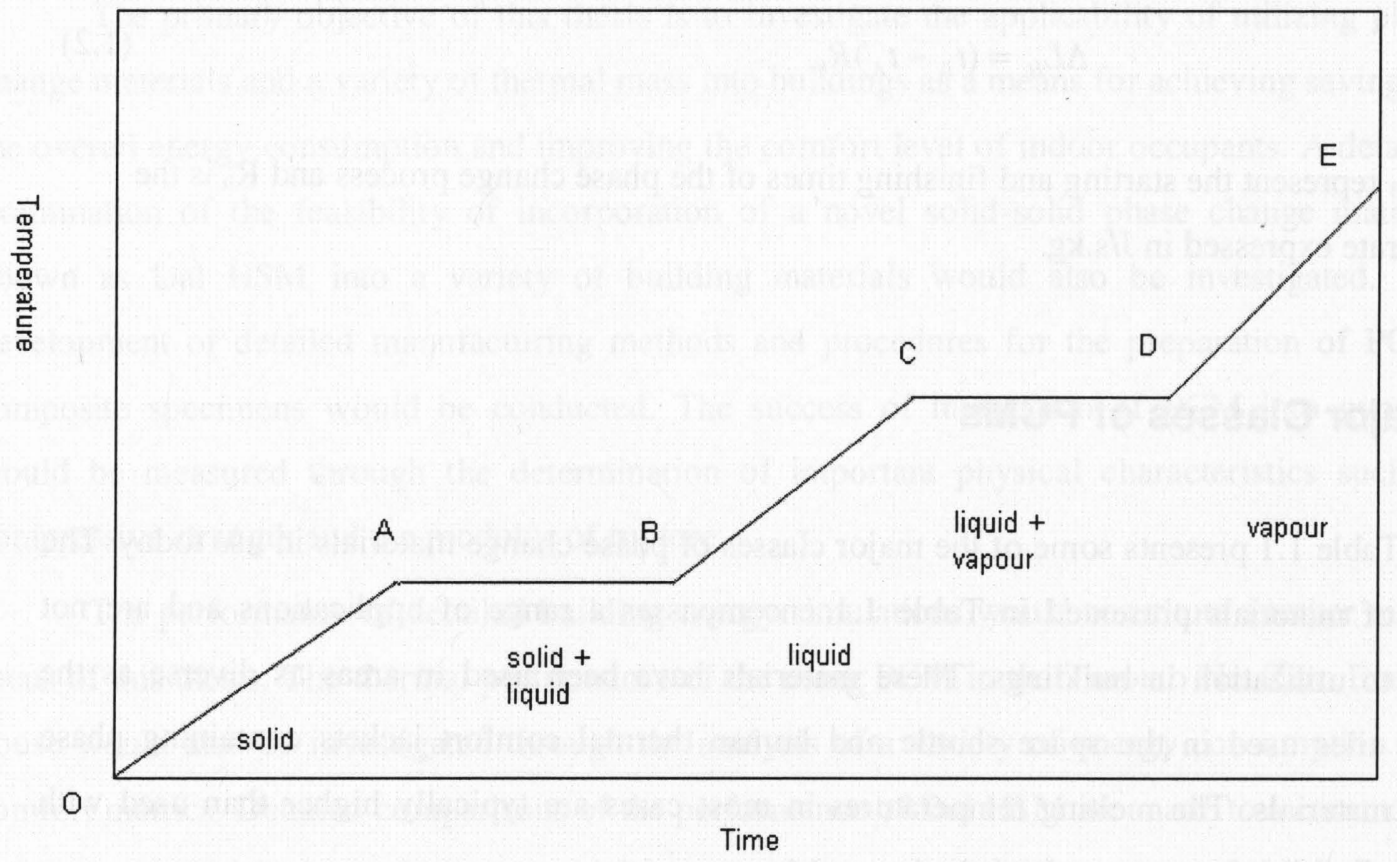

Figure 1.3: Heating curve of a typical solid-liquid PCM (Abhat, 1981)

Analyzing Figure 1.3, it is seen that the thermal energy is added to the material starting at point $\mathrm{O}$. The line $\mathrm{OA}$ represents the sensible heat that the material absorbs. This results in a temperature rise which is proportional to the specific heat of the material. The phase change process begins at point $\mathrm{A}$ and is completed at point $\mathrm{B}$. During this process, the melting creates a solid-liquid interface. The line BC again represents the sensible heat gain to the liquid phase. At point $\mathrm{C}$, another phase change process that transforms the liquid phase into vapour occurs. The addition of heat from point $\mathrm{O}$ to point $\mathrm{E}$ can be expressed by the following equation.

$$
Q=M\left[\int_{T_{O}}^{T_{A}} C_{p, s}(T) d T+L_{H}+\int_{T_{B}}^{T_{C}} C_{p, l}(T) d T+L_{H, v}+\int_{T_{D}}^{T_{E}} C_{p, v}(T) d T\right]
$$


Where: $\mathrm{M}$ represents the mass of the material and $\mathrm{Cp}$ is the sensible heat capacity of the material $\mathrm{L}_{\mathrm{H}}$ is the latent heat of fusion for the phase change between the solid and liquid state and $\mathrm{L}_{\mathrm{H}, \mathrm{v}}$ is the latent heat of fusion for the change in phase from the liquid to vapour state.

It is obvious that for a phase change material to be effective, it must possess a high latent heat. Referring to Figure 1.3, it is seen that the latent heat is directly proportional to the line $\mathrm{AB}$ on the curve. The latent heat of the material can be calculated as:

$$
\Delta L_{H}=\left(t_{B}-t_{A}\right) R_{h}
$$

$t_{A}$ and $t_{B}$ represent the starting and finishing times of the phase change process and $R_{h}$ is the heating rate expressed in $\mathrm{J} / \mathrm{s} . \mathrm{kg}$.

\subsection{Major Classes of PCMs}

Table 1.1 presents some of the major classes of phase change materials in use today. The variety of materials presented in Table 1.1 encompasses a range of applications and are not limited to utilization in buildings. These materials have been used in areas as diverse as the ceramic tiles used in the space shuttle and human thermal comfort jackets containing phase change materials. The melting temperatures in most cases are typically higher than used with PCMs in buildings.

Table 1.1: Major Classes of Phase Change Materials (Wirtz et al., 1999)

\begin{tabular}{|l|c|c|c|c|}
\hline \multicolumn{1}{|c|}{ Material type } & Transition & $\begin{array}{c}\text { Temp. range } \\
{ }^{\circ} \mathbf{C}\end{array}$ & $\begin{array}{c}\text { Latent Heat } \\
\text { Joule/cc }\end{array}$ & $\begin{array}{c}\text { Density } \\
\text { gm/cc }\end{array}$ \\
\hline Solid - Solid Organic Compounds (TCC) & S-S (dry) & $21-100$ & $144-212$ & $\sim 1.1$ \\
\hline Micro-encap. Paraffin (Thermosorb) & S-L (dry) & $6-101$ & $95-186$ & $\sim 0.9$ \\
\hline Paraffin (Eicosane, Docosane, etc.) & S-L (wet) & $-12-71$ & $128-197$ & $0.75-0.88$ \\
\hline Non-Paraffin Organics (Beeswax) & S-L (wet) & $-13-187$ & $131-438$ & $0.85-1.54$ \\
\hline Salt Hydrates (MgSO $\left.{ }_{4}-7 \mathrm{H}_{2} \mathrm{O}\right)$ & S-L (wet) & $28-137$ & $270-650$ & $1.5-2.2$ \\
\hline Metallics (Eutectic Bi-Cd-In) & S-L (wet) & $30-125$ & $200-800$ & $6-10$ \\
\hline
\end{tabular}

As can be seen from Table 1.1, the major classes of phase change materials exhibit a wide range of transition temperatures and latent heat. Depending on the specific application, a certain 
PCM or combination of the compounds could be used. Solid-Solid phase change materials typically have lower latent heat capacity when compared to the conventional solid-liquid type. Comparing Organic PCM to the Inorganic variety, a significant difference in the latent heat capacity is noted.

\subsection{Thesis Objective}

The primary objective of this thesis is to investigate the applicability of utilizing phase change materials and a variety of thermal mass into buildings as a means for achieving savings in the overall energy consumption and improving the comfort level of indoor occupants. A detailed examination of the feasibility of incorporation of a novel solid-solid phase change material known as Dal HSM into a variety of building materials would also be investigated. The development of detailed manufacturing methods and procedures for the preparation of PCMcomposite specimens would be conducted. The success of integration of PCM into gypsum would be measured through the determination of important physical characteristics such as compressive strength and the modulus of rupture.

The performance of detailed building energy simulations would constitute another major focus of this thesis. The thermal performance of the using PCM in the Toronto Net Zero Energy house would also be investigated through the analysis of a variety of energy consumption and comfort metrics. Detailed comparisons of the performance of Dal HSM are made to a commonly known commercial phase change material know as Micronal, and other types of thermal mass such as concrete slab. 


\section{CHAPTER 2: NUMERICAL AND ANALYTICAL TREATMENT OF PHASE CHANGE HEAT TRANSFER}

\subsection{Introduction}

In order for PCM to be utilized in building and other heat storage applications, a comprehensive understanding of its heat transfer mechanism must be developed. Mathematical treatment of solid-solid and solid-liquid PCM is similar in terms of the governing equations that apply to it.

One of the difficulties in analyzing the heat transfer mechanism in solid-liquid PCM is due to the non-linearity and the transient behaviour observed as the process of phase change begins. The change in phase creates a dynamic solid-liquid interface which is referred to as a moving boundary problem (Alexiades and Solomon,1993). As it is very difficult to analyze the heat transfer characteristics during a transient melting process, very few analytical solutions exist, mainly relating to simple geometries and boundary conditions. The Stefan problem is considered to be the most well known and precise analytical solution for one-dimensional moving boundary problems. In addition to the Stefan problem, various approximations for onedimensional problems using different boundary conditions have been used (Lamberg et al., 2004). These include the quasi-stationary approximation, perturbation methods, the Megerlin method and the heat-balance-integral method (Lamberg et al., 2004). The underlying assumption in these methods is the constant melting or solidification temperature. However, most of the PCMs researched have exhibited a wide range of temperatures where melting and solidification occurs. Technical grade Paraffin wax, as an example starts melting at $20-21^{\circ} \mathrm{C}$, and reaches the peak melting temperature at $27.7^{\circ} \mathrm{C}$ (Lamberg et al., 2004). Figure 2.1 provides an illustration of the DSC curve for technical grade Paraffin wax. It is clear from the curve that an overlap between the melting and solidification temperatures exists.

One major deficiency of these methods is that the analysis can only be applied to problems of infinite and semi-infinite storage, which makes it difficult to investigate a wide variety of finite storage problems encountered in reality (Lamberg et al., 2004). In order to obtain an accurate solution to heat storage problems with phase change, a two dimensional treatment at a minimum, preferably a three dimensional approach is required, which the idealized analytical solutions lack. In the absence of analytical solutions, numerical analysis is the preferred 
approach. The most common numerical methods used for analyzing PCMs are enthalpy and temperature based effective heat capacity methods (Lamberg et al., 2004).

DSC-curve

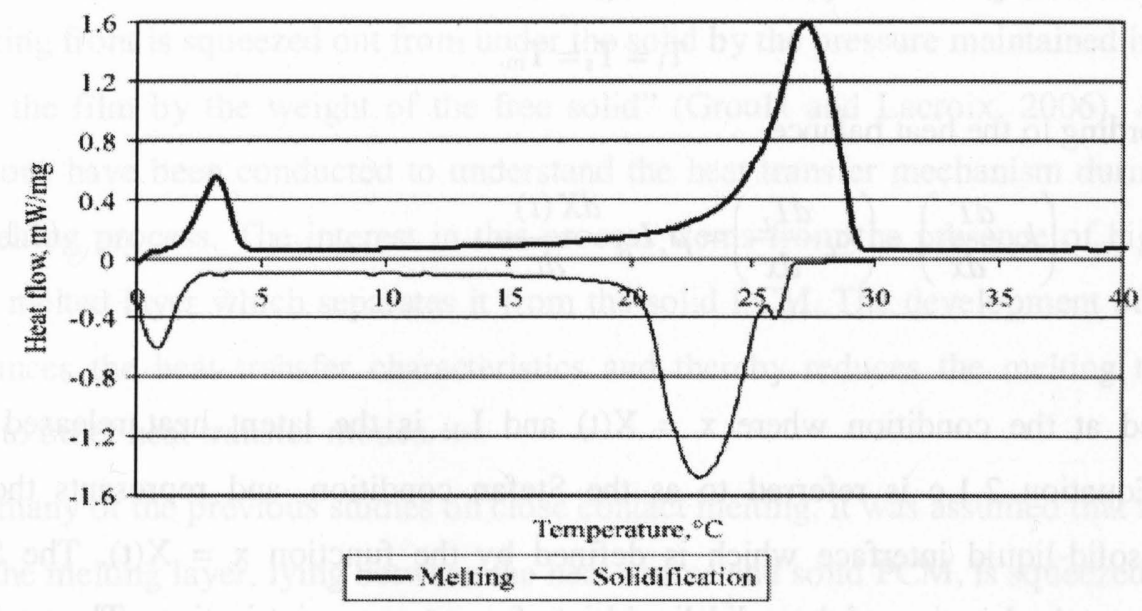

Figure 2.1: Differential Scanning Curve showing the range of melting and solidification of Paraffin wax (Lamberg et al., 2004)

\subsection{Classical Stefan Problem Applied to a Phase Change Material}

The most well known method of analysis for heat transfer involving a change in phase was formulated by Stefan in 1889 (Voller and Cross., 1981). Consider a material that can exist in two different phases; solid and liquid, fills the half space $\mathrm{x} \geq 0$. For times $t \leq 0$, the material is in the liquid phase and at a constant temperature of $T(x, 0)=T_{2}>T_{m}$, where $T_{m}$ is the phase change temperature. At time $t=0$, the surface of the solid $x=0$, is cooled and maintained at a temperature of $\mathrm{T}(0, \mathrm{t})=\mathrm{T}_{1}<\mathrm{T}_{\mathrm{m}}$. This causes the layer of liquid directly adjacent to the temperature source to solidify and as the cooling is continued, this layer expands in size. Assuming all the heat transfer is due to conduction, the Fourier heat conduction equation can be written for the solid and the liquid (Voller and Cross., 1981).

For the solid $\quad \frac{d}{d x}\left(k_{s} \frac{d T_{s}}{d x}\right)=\rho C_{s} \frac{d T_{s}}{d t}, 0 \leq x \leq X(t)$ 
For the liquid

$$
\frac{d}{d x}\left(k_{L} \frac{d T_{L}}{d x}\right)=\rho C_{L} \frac{d T_{L}}{d t}, X(t) \leq x
$$

At the phase change boundary, the following conditions are true,

$$
\mathrm{T}_{1}=\mathrm{T}_{\mathrm{s}}=\mathrm{T}_{\mathrm{m}}
$$

and according to the heat balance,

$$
\left(k_{s} \frac{d T_{s}}{d x}\right)-\left(k_{L} \frac{d T_{L}}{d x}\right)=\rho_{s} L_{H} \frac{d X(t)}{d t}
$$

Evaluated at the condition where $\mathrm{x}=\mathrm{X}(\mathrm{t})$ and $\mathrm{L}_{\mathrm{H}}$ is the latent heat released upon solidification. Equation 2.1.c is referred to as the Stefan condition, and represents the heat balance at the solid-liquid interface which is defined by the function $x=X(t)$. The Stefan condition expresses the location of the solid-liquid interface at any point in time. The analytical solution to equation 2.1.c is expressed as;

$$
X(t)=2 \lambda \sqrt{\alpha_{s} t}
$$

Where $\alpha_{s}=\frac{k_{s}}{\rho_{s} C_{s}}$ and $\lambda$ is a constant which can be obtained from the following transcendental equation;

$$
\lambda e^{\lambda^{2}} \operatorname{erf}(\lambda)=\frac{\text { Ste }}{\sqrt{\pi}}=\frac{C_{P}\left(T_{w}-T_{m}\right)}{L_{H} \sqrt{\pi}}
$$

Where: Ste is the Stefan number defined as Ste $=\frac{C_{p} \Delta T}{L_{H}}$ and $\mathrm{L}_{\mathrm{H}}$ is the latent heat of fusion as defined before.

One of the advantages of Equation 2.1.d is that it is possible to track the location of the solid-liquid interface at any point in time. This enables the determination of precisely the fraction of solid and liquid in the sample (Voller and Cross., 1981). 


\subsection{Heat Transfer Mechanism}

A variety of heat transfer mechanisms such as conduction, convection and close contact melting are involved in a Solid-Liquid PCMs undergoing phase change. "Close contact melting occurs when a solid melts while being in contact with a heat source. The liquid generated at the melting front is squeezed out from under the solid by the pressure maintained in the central section of the film by the weight of the free solid" (Groulx and Lacroix, 2006). A variety of investigations have been conducted to understand the heat transfer mechanism during the close contact melting process. The interest in this process stems from the presence of high heat flux across the melted layer which separates it from the solid PCM. The development of this melted layer enhances the heat transfer characteristics and thereby reduces the melting times, when compared to other heat transfer modes.

In many of the previous studies on close contact melting, it was assumed that the process by which the melting layer, lying between the heat source and solid PCM, is squeezed out, is quasi steady and the dominant mechanism of heat transfer through the liquid film is conduction. These assumptions have been modified as a result of recently conducted investigations which have concluded the presence of convection as the chief mechanism of heat transfer in the melted liquid film (Groulx and Lacroix., 2006). For instance, Saito et al. (1992) and Yoo et al. (1998) have carried out numerical analyses showing that the heat transfer in the liquid film is affected by convection in the case of Ste number larger than 0.1. It was also determined that the melting rate decreases at high Ste numbers because the heat capacity of molten liquid increases with the Ste number. Another situation that is of interest is the moving heat source, which imposes a relative velocity between the heat source and the liquid film. This modifies slightly the previously defined assumptions and incorporates convection and inertia force as the main processes involved in the melting of the PCM (Groulx and Lacroix, 2006).

\subsection{Mathematical Model}

A mathematical model of a PCM undergoing close contact melting can be constructed. Figure 2.2 shows a schematic representation of a solid-liquid PCM. The material is a solid block having an initial height of $\mathrm{H}$, a length of $\mathrm{L}_{x}$ and a depth of $\mathrm{L}_{z}$. It is initially at a sub cooled temperature of $T_{m}-T_{s c}$ and resting on a flat plate. At time $t=0$, the temperature of the plate is suddenly raised to a constant value of $T_{p}=T_{m}+\Delta T$, which triggers the melting of the solid PCM block. The melting of the solid creates a thin film of liquid layer of thickness $\delta$, between the flat plate and the solid block. This reduces the upward force acting on the solid portion of the 
PCM and it accelerates downwards at a speed of V, induced by the force of gravity. As the solid portion moves downwards, it squeezes the melted layer of liquid out of the thin gap of thickness $\delta$.

A few underlying assumption are now made to simplify the model and construct the governing equations. It is assumed that the melting process is quasi steady and the weight of the solid portion is balanced by the pressure developed in the liquid. The transfer of heat is considered to be one-dimensional and laminar fluid properties are assumed for the melted liquid. Furthermore, the thickness of the liquid layer is considered to be constant along the length and depth. The fluid properties are assumed to be temperature independent and are evaluated at the film temperature, $T_{\text {film }}=T_{m}+\Delta T / 2$.

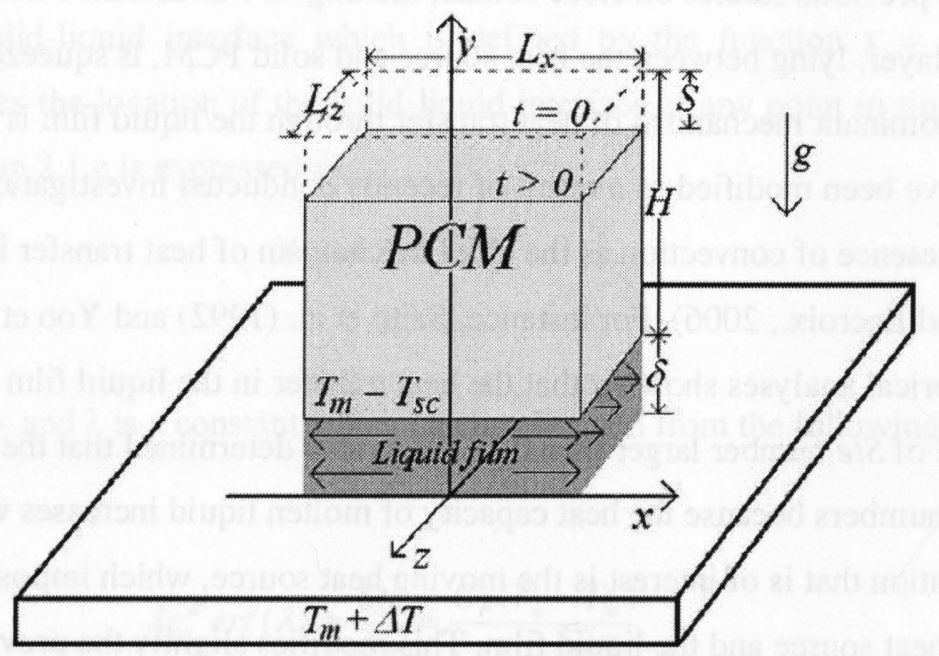

Figure 2.2: Physical model of a PCM undergoing close contact melting (Groulx et al., 2006)

Based on these assumptions, governing equations of mass, momentum and energy can be constructed as follows.

Mass Conservation

$$
\frac{\partial u}{\partial x}+\frac{\partial v}{\partial y}+\frac{\partial w}{\partial z}=0
$$




\section{Momentum Conservation}

Assuming:

$u$ is the velocity component in $x$.

$v$ is the velocity component in $y$.

$w$ is the velocity component in $z$.

$$
\begin{aligned}
& u \frac{\partial u}{\partial x}+v \frac{\partial u}{\partial y}+w \frac{\partial u}{\partial z} \\
& =-\frac{1}{\rho_{f}} \frac{d P}{d x}+v_{f}\left(\frac{\partial^{2} u}{\partial x^{2}}+\frac{\partial^{2} u}{\partial y^{2}}+\frac{\partial^{2} u}{\partial z^{2}}\right) \\
& u \frac{\partial w}{\partial x}+v \frac{\partial w}{\partial y}+w \frac{\partial w}{\partial z} \\
& =-\frac{1}{\rho_{f}} \frac{d P}{d z}+v_{f}\left(\frac{\partial^{2} w}{\partial x^{2}}+\frac{\partial^{2} w}{\partial y^{2}}+\frac{\partial^{2} w}{\partial z^{2}}\right)
\end{aligned}
$$

\section{Energy Conservation}

$$
\begin{aligned}
& u \frac{\partial T}{\partial x}+v \frac{\partial T}{\partial y}+w \frac{\partial T}{\partial z} \\
& =\alpha_{f}\left(\frac{\partial^{2} T}{\partial x^{2}}+\frac{\partial^{2} T}{\partial y^{2}}+\frac{\partial^{2} T}{\partial z^{2}}\right)+\frac{\mu_{f}}{\rho_{f} C_{f}} \Phi
\end{aligned}
$$

Furthermore, at the solid-liquid interface, an energy balance can be applied which yields

$$
-\left.k_{f} \frac{d T}{d y}\right|_{y=\delta}=\rho_{s} v\left(L_{H}, f_{s}+C_{s} T_{s c}\right)
$$

Where $\mathrm{L}_{\mathrm{H}, f s}$ is the latent heat capacity at the solid-liquid state:

Also a static equilibrium condition can be applied by assuming that the weight of the PCM block is equal to the pressure developed in the liquid. 


$$
\int_{-L_{x} / 2-L_{z} / 2}^{L_{x} / 2} \int_{L_{z} / 2}^{L_{z}} P(x, z) d x d z+F=\rho_{s}(H-B) L_{x} L_{z} g
$$

Where: $H$ is the initial height of the block

$F$ is the sum of forces other than pressure

Since these equations are very difficult to solve analytically, an order of magnitude analysis can be performed which leads to a very robust model known as Bejan's model (Groulx and Lacroix, 2006). In order to implement this model, two key assumptions are made namely; the heat transfer is considered to be one-dimensional and sub-cooling of the solid phase is ignored. Furthermore since convection has been shown to be important in close contact melting, it can thus be incorporated into Bejan's model to obtan the following equations (Bejan, 1994).

$$
\begin{aligned}
& \frac{\partial^{2} u}{\partial y^{2}}=\frac{1}{\mu_{f}} \frac{d P}{d x} \\
& \frac{\partial^{2} w}{\partial y^{2}}=\frac{1}{\mu_{f}} \frac{d P}{d z} \\
& \frac{\partial^{2} T}{\partial y^{2}}=-\frac{V}{\alpha_{f}} \frac{\partial T}{\partial y}
\end{aligned}
$$

These three equations along with Equations 2.1, 2.5 and 2.6 constitute the governing equations for this particular problem. The velocity component $v$ is approximated as the melting speed V. The boundary conditions for the momentum equations (2.7) and (2.8) are $u(y=0)=0$, $u(y=\delta)=0, w(y=0)=0$ and $w(y=\delta)=0$, respectively. The boundary conditions applied to (2.9) are $T(y=0)=T_{\mathrm{p}}=T_{\mathrm{m}}+\Delta T$ and $T(y=\delta)=T_{\mathrm{m}}$.

Upon solving equation 2.9, a temperature distribution in the liquid layer can be obtained as,

$$
T(y)=T_{m}+\Delta T \frac{\left\{\exp \left(-V y / \alpha_{f}\right)-\exp \left(-V \delta / \alpha_{f}\right)\right\}}{1-\exp \left(-V \delta / \alpha_{f}\right)}
$$


The temperature profile can then be plotted as shown Figure 2.3.

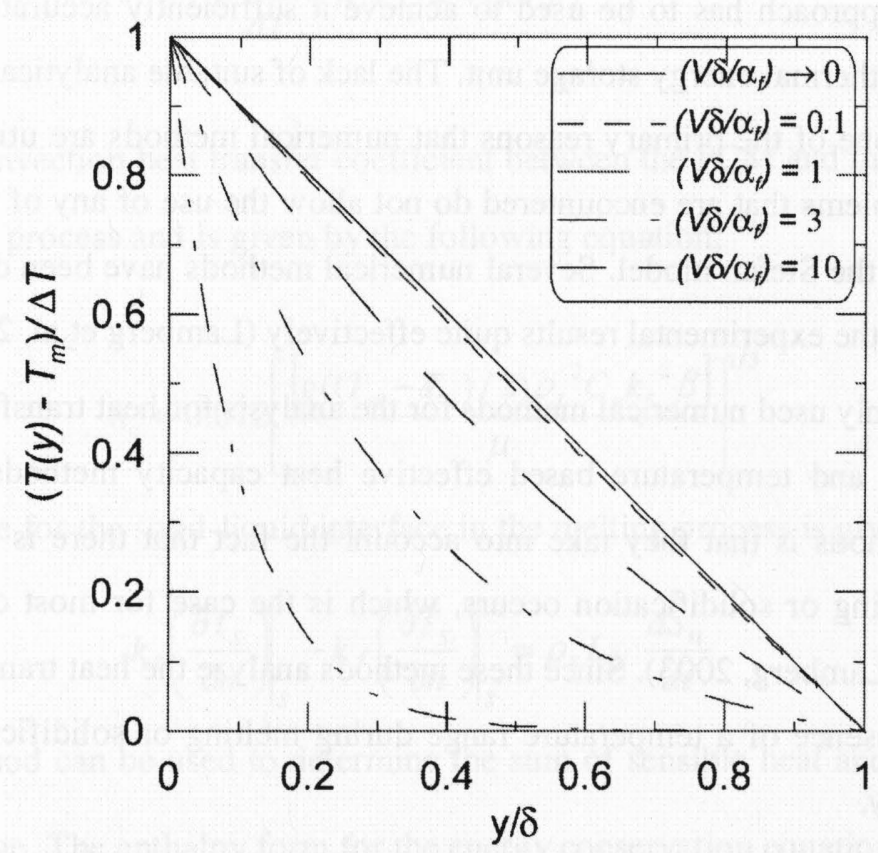

Figure 2.3: Temperature distribution in the melted liquid layer (Groulx et al., 2006)

As can be seen from Figure 2.3, convection becomes an increasingly important mechanism for heat transfer as $\left(V \delta / \alpha_{\mathrm{f}}\right)>0.1$, which means that as the velocity of the solid increases, the convection characteristics are enhanced. Furthermore as the parameter, $V \delta / \alpha_{\mathrm{f}}$, increases, the temperature of the liquid layer inches closer to the melting temperature $T_{m}$. This causes a reduction in the total heat flux and consequently a decrease in the melting rate (Groulx et al., 2006).

\subsection{Numerical Analysis of PCM}

Since phase change heat transfer is non-linear due to the moving solid-liquid interface, analytical solutions are only known for a few so-called moving boundary problems with simple geometry and simple boundary conditions. Technical grade paraffin, as an example, is known to have a wide temperature range between its melting and solidification phases. The use of the 
quasi-stationary approximation is only appropriate for calculating semi-infinite or infinite storage, but under typical experimental conditions, storage is considered to be finite and must be analyzed in the context of two or three dimensions so that a satisfactory solution can be achieved. Therefore, a numerical approach has to be used to achieve a sufficiently accurate solution for heat transfer in the latent thermal energy storage unit. The lack of suitable analytical solutions for heat transfer in PCM is one of the primary reasons that numerical methods are utilized. A large majority of practical problems that are encountered do not allow the use of any of the simplified models available such as the Stefan model. Several numerical methods have been developed that are accurate and validate the experimental results quite effectively (Lamberg et al, 2004).

The most commonly used numerical methods for the analysis for heat transfer in PCM are enthalpy based methods and temperature based effective heat capacity methods. One of the advantages of these methods is that they take into account the fact that there is a temperature range within which melting or solidification occurs, which is the case for most commonly use phase change materials (Lamberg, 2003). Since these methods analyze the heat transfer at distinct nodes and times, the presence of a temperature range during melting or solidification is easily dealt with mathematically.

\subsubsection{Enthalpy Method}

The standard enthalpy formulation which has been widely used makes use of the energy equation in terms of enthalpy. In this approach, no distinction is made between the solid and liquid phase, with the result that each of these is treated as a single domain (Trp, 2005). Even though this method is based on a weak solution of partial differential equations, very accurate results have been obtained. Voller et al. (1981) has extended this method to twodimensional formulation and has achieved accuracies of $0.1 \%$ when compared to the established methods. It has also been shown that an enthalpy method has been developed that can analyze situations where the phase change temperature does not exist as a range and is a single point (Voller et al., 1981). Costa et al. (1998) have utilized a fully implicit finite difference method (FDM) to implement the enthalpy formulation with the goal of obtaining the thermal performance of latent storage numerically. This method utilizes both the conduction and convection heat transfer in a one-dimensional model and only conduction in a two-dimensional model. The use of the enthalpy method incorporates the Stefan condition into the governing equation by formulating an enthalpy function $\mathrm{H}(\mathrm{T})$, which is the sum of sensible and latent heat 
required for the phase change (Lamberg et al., 2004). The energy equation expressed in terms of enthalpy for a solid PCM can be expressed as;

$$
\rho \frac{d H}{d T}+h_{c} \nabla T=\nabla(k \nabla T)
$$

Where $h_{c}$ is the convection heat transfer coefficient between the PCM and the surrounding air, during the melting process and is given by the following equation;

$$
h_{c}=0.072\left[\frac{\left[g\left(\left(T_{w}-T_{m}\right) / 2\right) \rho_{L}{ }^{2} C_{p} k_{L}{ }^{2} \beta\right]}{\mu}\right]^{1 / 3}
$$

The energy balance for the solid-liquid interface in the melting process is given by,

$$
\left.k_{s}\left(\frac{\partial T_{s}}{\partial n}\right)\right|_{s}-\left.k_{f}\left(\frac{\partial T_{s}}{\partial n}\right)\right|_{s}=\rho_{s} L_{H} \frac{d S_{n}}{d t}
$$

The enthalpy method can be used to determine the sum of sensible heat and latent heat required for the phase change. The enthalpy form for the energy conservation equation can be written as,

$$
\rho \frac{\partial H}{\partial t}+\left(\rho C U \bullet \nabla T_{f}\right) \nabla T=\nabla(k \nabla T)
$$

The boundary conditions can be given as;

$$
\begin{gathered}
T(x, y, z, 0)=T_{i} \\
T(0, y, z, t)=T\left(l_{x}, y, z, t\right)=T_{w}(t) \\
\frac{d T(x, 0, z, t)}{d y}=\frac{d T\left(x, l_{y}, z, t\right)}{d y}=0 \\
\frac{d T(x, y, 0, t)}{d z}=\frac{d T\left(x, y, l_{z}, t\right)}{d z}=0
\end{gathered}
$$

Where $\mathrm{H}$ is the enthalpy, $l$ is the length of the storage. The subscript, $i$, denotes initial, $w$ the wall, $x$ the $\mathrm{x}$-direction, $y$ the $\mathrm{y}$-direction and $z$ the $\mathrm{z}$-direction. 
One of the major advantages of the enthalpy method is that it can generate an enthalpy function which can be validated using DSC measurements, which also generates the data in terms of an enthalpy function (Lamberg et al., 2004).

\subsubsection{Effective Heat Capacity Method}

In the effective heat capacity method, the heat capacity of the material is considered to be directly proportional to the energy that is stored by the material during phase change and is inversely proportional to the width of the melting or solidification temperature range (Lamberg, 2003). At phase change, the equation for effective heat capacity can be written as;

$$
C_{e f f}=\frac{L_{H}}{T_{e}-T_{o}}+C
$$

Where $T_{\mathrm{o}}$ and $T_{\mathrm{e}}$ are the temperature of the onset and end of phase transition, respectively and $L_{H}$, represents the latent heat of fusion of the PCM upon undergoing phase change. Equation 2.19 is an approximate way of converting the latent energy of fusion of a solid into an effective heat capacity parameter. The effective heat is directly proportional to the latent heat and inversely proportional to the range of temperature over which phase change occurs.

The energy equation used with the effective heat capacity method is shown below:

$$
\rho_{f} C \frac{\partial T_{f}}{\partial t}+\left(\rho C U \bullet \nabla T_{f}\right) \nabla T=\nabla\left(k_{f} \nabla T_{f}\right)
$$

Where $C_{\text {eff }}=\left\{\begin{array}{lr}C_{s} & T<T_{o} \\ \frac{L_{H}}{T_{e}-T_{o}}+C & T_{o} \leq T \leq T_{e} \\ C_{f} & T>T_{e}\end{array}\right.$ 
Equation 2.21 shows that for temperatures falling outside the range of phase change, the effective heat capacity is equal to the specific heat of the material. As the phase change process begins, Equation 2.20 applies to the process. Overall, the method has been proven to be quite accurate when compared to analytical results. Bonacina et al(1973), has shown an accuracy of $3 \%$, when using the heat capacity method to evaluate a high latent heat along a small temperature range of $0.5^{\circ} \mathrm{C}$. 


\section{CHAPTER 3: APPLICATION OF PHASE CHANGE MATERIAL TO BUILDING MATERIALS}

The incorporation of phase change materials into building fabrics has gained prominence mainly because of the need to reduce the overall energy consumption associated with maintaining the thermal comfort of the buildings. These materials can be easily implemented into building materials and contribute significantly to the overall comfort of the occupants. The use of PCMs has demonstrated the reduction of temperature fluctuations and has been found to be effective in shifting the overall peak consumption of buildings.

Solar radiation on clear day, for instance, constitutes one of the primary sources of temperature rise in buildings (Zhang et al., 2007). Without the presence of any heat storage mechanism, most of the thermal energy would go towards increasing the indoor temperature inside the building, making it uncomfortable for the occupants. The use of heat storage materials would not only ensure a comfortable temperature within the building but it would also minimize large temperature fluctuations. At night, when the outside temperature drops, most of the stored thermal energy could be extracted to provide a cost effective heating solution.

\subsection{Building Energy Consumption}

Reduction of the total energy consumption in buildings is one of the main applications of building integrated phase change materials. With the development of new technologies such as the Time of Use (TOU) pricing and smart electricity meters, it is now possible to exploit the benefits of PCM as a heat storage mechanism, to shift the overall energy demand profile of buildings. In order to encourage conservation many electrical utilities have instituted a system of differential pricing whereby the price of electricity is higher during the peak demand period and is reduced considerably during the off peak times. As an example, currently in Ontario, a system of TOU has been considered and is scheduled to be adopted by the most of the electrical utilities once most of the details regarding the provision of the smart meters are determined (Ontario Energy Board, 2008). Table 3.1 shows the details of the proposed TOU pricing in Ontario as recommended by the Ontario Energy Board. 
Table 3.1: Time of Use Price in Ontario as of Nov 2008 (Ontario Energy Board, 2008)

\begin{tabular}{|l|l|l|c|}
\hline Day of the Week & Time & Time-of-Use & $\begin{array}{l}\text { Price } \\
\text { (cents/kWh) }\end{array}$ \\
\hline Weekends \& holidays & All day & Off-peak & 4.0 \\
\hline \multirow{4}{*}{$\begin{array}{l}\text { Summer Weekdays } \\
\text { (May 1st - Oct 31st) }\end{array}$} & $7: 00$ a.m. to 11:00 a.m. & Mid-peak & 7.2 \\
\cline { 2 - 4 } & 11:00 a.m. to 5:00 p.m. & On-peak & 8.8 \\
\cline { 2 - 4 } & 5:00 p.m. to 10:00 p.m. & Mid-peak & 7.2 \\
\cline { 2 - 4 } & 10:00 p.m. to 7:00 a.m. & Off-peak & 4.0 \\
\hline \multirow{4}{*}{$\begin{array}{l}\text { Winter Weekdays } \\
\text { (Nov 1st - Apr 30th) }\end{array}$} & 7:00 a.m. to 11:00 a.m. & On-peak & 8.8 \\
\cline { 2 - 4 } & $11: 00$ a.m. to 5:00 p.m. & Mid-peak & 7.2 \\
\cline { 2 - 4 } & $5: 00$ p.m. to 8:00 p.m. & On-peak & 8.8 \\
\cline { 2 - 4 } & $8: 00$ p.m. to 10:00 p.m. & Mid-peak & 7.2 \\
\cline { 2 - 4 } & $10: 00$ p.m. to 7:00 a.m. & Off-peak & 4.0 \\
\hline
\end{tabular}

It is noticeable that there is a very large difference in the price of electricity depending on the time during the day in which it is used. On a typical summer day, the price of on-peak electricity is almost double that of the off-peak price. The primary reason for this is the use of air-conditioning to provide comfort for the building occupants which creates a spike in the demand. Interestingly, the On-peak price of 8.8 cents $/ \mathrm{kWh}$ also coincides with the peak solar gain experienced during the daytime, during the hours of $11 \mathrm{am}-5 \mathrm{pm}$. Figure 3.1 shows the incident solar radiation in Toronto on a typical summer day such as on July $15^{\text {th }}$.

It can be seen from Figure 3.1 that the peak solar gain would occur sometime between $12 \mathrm{pm}$ and $2 \mathrm{pm}$, which falls within the range of the on-peak electricity charge which runs from $11 \mathrm{am}$ to $5 \mathrm{pm}$. A building integrated with phase change materials would thus be able to absorb the incident solar radiation thereby delaying the effect of the solar gain on the room temperature and releasing this energy during the night when temperatures moderate. The reduction in the solar gain during the peak hours would reduce the electrical consumption associated with the operation of air-conditioners. Another way the PCM could be utilized in the summer is by allowing the materials to cool below the phase change temperature, either by natural means such as free cooling at night, or through the use of off-peak electrical rates to reduce the temperature at night. 


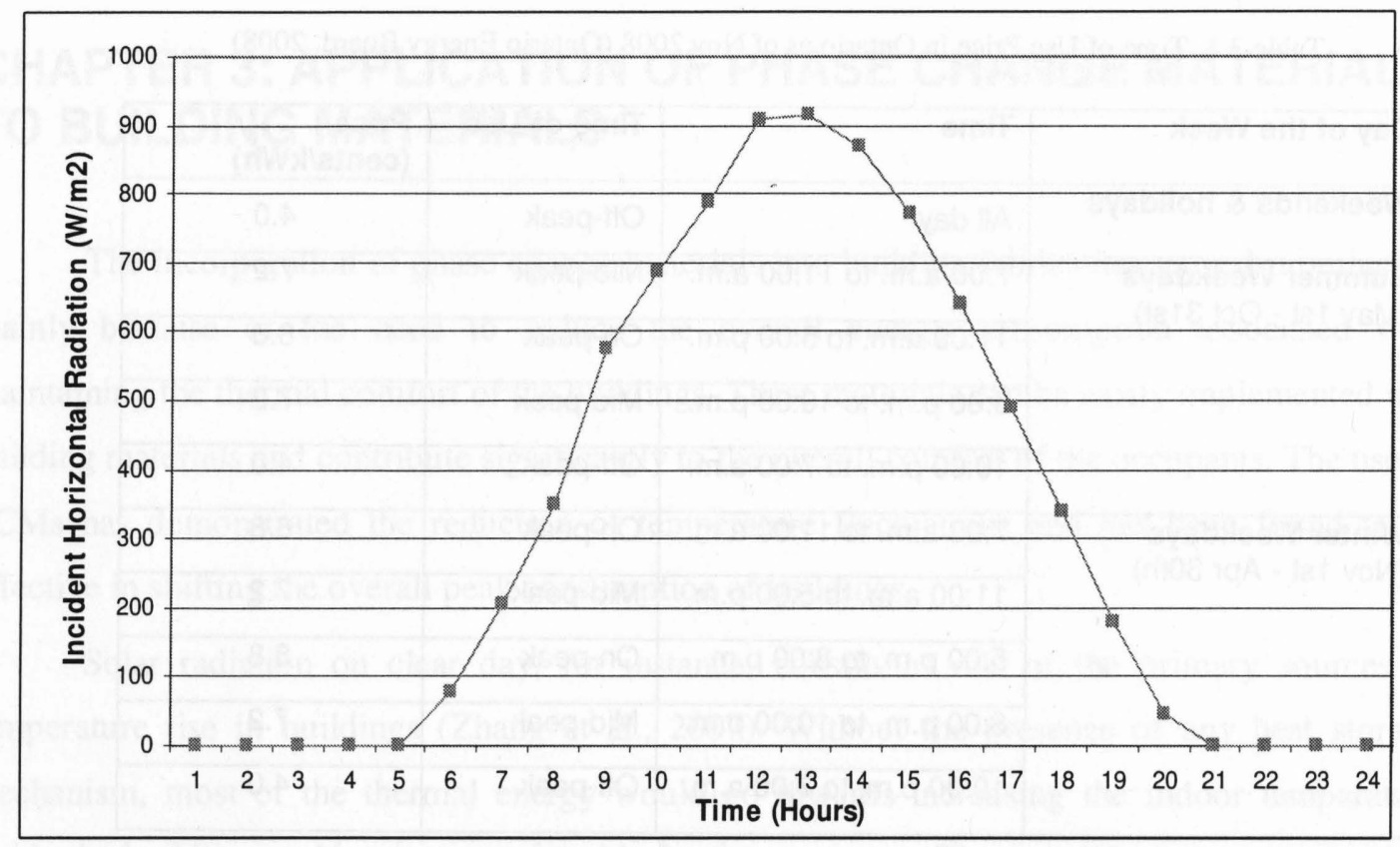

Figure 3.1: Solar radiation in Toronto on a typical summer day (TRNSYS Simulation performed).

PCMs can also be utilized during the winter as a means to reduce the heating costs. As can be observed from Table 3.1, between $5 \mathrm{pm}$ and $8 \mathrm{pm}$ during the winter season, peak electricity rates apply. Even though the building (commercial and office buildings) would not be occupied during these times, some form of heating would still be necessary to provide a comfortable environment for the occupants the next day. This would come in the form of energy that the PCM has stored between $11 \mathrm{am}$ and $5 \mathrm{pm}$. This stored energy would then be released between $5 \mathrm{pm}$ and $8 \mathrm{pm}$, which constitutes the on-peak electricity period, thereby eliminating the need for any electrical energy for the purposes of heating.

Extensive research has been conducted to determine the overall reduction in the energy consumption as a result of using phase change integrated building materials. Stoval and Tomlinson (1991) have analyzed the use of PCM wallboard as a load management device for passive solar applications and energy savings. Peippo et al. (1991) have shown energy reduction potential of almost $4 \mathrm{GJ} /$ year (or $15 \%$ of the annual energy cost) for a $120 \mathrm{~m}^{2}$ in Madison, Wisconsin $\left(43^{\circ} \mathrm{N}\right)$. They have also shown that a melting temperature that is $1-3^{\circ} \mathrm{C}$ above the average room temperature provides the most optimal heat storage.

On the larger scale, the ability of the PCM to shift the peak power demand and its use in buildings could contribute to the lowering of the capital investment in large electrical power 
plants that are constructed for the sole purpose of meeting the peak power demands. Unlike the plants dedicated to meeting only the base load, these power plants usually operate on fossil fuels and contribute to the emission of greenhouse gases and other harmful pollutants.

\subsection{Incorporation of PCM in buildings}

A variety of different methods are available for the integration of phase change materials into building fabrics. Three of the principal methods are; direct incorporation, immersion and encapsulation.

\subsubsection{Direct Incorporation}

Direct incorporation relies mainly on the mechanical mixing of the PCM into the building material. For solid-liquid PCM care is taken to ensure that the material is in solid phase when it is mixed. Depending on the texture of the material, it can either be crushed into a fine powder or inserted in the form of solid particles. However, it must be ensured that the introduction of the PCM to the mix does not interfere with the hydration process nor should it react chemically with the building material (Hawes et al., 1989). Hawes et al. (1990) have also shown an improvement in plasticity of the concrete mixture when PCMs in powdered form are used. Direct incorporation has been found to be very convenient in terms of controlling the quantity of PCM incorporated and support a wide variety of concrete pouring techniques.

\subsubsection{Immersion}

Immersion remains the most popular and flexible technique since it can be applied to a wide range of phase transition temperatures. It involves the immersion of a finished building material into PCM in a liquid form, allowing the porosity of the building material to absorb the PCM. It has been found to be easy to control and is particularly suited for the production of PCM in a continuous production process such as batch production (Hawes et al., 1990). Another major advantage is that it can be applied to a variety of building material shapes and sizes. 


\subsubsection{Encapsulation}

There are two principal methods used for the encapsulation of the phase change materials into building materials. These are microencapsulation and macroencapsulation. Microencapsulation involves the addition of small, spherical or round shape particles into a thin, high molecular weight polymeric film. This is made possible through the process of emulsification. This is followed by the formation of membrane around the microscopic PCM particles by interfacial polymerization (Hawes et al., 1990). The membrane enclosing the PCM particles can then be easily incorporated into the building material through direct immersion. One limitation inherent in this method is the requirement that the film must be compatible with both the PCM and the matrix.

Macroencapsulation involves the insertion of the phase change material into some form of a tube, pouch or capsule. These individual units containing phase change materials can then be inserted into the building material. One of the drawbacks of using macroencapsulation when compared to other methods is the reduced surface area of heat transfer which means a larger volume is required (Hawes et al., 1989). However, encapsulation provides excellent geometric stability when the material is subjected to thermal cycling (Zalba et al., 2003).

As of currently, the cost involved in encapsulating the PCM is significant and it makes the use of PCM for the purposes of energy savings infeasible. However in order to use solidliquid PCM with building materials, it is essential that encapsulation be used so as to ensure that the melting process does not degrade the structural integrity of the building material. Further research into the use of solid-solid phase change materials would effectively eliminate the need for encapsulation, thereby reducing the manufacturing cost and making these materials feasible.

\subsection{PCM compatible building materials}

A variety of building materials have been investigated for the purpose of incorporating phase change materials. The most attention has been paid to gypsum and concrete/Portland cement since these are readily available and cheap to produce.

\subsubsection{PCM integrated gypsum and manufacturing methods}

One of the most commonly used building materials is gypsum, also known as drywall. Extensive research has been conducted into the use of gypsum/PCM composite as a means for 
heat storage and residential cooling (Darkwa and Kim., 2005). Feustel and Stetiu (1997) have carried out simulations on PCM wallboard for the purpose of residential cooling. Darkwa and Kim. (2005) have investigated the dynamics of energy storage in gypsum wallboards and found that the laminated PCM board provided improved thermal characteristics when compared to randomly distributed PCM. The laminated boards were found to release $27 \%$ more heat compared to the randomly distributed samples. Kedl and Stovall (1989) used paraffin wax incorporated into gypsum wallboards using the immersion process. They found that there were two key methods in which the PCM wallboard could be manufactured. It could either be melted into a liquid and then absorbed into the porous gypsum wallboard or it could be added during the plasterboard manufacturing process, where it is added to the wet plaster Shapiro et al (1987) also expanded on the use of different manufacturing methods to produce PCM wallboard. Gypsum was integrated with a variety of PCMs such as methyl palmitate, methyl stearate and capric acid.

Darkwa and O'Callaghan (2006) carried out thermal simulations of the phase change drywalls in a passive solar building. The model room measured $3 \mathrm{~m} \times 4 \mathrm{~m} \times 2.5 \mathrm{~m}$ in dimension with one window measuring $1.5 \mathrm{~m} \times 1 \mathrm{~m}$ and facing south. The walls were of lightweight construction with the interior surfaces lined with $12 \mathrm{~mm}$ thick PCM wallboard. Simulations for the room were done numerically by applying an implicit FDM based on the fixed mesh method. The method involves the solution of a continuous system with an implicit representation of the phase change. In order to reduce errors in the analysis, each conduction term was therefore introduced to cover series connections for different materials. If one of the surfaces of the finite volumes was exposed to the convection zone, corresponding conduction term was subsequently replaced by the convection term. The step size of uniform square grid was fixed to $2 \mathrm{~mm}$ and the time step at $60 \mathrm{~s}$ in their study. The PCM used for simulation has a latent heat of $205 \mathrm{~kJ} / \mathrm{kg}$ and a phase change temperature at $18^{\circ} \mathrm{C}$.

Studies were carried out by Feldman et al. (1991), where a PCM gypsum board was produced by soaking conventional gypsum in liquid butyl stearate, which has a phase change temperature between $16-20.8^{\circ} \mathrm{C}$. Concentrations of up to $25 \%$ of butyl stearate by weight were successfully produced. Neeper (1990) investigated the use of gypsum wallboard with PCM for newly constructed buildings and found that it creates an opportunity for passive solar heating as well as ventilate cooling and time shifting of mechanical loads. Furthermore in terms of cost, it was determined that the PCM wallboards were economically viable when compared to ordinary wallboards. Neeper (1990) also identified the parameters that influence the amount of energy 
absorbed by the PCM wallboard. These include the temperature of the melt, the range of temperature of where melting occurs, thermal conductivity of the material and the latent heat capacity of the wallboard. Drake et al. (1987) found that the optimal melt temperature is proportional to the amount of solar energy that is absorbed. Peippo et al (1991) found that the optimal storage of energy occurs when the melt temperature is $1-3^{\circ} \mathrm{C}$ above the average indoor temperature. Athienitis et al. (1997) constructed a full scale indoor test room with PCM gypsum board for the purpose of conducting an experimental and numerical study. Using an explicit finite difference model, the transient heat transfer characteristic of the wallboard along with the temperature history was determined. Simulations were also conducted by Kalousck and Hirs (2002) investigating the thermal comfort of two rooms in an attic house during the summer, with one of the rooms having a conventional wallboard and the other using TH29 as the PCM with a melting point of $29^{\circ} \mathrm{C}$. It was found that the average surface temperature and indoor air temperature decreased by 3.5 and $2.5^{\circ} \mathrm{C}$ respectively.

A variety of methods have been used to manufacture PCM integrated wallboard and these have been successfully tested at the laboratory level. The Oak Ridge National Laboratory conducted large scale efforts to develop an immersion process of wax pellets in wallboard. It was found that the immersion process has the potential for providing higher storage capacities than encapsulation of wax pellets (Khudhair et al., 2004). A laboratory scale gypsum wallboard with PCM was developed that used 21-22\% commercial grade butyl stearate (BS). Dispersing agents were added to enhance the mixing process. Furthermore, in addition to the favourable thermal properties obtained, the physical and mechanical properties were quite comparable to those of the ordinary wallboard meaning there was negligible degradation to wallboard structure. In studies conducted by the Fraunhofer institute evaluating the performance of building materials with differing amounts of PCM, it was found that the larger the proportion of PCM, the longer the cooling and heating process lasted (Khudhair et al., 2004).Heim (2005) has shown the effectiveness of gypsum as a means for thermal storage using ESP-r simulation.

Analysis of manufacturing results of PCM/gypsum composite conducted by Hawes et $\mathrm{al}(1993)$ have found that wallboards can absorb up to $50 \%$ of their own weight, however optimal thermal performance was obtained at mass percentage of between $25-30 \%$. Flexural strength of PCM integrated drywall was found to be comparable to conventional wallboard. The absorption of moisture which is undesirable was found to be only one third that of conventional wallboard which makes it well suited for building applications. 


\subsubsection{Experimental simulation of PCM/Gypsum wall board}

As mentioned previously, extensive experimentation has been conducted at the Fraunhofer Institute evaluating the thermal properties of PCM gypsum composite wallboard. For this purpose, two full scale testing rooms were constructed, with one of them using a PCM integrated wallboard and the other utilizing a conventional gypsum wallboard. Both of the rooms were provided identical measuring equipment and were located in the south direction to take advantage of the maximum solar gain (Schossig et al., 2005). The concentration of PCM tested was $20 \%$ and $40 \%$ respectively. The thickness of these samples was $6 \mathrm{~mm}$ and $15 \mathrm{~mm}$ respectively. The transition temperature of the phase change material was between $24^{\circ} \mathrm{C}$ and $27^{\circ} \mathrm{C}$ and it was noticed that at this range, the temperature of the PCM room rose much slowly when compared to other room. After the temperature reached $27^{\circ} \mathrm{C}$, there was a parallel rise in temperature in both of the rooms. Furthermore, the temperature peak was reached one hour later in the PCM room compared to the other room. Figure 3.2 illustrates the temperature profiles of both the PCM wall and the ordinary wall. It is obvious that the PCM contributes significantly in reducing the peak wall temperatures (Schossig et al., 2005).

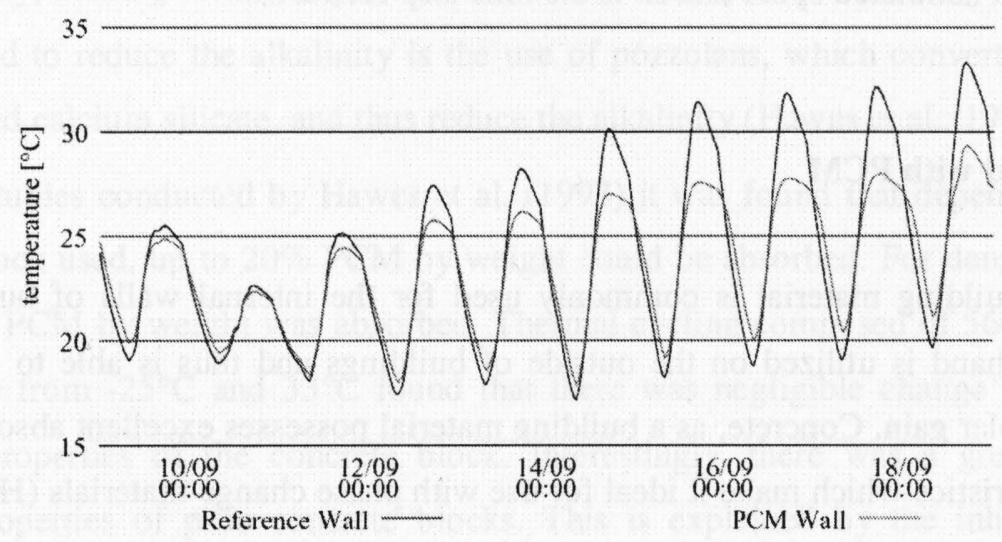

Figure 3.2: Comparison of PCM wall with conventional wall board (Schossig et al., 2005) 


\subsubsection{Numerical Analysis of Composite of PCM/Gypsum}

Darkwa and Kim (2005) have utilized the finite difference method to simulate the storage and recovery processes in a PCM/gypsum composite. Considering a simulated space of $\mathrm{m} \times \mathrm{n} \times \mathrm{s}$ cubic finite volume elements, for a two-dimensional case (i.e. a thin elemental section), the $s$ factor is ignored. Therefore the implicit energy balance for one of the inner elements indexed $j$ at time $i$ can be expressed as:

$$
\begin{aligned}
& \frac{2 k_{j} k_{j-1}}{k_{j}+k_{j-1}}\left(T_{j-1}^{i}-T_{j}^{i}\right)+\frac{2 k_{j} k_{j+1}}{k_{j}+k_{j+1}}\left(T_{j+1}^{i}-T_{j}^{i}\right) \\
& +\frac{2 k_{j} k_{j-n}}{k_{j}+k_{j-n}}\left(T_{j-n}^{i}-T_{j}^{i}\right)+\frac{2 k_{j} k_{j+n}}{k_{j}+k_{j+n}}\left(T_{j+n}^{i}-T_{j}^{i}\right) \\
& +\frac{2 k_{j} k_{j-m n}}{k_{j}+k_{j-m n}}\left(T_{j-m n}^{i}-T_{j}^{i}\right)+\frac{2 k_{j} k_{j+m n}}{k_{j}+k_{j+m n}}\left(T_{j+m n}^{i}-T_{j}^{i}\right) \\
& =\frac{\rho_{j} C_{j}^{i-1} d^{2}}{\Delta t}\left(T_{j}^{i}-T_{j}^{i-1}\right)
\end{aligned}
$$

Where $i$ is index for time step, $j$ for node location, $T$ is the temperature of indexed node, $d$ is the elemental width of simulated space and $\Delta t$ is the time step for FDM.

\subsection{Concrete integrated with PCM}

Gypsum as a building material is commonly used for the internal walls of buildings. Concrete on the other hand is utilized on the outside of buildings and thus is able to directly capture any resulting solar gain. Concrete, as a building material possesses excellent absorptivity and emissivity characteristics which make it ideal for use with phase change materials (Hawes et al., 1989). There are two principal methods by which PCM integrated concrete samples could be produced. The first involves the immersion method, by which fully cured concrete blocks are immersed in liquid PCM to absorb the liquid. The other method is based on the direct incorporation approach, whereby the phase change materials are added to the concrete/water mixture and mixed vigorously to ensure a uniform concentration. This mixture could then be poured into moulds to achieve any desired shape. The advantage of this method is the flexibility in producing a wide variety of concrete/PCM blocks with varying shapes. 
Concrete blocks, because of their versatility, are produced with some minor variations in the ingredients depending on the specific application. Some of the most commonly produced blocks in North America are (Hawes et al., 1989);

- Regular Concrete with limestone aggregate and sand which is steam cured at atmospheric pressure

- Lightweight Concrete using expanded slag aggregate and steam cured at high pressure

- Lightweight Concrete using shale aggregate and steam cured at atmospheric pressure

- Lightweight Concrete using Grecian pumice and aggregate and steam cured at atmospheric pressure.

Because of the difference in the chemical composition of the different types of concrete, it is essential that the exact chemical makeup of the phase change material be determined to prevent any adverse interaction. It is known that the alkaline nature of concrete makes it unsuitable for use with many phase change materials such as fatty acids and fatty esters (Hawes et al., 1989). It is known that autoclaved concrete blocks have low levels of calcium hydroxide and thus have low alkalinity, making them compatible with a wide variety of phase change materials. Another method used to reduce the alkalinity is the use of pozzolans, which convert calcium hydroxide into hydrated calcium silicate, and thus reduce the alkalinity (Hawes et al., 1993).

In studies conducted by Hawes et al. (1993) it was found that depending on the type of concrete block used, up to $20 \%$ PCM by weight could be absorbed. For denser concrete blocks, only $5 \%$ of PCM by weight was absorbed. Thermal cycling composed of 560 cycles, ranging in temperature from $-25^{\circ} \mathrm{C}$ and $33^{\circ} \mathrm{C}$ found that there was negligible change in the physical and structural properties of the concrete block. Interestingly, there was a greater change in the physical properties of pure concrete blocks. This is explained by the inhibition of moisture absorption that phase change materials cause. It is the presence of moisture during the freeze thaw thermal cycling that cause structural damage to the concrete blocks. Tests conducted on flexural strength were also favourable and found no significant change. The energy storage capacity of PCM/Concrete was found to be more than $200-230 \%$ when compared to pure concrete blocks (Hawes et al., 1989). In terms of the manufacturing methods suitable for 
producing PCM integrated blocks, it was found that direct incorporation and immersion are equally effective.

Hawes et al. have conducted several studies investigating the suitability of incorporating phase change materials into concrete (Hawes et al., 1990). Relationship between the method used for curing and the effect it has on the strength, alkalinity and absorptivity was determined. It was determined that steam curing at a high pressure and a temperature of $180^{\circ} \mathrm{C}$ was found to be the most effective manner in which strong and stable concrete could be produced (Hawes et al.,1990). Another parameter that was varied was the temperature of the concrete at immersion. Significant improvements in absoprtivity were noticed when the temperature of concrete was increased to $160^{\circ} \mathrm{C}$, while the PCM was kept at a constant temperature of $80^{\circ} \mathrm{C}$. The use of thinners to increase the absorptivity was also evaluated and found that it had an adverse effect on latent heat of the material. A favourable characteristic that was noticed was a reduction in the absorption of moisture when the concrete was integrated with a phase change material (Hawes et al., 1990). 


\section{CHAPTER 4: ENERGY MODELLING AND ANALYSIS OF PCM}

\subsection{Introduction}

The use of building simulation provides a convenient and accurate platform through which detailed energy modeling of a variety of buildings and structures can be conducted. It is essential for the designer to have an estimate of a variety of important parameters related to energy use in a building such as energy consumption, occupant thermal comfort and system loads. Several methods exist that allow the determination of these parameters described above, through the performance of whole building energy simulations. The most popular methods are the Heat Balance Method, Weighting Factor Method and Thermal Network Method. Several variations have been developed for the Weighting Factor Method to reduce the computational complexity. The most popular of these is the Transfer Function Method (TFM), which relies on weighting factors or Conduction Transfer Functions (CTF) to calculate the heat gain through the various surfaces in a building (McQuiston et al,2004). Table 4.1 provides a summary of some of the most commonly used energy estimating methods.

Table 4.1: Commonly used energy estimating methods (ASHARE Fundamentals Handbook, 2005)

\begin{tabular}{|c|c|}
\hline Method & Comments \\
\hline \multicolumn{2}{|c|}{ Steady State Models } \\
\hline Modified degree day method & Based on fixed reference temperature of $65^{\circ} \mathrm{F}$ \\
\hline Variable base degree day method & Variable reference temperature \\
\hline ASHRAE bin method & $\begin{array}{l}\text { Hours in temperature bin times the load for that } \\
\text { bin }\end{array}$ \\
\hline ASHRAE modified bin method & Modified bin methods with cooling load factors \\
\hline \multicolumn{2}{|c|}{ Dynamic Models } \\
\hline Thermal Networks & $\begin{array}{l}\text { Uses equivalent thermal parameters } \\
\text { (inverse node) }\end{array}$ \\
\hline Response Factors & Tabulated or as used in simulation programs \\
\hline Fourier Analysis & $\begin{array}{l}\text { Frequency domain analysis convertible to the } \\
\text { time domain }\end{array}$ \\
\hline BEVA, PSTAR & $\begin{array}{l}\text { Combination of ARMA and Fourier series, } \\
\text { includes loads in time domain }\end{array}$ \\
\hline Modal Analysis & $\begin{array}{l}\text { Building described by diagonalized differential } \\
\text { equations using nodes }\end{array}$ \\
\hline $\begin{array}{l}\text { Computer simulation } \\
\text { (DOE-2, BLAST) }\end{array}$ & $\begin{array}{l}\text { Hourly simulation programs with system } \\
\text { models }\end{array}$ \\
\hline $\begin{array}{l}\text { Computer simulation } \\
\text { (HVACSIM+, TRNSYS) }\end{array}$ & Sub-hourly simulation programs \\
\hline
\end{tabular}


These methods rely on their accuracy through a detailed accounting of energy flows into and out of the building every hour. The time step can be reduced further from an hour, if additional accuracy is desired. One of the drawbacks of these methods is the tedious nature of the calculations involved, which makes them particularly well suited for implementation on the computer. A variety of commercial and educational versions of whole building simulation software exist in the marketplace to assist with the performance of detailed annual energy simulations. They range in complexity from easy to use GUI interface with self explanatory inputs for the novice user to standalone simulation engine with DOS Inputs for the expert user. Some of the most commonly used building simulation software includes ESP-r, TRNSYS, EnergyPlus, eQUEST etc.

\subsection{Energy Estimating Methods}

Transient heat conduction into a building is a complex non-linear process that depends on a range of factors. While heat loss from a building is strongly dependent on the outdoor air temperature, heat gain, which is a measure of the rate of energy transfer into the building, relies on several factors. These include (McQuiston et al., 2005):

- Solar radiation through the windows

- Heat conduction through the walls and other surfaces

- Sensible and latent heat from internal objects such as electrical equipment and people.

- Ventilation and infiltration of outside air into the conditioned space.

While these heat gains are undesirable during the summer as they contribute to the cooling load, during the winter months, they assist in reducing the heating load. The sizing of the air-conditioning equipment would strongly be dependent on the cooling load of the building. The presence of thermal mass in the building could be used to delay the cooling load to a later time during the day, when the temperatures have moderated.

The heat conduction through a wall or a roof can be expressed through a differential equation with time dependent boundary conditions. A simplifying assumption that is made is to 
consider the wall and roof assembly as single homogeneous slab. This is shown by Equation (4.1) below:

$$
\frac{\partial T}{\partial t}=\frac{k}{\rho C_{p}} \frac{\partial^{2} T}{\partial x^{2}}
$$

Where:

$T=$ the local temperature at a point in the slab, ${ }^{\circ} \mathrm{C}$

$t=$ time, sec

$k / \rho C_{p}=$ thermal diffusivity of the slab, $\mathrm{m}^{2} / \mathrm{s}$

$x=$ length, $\mathrm{m}$

Due to the analytical complexity of this problem, with the interior and exterior surface temperatures to be determined simultaneously, the problem can only be solved through the use of a computer. The solution methodology used to solve this problem forms the basis of the heat balance method.

\subsubsection{Heat Balance Method}

The heat balance method derived from the first law of thermodynamics, provides for a detailed accounting of all the energy flows through a building. This is accomplished through the use of energy balance equations for zone air and all the interior and exterior surfaces of each wall, roof and floor. The planar surfaces are treated differently from the solid surfaces such as walls and roof. The solid surfaces are subjected to transient conduction heat transfer equations. These sets of equations are then combined with weather data to incorporate parameters such as dry bulb temperature, solar radiation etc. The method can be illustrated by considering a building with six surfaces, four walls, a roof and a floor. The energy balance equations for a surface of a single wall or roof element can be written for the $j$ exterior surface at time $t$. This is shown by Equation (4.2) below (McQuiston et al, 2004):

$$
q_{\text {conduction }, \text { ext }, j, t}^{\prime \prime}=q_{\text {solar }, \text { ext }, j, t}^{\prime \prime}+q_{\text {convection }, \text { ext }, j, t}^{\prime \prime}+q_{\text {radiation }, \text { ext }, j, t}^{\prime \prime}
$$


Where:

$$
\begin{aligned}
& q_{\text {conduction, }, x t, j, t}^{\prime \prime}=\text { conduction heat flux, } \mathrm{W} / \mathrm{m}^{2} \\
& q_{\text {solar }, e x t, j, t}^{\prime \prime}=\text { absorbed solar heat flux, } \mathrm{W} / \mathrm{m}^{2} \\
& q_{\text {convection, }, \text { ext }, j, t}^{\prime \prime}=\text { convection heat flux, } \mathrm{W} / \mathrm{m}^{2} \\
& q_{\text {radiation, }, x t, j, t}^{\prime \prime}=\text { thermal radiation, } \mathrm{W} / \mathrm{m}^{2}
\end{aligned}
$$

Similar equations for the heat balance can be written for the $j$ th interior surface at time $t$. This is shown below in Equation (4.3).

$$
q_{\text {conduction }, i n, j, t}^{\prime \prime}+q_{\text {solar }, \text { in }, j, t}^{\prime \prime}=q_{\text {convection }, i n, j, t}^{\prime \prime}+q_{\text {radiation }, i n, j, t}^{\prime \prime}
$$

Where:

$$
\begin{aligned}
& q_{\text {conduction, }, \mathrm{n}, j, t}^{\prime \prime}=\text { conduction heat flux, W/m } \mathrm{m}^{2} \\
& q_{\text {solar }, i n, j, t}^{\prime \prime}=\text { absorbed solar heat flux, } \mathrm{W} / \mathrm{m}^{2} \\
& q_{\text {convection, }, \mathrm{n}, j, t}^{\prime \prime}=\text { convection heat flux, } \mathrm{W} / \mathrm{m}^{2} \\
& q_{\text {radiation, }, \mathrm{n}, j, t}^{\prime \prime}=\text { thermal radiation, } \mathrm{W} / \mathrm{m}^{2}
\end{aligned}
$$

Figure 4.1 shows a schematic illustrating all the energy balances occurring at the interior and exterior surfaces. The energy balance at the interior and exterior surfaces is shown to illustrate the flow of energy through the building. The outside surface is subjected to direct solar radiation, convection from the air surrounding it and indirect radiation from other surfaces. The heat transfer through the exterior surface into the building is by means of conduction heat transfer. The heat conducted through the interior surface is balanced by the radiation escaping from the building and the convection and radiation generated as a result of the conduction through the interior surface. The heat balance equations for the zone air follows a similar methodology, whereby the total energy flow in is balanced the total outflow. In this case, the total heat gain/loss of the indoor air must take into account the infiltration, convection as a result of the internal gains and the heating/cooling energy delivered by the heating/cooling system. 


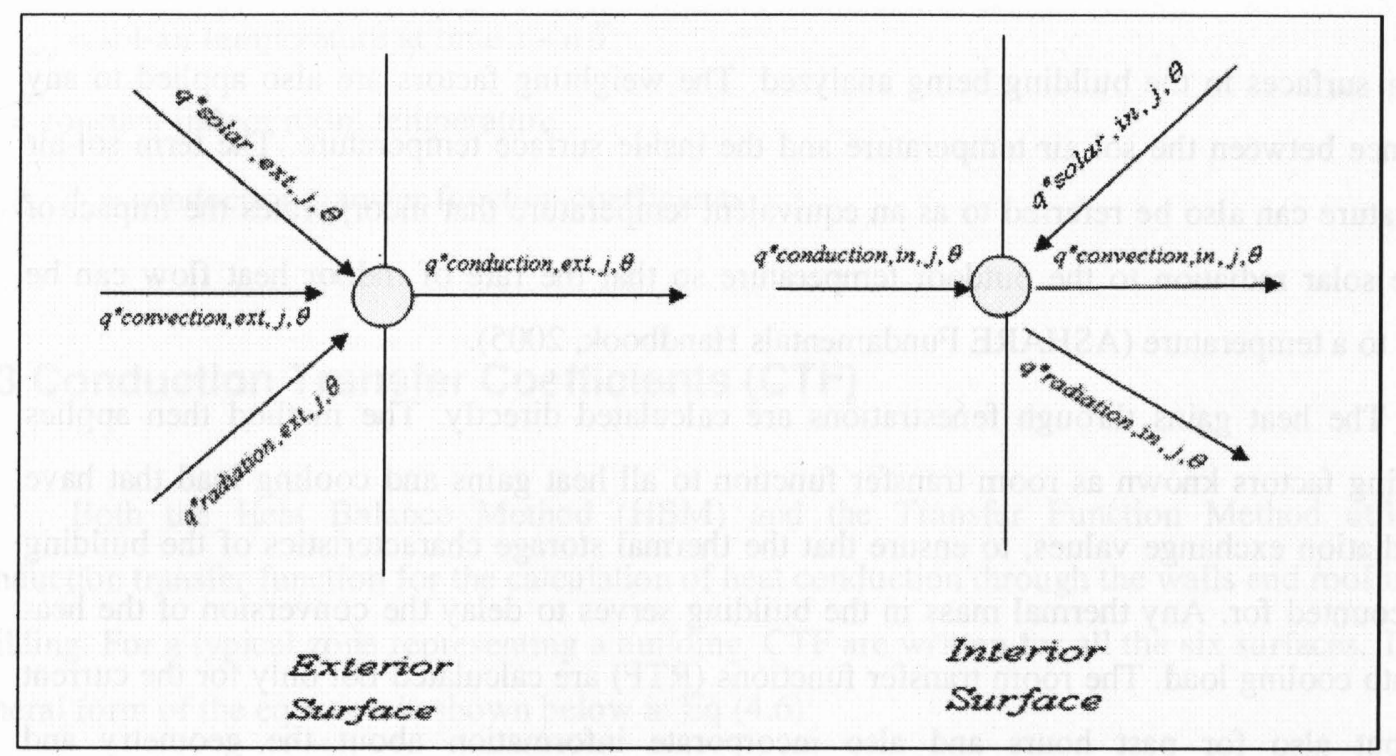

Figure 4.1: Graphical representation of the energy balance at the interior and exterior surfaces (McQuiston et al, 2004)

Finally, the heat balance equations can be written for the zone air. This is shown below in Equation (4.4):

$$
\sum_{j=1}^{N} A_{j} q_{\text {convection }, i n, j, t}^{\prime \prime}+\dot{q}_{\text {inf iltration }, t}+\dot{q}_{\text {system }, t}+\dot{q}_{\text {int ernal, }, \text { conv }, t}=0
$$

Where:

$A_{j}=$ area of the $j$ th surface, $\mathrm{m}^{2}$

$\dot{q}_{\text {inf iltration, }}=$ heat gain due to infiltration, $\mathrm{W}$

$\dot{q}_{\text {system,t }}=$ heat gain due to heating/cooling system, W

$\dot{q}_{\text {int ernal,conv, }}=$ convective portion of internal heat gains due to people, lights or equipment, $\mathrm{W}$

\subsubsection{Transfer Function Method}

The transfer function method represents a simplification of the heat balance method through the use of a two step process whereby the heat gains from all sources are first determined and then converted into a corresponding cooling load value. The method similar in nature to the weighting factor method applies conduction transfer functions coefficients $(\mathrm{CTF})$ to the various 
exterior surfaces in the building being analyzed. The weighting factors are also applied to any difference between the sol-air temperature and the inside surface temperature. The term sol-air temperature can also be referred to as an equivalent temperature that incorporates the impact of outside solar radiation to the outdoor temperature so that the rate of indoor heat flow can be related to a temperature (ASHARE Fundamentals Handbook, 2005).

The heat gains through fenestrations are calculated directly. The method then applies weighting factors known as room transfer function to all heat gains and cooling load that have any radiation exchange values, to ensure that the thermal storage characteristics of the building are accounted for. Any thermal mass in the building serves to delay the conversion of the heat gain into cooling load. The room transfer functions (RTF) are calculated not only for the current hour but also for past hours and also incorporate information about the geometry and configuration of the building. These transfer functions, in simple terms relate an output function at a given time to a driving function.

The calculation methodology for transfer function method (TFM) ensures that a detailed hourly cooling load estimate be made, with the ability to predict the load under varying environmental conditions. A few simplifying assumption made in this method include using the sol-air temperature to represent the outdoor dry bulb temperature, a constant indoor temperature and constant values for the indoor and outdoor surface heat transfer coefficients. Equation (4.5) below presents the terms utilized by the TFM to calculate heat gain through a wall or a roof (ASHARE Fundamentals Handbook, 2005).

$$
q_{e, t}=A\left[\sum_{n=0} b_{n}\left(T_{e, t-n \delta}\right)-\sum_{n=1} \frac{d_{n}\left(q_{e, t-n \delta}\right)}{A}-T_{r c} \sum_{n=0} c_{n}\right]
$$

Where:

$q_{e, t}=$ heat gain through roof or wall at time $t$

$A=$ indoor surface area of a wall or roof

$t=$ time

$\delta=$ time interval

$n=$ summation index 
$T_{e, t-n \delta}=$ sol-air temperature at time $t-n \delta$

$T_{r c}=$ constant indoor room temperature

$b_{n}, c_{n}, d_{n}=$ conduction transfer function coefficients

\subsection{Conduction Transfer Coefficients (CTF)}

Both the Heat Balance Method (HBM) and the Transfer Function Method utilize conduction transfer function for the calculation of heat conduction through the walls and roof in a building. For a typical zone representing a building, CTF are written for all the six surfaces. The general form of the equation is shown below in $\mathrm{Eq} \mathrm{(4.6):}$

$$
q_{i n, t}=\sum_{m=1}^{M} Y_{k, m} T_{o, t-m+1}-\sum_{m=1}^{M} Z_{k, m} T_{i n, t-m+1}+\sum_{m=1}^{M} F_{m} q_{i n, t-m}
$$

Where:

$q=$ rate of heat conducted into a specific surface at a particular time

in $=$ inside surface subscript

$k=$ order of the CTF

$m=$ time index variable

$M=$ number of non-zero CTF values

$o=$ outside surface subscript

$T=$ temperature

$t=$ time

$x=$ exterior CTF values

$Y=$ cross $\mathrm{CTF}$ values

$Z=$ interior CTF values

$F_{m}=$ flux history coefficients

\subsection{Other Energy Calculation Methods}

A variety of other building energy calculation methods are also in existence and could be utilized depending on the circumstances. These include the Total Equivalent Temperature 
Differential Method (TETD), which uses response factors with wall and roof assemblies to calculate TETD values as a function of the sol-air temperature and the indoor temperature. All the relevant heat gains are added to the internal gains and used to define a cooling load. Due to the complexity of this method, it is better to implement it on the computer for better results (ASHARE Fundamentals Handbook, 2005). Thermal Network Method is another commonly used building energy transfer calculation tool that utilizes nodes within the building to define temperature and thermal energy flow. It is a refinement of the heat balance method, which considers only one node for the zone air. The equations underlying the Thermal Network Method include ordinary differential equations, which can be solved using a range of methods including graph theory with the Newton-Raphson Method and the Euler explicit integration method. Compared to other methods, the Thermal Network Method produces fairly accurate results but at the expense of increased computational effort (ASHARE Fundamentals Handbook, 2005).

\subsection{Simulations with TRNSYS}

TRNSYS, an acronym for Transient Systems Simulations, is a comprehensive and powerful building simulation software that can provide whole building simulations with the added capability of easily integrating a variety of renewable energy and HVAC components. It is this software that would be utilized for conducting detailed energy simulations on a variety of building models to assess the impact of integrating thermal mass and phase change materials (PCM) into the building envelope (TRNSYS, 2006).

TRNSYS is a modular simulation program, based on the FORTRAN programming language. It utilizes standalone components and mathematical modules for a wide variety of applications, such as heat pumps and PV panels etc, in a user-friendly graphical interface. Each of these components can be connected together to represents the flow of information during the simulation. The TRNSYS engine calls the system components based on the input file and iterates at each time-step until the system of equations is solved. Weather data is needed to perform the simulations with TRNSYS. TRNSYS runs through hourly values of various weather parameters included in a typical meteorological year (TMY) file. The weather file included with TRNSYS contains detailed weather data for thousands of locations around the world (Klein et al., 1998). Each component in TRNSYS is defined as a TYPE and contains all the relevant mathematical parameters to integrate it in to the overall TRNSYS model. Building models are defined as TYPE 56. 
The DLL-based architecture allows users and third-party developers to easily add custom component models, using all common programming languages $(\mathrm{C}, \mathrm{C}++$, PASCAL, FORTRAN, etc.). In addition, TRNSYS can be easily connected to many other applications, for pre- or post processing or through interactive calls during the simulation (e.g. Microsoft Excel, Matlab, COMIS, etc.). Some of the commonly used TRNSYS applications include (TRNSYS, 2006):

- Solar systems (solar thermal and PV)

- Low energy buildings and HVAC systems with advanced design features (natural ventilation, slab heating/cooling, double façade, etc.)

- Renewable energy systems

- Cogeneration

- Fuel cells

\subsubsection{TRNSYS Suite}

One of the factors that make TRNSYS especially user friendly is the interconnectedness of a suite of software programs that combine to form the overall software package. These include the TRNSYS Simulation Studio (TRNExe.exe), the building interface program called TRNBuild (TRNbuild.exe) and TRNED (TRNEd.exe). The Simulation Studio forms the heart of the package, and utilizes a graphical user interface whereby the user can visually drag and drop a variety of components into the workspace (TRNSYS, 2006). These components can be connected to each other through the use of relationships that depend upon the logical flow of information. Each component has associated with it a set of inputs and outputs. As an example, a pump would have an input of total flow rate of water entering it, while an output could be the total electrical consumption of the pump. The Simulation Studio also includes an output manager where all the variables are integrated, printed or plotted, and a detailed error log that provides information on the source of errors that prevent a simulation from running to completion. Figure 4.2 shows a screenshot of the TRNSYS Simulation Studio. The interconnection between the various components is illustrated. In this case, a model of a solar hot water collector system is depicted. The connections between the various components closely resembles the actual physical model of a solar hot water collector. The connection for the solar collectors is linked to the hot water tank, as would normally be the case for a physical system. 


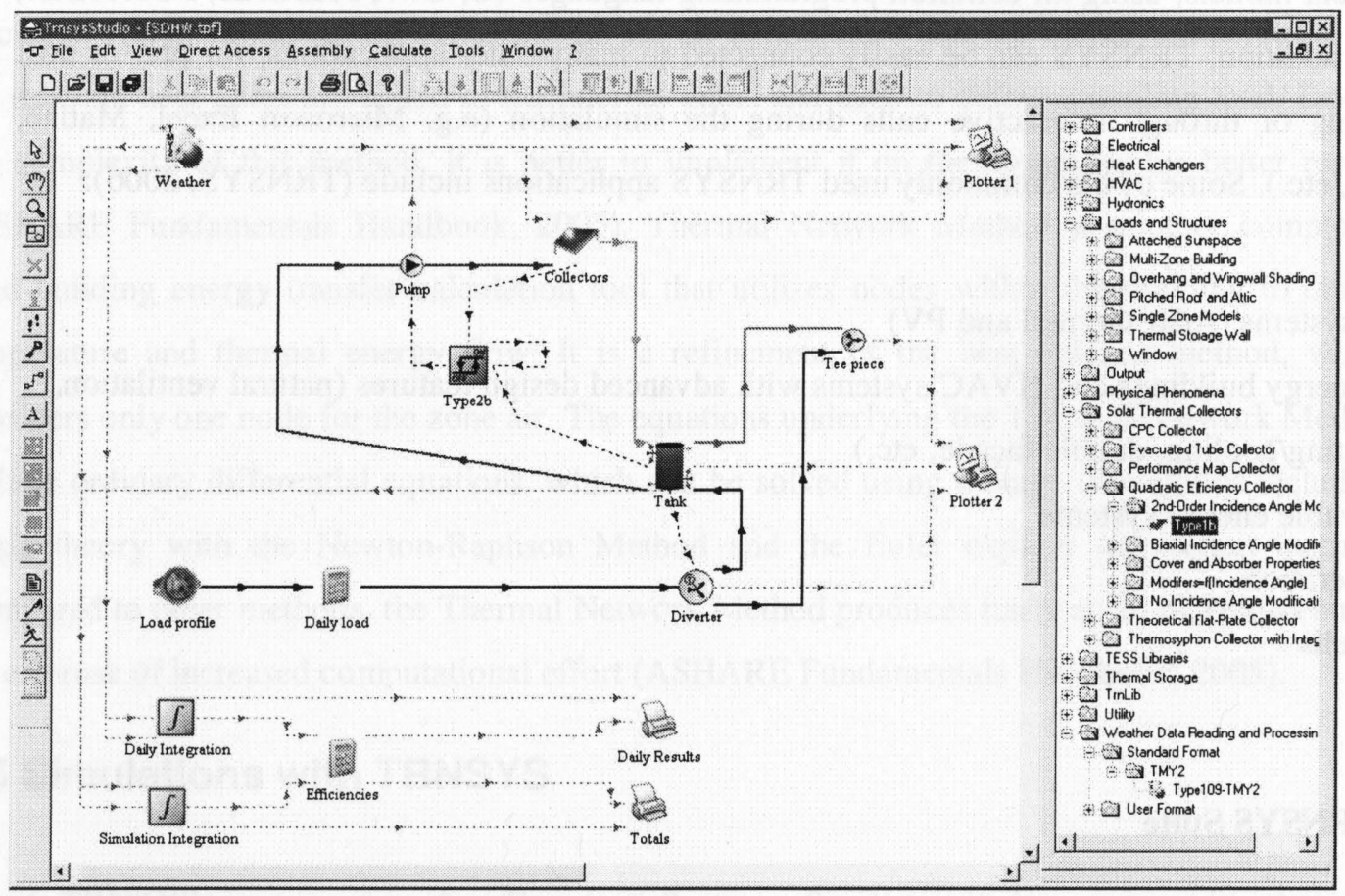

Figure 4.2: TRNSYS Simulation Studio (TRNSYS, 2006).

TRNSYS also includes a powerful building interface called TRNBuild, which is a comprehensive modeling tool that can be used to define a variety of parameters of a building envelope. It generates a BUI file that can be incorporated into the TRNSYS Simulation Studio. Unlike other building simulation programs, in TRNSYS, the Simulation Studio and building files are kept separate, which enables modifications to be made to the components connecting to the house without affecting the building model. TRNBuild also contains detailed libraries containing data for windows, walls, shading, ventilation etc. Figure 4.3 provides a graphical representation of TRNBuild.

TRNEdit is a specialized editor in TRNSYS that enables the user to create and compile a variety of new components that can be integrated into TRNSYS Simulation Studio. One factor that makes it particularly powerful is the ability to create executable files of any new components, which can then be distributed to any end users who do not have a licenced version of TRNSYS (TRNSYS, 2006). 


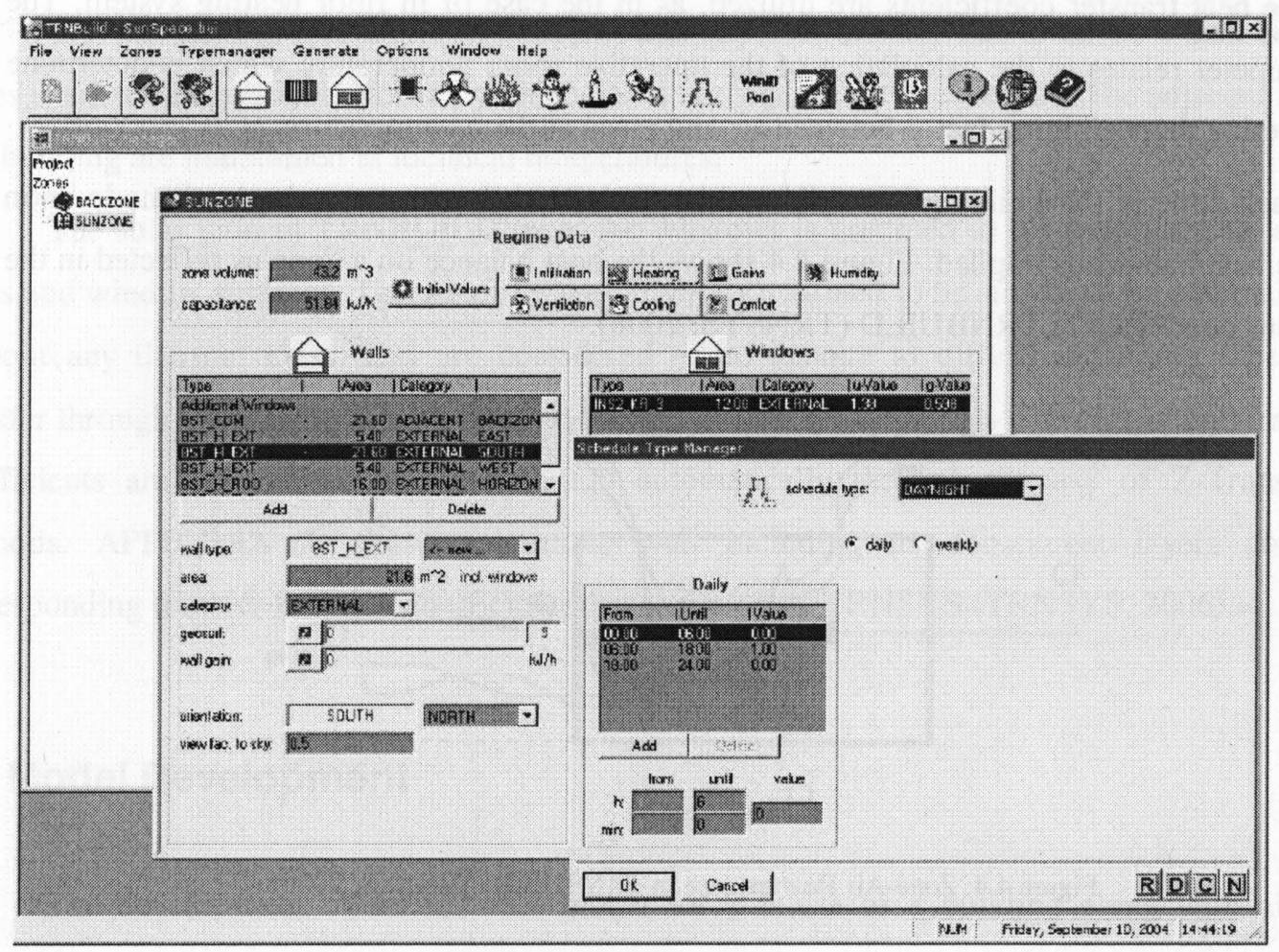

Figure 4.3: Graphical representation of TRNBuild (TRNSYS, 2006).

\subsection{Building Energy Transfer in TRNSYS}

Since TRNSYS provides the user the capability of analyzing transient heat conduction in buildings, the ASHRAE Transfer Function Method as described in Section 4.2, is the most appropriate method for conducting the analysis and is used by TRNBuild for the calculation of energy flow in buildings. The analysis procedure that TRNBuild uses is to divide the building into a thermal zone. The TRNBUILD program then reads in and processes a file containing the building description and generates two files that will be used by the TYPE 56 component during a TRNSYS simulation (TRNSYS, 2006).

The building description file processed by TRNBUILD can also be generated by any commonly used text editor. In order to complete the simulation, a total of three parameters are required by the TYPE 56 component. The first parameter is the FORTRAN logical unit for the data file with the building data (*.BUI). The second parameter is set to 1 if time-dependent 
convective heat transfer coefficients are utilized, as in the case of in floor heating system. The third parameter relates to the calculation of the operative room temperature which is determine by considering the weighting factor between air and mean surface temperature.

Each zone in the building is considered by TRNBUILD to have a single air-node upon which the heat balance is applied. Figure 4.4 shows the heat balance on a zone as reflected in the calculations conducted in TRNBUILD (TRNSYS, 2006).

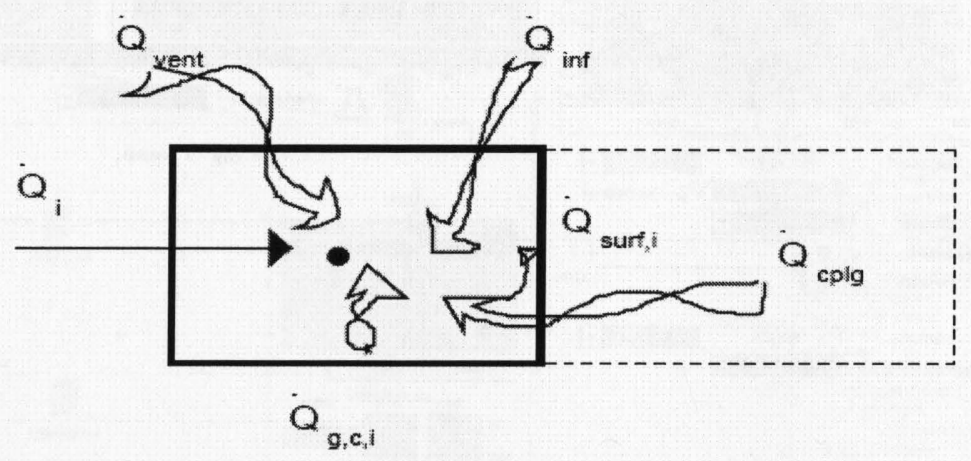

Figure 4.4: Zone-Air Heat balance in TRNBUILD (TRNSYS, 2006).

Utilizing the heat balance method, the energy transfer equations can be written as shown in Eq (4.7) below:

$$
\dot{Q}_{i}=\dot{Q}_{\text {surf }, i}+\dot{Q}_{\mathrm{inf}, i}+\dot{Q}_{v e n t}+\dot{Q}_{g, c, i}+\dot{Q}_{c p \lg , i}
$$

Where:

$\dot{Q}_{i}=$ the total heat gain for the zone (W)

$\dot{Q}_{\text {surf }, i}=$ convective heat flow from all the inside surfaces (W)

$\dot{Q}_{\text {inf }, i}=$ total infiltration gains (W)

$\dot{Q}_{\text {vent }}=$ gains from ventilation $(\mathrm{W})$

$Q_{g, c, i}=$ gains from people, equipment, lighting etc, (W)

$\dot{Q}_{c p \lg , i}=$ gains due to airflow from other zones (W) 
The last term in Equation (4.7) ensures that any heat transfer due to air flow between the zones is taken into account. Normally, this term is not significant in case when the adjacent zones in a building are maintained at identical temperatures.

The solar gain in TRNBUILD from the windows is assumed to be distributed to all the walls and window surfaces. The windows are thermally assumed to be similar to an external wall without any thermal mass, and are considered to be opaque to diffuse radiations. The heat transfer through walls is dealt with through the use of transfer functions. The conduction transfer coefficients are determined by TRNBUILD automatically through the use of Z-Transform methods. APPENDIX A shows a sample wall including its constituent layers and its corresponding transfer function coefficients as calculated by TRNSYS (TRNSYS, 2006).

\subsection{Model Development}

The development of an accurate model for a house or a building along with all the relevant parameters that define its unique characteristics is essential for the evaluation of the impact of any factor such as the use of thermal mass and phase change materials. Any investigation of the impact of thermal mass in a building must also take into account the unique properties of the building envelope. Buildings that are highly insulated behave in a significantly different manner when it comes to heat transfer and storage than buildings that are of light construction, when it comes to the indoor temperature fluctuations and comfort levels. Utilizing this fact, a total of two different house models representing buildings with unique building envelopes and equipment were developed in TRNSYS. These models consist of the Toronto SUI Net Zero Townhouse in the Davenport Road neighbourhood of downtown Toronto (Sustainable Urbanism Initiative, 2006) and the CCHT Twin Research House in Ottawa, ON (Natural Resources Canada, 2004). While the latter represents a home constructed according to the conventional and popular construction standard in Canada, the R-2000, and the former is a state of the art housing project, with a goal of demonstrating the feasibility of net zero energy housing in Canada. The selection of a particular model for the integration of thermal mass depends on the desired objectives of the designer. The response of a net-zero energy house to any changes in the building envelope would be significantly different when compared to a typical R-2000 house. 
The focus of this thesis would be on the implementation of thermal mass in the Toronto Net Zero Energy house.

\subsection{Toronto SUI Net Zero House}

The Toronto Net Zero Energy house represents an award winning design initiative that represents the collaboration between the Sustainable Urbanism Initiative Toronto (SUI) and a host of architectural and engineering firms, with the objective of increasing public awareness and adoption of energy efficient homes in Canada. In order to conduct detailed simulations and analyses of the impact of using phase change materials, a detailed model of the Net Zero Energy House located in the downtown area of Toronto, ON is developed in TRNSYS. Detailed information about the input parameters used in the modelling of the Toronto Net Zero Energy House are presented in APPENDIX D.

The concept behind a Net Zero or Low Energy house is the design of thermal and structural systems for a residential unit in a manner that minimizes the energy consumption with the aim of making the house energy self sufficient. This is achieved through the use of high quality insulation materials and the utilization of renewable energy technologies such as PV and geothermal for production of energy. The townhouse has a heated area of $210 \mathrm{~m}^{2}$ and the orientation of the house is $37^{\circ}$ west of south. The orientation and location of the houses have been optimized to ensure that a maximum amount of solar energy can be captured to operate the photovoltaic and solar thermal panels for the generation of electricity and hot water respectively for the house. A ground source heat pump is also utilized during the winter to provide a reliable and efficient source of heating. Figure 4.5 shows a computer generated 3-D model of the house. The building envelope of the Net Zero Energy House is designed with intention of minimizing the heat transfer to the outside, thereby saving energy and contributing to occupant thermal comfort. However, one of the drawbacks with a highly insulated building envelope is the potential for over-heating as a result of any solar gains. This fact should be taken into consideration in the design of the building envelope to ensure that there is a thermal storage capacity within the building envelope to absorb any unneeded solar gains. The Toronto Net Zero Energy house is of a light weight construction and due to the large glazing area, is highly susceptible to over heating during both the winter and summer seasons. It is this fact that makes a building such as ideal for the implementation of thermal mass for the comfort of the indoor occupants. 


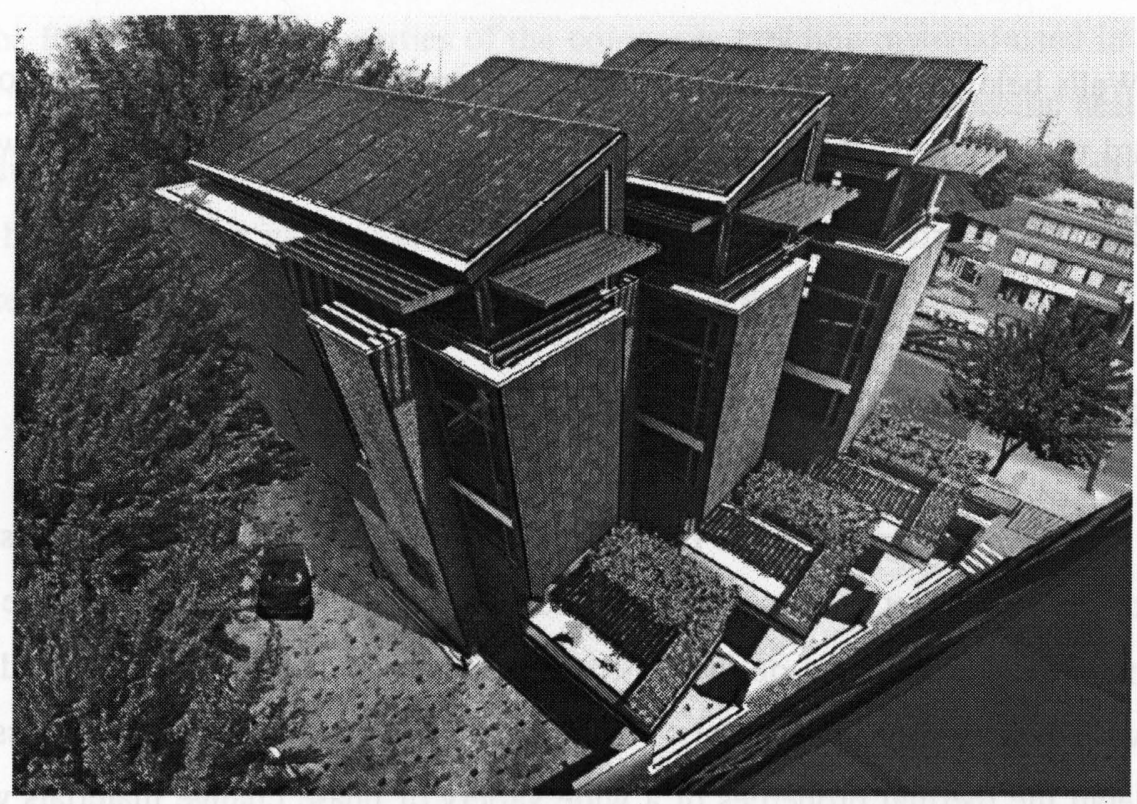

Figure 4.5: 3-D computer representation of one of the three identical Toronto Net Zero Energy Homes (Sustainable Urbanism Initiative Toronto, http://www.sui-toronto.com, 2008)

The external walls have been insulated with sprayed polyisocyanurate foam insulation, which provides an overall insulation value of R-60 (RSI-10.6).The roof assembly consists of drywall on $19 \times 19 \mathrm{~mm}$ furring and $0.15 \mathrm{~mm}$ polyethylene vapour retarder attached to the bottom of the $294 \mathrm{~mm}$ pre-engineered I-joists. Sprayed polyisocyanurate foam is applied between joists as roof insulation. Table 4.2 shows the various layers used within the building envelope.

Table 4.2: Wall layers used in the Net Zero Energy House

\begin{tabular}{|l|}
\hline Gypsum Board (Dry Wall), $13 \mathrm{~mm}$ \\
\hline $19 \times 19 \mathrm{~mm}$ Furring \\
\hline Polyethylene Vapour Retarder, 0.15mm \\
\hline (2x6) Wood Studs @600mm (24") O.C \\
\hline Sprayed Polyisocyanurate Closed Cell Foam 139mm RSI-6.5 \\
\hline OSB Structural Sheathing with STO Gold Coat 13mm \\
\hline $\begin{array}{l}\text { Rigid Insulation-Extruded Polystyrene 100mm RSI 3.48 } \\
\text { (R-20) }\end{array}$ \\
\hline Air Space 25mm \\
\hline Face Brick 100mm \\
\hline
\end{tabular}

The roof has an insulation value of R-76 (RSI-13.4). The windows used in the house have low emissivity and are argon filled with a fibreglass frame and have an overall insulation value of 
R-4 (RSI-0.7). Walls below grade are of the insulating concrete form and have a 2.5 in of rigid polystyrene board with a waterproof membrane. The overall insulation value of the below grade wall is R-35(RSI-6.27).

\subsection{TRNSYS Type 204 PCM Component}

Prior to the development of the TYPE 204 model in TRNSYS, it was impossible to directly simulate the real effect of heat transfer through a wall containing PCM. While in the past, most of the work was focussed on the experimental analysis of building integrated PCM, more recently, with the development of robust building simulation software, it is now possible to investigate in detail the thermal properties of a wide variety of phase change materials without the need for elaborate experimentation.Building simulation also provides a valuable tool for validation of the experimental data.

Despite the abundance of research in the field of building integrated PCM, one area where relatively little attention has been focussed on, is the integration of PCMs with building modules developed using some of the widely used building simulation software such as TRNSYS, EnergyPlus and ESP-r etc. Prior to the development of the TYPE 204 PCM module in TRNSYS, the only manner in which effect of PCMs in buildings could be investigated was through the development of an active layer within the building envelope. Ibanez et al(2005) presented a methodology in TRNSYS, whereby through the definition of an active wall, containing tubes, through which a fluid was circulated; the overall thermal effect of phase change materials could be determined. Even though this approach did not simulate the real heat transfer process through a PCM wall, the overall impact in terms of energy transfer was quite similar to what would be expected with a PCM integrated wall (Ibanez et al, 2005).

The TYPE 204 component was developed in FORTRAN and integrated into TRNSYS by a team based at the Helsinki University of Technology (Lamberg, 2003). Utilizing the finite difference method with a Crank-Nicholson scheme, the model simulates heat transfer through a 3-D PCM composite wall component containing a total of 729 node (9 nodes each in the $x, y$ and $\mathrm{z}$ directions). At each node, the conduction and convection heat transfer, along with the temperature is calculated (Ahmad et al, 2006). The surface nodes deal with the radiation heat transfer. The 3-D wall element can be defined precisely to specify the concentration and melting 
points of the PCM used. The properties of the composite building material used in conjunction with the PCM can also be easily defined. To account for the changes in specific heat capacity of the PCM due to temperature variations, the model uses the effective heat capacity method to define the heat capacity at each phase, i.e liquid or solid. The effective heat capacity method approximates the specific heat capacity by (Jokisalo et al, 1999):

$$
\begin{aligned}
& C_{e f f}=\frac{L_{H}}{T_{e}-T_{o}}+C \\
& C_{e f f}=\left\{\begin{array}{lr}
C_{s} & T<T_{o} \\
\frac{L_{H}}{T_{e}-T_{o}}+C & T_{o} \leq T \leq T_{e} \\
C_{f} & T>T_{e}
\end{array}\right.
\end{aligned}
$$

Where:

$C_{\text {eff }}=$ Effective Specific heat, $\left(\mathrm{J} \mathrm{kg}^{-1} \mathrm{~K}^{-1}\right)$

$L_{H} \quad=$ Latent heat of fusion, $\left(\mathrm{J} \mathrm{kg}^{-1}\right)$

$T_{o}=$ Temperature at the onset of the melting process, $\left({ }^{\circ} \mathrm{C}\right)$

$T_{e}=$ Temperature at the end of the melting process, $\left({ }^{\circ} \mathrm{C}\right)$

$C_{s}=$ Specific heat at the solid state, $\left(\mathrm{J} \mathrm{kg}^{-1} \mathrm{~K}^{-1}\right)$

$C_{f}=$ Specific heat at the liquid state, $\left(\mathrm{J} \mathrm{kg}^{-1} \mathrm{~K}^{-1}\right)$

The Type 204 PCM module in TRNSYS has the following input paramters that must be entered into the model to accurately represent a particular phase change material. These properties are described in detail below:

- Number of Iterations: This parameter can be give any value between 1 and infinity and is used primarily for the sake of accuracy. Utilizing more than one iteration would involve the solution of relevant heat transfer equations multiple times and generally provide more accurate solutions. The only drawback is increased computation time. 
- Melting Temperature: This characteristic is concerned with the initial temperature during which the phase change material undergoes phase transition.

- Crystallization Temperature: The crystallization temperature is determined by the point where the PCM changes phase back to a solid. This temperature is always lower than the melting temperature.

- Range in Crystallization Temperature: Unlike pure materials such as water which changes phase at a distinct temperature of $0^{\circ} \mathrm{C}$, most phase change undergo the phase change process within a temperature range. This parameter could be used to define the phase change range of a particular PCM.

- Latent Heat of PCM: This parameter measures the total heat storage / release capacity of a particular phase change material at the phase change temperature.

- PCM Density: The density of the pure PCM can be entered into the model using this parameter.

- $\quad$ PCM $C_{p}$ : This parameter is concerned with the specific heat capacity of the PCM. It is an important characteristic since it provides a measure of the energy storage/release capacity of a particular PCM at a temperature outside the temperature range of phase transition.

- Density of Other Material in PCM Node: The density of any other that has been integrated with the PCM can be entered through this parameter

- $C_{p}$ of Other Material: The specific heat capacity of any other materials incorporated with the PCM can be entered through this parameter.

- Volume Fraction of PCM in Node: The overall concentration of PCM in a particular specimen can be entered through this parameter. Since most studies characterize the overall concentration of PCM by weight, this value must be converted into volume fraction to reflect the input requirements of the parameter.

\subsection{Simulation Parameters}

For the particular case study on the Toronto Net Zero Energy house, the weather data for the city of Toronto is used. For each of the different scenarios, the simulations are run for one year with a time step of one hour, as is the standard in typical building simulation analysis. The simulations are run with the house unconditioned, which means that other than the solar gain and 
heat loss, there is no artificial heating or cooling of the house. This is to ensure that the there is no interference with the heating/cooling equipment of the thermal mass effect provided by the building envelope. The house consists of 5 zones which represent the Garage, 1st Floor, 2nd Floor, 3rd Floor and Mezzanine. As a means of comparison all of the results shown are for the 3rd floor of the house, since this is the location where the temperature peaks and fluctuations are expected to be the greatest because of the large glazing area. Figure 4.6 illustrates the complete TRNSYS model of the Toronto Net Zero Energy house with the Type 204 model integrated within the building model.

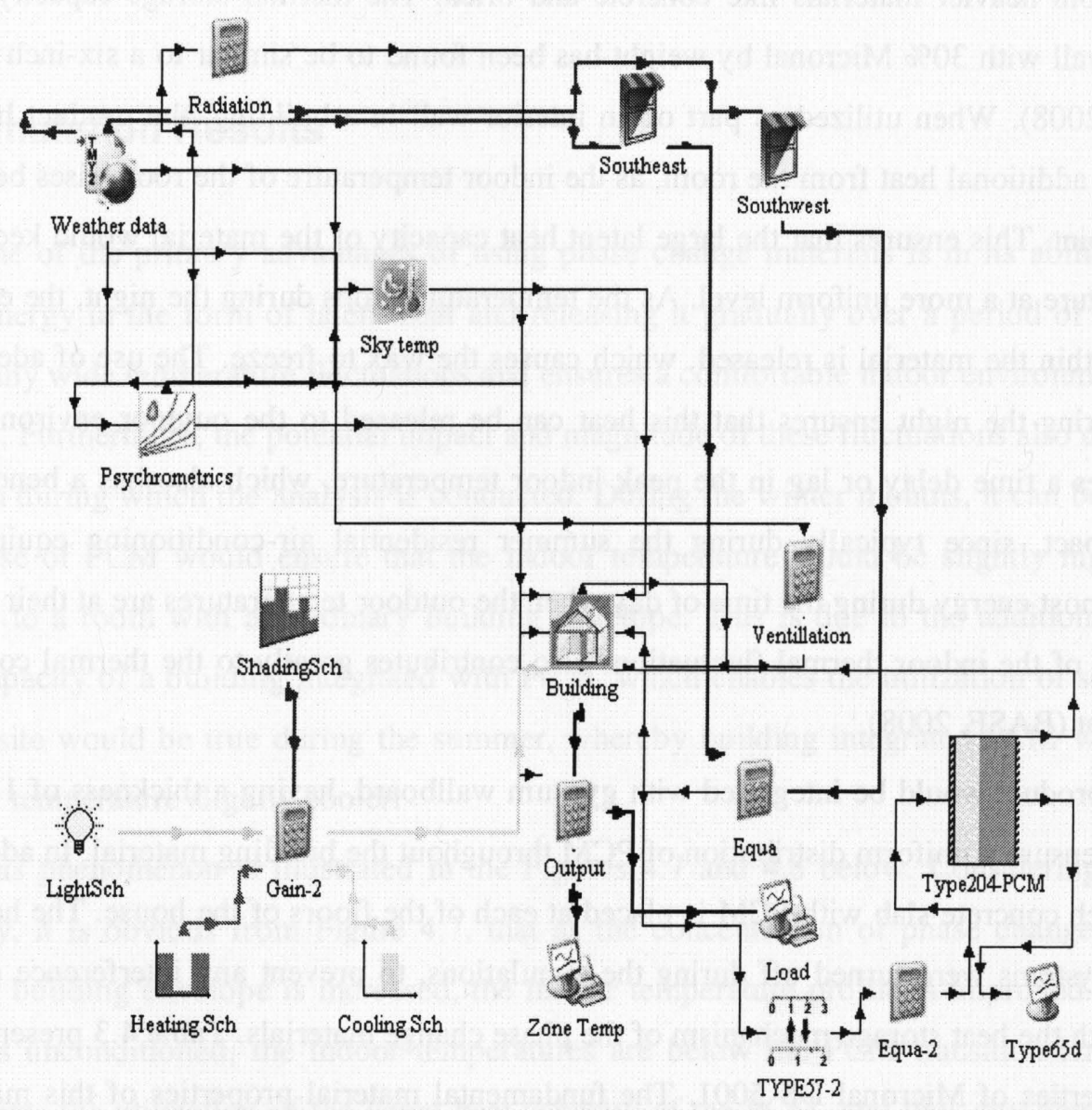

Figure 4.6: TRNSYS Model of the Toronto Net Zero Energy House 


\subsection{PCM Material Properties:}

For the purposes of the simulation, a commercial phase change material product by the name of MICRONAL DS 5001 would be utilized. Manufactured by BASF, the PCM is composed of microscopically encapsulated plastic spheres containing a wax medium. The wax is contained inside hard acrylic polymer shells, with the total diameter of the shell of only 2 to 20 micrometers. It has a melting temperature of between $23^{\circ} \mathrm{C}-26^{\circ} \mathrm{C}$ and a latent heat of $110 \mathrm{~kJ} / \mathrm{kg}$ (BASF,2008).The use of Micronal has been demonstrated to enable modern buildings of a lightweight construction to provide a similar degree of comfort to what is experienced in buildings constructed from heavier materials like concrete and brick. The thermal storage capacity of a half-inch drywall with $30 \%$ Micronal by weight has been found to be similar to a six-inch brick wall (BASF, 2008). When utilized as part of an interior wall in a building, the product begins absorbing any additional heat from the room, as the indoor temperature of the room rises beyond the melting point. This ensures that the large latent heat capacity of the material would keep the room temperature at a more uniform level. As the temperature drops during the night, the excess heat stored within the material is released, which causes the wax to freeze. The use of adequate ventilation during the night ensures that this heat can be released to the outdoor environment. This introduces a time delay or lag in the peak indoor temperature, which also has a beneficial economic impact, since typically during the summer residential air-conditioning equipment consume the most energy during the time of day when the outdoor temperatures are at their peak. The reduction of the indoor thermal fluctuations also contributes greatly to the thermal comfort of the occupant (BASF, 2008).

This product would be integrated with gypsum wallboard, having a thickness of $13 \mathrm{~mm}$ (0.5 inch), to ensure a uniform distribution of PCM throughout the building material. In addition to that, a 4 inch concrete slab with PCM is placed at each of the floors of the house. The heating and cooling systems were turned off during the simulations, to prevent any interference of the equipment with the heat storage mechanism of the phase change materials. Table 4.3 presents the material properties of Micronal DS 5001. The fundamental material properties of this material are designed with the intention that this material could be used in buildings where the comfort of the occupants is an important parameter. 
Table 4.3: Material Properties of Micronal DS 5001(BASF, 2008)

\begin{tabular}{|l|l|}
\hline PCM Model Number & DS 5001 \\
\hline Melting Point & $23^{\circ} \mathrm{C}-26^{\circ} \mathrm{C}$ \\
\hline $\begin{array}{l}\text { Overall heat storage capacity (including } \\
\text { sensible energy) }\end{array}$ & $145 \mathrm{~kJ} / \mathrm{kg}$ \\
\hline Latent heat capacity & $110 \mathrm{~kJ} / \mathrm{kg}$ \\
\hline Density & $250-350 \mathrm{~kg} / \mathrm{m}^{3}$ \\
\hline
\end{tabular}

\subsection{Simulation Results}

One of the primary advantages of using phase change materials is in its ability to store thermal energy in the form of latent heat and releasing it gradually over a period of time. This prevents any wide temperature fluctuations and ensures a comfortable indoor environment for the occupants. Furthermore, the potential impact and magnitude of these fluctuations also depends on the season during which the analysis is conducted. During the winter months, it can be expected that the use of PCM would ensure that the indoor temperature would be slightly higher when compared to a room with an ordinary building envelope. This is due to the additional thermal storage capacity of a building integrated with PCM, which enables the utilization of solar gains. The opposite would be true during the summer, whereby building integrated PCM would keep the indoor temperature slightly cooler.

This phenomenon is illustrated in the Figures 4.7 and 4.8 below. Considering a typical winter day, it is obvious from Figure 4.7, that as the concentration of phase change materials within the building envelope is increased, the indoor temperature profile is improved. Since the building is unconditioned, the indoor temperatures are below the PCM transition temperature. This prevents the utilization of the latent heat capacity of the PCM, and thus any improvements in the indoor temperature profile is attributable to the increased sensible storage capacity of the PCM/drywall in comparison with the ordinary building envelope containing no PCM. This would translate into an overall reduction in the heating load requirement of the building during the winter. 
The impact of using PCM during a typical summer day is illustrated by Figure 4.8. A typical summer day in Toronto would be defined as July $15^{\text {th }}$, while a typical winter day would be defined as February 1st. Appendix E presents the detailed temperature profiles for the typical summer and winter days for Toronto. One key difference that is obvious when the two figures are compared, is the magnitude of the temperature change, which is significantly higher during the summer. This can be interpreted by considering that the melting temperature of PCM used for the simulations is between $23^{\circ} \mathrm{C}-26^{\circ} \mathrm{C}$. Thus, it is obvious that during the winter months, this temperature would be rarely achieved and the only heat transfer mechanism for the PCM during this time would be sensible heat transfer, which produces only a small change in temperature magnitude. However, during the summer, complete melting of the PCM occurs as most of the temperatures are above the melting point of the PCM. It is clear from Figure 4.8 that not only is there is a reduction in the peak temperature but also a time delay of 3-4 hours when that temperature peak occurs. For the case where no PCM is used, the indoor temperature registers a peak at around $4 \mathrm{pm}$ as opposed to $8 \mathrm{pm}$, when $10 \%$ PCM is used.

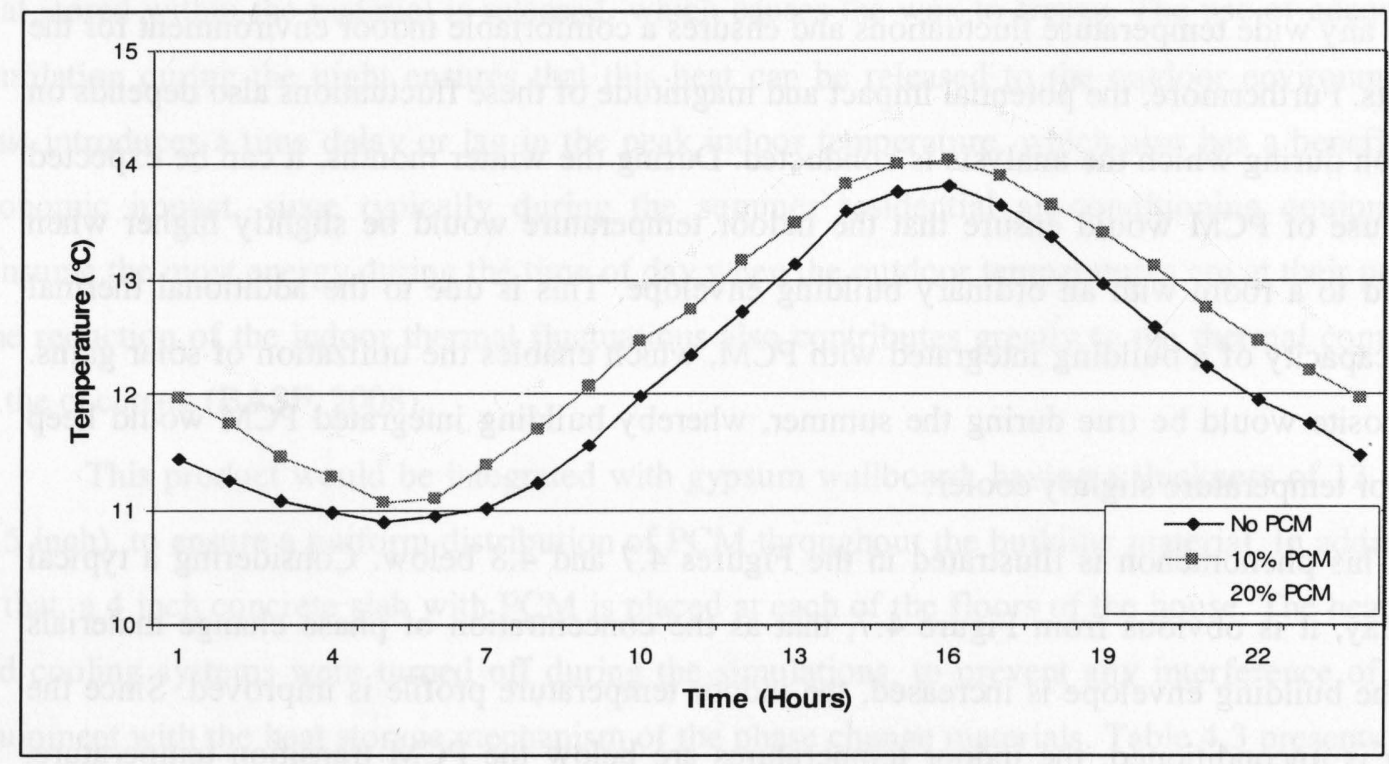

Figure 4.7: Temperature profile of the 3rd floor of the Net Zero Energy house on a typical winter day with varying PCM concentration.

The appropriate selection of the type and quantity of thermal mass depends strongly upon the climate and intensity of the solar radiation for a particular location. Depending on the diurnal temperature range of a location, the type and quantity of thermal mass to be used can be easily 
determined. For places, where a large divergence exists between the day and night temperatures, the use of a concrete slab as thermal mass would provide results similar to what could be achieved using PCM. It can be observed that the use of a 2 inch concrete slab as thermal mass produces a sizable reduction in the peak indoor temperature during the summer. This can be contrasted to the results for the $10 \%$ and $20 \%$ PCM. Performing further simulations, it can be concluded that the overall impact of using a 2 inch concrete slab is similar to what would be achieved when PCM concentration of 5-6\% are used. This is shown in Figure 4.9, where the temperature profiles of using 5\% PCM and a 2 inch concrete slab are directly compared. It is clear that in terms of producing peak temperature reduction, the performance of a 2 inch concrete slab is similar to using the 5\% Micronal PCM. Depending on the particular design requirements, the option of selecting a particular thermal mass depends on the comfort requirements and the economic considerations. Based on the results, the thermal performance of the $5 \%$ Micronal was found to be similar to a 2 inch concrete slab, but when the economic considerations are taken into account, it is clear that the cost of a commercial PCM product would be significantly higher when compared to a concrete slab. However, if the heating/cooling loads of the building are significantly higher, then it might be economically feasible to implement phase change materials with higher concentrations into the building as opposed to increasing the thickness of the concrete slabs.

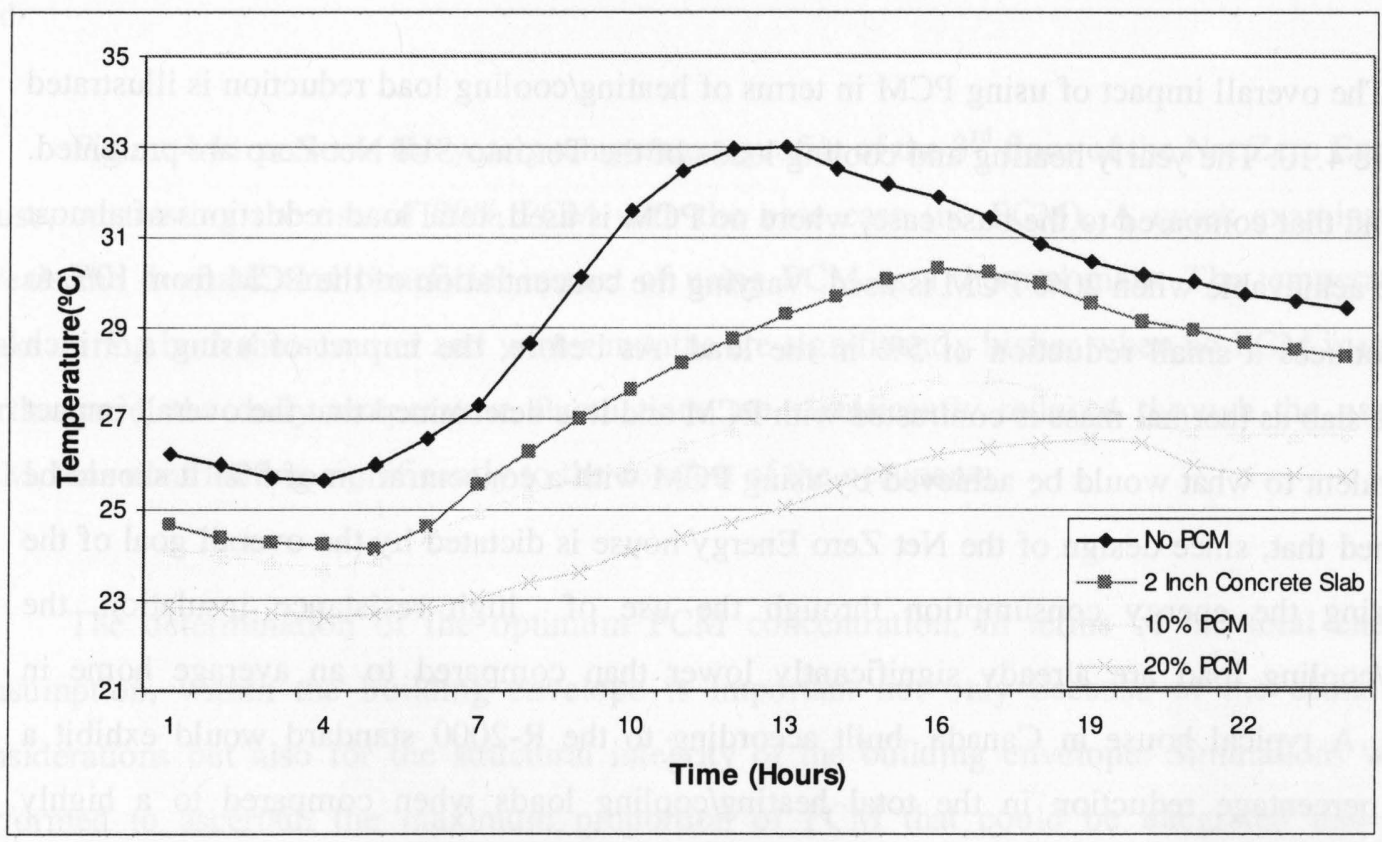

Figure 4.8: Temperatures profile of the 3rd floor of the Net Zero Energy house on a typical summer day when PCM and concrete slab is used 


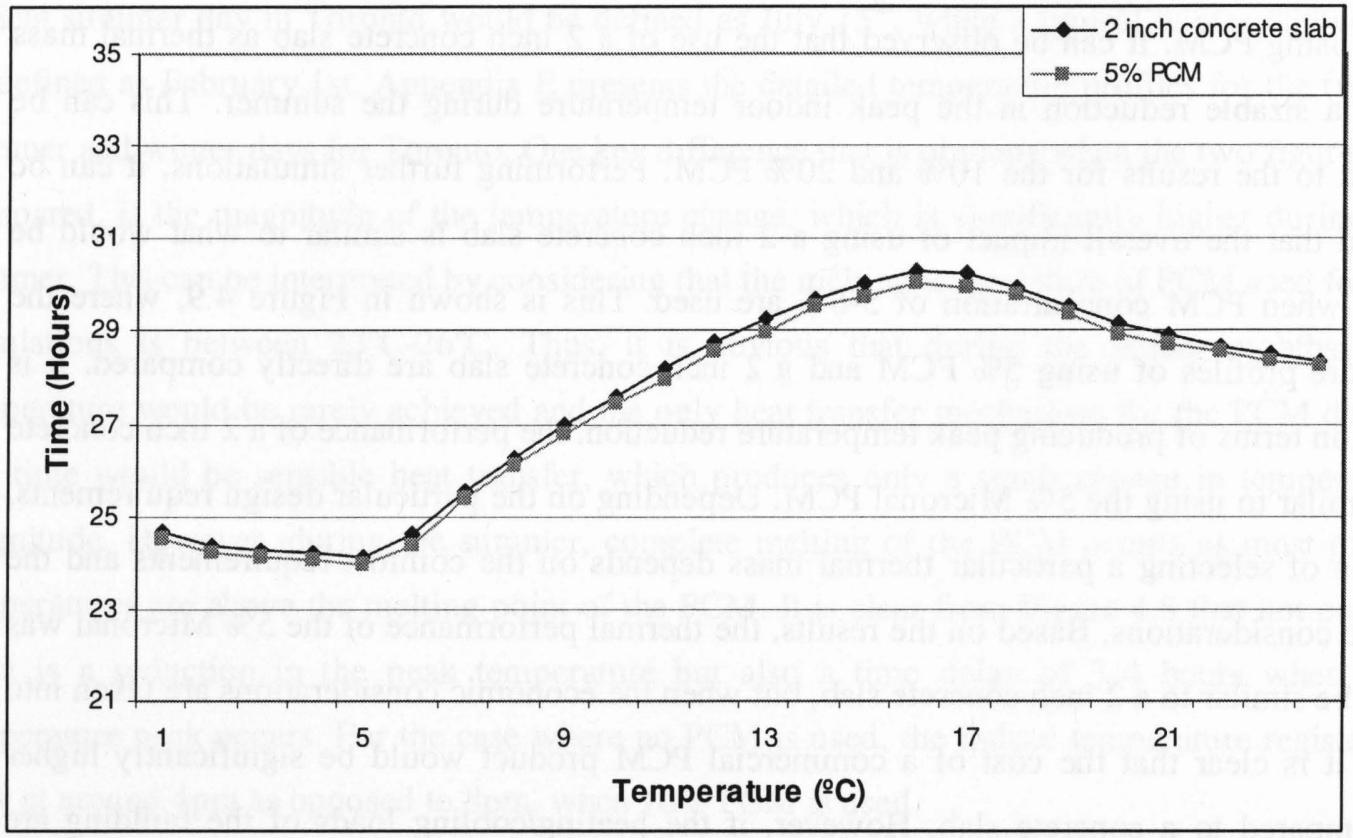

Figure 4.9: Temperatures profile of the 3rd floor of the Net Zero Energy house on a typical summer day when $5 \%$ PCM is contrasted with the 2 inch concrete slab

The overall impact of using PCM in terms of heating/cooling load reduction is illustrated by Figure 4.10. The yearly heating and cooling loads of the Toronto SUI Net Zero are presented. It is found that compared to the base case, where no PCM is used, total load reductions of almost $15 \%$ are achievable when $20 \%$ PCM is used. Varying the concentration of the PCM from $10 \%$ to $20 \%$ produces a small reduction of $5 \%$ in the load. As before, the impact of using a 2 inch concrete slab as thermal mass is contrasted with PCM and it is determined that the overall impact is equivalent to what would be achieved by using PCM with a concentration of 5\%. It should be mentioned that, since design of the Net Zero Energy house is dictated by the overall goal of the minimizing the energy consumption through the use of high resistance insulation, the heating/cooling load are already significantly lower than compared to an average home in Canada. A typical house in Canada, built according to the R-2000 standard would exhibit a higher percentage reduction in the total heating/cooling loads when compared to a highly insulated building such as the Toronto Net Zero Energy house. 


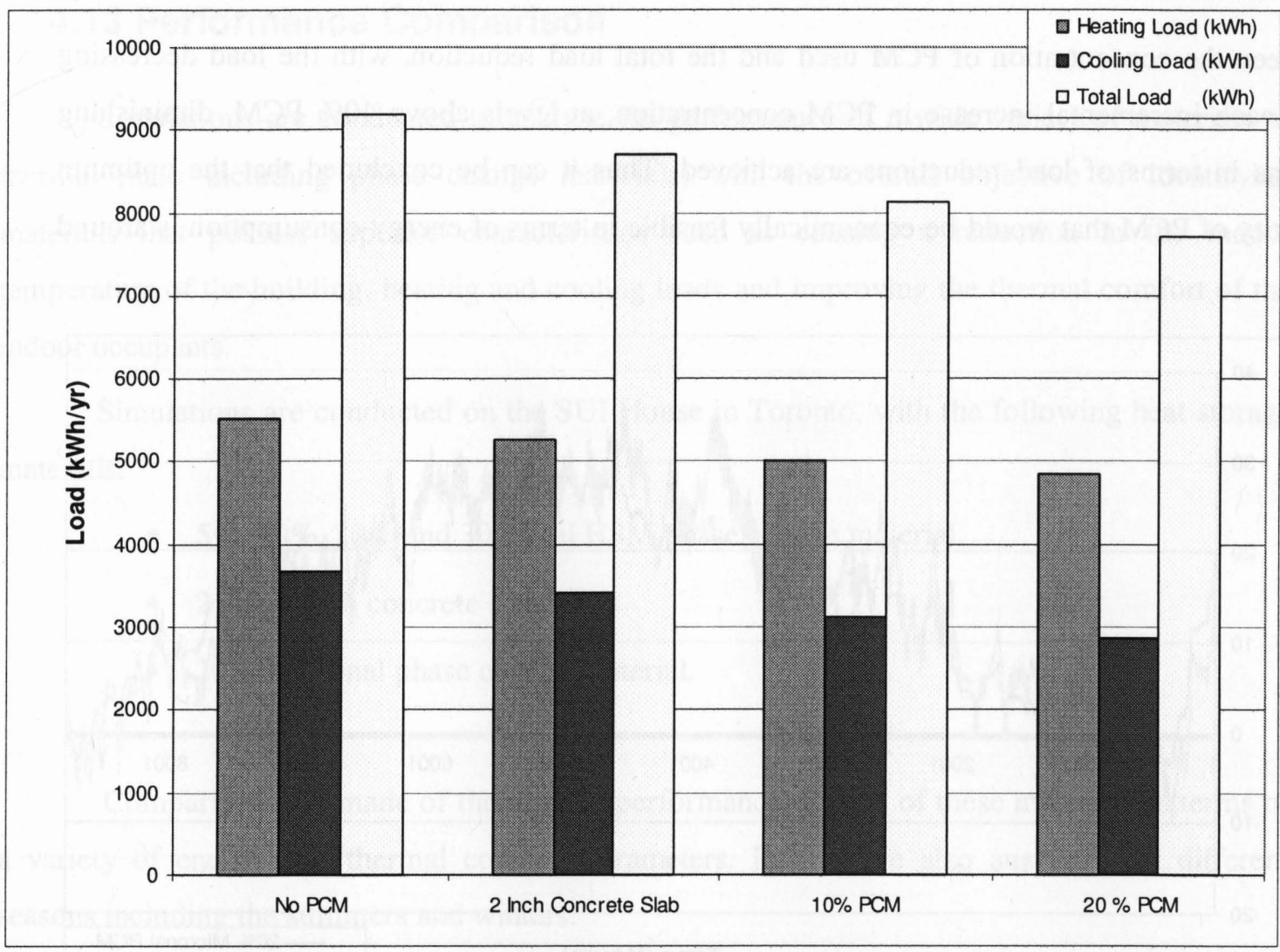

Figure 4.10: Yearly heating/cooling load requirements of the Net Zero Energy house for a variety of thermal mass used.

Figure 4.11 presents the yearly temperature profile of the $3^{\text {rd }}$ floor of the Net Zero Energy house, contrasting the use of $20 \%$ PCM with the base case (no PCM). A quick examination reveals the dramatic and beneficial impact of using PCM as a thermal mass. The temperature peaks during both the summer and winter months are significantly higher when no PCM is used. Furthermore, the daily temperature fluctuations are significantly reduced through the use of PCM, thus contributing significantly to the comfort of the occupants.

The determination of the optimum PCM concentration, in terms of the total energy consumption, within the building envelope is important not only because of the economic considerations but also for the structural integrity of the building envelope. Simulations were performed to ascertain the maximum proportion of PCM that could be integrated into the building envelope so that a sizeable reduction in the total energy consumption is achieved. Figure 4.12 presents the results of the analysis. While it was found that a definite relationship exists 
between the concentration of PCM used and the total load reduction, with the load decreasing with each incremental increase in PCM concentration, at levels above 40\% PCM, diminishing returns in terms of load reductions are achieved. Thus it can be concluded that the optimum quantity of PCM that would be economically feasible in terms of energy consumption is around $40 \%$.

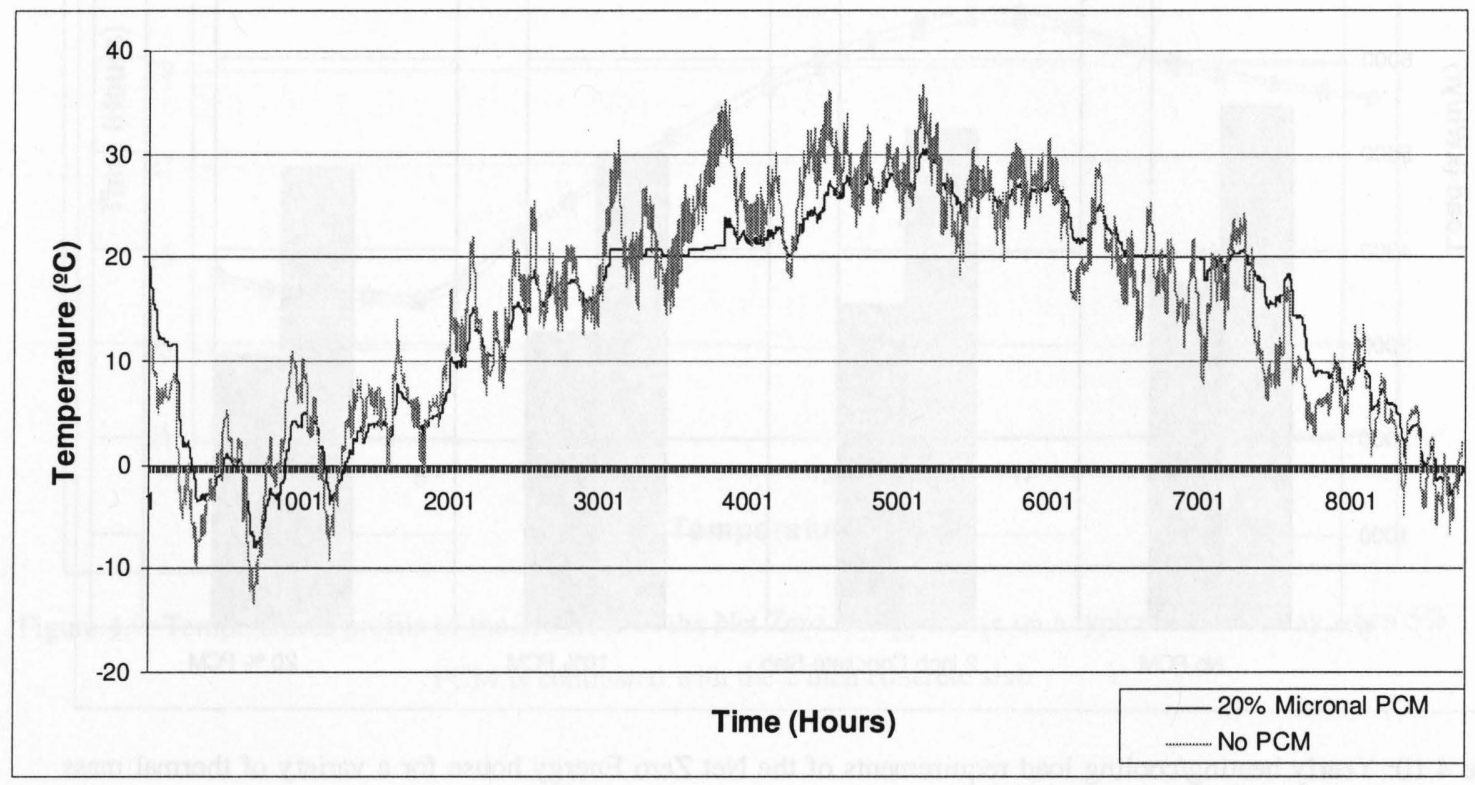

Figure 4.11: Yearly un-conditioned temperature profile of the 3rd floor of the Net Zero energy house, illustrating the impact of using PCM.

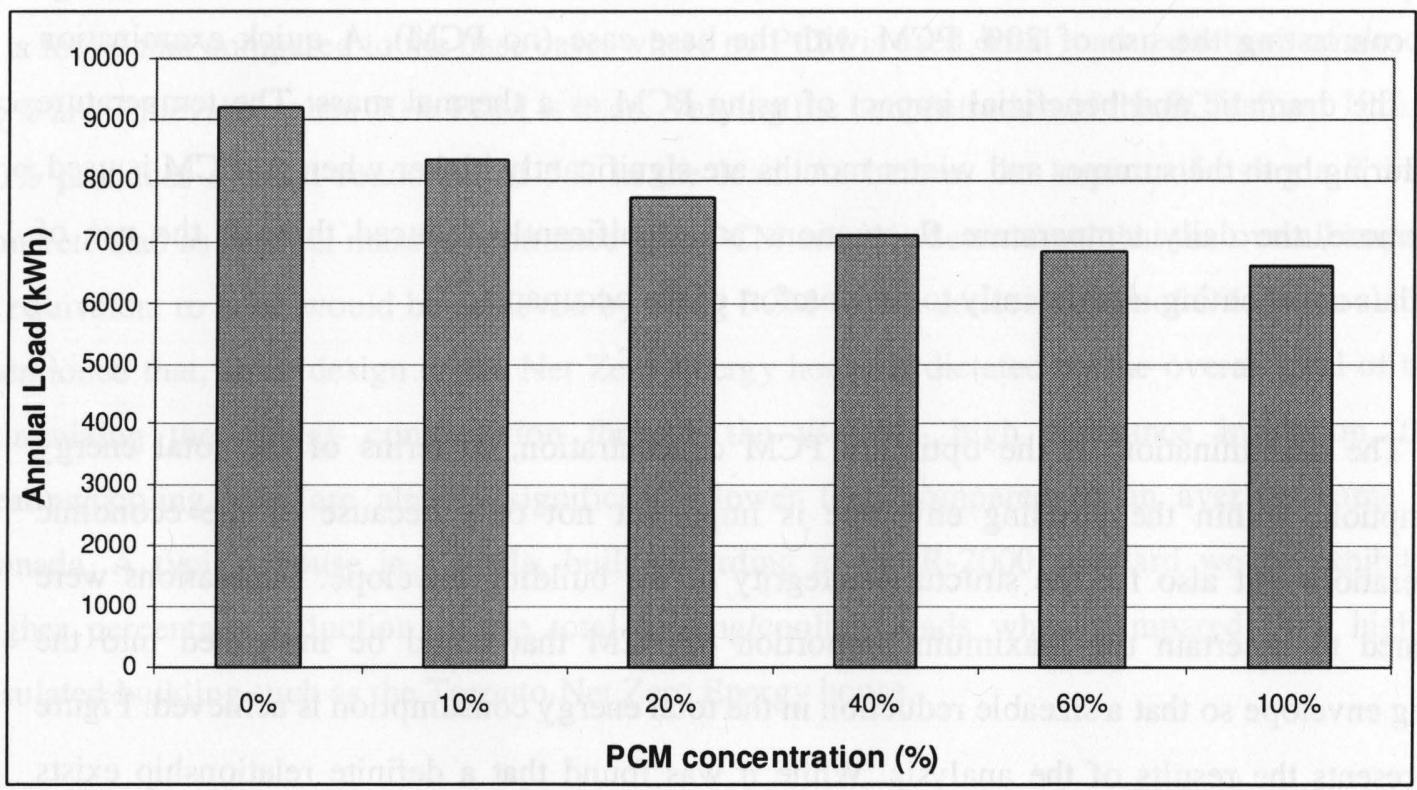

Figure 4.12: Yearly Heating/Cooling Load of the Net Zero Energy House as the concentration of PCM is varied. 


\subsection{Performance Comparison}

Simulations are conducted to analyze the performance of a wide variety of materials as thermal mass including phase change materials, with the overall objective of identifying materials that possess superior characteristics such as causing a reduction in the indoor temperature of the building, heating and cooling loads and improving the thermal comfort of the indoor occupants.

Simulations are conducted on the SUI House in Toronto, with the following heat storage materials.

- $5 \%, 10 \%, 20 \%$ and $30 \%$ Dal HSM phase change material.

- 2 and 4 inch concrete slab.

- $20 \%$ Micronal phase change material.

Comparisons are made of the relative performance of each of these materials in terms of a variety of energy and thermal comfort parameters. Results are also analyzed for different seasons including the summers and winters.

\subsubsection{Dal HSM Material Properties}

Dal HSM belongs to the Solid-Solid class of phase change materials, which remain in the solid state upon phase transition. The material is available in the form of coarse particles, which can be grounded into a very fine powder, to assist with integration of the PCM into any building material. It possesses excellent solid-solid phase change characteristics in the temperature range of $25 \mathrm{~K}$ and $350 \mathrm{~K}$ (Van Oort and White,1988). The adiabatic calorimetry experiments have shown that the phase transition of this PCM occurs at $24.7^{\circ} \mathrm{C}$ with a molar heat of transition of $16000 \mathrm{~J} / \mathrm{mol}$. The high entropy in the solid-solid phase transition indicates solid state alkyl-chain melting. It is through the melting of these chains in the solid state that the material is able to absorb energy without actually changing state from solid to liquid (Van Oort et al., 1988). Some of the fundamental material properties of the PCM used for the simulation are tabulated below in Table 4.4. 
Table 4.4: Selected Material properties of the Dal HSM

\begin{tabular}{|c|c|}
\hline Property & Value \\
\hline Density $(\rho) \mathrm{kg} \cdot \mathrm{m}^{-3}$ & 800 \\
\hline Thermal conductivity $(k) \mathrm{W} \cdot \mathrm{m}^{-1} \mathrm{~K}^{-1}$ & 0.3 \\
\hline Specific heat $\left(C_{p}\right) \mathrm{kJ} \mathrm{kg}^{-1} \mathrm{~K}^{-1}$ & 1.6 \\
\hline $\begin{array}{l}\text { Onset phase change temperature upon } \\
\text { heating/cooling }\left(T_{0}\right){ }^{\circ} \mathrm{C}\end{array}$ & $20 / 22$ \\
\hline $\begin{array}{l}\text { End phase change temperature upon } \\
\text { heating/cooling }\left(T_{\mathrm{e}}\right)^{\circ} \mathrm{C}\end{array}$ & $20 / 22$ \\
\hline \multicolumn{2}{|c|}{ Latent heat of transition on heating $(L), \mathrm{kJ} \cdot \mathrm{kg}^{-1}, \quad 80$} \\
\hline \multicolumn{2}{|c|}{ Latent heat of transition on cooling $(L), \mathrm{kJ} \cdot \mathrm{kg}^{-1}, \quad 80$} \\
\hline
\end{tabular}

\subsubsection{Comparison Results and Analysis}

The impact of using a variety of thermal mass on the annual heating and cooling loads was analyzed and is presnted in Table 4.5 below.

Table 4.5: Annual heating and cooling loads for the Toronto SUI Net Zero Energy house using different types of thermal mass

\begin{tabular}{|l|l|l|}
\hline Scenario & Heating Load (kWh) & $\begin{array}{l}\text { Cooling Load } \\
\text { (kWh) }\end{array}$ \\
\hline $\begin{array}{l}\text { Base Case (No Thermal } \\
\text { Mass) }\end{array}$ & 5511 & 3681 \\
\hline 2-Inch Concrete Slab & 5271 & 3429 \\
\hline 4-Inch Concrete Slab & 4895 & 2902 \\
\hline 20\% Micronal PCM & 4846 & 2861 \\
\hline 5\% Dal HSM & 5348 & 3553 \\
\hline 10\% Dal HSM & 5203 & 3489 \\
\hline 20\% Dal HSM & 5038 & 3378 \\
\hline 30\% Dal HSM & 4911 & 3209 \\
\hline
\end{tabular}

Examining the results from Table 4.5, it is obvious that there is a reduction in the heating and cooling loads as a result of using a wide variety of thermal mass. The performance of $20 \%$ Micronal PCM is comparable to that of a 4 inch concrete slab. The performance of the Dal HSM is found to be inferior to especially when the cooling loads are taken into consideration. As can be expected, due to the slightly lower latent heat capacity, the $30 \%$ Dal-HSM performs comparably with Micronal 20\% for heating season. However, the Dal-HSM does not have much effect on cooling. The total cooling load is $10 \%$ higher when $30 \%$ Dal HSM is used as compared to the $20 \%$ Micronal PCM. This is attributable to the lower latent heat capacity, phase transition 
below the cooling set point and a smaller density of the material. Since the cooling set point is higher than the phase transition temperature of Dal HSM, any thermal energy stored by the PCM does not have opportunity to be released.

The peak heating and cooling loads are also tabulated and are shown below in Table 4.6. A similar trend is noticed for the peak heating and cooling load as was observed for the annual loads, where the performance of Dal HSM is inferior especially during the summer when cooling is required.

Table 4.6: Peak heating and cooling loads for the Toronto SUI Net Zero Energy house using different types of thermal mass

\begin{tabular}{|l|l|l|}
\hline Scenario & Heating Load $(\mathbf{k W})$ & $\begin{array}{l}\text { Cooling Load } \\
(\mathbf{k W})\end{array}$ \\
\hline $\begin{array}{l}\text { Base Case (No Thermal } \\
\text { Mass) }\end{array}$ & 5.75 & 3.52 \\
\hline 2-Inch Concrete Slab & 5.34 & 2.08 \\
\hline 4-Inch Concrete Slab & 5.21 & 1.64 \\
\hline 20\% Micronal PCM & 4.98 & 1.33 \\
\hline 5\% Dal HSM & 5.56 & 3.50 \\
\hline 10\% Dal HSM & 5.39 & 3.44 \\
\hline 20\% Dal HSM & 5.30 & 3.39 \\
\hline 30\% Dal HSM & 5.22 & 3.33 \\
\hline
\end{tabular}

A detailed analysis of the occupant thermal comfort is also conducted by analyzing the total number of hours the indoor temperature exceeds the heating set point of $21^{\circ} \mathrm{C}$. This is shown below in Table 4.7:

Table 4.7: Total number of hours during the winter season, the indoor temperature exceeds the heating set point, $21^{\circ} \mathrm{C}$

\begin{tabular}{|l|l|l|l|l|}
\hline Scenario & $\mathbf{3}^{\text {rd }}$ Floor & $\mathbf{2}^{\text {nd }}$ Floor & $\begin{array}{l}\text { Mezzanine } \\
\text { Floor }\end{array}$ & $\mathbf{1}^{\text {st }}$ Floor \\
\hline $\begin{array}{l}\text { Base Case (No } \\
\text { Thermal Mass) }\end{array}$ & 1603 & 653 & 358 & 477 \\
\hline 2-Inch Concrete Slab & 1186 & 577 & 299 & 394 \\
\hline 4-Inch Concrete Slab & 1039 & 523 & 255 & 368 \\
\hline 20\% Micronal PCM & 998 & 527 & 237 & 383 \\
\hline 5\% Dal HSM & 1564 & 640 & 344 & 464 \\
\hline 10\% Dal HSM & 1335 & 598 & 321 & 441 \\
\hline 20\% Dal HSM & 1209 & 564 & 289 & 407 \\
\hline 30\% Dal HSM & 1066 & 542 & 271 & 387 \\
\hline
\end{tabular}


Further analysis is conducted to determine the total number of hours where the temperature exceeds $25^{\circ} \mathrm{C}$, which is considered to be an uncomfortable temperature for indoor occupants. This is shown below in Table 4.8.

Table 4.8: Total number of hours during the winter season, the indoor temperature exceeds $25^{\circ} \mathrm{C}$

\begin{tabular}{|l|l|l|l|l|}
\hline Scenario & $\mathbf{3}^{\text {rd }}$ Floor & $\mathbf{2}^{\text {nd }}$ Floor & $\begin{array}{l}\text { Mezzanine } \\
\text { Floor }\end{array}$ & $\mathbf{1}^{\text {st }}$ Floor \\
\hline $\begin{array}{l}\text { Base Case No } \\
\text { Thermal Mass) }\end{array}$ & 602 & 454 & 161 & 290 \\
\hline 2-Inch Concrete Slab & 386 & 377 & 109 & 234 \\
\hline 4-Inch Concrete Slab & 273 & 323 & 92 & 207 \\
\hline 20\% Micronal PCM & 256 & 311 & 92 & 199 \\
\hline $5 \%$ Dal HSM & 577 & 445 & 158 & 277 \\
\hline 10\% Dal HSM & 443 & 413 & 127 & 254 \\
\hline 20\% Dal HSM & 379 & 374 & 111 & 221 \\
\hline $30 \%$ Dal HSM & 334 & 355 & 101 & 209 \\
\hline
\end{tabular}

As can be observed from Tables 4.7 and 4.8, the use of thermal mass significantly reduces the total number of hours where the temperature exceeds the hetaing set points. During the winter months, the combination of an active heating system and admittance of solar radiation during the day creates a condition of over-heating which is further exacerbated by the highly insulated building envelope, which traps the thermal energy inside. This phenomenon typically occurs during the daytime on a sunny winter day, when the peak level of radiation is incident on the building. This causes the temperature of the building to rise. Due to the declination of the sun during the winter, there are only a few hours when the direct solar radiation impacts the indoor temperature, as a result of solar gains through the glazing. The use of thermal mass in such a situation would enable this unnecessary solar gain during the day time to be stored and released during the evening when the temperature drops.

Analyzing Tables $4.7 \& 4.8$, it is clear that the use of thermal mass is most effective on the $3^{\text {rd }}$ floor, where the glazing area is the highest compared to other areas of the house. Temperature profiles are also developed for a typical summer and winter week, to analyze the variation of temperature with time. The typical winter and summer weeks are defined as occurring between Feb $1^{\text {st }}-$ Feb $7^{\text {th }}$ and Jul $15^{\text {th }}-\mathrm{Jul} 21^{\text {st }}$ respectively. The detailed temperature profiles of these weeks are presented in Appendix E. Figure 4.13 shows the temperature profile of the $3^{\text {rd }}$ floor of the Toronto Net Zero Energy house for a typical winter week. 


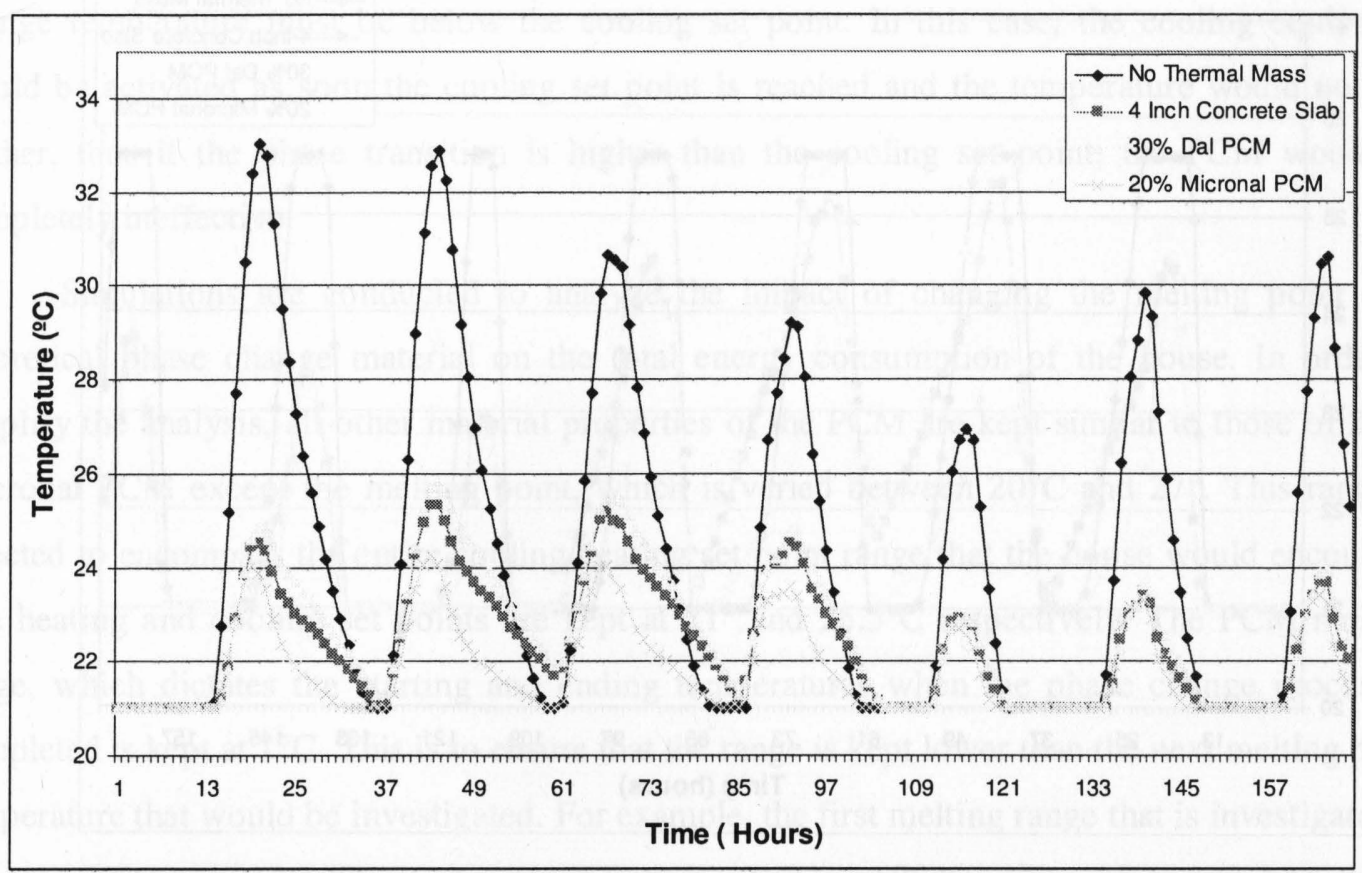

Figure 4.13: Temperature profile of the $3^{\text {rd }}$ floor of the Toronto Net Zero Energy house for a typical winter week

As can be observed from Figure 4.13, the indoor temperature rises dramatically without any thermal mass present in the house. The rate of temperature rise is slowed by the presence of a wide variety of thermal mass. In this case the peak temperature without the use of thermal mass is almost $8^{\circ} \mathrm{C}$ higher than when thermal mass is used.

Figure 4.14 shows the temperature profile of the $3^{\text {rd }}$ floor of the house for a typical summer day. In this case the degree of temperature reduction is not as great for the winter case. This can be explained by complex interaction of air-conditioning equipment which dictates the degree of temperature rise based on the set. Once the set point of $25.5^{\circ} \mathrm{C}$ is reached, the cooling equipment is activated. If the temperature were allowed to rise beyond the cooling set point, a similar trend as the winter case would be observed and would create extremely uncomfortable conditions for the indoor occupants.

\subsection{Sensitivity Analysis}

A detailed sensitivity analysis investigating the impact of varying the material properties of a theoretical phase change material on the energy performance in the Toronto Net Zero Energy house is conducted. 


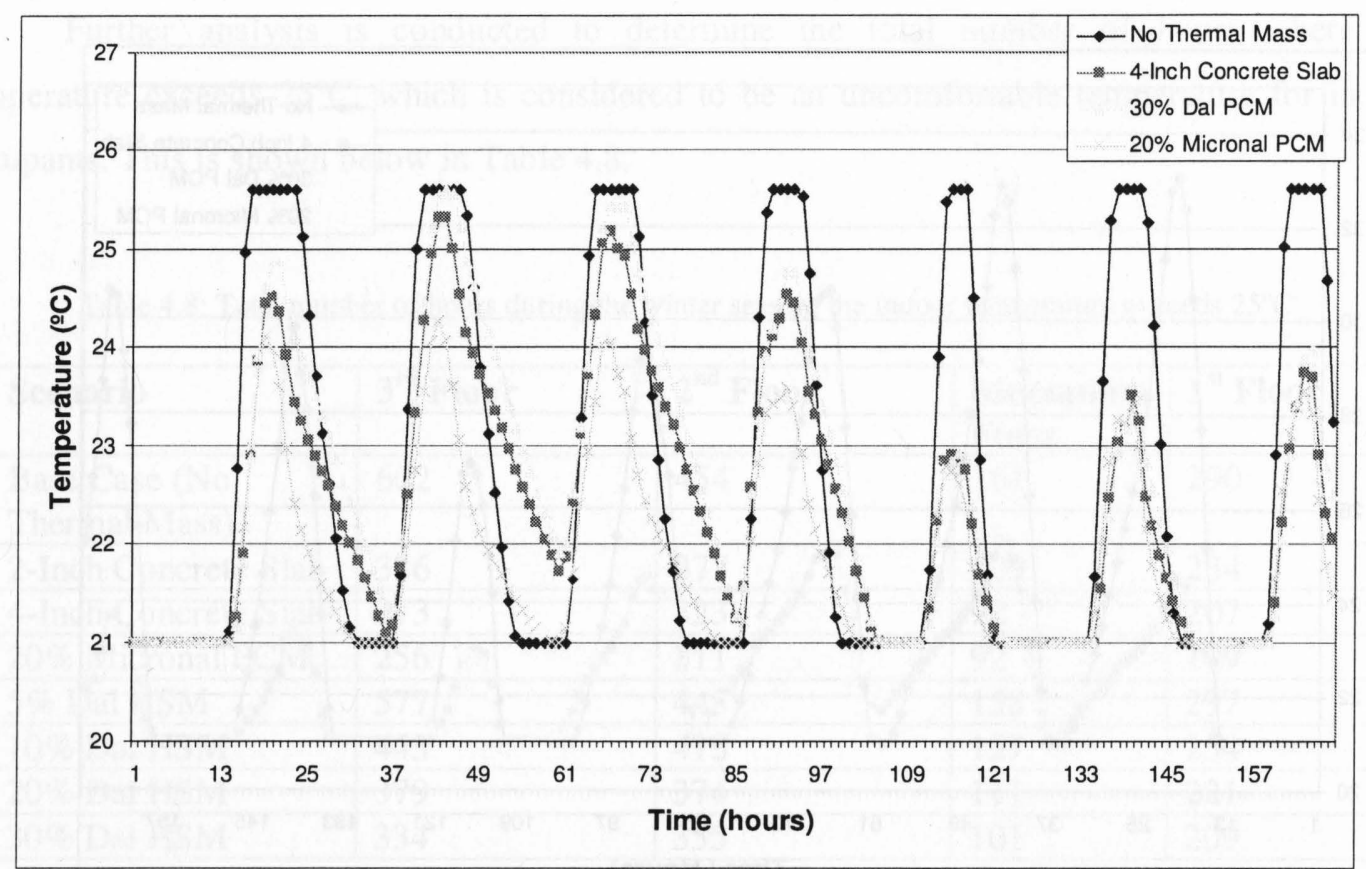

Figure 4.14: Temperature profile of the $3^{\text {rd }}$ floor of the Toronto Net Zero Energy house for a typical summer week

The objective of the examination is to determine the effect of changing key PCM characteristics such as melting point, latent heat capacity etc on the overall energy consumption and peak energy loads. As demonstrated in Section 4.13, there can be a significant variation in the energy performance of a particular phase change material, if differences exist in the thermal and physical characteristics of the material. The use of 30\% Dal HSM, due to its lower melting point and latent heat capacity yielded inferior performance when compared to the $20 \%$ Micronal PCM.

\subsubsection{Varying the PCM Melting Point}

The temperature at which a particular phase change material undergoes phase transition is a critical parameter that influences the total energy consumption and peak load in a building. The interaction between the phase change temperature and the heating/cooling set point is a complex phenomenon and depends upon the relative values of each of the parameters. If during the heating season, the phase change temperature is lower than the heating set point, then the PCM would have a minimal effect on the heating consumption of the house, as the heating equipment would be activated as soon as the indoor temperature drops below the set point. Thus, during the winter season, the phase change material must have a phase transition temperature higher than 
the heating set point. However, during the summer season the situation is reversed and the phase change temperature must be below the cooling set point. In this case, the cooling equipment would be activated as soon the cooling set point is reached and the temperature would not rise further, thus if the phase transition is higher than the cooling set point, the PCM would be completely ineffective.

Simulations are conducted to analyze the impact of changing the melting point of a theoretical phase change material on the total energy consumption of the house. In order to simplify the analysis, all other material properties of the PCM are kept similar to those of $20 \%$ Micronal PCM except the melting point, which is varied between $20^{\circ} \mathrm{C}$ and $27^{\circ}$. This range is selected to encompass the entire cooling/heating set point range that the house would encounter. The heating and cooling set points are kept at $21^{\circ}$ and $25.5^{\circ} \mathrm{C}$ respectively. The PCM melting range, which dictates the starting and ending temperatures when the phase change process is completed is kept at $1^{\circ} \mathrm{C}$. This is to ensure that the range is kept lower than the next melting point temperature that would be investigated. For example, the first melting range that is investigated is between $20^{\circ} \mathrm{C}$ and $21^{\circ} \mathrm{C}$. The next range is between $21^{\circ} \mathrm{C}$ and $22^{\circ} \mathrm{C}$ and so on. Figure 4.15 shows the annual heating and cooling load of the Toronto Net Zero Energy house when the melting point of the phase change material is varied between $20^{\circ} \mathrm{C}$ and $27^{\circ} \mathrm{C}$.

Analyzing Figure 4.15 , the effect of varying the PCM melting temperature can be observed. It is clear that as the melting temperature is increased from $20^{\circ} \mathrm{C}$, the heating and cooling load is reduced. This trend continues until the minimum heating load is achieved at $23^{\circ} \mathrm{C}$ and the minimum cooling load occurs at $24^{\circ} \mathrm{C}$. The heating and cooling loads gradually increase as the melting point is increased further. At $26^{\circ} \mathrm{C}$, which is the cooling set point, the effectiveness of PCM is negligible since the phase change occurs at as soon as the cooling equipment is activated. Since the temperature is not allowed to rise above $26^{\circ} \mathrm{C}$, there is no opportunity for the phase change material to store any thermal energy. The same trend is noted for the case where the PCM melting temperature is $20^{\circ} \mathrm{C}$. In this case, since the heating set point of $21^{\circ} \mathrm{C}$ is higher than the PCM melting point, there is no opportunity for the phase change process to occur.

The impact of changing the PCM melting point on the peak heating/cooling load is also analyzed. As before, the melting point is varied between $20^{\circ}$ and $27^{\circ} \mathrm{C}$. This is shown below in Figure 4.16. The peak heating and cooling load is found to reach a minimum at the PCM melting temperature of $23^{\circ} \mathrm{C}$. 


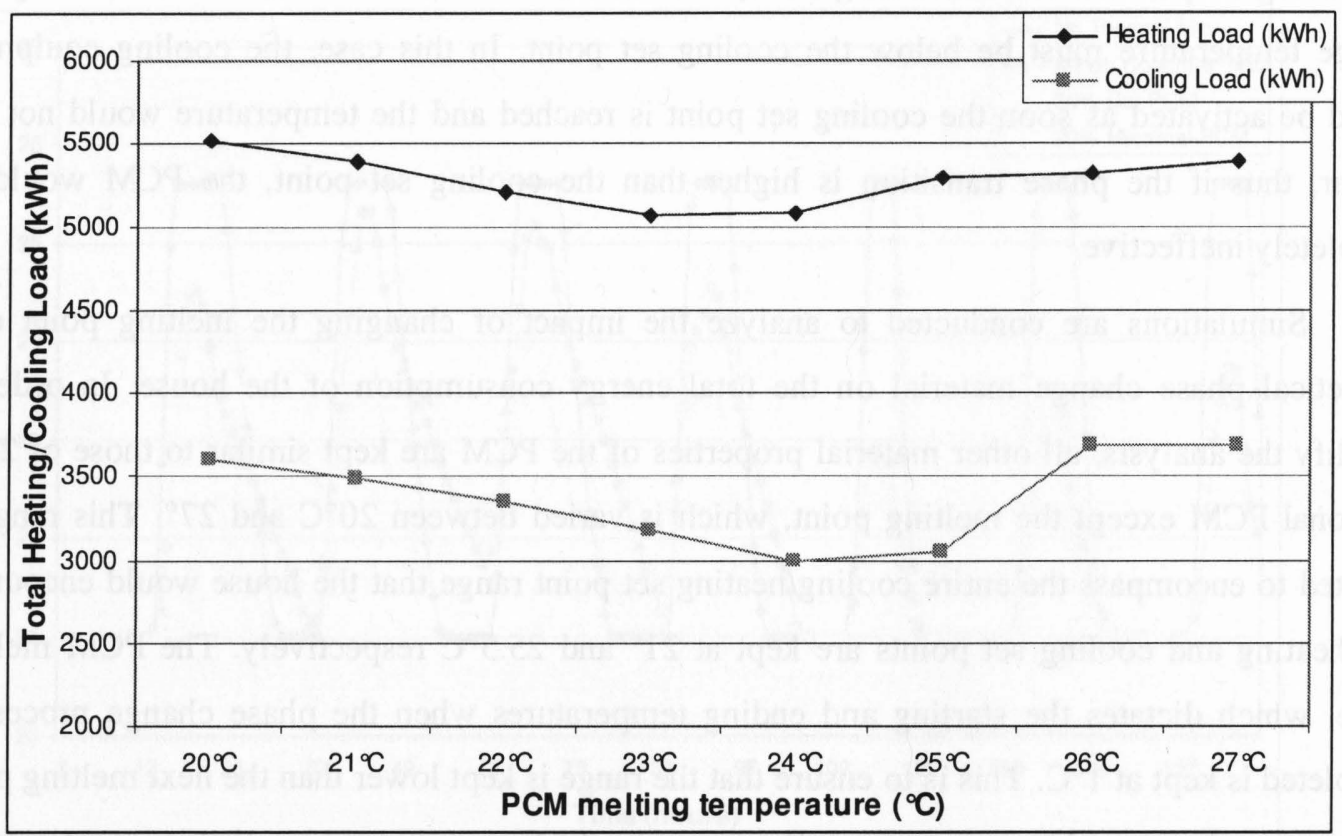

Figure 4.15: Annual heating and cooling load of the Toronto Net Zero Energy house as a function of varying PCM melting temperature

As the melting temperature is increased there is a sharp rise in the peak cooling load until it reaches the temperature set point of $26^{\circ} \mathrm{C}$, where the PCM ceases to have any impact on the peak cooling load. The peak heating load follows a similar trend, however, the rise in the load as a result of increasing the melting temperature is not as steep as in the case of the cooling load.

\subsubsection{Varying the PCM latent capacity}

The total latent heat capacity of a particular phase change material is a fundamental characteristic that determines the effectiveness and performance it would exhibit in a building. It is quantified in terms of the total thermal energy that a PCM can absorb while undergoing a change in phase. The higher this capacity, the slower would be the temperature rise within a building containing phase change materials within the building envelope.

An examination of the impact of changing the latent heat capacity of a theoretical phase change material on the total heating and cooling loads is also performed. As before, other relevant PCM material properties would be kept constant and similar to those of the $20 \%$ Micronal PCM. 


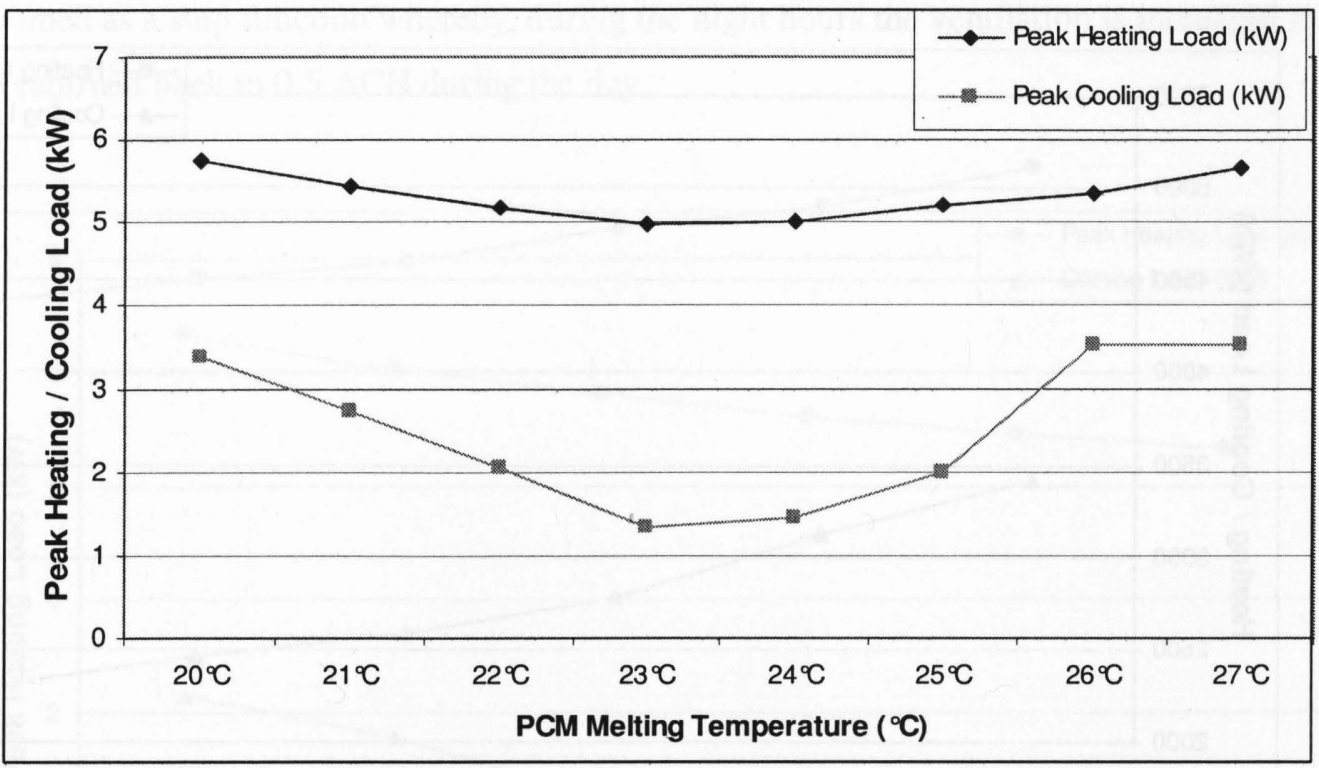

Figure 4.16: Peak heating and cooling load of the Toronto Net Zero Energy house as a function of varying PCM melting temperature

The latent heat capacity would be varied between $50 \mathrm{~kJ} / \mathrm{kg}$ and $300 \mathrm{~kJ} / \mathrm{kg}$ in increments of $50 \mathrm{~kJ} / \mathrm{kg}$. Figure 4.17 shows the variation of the PCM latent heat capacity on the annual heating and cooling loads of the Toronto Net Zero Energy house. As can be observed from Figure 4.17, an increase in the latent heat capacity of the PCM contributes to a reduction in the annual heating and cooling loads. Furthermore, the impact on the cooling load is much more significant in contrast to the heating load, as can be seen by the steeper slope of the cooling load in reference to the increase in the latent heat capacity.

It is clear that the performance of a particular phase change material during the summer season improves as the latent heat capacity is increased. This can be attributed to the highly insulated building envelope of the Toronto Net Zero Energy house, which traps a significant amount of heat indoors during the summer season. Any increase in the latent heat capacity allows this energy to be absorbed by the PCM, thus reducing the air-conditioning load.

The impact of varying the latent heat capacity on the peak heating and cooling loads is also analyzed and presented below in Figure 4.18. The trend of decreasing heating/cooling load as a result of an increase in the latent heat capacity is obvious. As before, the peak cooling load exhibits a sharper drop as the latent heat capacity is increased from $50 \mathrm{~kJ} / \mathrm{kg}$ to $150 \mathrm{~kJ} / \mathrm{kg}$, when compared to the peak heating load. 


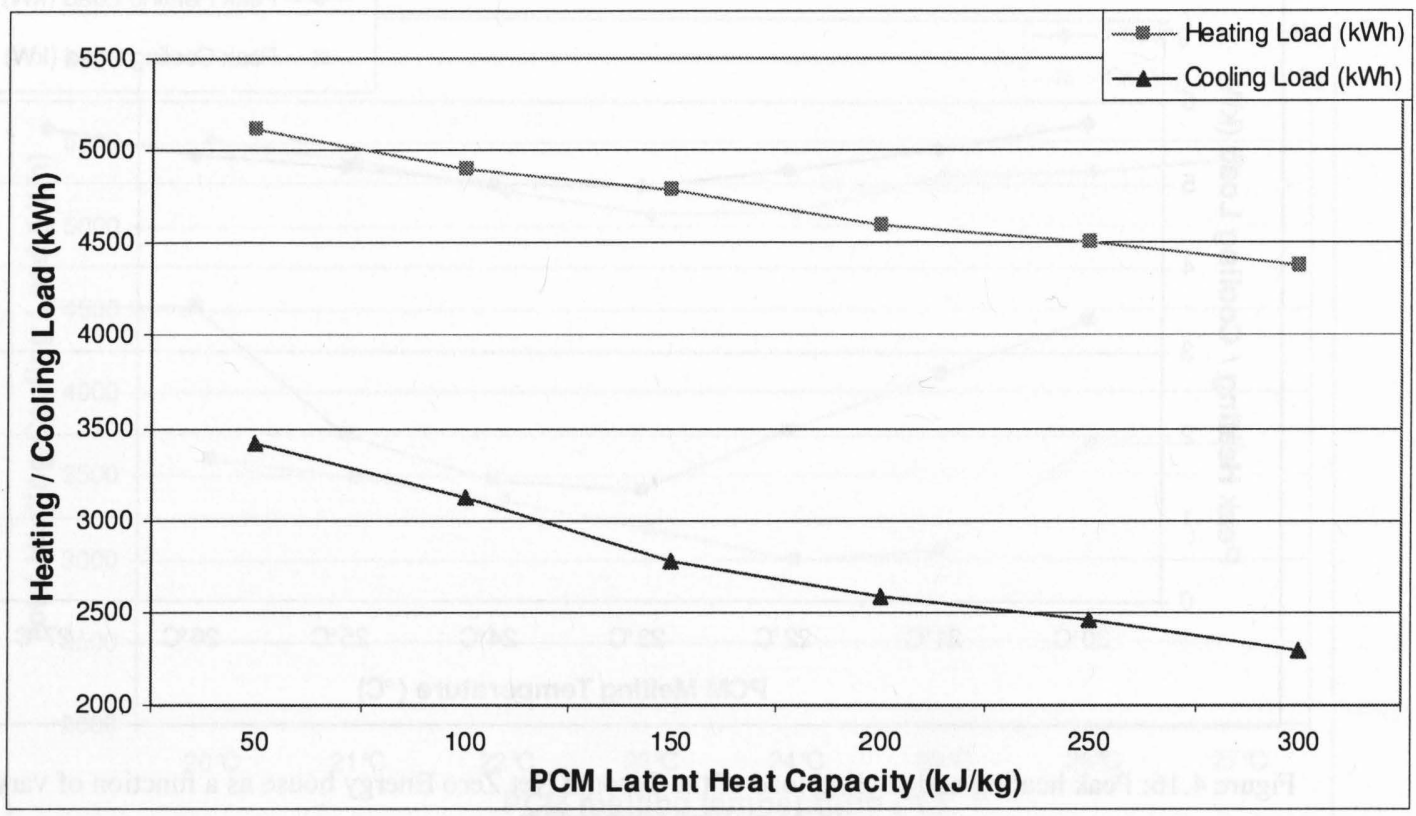

Figure 4.17: Annual heating and cooling load of the Toronto Net Zero Energy house as a function of varying PCM latent heat

\subsubsection{Varying the ventilation rate during the night}

One of the primary drawbacks in a highly insulated building is the tendency for any solar gains to become trapped within the building and contribute to overheating. Any solar gains during the day are readily absorbed by the building and contribute to a cooling load even during the night time when temperatures have moderated. One approach that has been successfully used before is the concept of free cooling during the night, where outside air is drawn into the building to reduce the loads on the air-conditioning equipment (Mehling and Cabeza, 2008). The cool outside air can also be used to reduce the temperature of any thermal mass within the building, thereby improving its capacity to absorb thermal energy the next day.

A detailed simulation was conducted for the Toronto SUI Net Zero Energy house, whereby the ventilation air change rate $(\mathrm{ACH})$ was increased from $0.5 \mathrm{ACH}$ to $5 \mathrm{ACH}$, only during the night hours to take advantage of the cooling capacity of the air. In both cases, the concentration of PCM used within the building envelope is $20 \%$. The ventilation rate is controlled through the use of a control function in TRNSYS, which operates in a manner similar to a step function. Utilizing this function, the total ventilation rate of the house is kept at 0.5 $\mathrm{ACH}$ between 6 am and $10 \mathrm{pm}$. During the night the ventilation rate is increased to $5 \mathrm{ACH}$. Figure 4.19 below shows the control strategy used for the ventilation. In this case, the controller 
is programmed as a step function whereby, during the night hours the ventilation is increased to 5 $\mathrm{ACH}$ and returned back to $0.5 \mathrm{ACH}$ during the day.

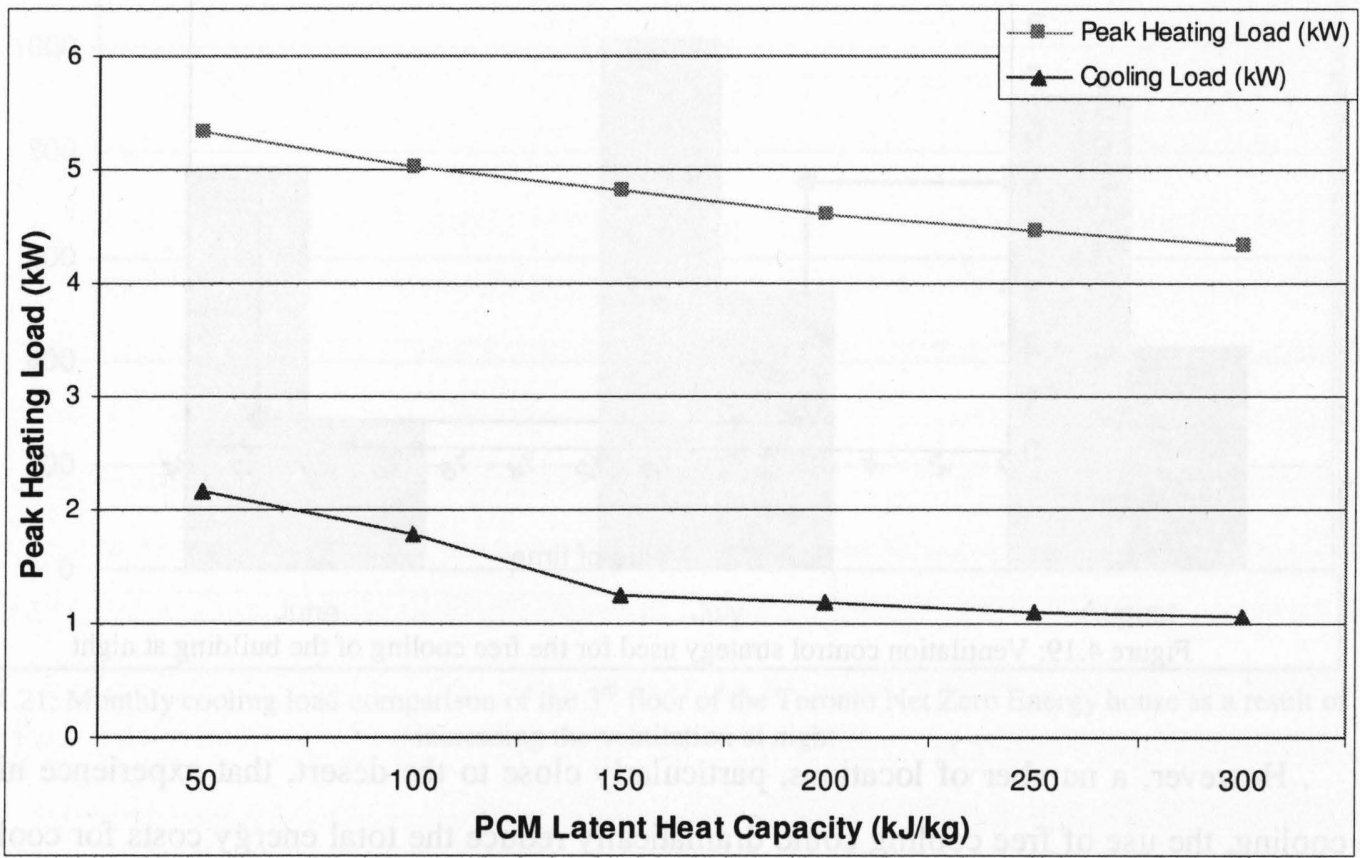

Figure 4.18: Peak heating and cooling load of the Toronto Net Zero Energy house as a function of varying PCM latent heat capacity

The temperature profile of the $3^{\text {rd }}$ floor of the Toronto Net Zero house for a typical summer week can be seen in Figure 4.20. The impact of increasing the ventilation rate from 0.5 $\mathrm{ACH}$ to $5 \mathrm{ACH}$ is clearly illustrated by the temperature reduction at night. The average low temperature in Toronto during the summer season ranges between $14^{\circ} \mathrm{C}$ and $18^{\circ}$ and this mostly occurs during the night and early morning periods (Environment Canada, 2009).

It can been seen from the figure that during some nights, as a result of increasing the ventilation rate to $5 \mathrm{ACH}$, the temperature reaches close to the outdoor temperature for that particular night. Furthermore, as a result of the cooling of the thermal mass within the building, the air-conditioning load and the duration during which the equipment is in operation are reduced. Figure 4.21 compares the cooling load of the building as a result of implementing this ventilation strategy. Results are shown for the months of June, July and August. This strategy would not be effective for other months as the nighttime temperatures are considerably lower in Toronto during most of the year 


\section{Function editor}

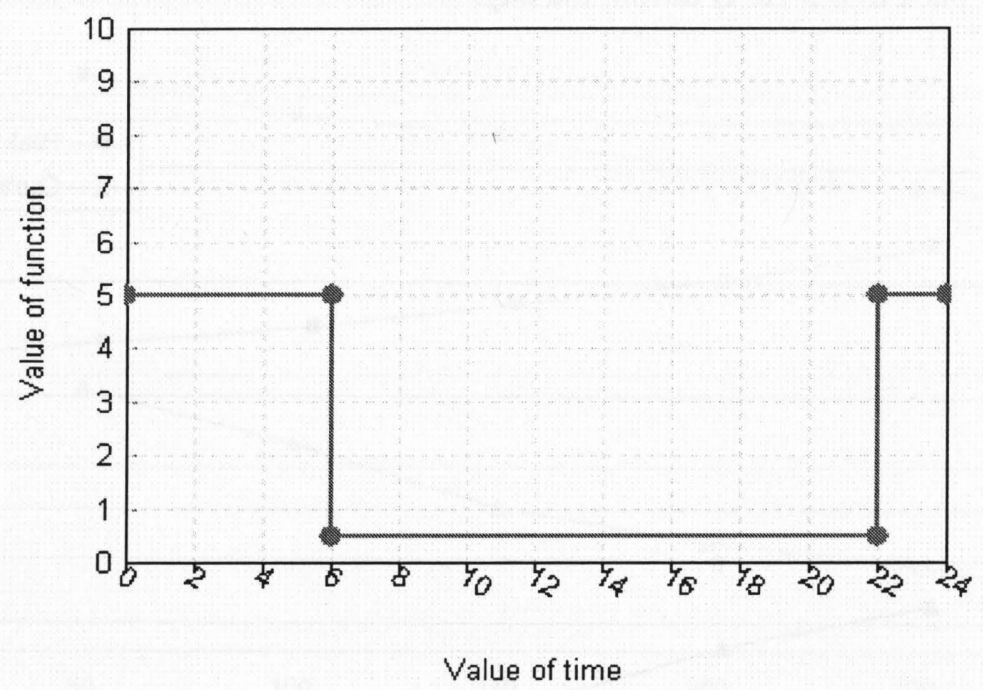

Figure 4.19: Ventilation control strategy used for the free cooling of the building at night

. However, a number of locations, particularly close to the desert, that experience night time cooling, the use of free cooling could dramatically reduce the total energy costs for cooling the building during the day. Thus, in order for this strategy to be implemented, the key requirements are a large variation between the temperatures during the day and night time, low relative humidity at night and the night time temperature dropping below the PCM transition temperature.

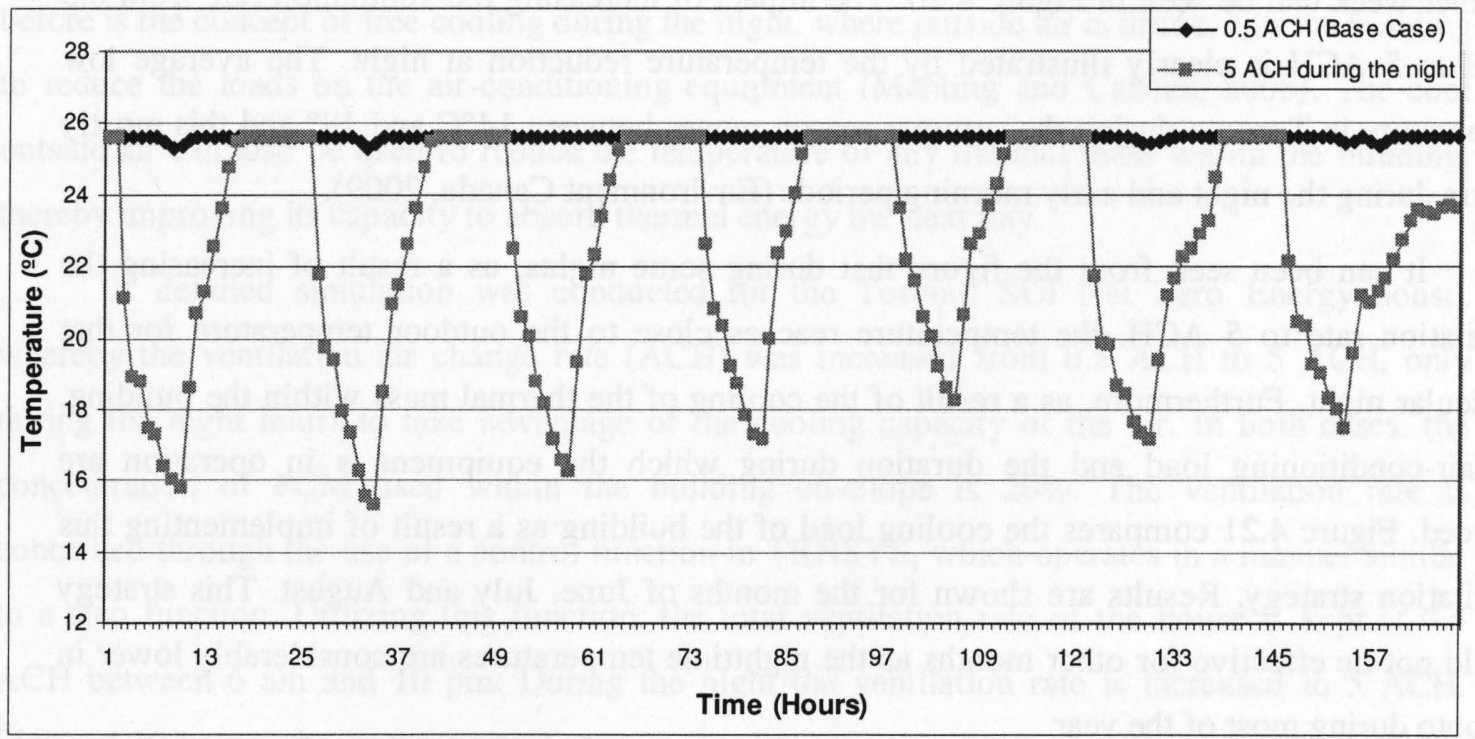

Figure 4.20: Temperature profile of the $3^{\text {rd }}$ floor of the Toronto Net Zero Energy house during a typical summer week showing the effect of increasing the ventilation rate at night 


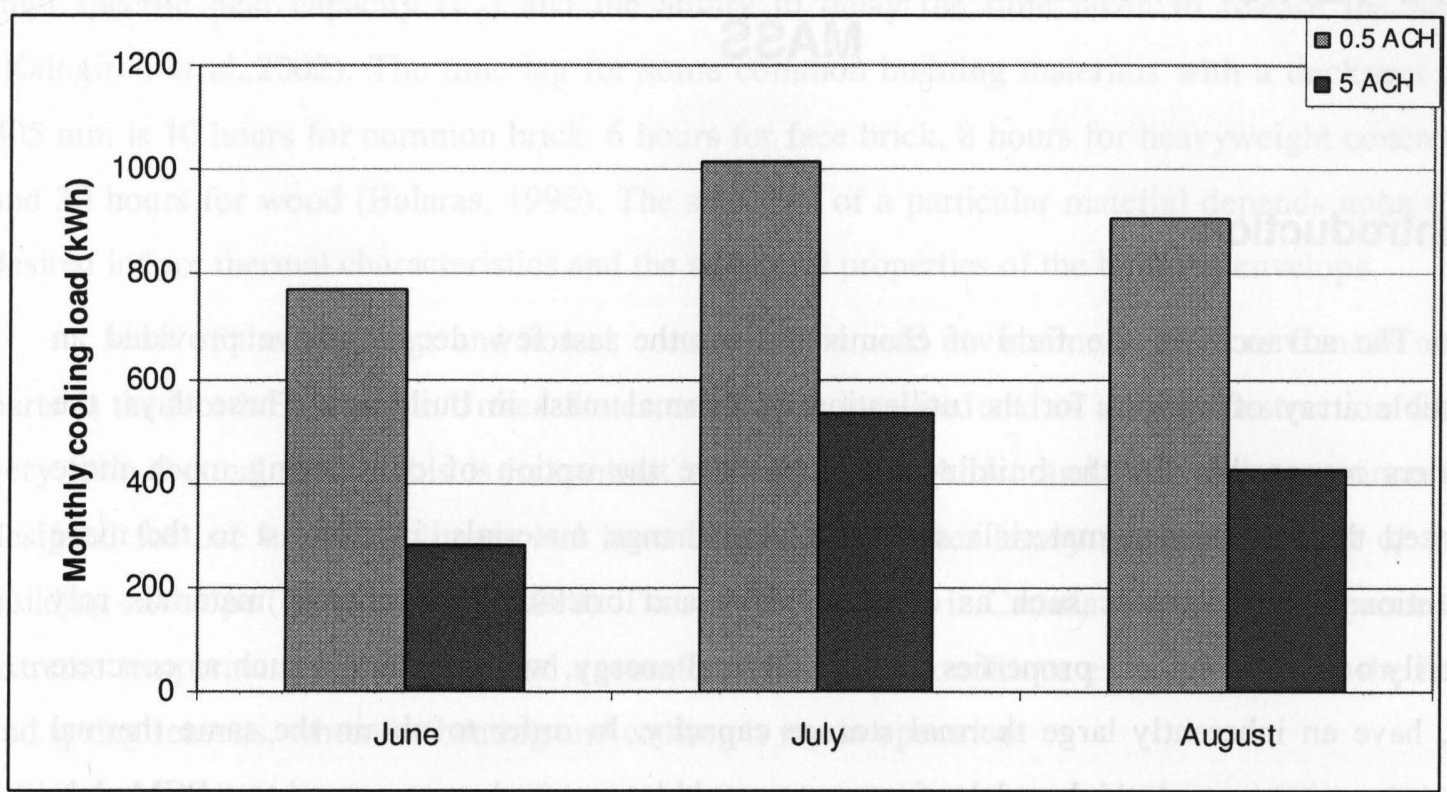

Figure 4.21: Monthly cooling load comparison of the $3^{\text {rd }}$ floor of the Toronto Net Zero Energy house as a result of increasing the ventilation at night 


\section{CHAPTER 5: ANALYSIS OF CONCRETE SLAB AS THERMAL MASS}

\subsection{Introduction}

The advances in the field of chemistry over the last few decades have provided an incredible array of options for the utilization of thermal mass in buildings. These days, the designers responsible for the building envelope have the option of considering much more advanced thermal storage materials such as phase change materials, in contrast to the more conventional thermal mass such as concrete slabs and bricks. Phase change materials rely primarily on their chemical properties to store thermal energy, while materials such as concrete slabs, have an inherently large thermal storage capacity. In order to obtain the same thermal storage capacity, a much thicker slab of concrete would be required as compared to a PCM slab. This illustrates one of the key advantages of using more advanced forms of thermal mass such as PCM, when buildings with a lighter construction is desired.

Buildings are responsible for more than $30 \%$ of the total energy consumed in Canada (NSERC SBRN, 2007). As the price of energy increases and concerns for sustainability and conservation grow, it has become essential to devise ways of reducing the overall energy use in buildings. The use of thermal mass incorporated into the building envelope has been found to be an effective way to reduce the heating and cooling loads. Furthermore, in climates where a large daily temperature fluctuation exists, the use of thermal mass has contributed to the lowering of the indoor temperature peaks and smoothing of the temperature fluctuations, thereby contributing significantly to the occupant comfort (Kalogirou et al., 2002).

Much of the work done previously on the use of thermal mass in buildings has been experimental in nature and has focussed mainly on conventional brick construction in hot climates such as Asia and Africa. This research will analyze the impact of using thermal mass with a building envelope that is highly insulated, and of a light construction, such as that used in Low Energy or Net Zero Energy housing. Furthermore, this analysis would also evaluate the impact of using thermal mass in a cold climate such as that found in Canada.

Thermal mass is defined as any building material having a high heat storage capacity that can be integrated into the structural fabric of the building to effectively utilize the passive solar energy for the purposes of heating and cooling. Some of the commonly used materials include concrete slabs, bricks and ceramic blocks (Shaw et al., 1994). The selection of a particular 
material to function as thermal mass depends on a variety of factors such as a high density $(\rho)$, a high specific heat capacity $\left(C_{p}\right)$ and the ability to delay the time taken to release the heat (Kalogirou et al.,2002). The time lag for some common building materials with a thickness of $305 \mathrm{~mm}$ is 10 hours for common brick, 6 hours for face brick, 8 hours for heavyweight concrete and 20 hours for wood (Balaras, 1996). The selection of a particular material depends upon the desired indoor thermal characteristics and the structural properties of the building envelope.

Most of the buildings and homes constructed in cold environments such as Canada and parts in the North East of the United States, are highly insulated and of a light construction with very little thermal mass. This is in contrast to buildings in Africa and Asia that are primarily designed for use in a hot climate and have concrete and other heavy materials as part of the building envelope (Gregory et al., 2008). Thus, most buildings in Canada and the US are prone to extreme temperature fluctuations and uncomfortable indoor conditions especially during the fall and spring seasons, when the heating and cooling is not in operation.

One aspect by which thermal mass proves to be more effective when compared to conventional insulation is in its ability to delay the peak loads during the winter and summer seasons. In winter, any excess solar radiation that is stored by the building mass during the daytime is progressively released later during the evening, when the heating load can be significant. This can have a significant impact on the overall heating load of the building.

Kalogirou et al (2002) have shown a total reduction in heating load of $47 \%$ through the application of thermal mass in a south facing wall using TRNSYS. During the summer, the use of thermal mass can provide a significant improvement in the overall occupant comfort by reducing the possibility of indoor overheating. The peak air-conditioning load which occurs during the afternoon can also be drastically reduced by incorporating south facing walls with thermal mass. Ruud et al. (1990) demonstrated through the use of test chamber in Florida, the impact of using thermal mass causing a reduction of $18 \%$ in the cooling load during the day time. Brown (1990) conducted detailed simulations on an office building to determine the effect of varying the thermal mass. It was concluded that that an increase in thermal mass from 21 to $201 \mathrm{~kg} / \mathrm{m}^{2}$ of floor area, in closed and ventilated buildings, can reduce the peak indoor temperature by between $1^{\circ} \mathrm{C}$ and $2^{\circ} \mathrm{C}$.

Ogoli(2003) in tests conducted in Nairobi, Kenya, showed that thermal mass in the form of heavy concrete tile and timber panelling was able to maintain the indoor temperature within the comfort zone of around $25^{\circ} \mathrm{C}$, when the outdoor temperature hovered around $33^{\circ} \mathrm{C}$. The location of thermal mass within the building envelope is also very important. Balaras (1996) has 
determined that it is more effective when the thermal mass is placed in between the insulation. It can also be placed on the outside of the building envelope thus providing direct exposure to the solar radiation Furthermore, the orientation of the thermal mass within the building is essential, as it dictates the time delay of the temperature peaks. North and east facing building envelopes have little need for a time delay. For the building envelopes facing the south and west directions respectively, an $8 \mathrm{~h}$ time lag is sufficient to delay heat transfer from midday until the evening hour (Ogoli, 2003).

\subsection{Modelling and Simulation}

A variety of simulations would be conducted to analyze the impact of using conventional thermal mass such as concrete slabs on the overall energy consumption and temperature profile within the building. A detailed model of the Toronto SUI Net Zero Energy house has been developed in TRNSYS as described in Chapter 4 and would be utilized for the simulations. For each of the different scenarios, the simulations are run for one year with a time step of one hour, as is normally the case for building simulation analysis. The simulations are run with the heating and cooling set points at $21^{\circ} \mathrm{C}$ and $25.5^{\circ} \mathrm{C}$ respectively, which means that there is a complex interaction of heat transfer between the incident solar radiation, thermal mass and the heating/cooling equipment. As a means of comparison all of the results are shown for either the $2^{\text {nd }}$ floor or the $3^{\text {rd }}$ floor or the mezzanine, since these are locations where the temperature peaks and fluctuations are expected to be the greatest. For modelling PCM, a TYPE 204 component as described in Chapter 4 is used. This would ensure a direct comparison between the more conventional forms of thermal mass such as concrete and more advanced chemical storage materials such as PCM.

\subsection{Results for the conditioned Space}

The results are presented for the case where the heating and cooling equipment is in operation. This would be contrasted with the situation where the HVAC equipment would be disabled so that any interaction by the conditioning equipment on the indoor temperature could be minimized. 
The use of concrete slab of varying thickness and PCM is modelled as thermal mass through the addition of these layers to the building envelope of the house. Yearly simulations are conducted to analyze the impact of using thermal mass during both the summer and winter months. In a highly insulated house of a light weight construction such as the one modelled in this project, one of the key factors impacting the comfort of the occupants is the fluctuations in the indoor temperature caused by interplay of a variety of factors such as the incident solar radiation, HVAC system and heating/cooling set points etc. During the winter months, overheating of the indoor environment is a major concern, especially on a clear, sunny day, where the house is exposed to direct incident radiation. These solar gains, when combined with the regular winter heating capability, dramatically exacerbate the degree of discomfort for the occupant. This effect is further compounded for portions of the building that have a large window area.

The use of thermal mass integrated with the building envelope is an effective method that can be adopted to increase the indoor thermal comfort by reducing the degree of overheating during the winter. A strategically placed unit of thermal mass, such as a concrete slab, within the building envelope can not only minimize the indoor temperature fluctuations, but also contribute to a reduction in the cooling load of the building. This is achieved through the storage of any unwanted solar gains during the day, and the subsequent release of this energy during the evening when the temperature drops.

Figure 5.1 illustrates the impact of using a concrete slab with varying thickness as thermal mass, for mitigating the occasional indoor overheating experienced by occupants. Results are presented for a typical winter week for the mezzanine floor. A typical winter week for Toronto is defined as occurring between Feb $1^{\text {st }}-$ Feb $7^{\text {th }}$. The detailed temperature profiles can be seen in Appendix E. It can be observed that during the week, the indoor temperature occasionally exceeds the heating set point of $21^{\circ} \mathrm{C}$ for a few hours. This could occur on a clear sunny day, where the incoming solar radiation incident on the windows, exceeds the heat loss through the building envelope. The impact of using the 2 -inch and the 4 -inch concrete slabs can be seen by comparing the peak indoor temperatures, which remain below $21.5^{\circ} \mathrm{C}$ throughout the week, as opposed to temperatures which rise to $23^{\circ} \mathrm{C}$ when no thermal mass is used. Despite the fact, that the mezzanine floor has only approximately $20 \%$ of its facade area comprised of glazing and thus exposed to the incident solar radiation, there were occasional periods where the temperature rose above $21^{\circ} \mathrm{C}$. 


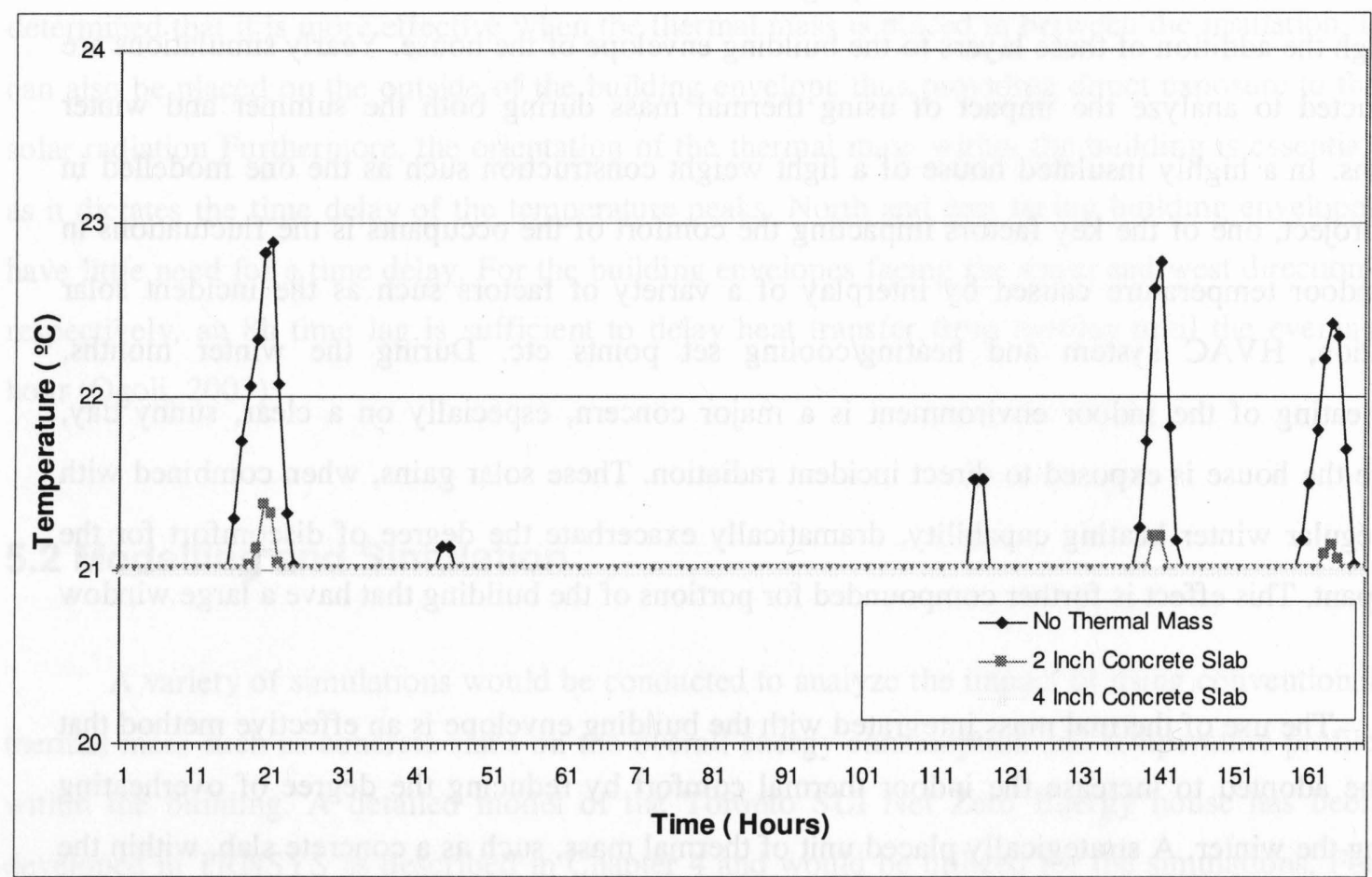

Figure 5.1: Temperature profile of the Mezzanine floor of the Net Zero Energy house during a typical winter week with varying thermal mass.

This situation is in contrast to the $3^{\text {rd }}$ floor which has almost $80 \%$ of its facade area covered with the windows. Therefore, there can be an expectation that the indoor temperature would fluctuate much more than what was observed on the mezzanine floor. This is observed in Figure 5.2. The 4-inch concrete slab significantly reduces the peak indoor temperatures during the week; while towards the end of the week, the impact of the temperature reduction is further magnified with both the 2-inch and 4-inch concrete slabs. Because of the presence of a large window area, even with thermal mass present, the indoor temperature of the $3^{\text {rd }}$ floor rises beyond the heating set point. One way this could be controlled would be through the use of additional thermal mass or by lowering the heating set point.

The impact of thermal mass was also analyzed for both the mezzanine and 3rd floor of the house for a typical summer week and the results are presented in Figures 5.3 and 5.4 respectively. A typical summer week in Toronto is defined as occurring between Jul $15^{\text {th }}$ and Jul $21^{\text {st }}$. The detailed temperature profiles can be seen in Appendix E. 


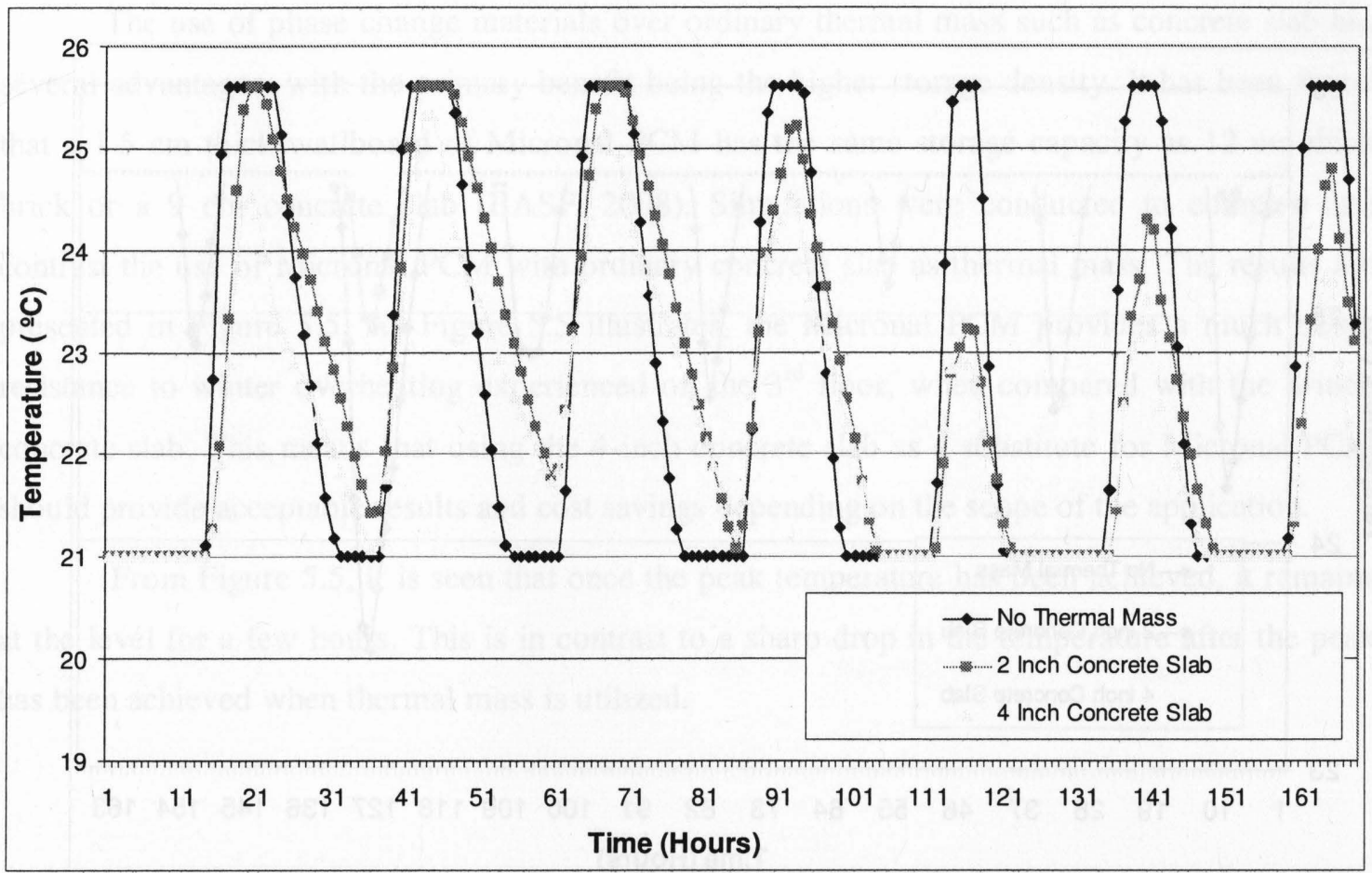

Figure 5.2: Temperature profile of the 3rd floor of the Net Zero Energy house during a typical winter week with varying thermal mass.

As can be observed from these figures, the presence of thermal mass ensures that the temperature is maintained within a comfortable range of the cooling set point. From Figure 5.3, it is seen that the indoor temperature remains constant in response to a drop in the ambient temperature and incident solar radiation, when thermal mass is utilized. This is in contrast to a dramatic drop in the indoor temperature when no thermal mass is present. It is obvious that during the summer there is a possibility of over-cooling the building when little or no thermal mass is present, thereby increasing the cooling energy requirement. The use of thermal mass would prevent that possibility by storing the excess thermal energy and releasing it later. During a typical summer day, the cooling equipment in the building ensures that the temperature is maintained within a comfortable range. However, as the temperature and the solar gain decrease during the evening, a building with adequate thermal mass is better able to resist any sharp downward fluctuations in temperature. Figure 5.4 shows a similar phenomena but with a much more visible trend showing the impact of thermal mass. 


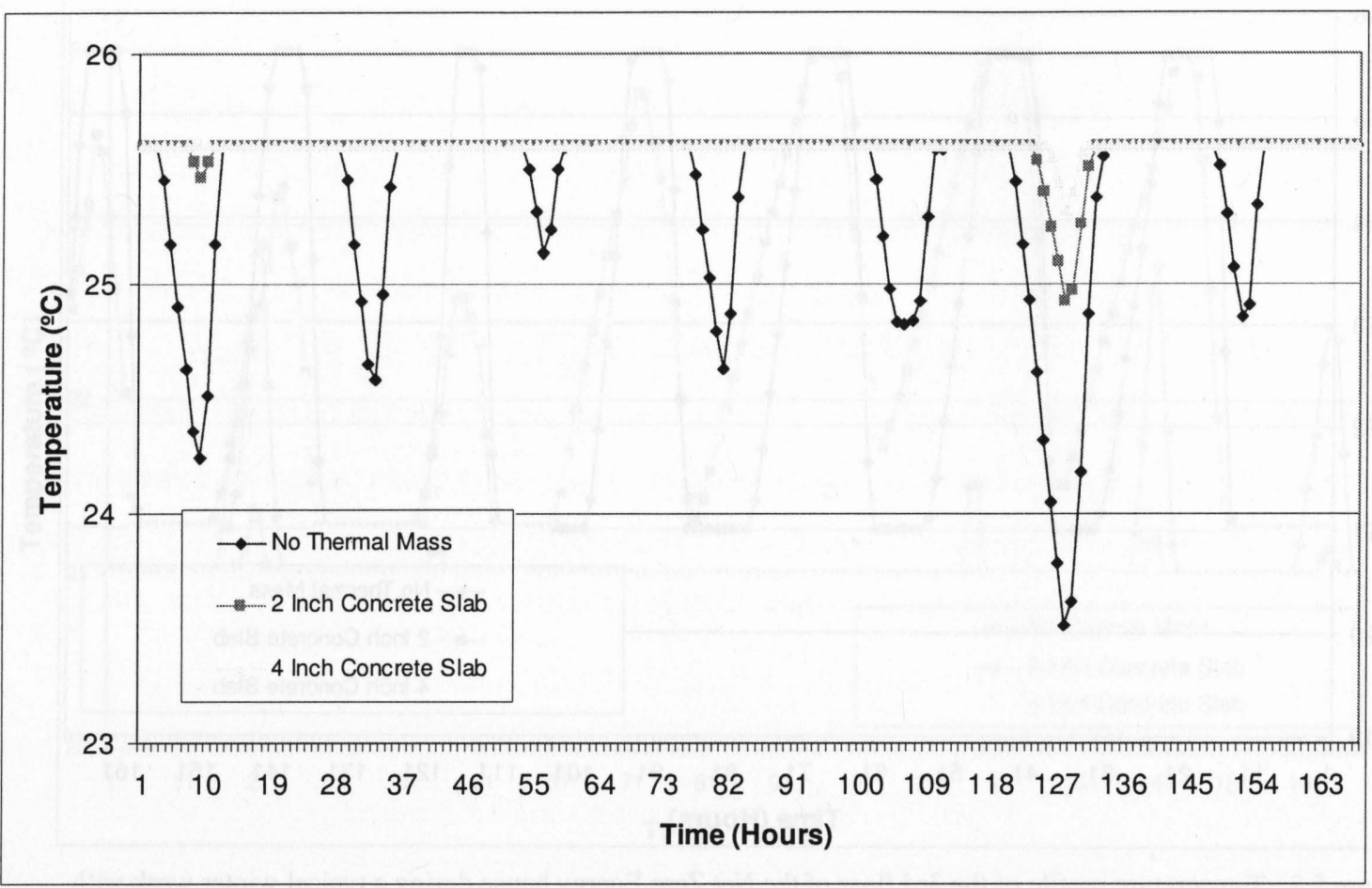

Figure 5.3: Temperature profile of the Mezzanine floor of the Net Zero Energy house during a typical summer week with varying thermal mass.

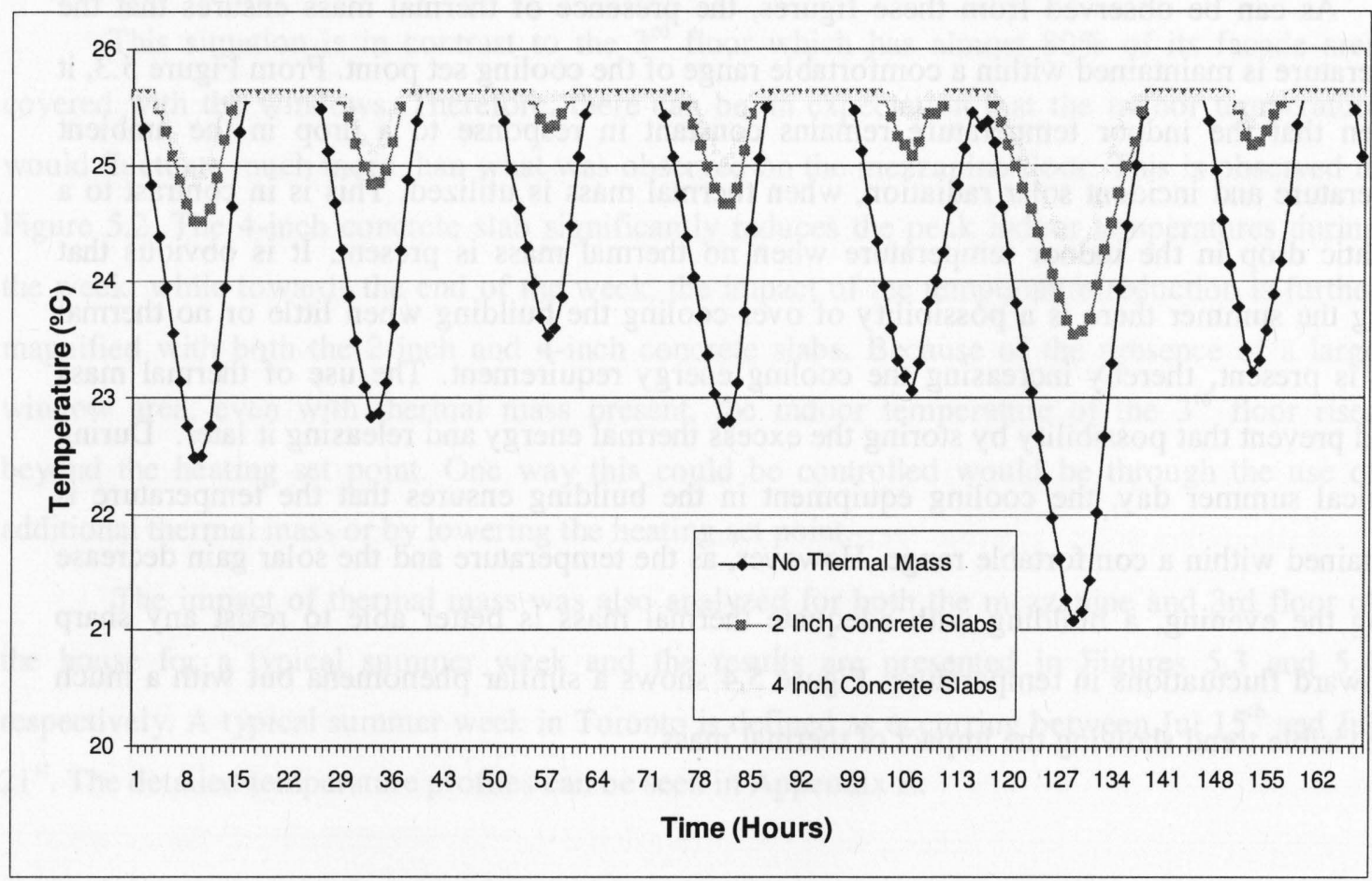

Figure 5.4: Temperature profile of the 3rd floor of the Net Zero Energy house during a typical summer week with varying thermal mass. 
The use of phase change materials over ordinary thermal mass such as concrete slab has several advantages, with the primary benefit being the higher storage density. It has been found that a $1.5 \mathrm{~cm}$ thick wallboard of Micronal PCM has the same storage capacity as $12 \mathrm{~cm}$ thick brick or a $9 \mathrm{~cm}$ concrete slab (BASF, 2008). Simulations were conducted to compare and contrast the use of Micronal PCM with ordinary concrete slab as thermal mass. The results are presented in Figure 5.5. As Figure 5.5 illustrates, the Micronal PCM provides a much better resistance to winter overheating experienced on the $3^{\text {rd }}$ floor, when compared with the 4-inch concrete slab. This means that using the 4 -inch concrete slab as a substitute for Micronal PCM should provide acceptable results and cost savings depending on the scope of the application.

From Figure 5.5, it is seen that once the peak temperature has been achieved, it remains at the level for a few hours. This is in contrast to a sharp drop in the temperature after the peak has been achieved when thermal mass is utilized.

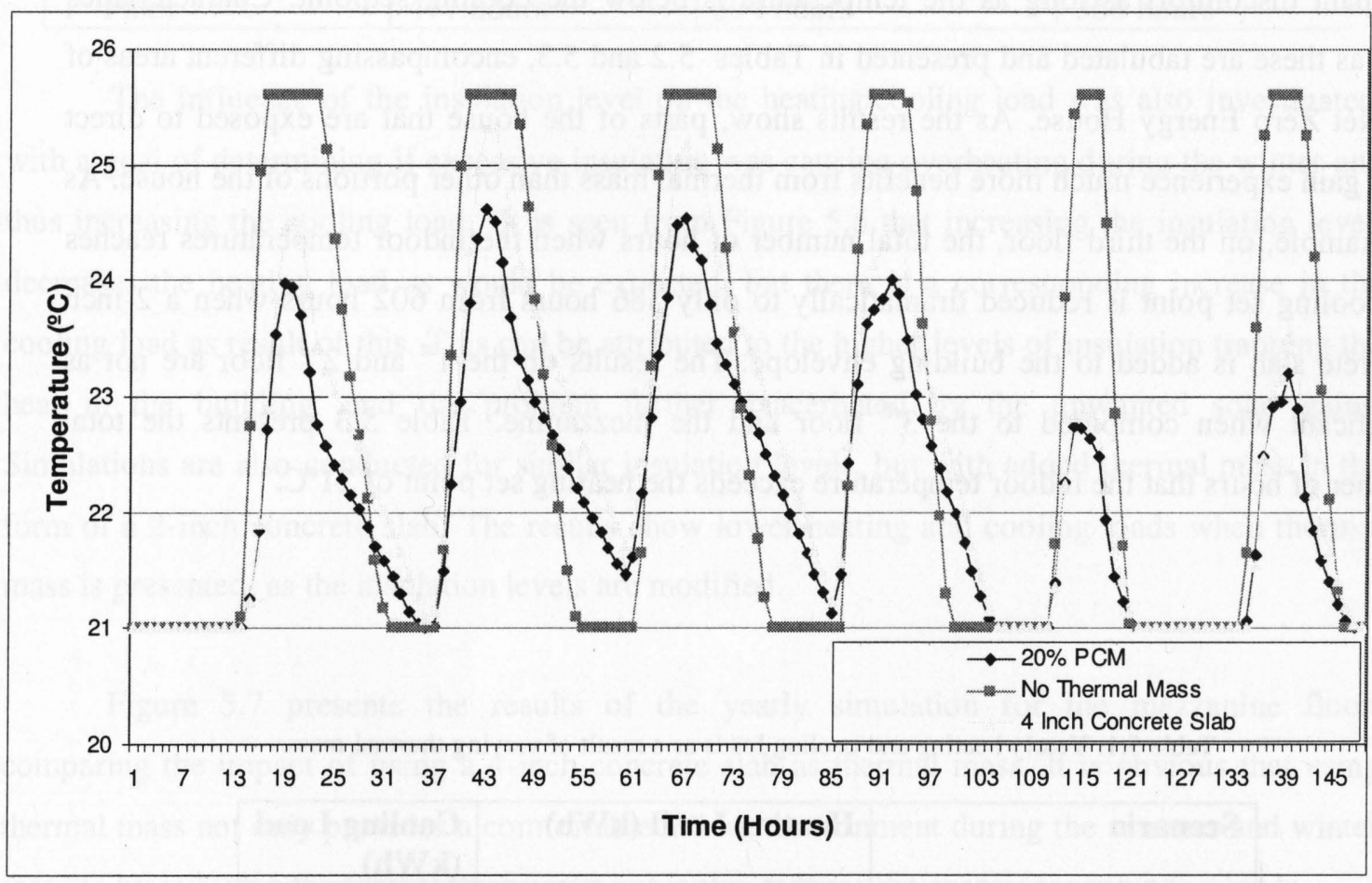

Figure 5.5: Temperature profile comparing the thermal mass effect of 20\% Micronal PCM and 4-Inch Concrete Slab for the 3rd floor of the Net Zero Energy house during a typical winter week. 
It is interesting to note that in addition to the reduction in peak temperature as a result of using thermal mass, there is also a reduction in the total duration that the peak temperature occurs for.

The impact of using thermal mass in terms of the total yearly energy savings is presented in Table 5.1. As is obvious, there is a progressive decrease in the annual heating and cooling loads as the quantity of thermal mass is increased. The total savings in the cooling load are between $5-7 \%$ and $8-15 \%$ for the heating and cooling loads respectively. Annual energy consumption for the 4 -inch concrete slab and $20 \%$ Micronal yield almost similar results. This further validates the conclusion regarding the similarity of the heat storage capacity of the 4-inch concrete slab and 20\% Micronal PCM, as established by Figure 5.5.

Another metric that is of importance to the comfort of the occupants is the frequency of the temperature deviation from the set points. During the winter season, the temperature frequently rises above the heating set point as result of solar gains. This would not contribute to occupant discomfort as long as the temperature is below the cooling setpoint. Characteristics such as these are tabulated and presented in Tables 5.2 and 5.3, encompassing different areas of the Net Zero Energy House. As the results show, parts of the house that are exposed to direct solar gain experience much more benefits from thermal mass than other portions of the house. As an example, on the third floor, the total number of hours when the indoor temperatures reaches the cooling set point is reduced dramatically to only 386 hours from 602 hours when a 2-inch concrete slab is added to the building envelope. The results on the $1^{\text {st }}$ and $2^{\text {nd }}$ floor are not as significant when compared to the $3^{\text {rd }}$ floor and the mezzanine. Table 5.3 presents the total number of hours that the indoor temperature exceeds the heating set point of $21^{\circ} \mathrm{C}$.

Table 5.1: Yearly heating and cooling loads as a result of varying thermal mass.

\begin{tabular}{|l|l|l|}
\hline Scenario & Heating Load (kWh) & $\begin{array}{l}\text { Cooling Load } \\
(\mathbf{k W h})\end{array}$ \\
\hline $\begin{array}{l}\text { Base Case (No Thermal } \\
\text { Mass) }\end{array}$ & 5511 & 3681 \\
\hline 2-Inch Concrete Slab & 5271 & 3429 \\
\hline 4-Inch Concrete Slab & 4895 & 2902 \\
\hline 20\% Micronal PCM & 4846 & 2861 \\
\hline
\end{tabular}


Table 5.2: Total number of hours during the winter season, the indoor temperature overheats to the cooling set point, $25^{\circ} \mathrm{C}$.

\begin{tabular}{|l|l|l|l|}
\hline Part of the House & No Thermal Mass & 2-Inch Concrete Slab & $\begin{array}{l}\text { 4-Inch Concrete } \\
\text { Slab }\end{array}$ \\
\hline $3^{\text {rd }}$ Floor & 602 hours & 386 hours & 273 hours \\
\hline 2 nd Floor & 454 hours & 377 hours & 323 hours \\
\hline Mezzanine & 161 hours & 109 hours & 92 hours \\
\hline $1^{\text {st }}$ Floor & 290 hours & 234 hours & 207 hours \\
\hline
\end{tabular}

Table 5.3: Total number of hours during the winter season, the indoor temperature exceeds the heating set point, $21^{\circ} \mathrm{C}$.

\begin{tabular}{|l|l|l|l|}
\hline Part of the House & No Thermal Mass & 2-Inch Concrete Slab & $\begin{array}{l}\text { 4-Inch Concrete } \\
\text { Slab }\end{array}$ \\
\hline $3^{\text {rd }}$ Floor & 1603 hours & 1186 hours & 1039 hours \\
\hline 2nd Floor & 653 hours & 577 hours & 523 hours \\
\hline Mezzanine & 358 hours & 299 hours & 255 hours \\
\hline $1^{\text {st }}$ Floor & 477 hours & 394 hours & 368 hours \\
\hline
\end{tabular}

The influence of the insulation level on the heating/cooling load was also investigated, with a goal of determining if excessive insulation was causing overheating during the winter and thus increasing the cooling load. It is seen from Figure 5.6 that increasing the insulation level, decreases the heating load as would be expected, but there is a corresponding increase in the cooling load as result of this. This can be attributed to the higher levels of insulation trapping the heat in the building, and the problem further exacerbated by the unwanted solar gains. Simulations are also conducted for similar insulation levels, but with added thermal mass in the form of a 2-inch concrete slab. The results show lower heating and cooling loads when thermal mass is presented, as the insulation levels are modified.

Figure 5.7 presents the results of the yearly simulation for the mezzanine floor, comparing the impact of using a 4-inch concrete slab as thermal mass. It is obvious that using thermal mass not only provides a comfortable indoor environment during the summer and winter seasons by reducing the temperature peaks but it also reduces the energy consumption loads.

Figure 5.8 illustrates the temperature profile for the $3^{\text {rd }}$ floor for a period of only 48 hours. The objective is to illustrate some key benefits of using thermal mass. In addition to the reduction in the temperature peaks and fluctutations, there is also a shift in when the peak temperature occurs and the duration that it lasts for. Referring to Figure 5.8, it observed that the temperature 
peaks at $25.5^{\circ} \mathrm{C}$ and remains at the level for $4-5$ hours. This is contrasted with a peak temperature that lasts at most 1-2 hours when a 2-inch concrete slab is used.

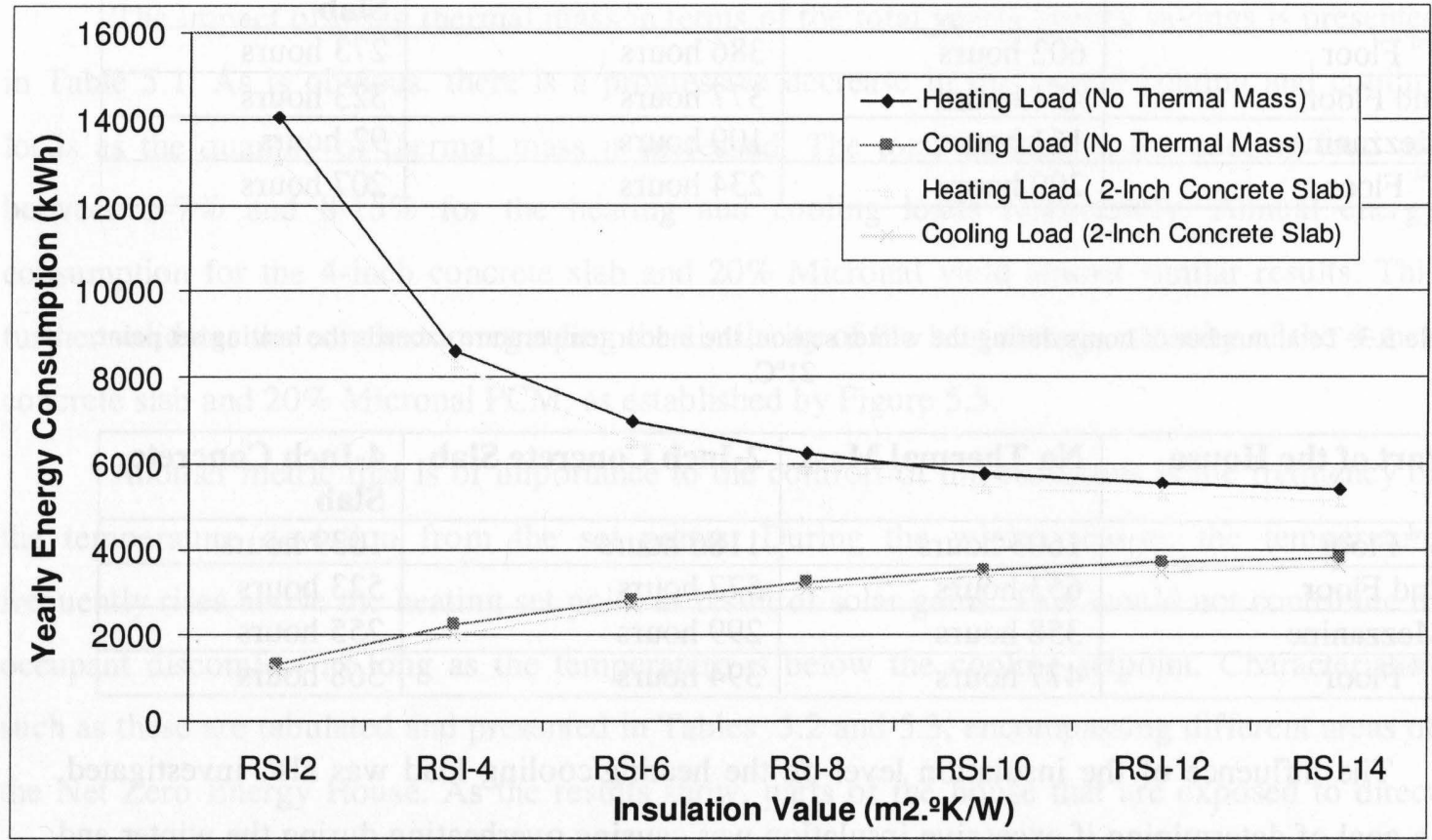

Figure 5.6: Comparison of the impact on the heating and cooling loads as insulation levels are varied when thermal mass is used versus no thermal mass.

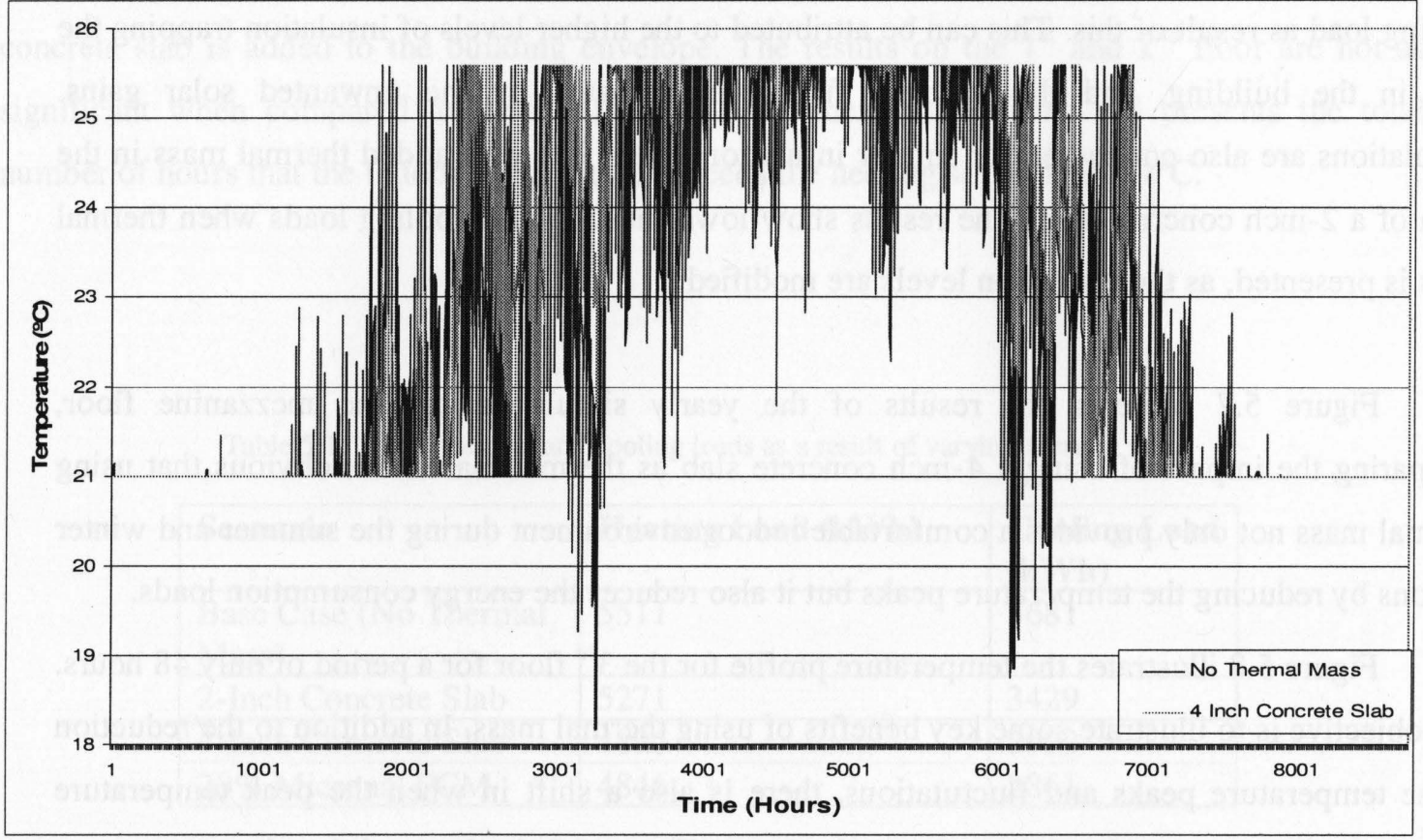

Figure 5.7: Yearly temperature profile of the Mezzanine Floor of the house comparing the impact of using a 4-inch thick concrete slab. 


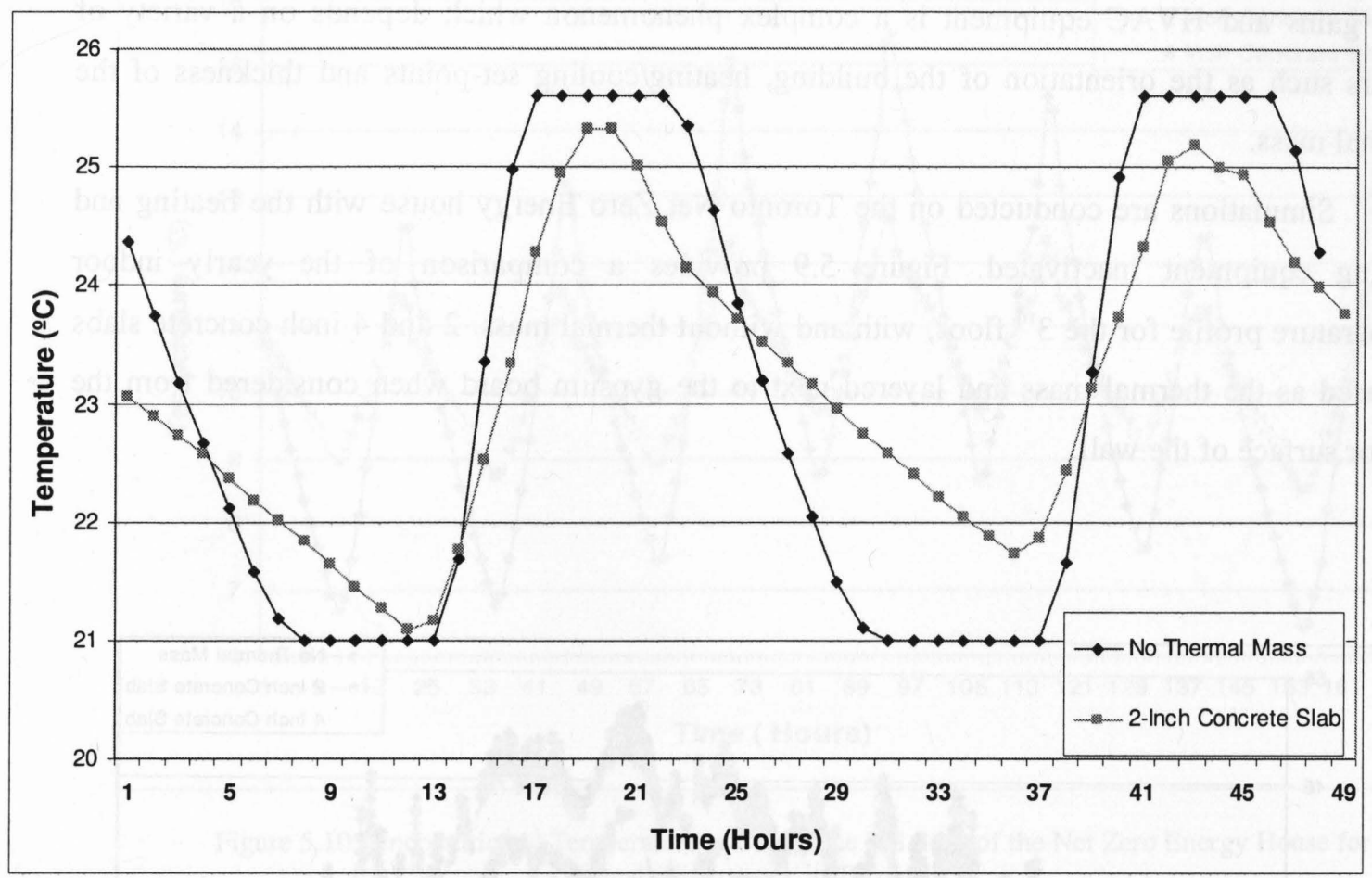

Figure 5.8: Temperature profile of the 3rd Floor of the house for a 48-hour duration for the winter season, comparing the impact of using a 4-inch thick concrete slab.

It was found that the use of thermal mass with the Net Zero Energy house in Toronto provides excellent results in terms of the reductions in the daily indoor temperature fluctuations along with a decrease in the annual heating and cooling loads. The problem of overheating during the winter was also addressed effectively with PCM and concrete slabs as thermal mass. The effectiveness of Micronal PCM was also compared to ordinary thermal mass such as a concrete slab and was found to yield similar results in terms of the total energy consumption. The frequency of the temperature deviation from the cooling and heating set points was also determined and it was found that thermal mass is the most effective when a particular portion of the house is exposed to direct solar radiation. The relationship between the insulation level and its contribution to the heating load was also established and it was determined that reducing the level of insulation would decrease the cooling load.

\subsection{Results for the Un-Conditioned Space}

The behaviour of thermal mass within an unconditioned building is significantly different from a building that is being actively heated and cooled. The interaction between thermal mass, 
solar gains and HVAC equipment is a complex phenomenon which depends on a variety of factors such as the orientation of the building, heating/cooling set-points and thickness of the thermal mass.

Simulations are conducted on the Toronto Net Zero Energy house with the heating and cooling equipment inactivated. Figure 5.9 provides a comparison of the yearly indoor temperature profile for the $3^{\text {rd }}$ floor, with and without thermal mass. 2 and 4 inch concrete slabs are used as the thermal mass and layered next to the gypsum board when considered from the indoor surface of the wall.

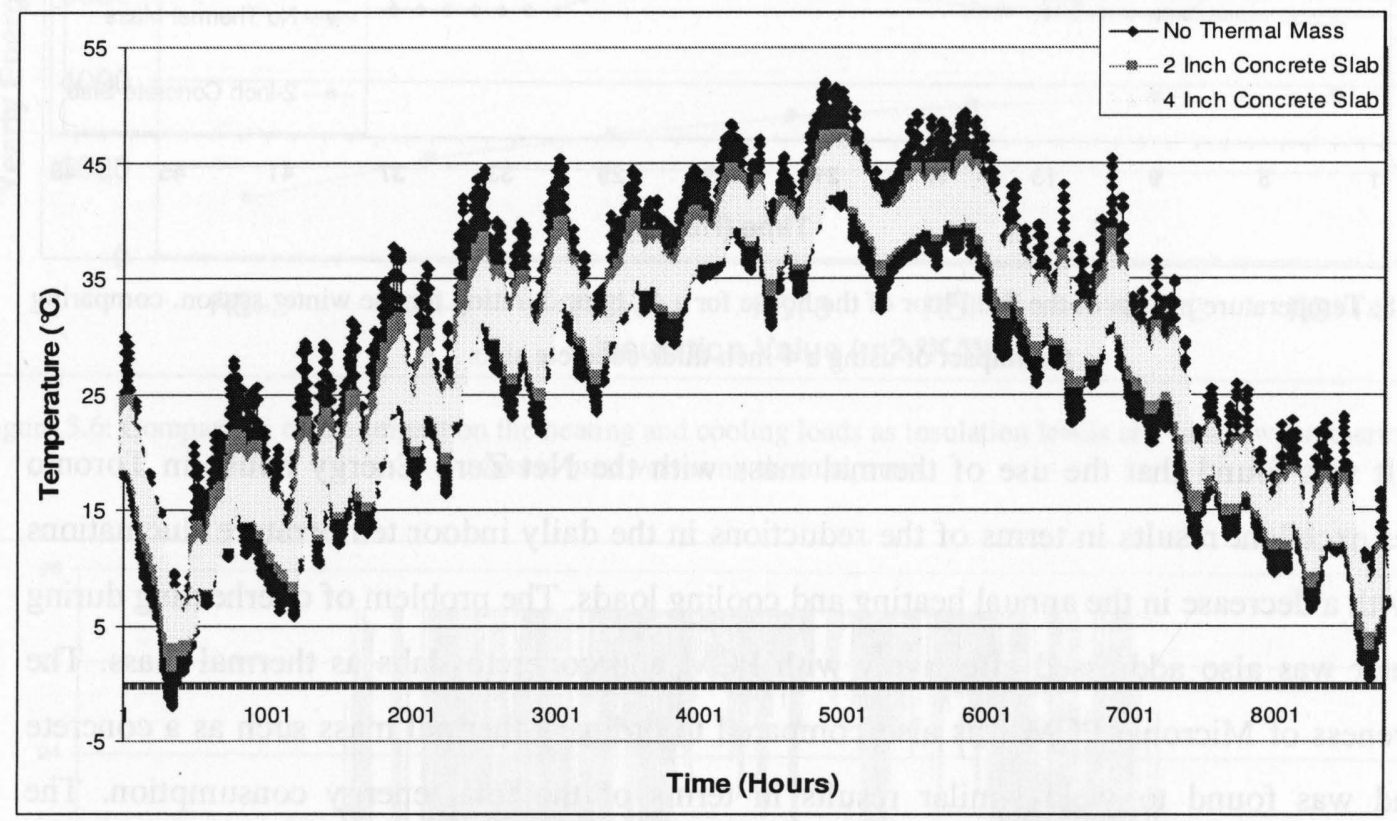

Figure 5.9: Yearly unconditioned temperature profile of the 3rd floor of the Net Zero Energy House.

Figure 5.10 shows a comparison of the temperature profile for the $3^{\text {rd }}$ floor, with and without thermal mass for a typical winter week in Toronto. Two concrete slabs of thicknesses of 2 and 4 inch are used as the thermal mass. Analyzing Figure 5.10, it is seen that for the $3^{\text {rd }}$ floor of the Net Zero Energy house, during the winter season, the use of thermal mass prevents the indoor temperature from dropping below $9^{\circ} \mathrm{C}$ during most of the week, while it drops below $7^{\circ} \mathrm{C}$ when no thermal mass is present. 


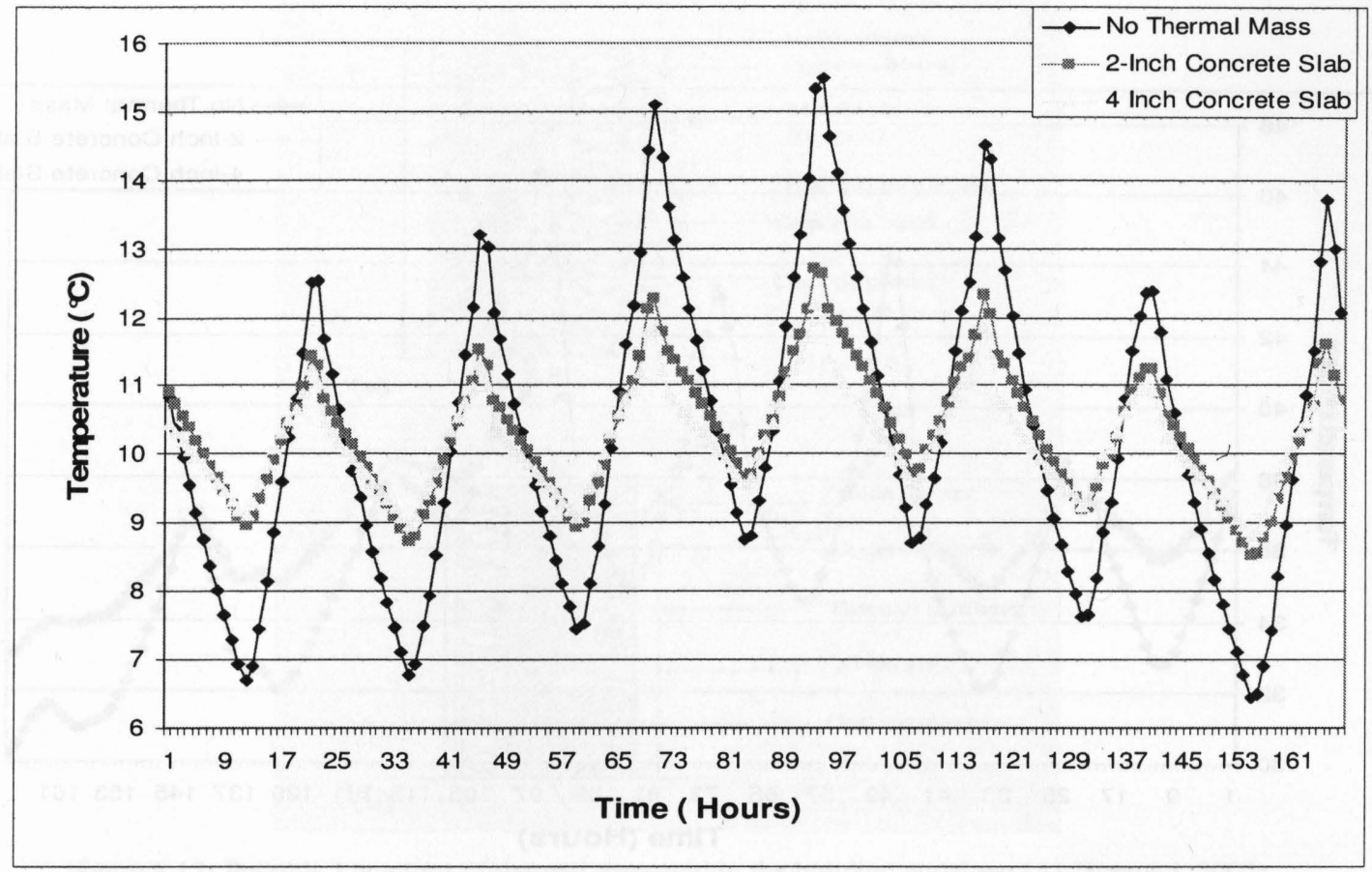

Figure 5.10: Unconditioned Temperature profile of the 3rd floor of the Net Zero Energy House for a typical winter week in Toronto.

Figure 5.11 shows a comparison of the temperature profile for the $3^{\text {rd }}$ floor, with and without thermal mass for a typical summer week in Toronto. A total of 2 concrete slabs of thicknesses of 2 and 4 inches are used as the thermal mass. A key characteristic of using thermal mass with the building envelope is a reduction in the indoor temperature fluctuations and the peak temperature during the winter and summer seasons respectively.

The results for the summer season as illustrated by Figure 5.11 show the impact of thermal mass in reducing the indoor peak temperature. For most days during the week, the indoor temperature peak is lower by $3^{\circ} \mathrm{C}$ to $4^{\circ} \mathrm{C}$. It is clear from these results that the use of thermal mass provides more effective results in the summer in contrast to the winter season. This can be explained by considering that during the summer there is a full utilization of the thermal storage capacity of the thermal mass due to the excessive solar radiation during the summer.

While in the winter, the concrete slabs absorb any additional solar radiation, due to the weather conditions, this absorbed energy is not sufficient to cause a significant change in the indoor temperature. However, during the summer season, all the excess solar energy that is stored by the thermal mass and prevented from contributing to the indoor solar gain, causes a much greater change in the indoor temperature. 


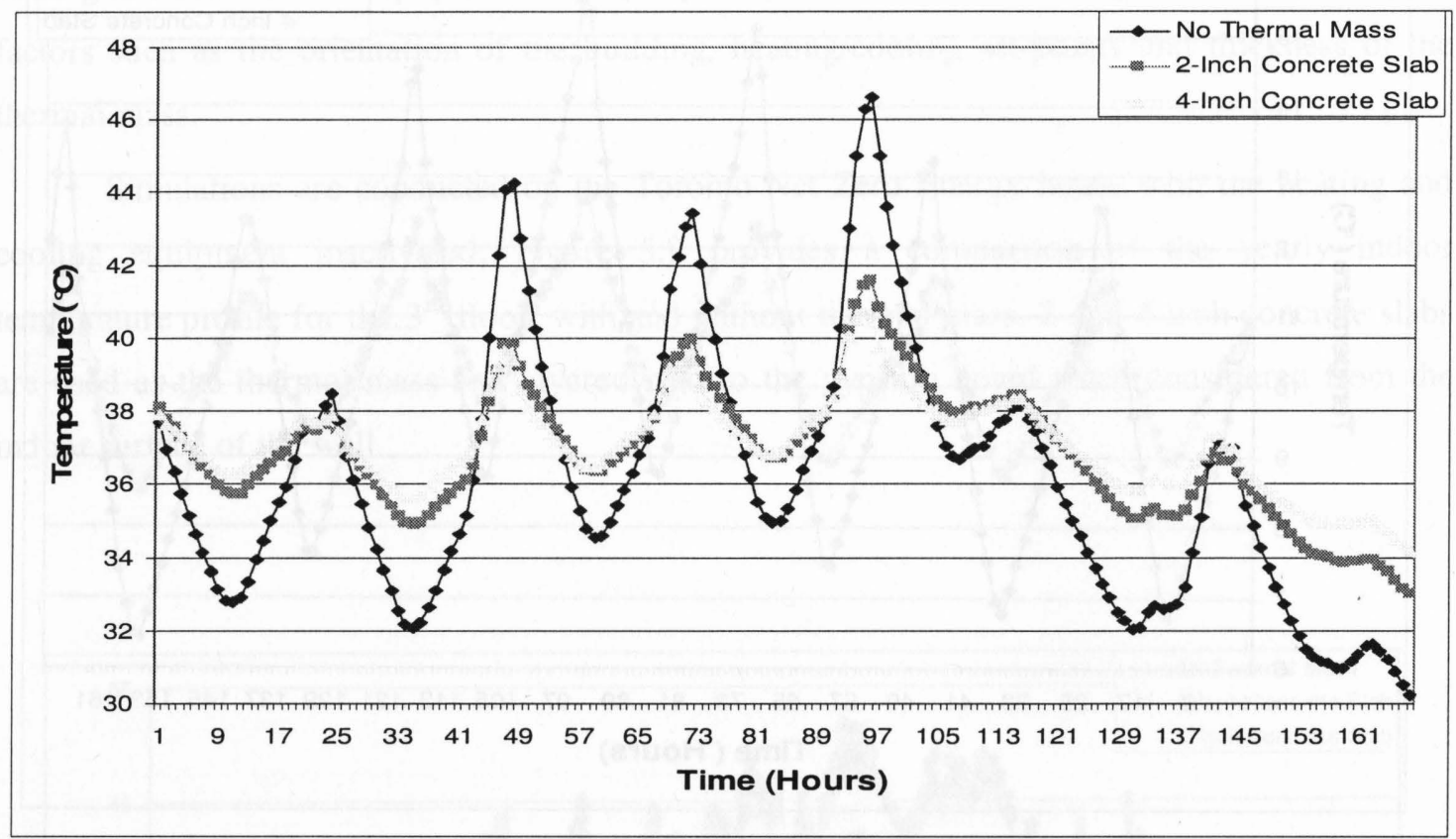

Figure 5.11: Unconditioned Temperature profile of the 3rd floor of the Net Zero Energy House for a typical summer week in Toronto.

The location of the thermal mass within the building envelope is an important consideration that has a significant impact on the overall effectiveness of the thermal mass. A variety of simulations were conducted to determine the optimal location within the building envelope that the thermal mass can be placed. Figure 5.13 shows the temperature profiles obtained as a result of applying thermal mass to three locations within the building envelope of the Net Zero Energy house. It can either be attached to the outside surface of the walls to directly absorb the solar radiation or it can be placed within the interior walls, right next to the gypsum board (Brown, 1990).

Result of the simulation conducted to determine the effectiveness of thermal mass when placed at different locations within the building envelope is given below. In this scenario, the thermal mass in the form of a 2 inch concrete slab was placed at three different locations; right next to the inside plaster, corresponding to scenario (b) in Figure 5.12, right next to the outside plaster, which corresponds to scenario (a) in Figure 5.12 and at the middle of the building envelope next to the insulation. 


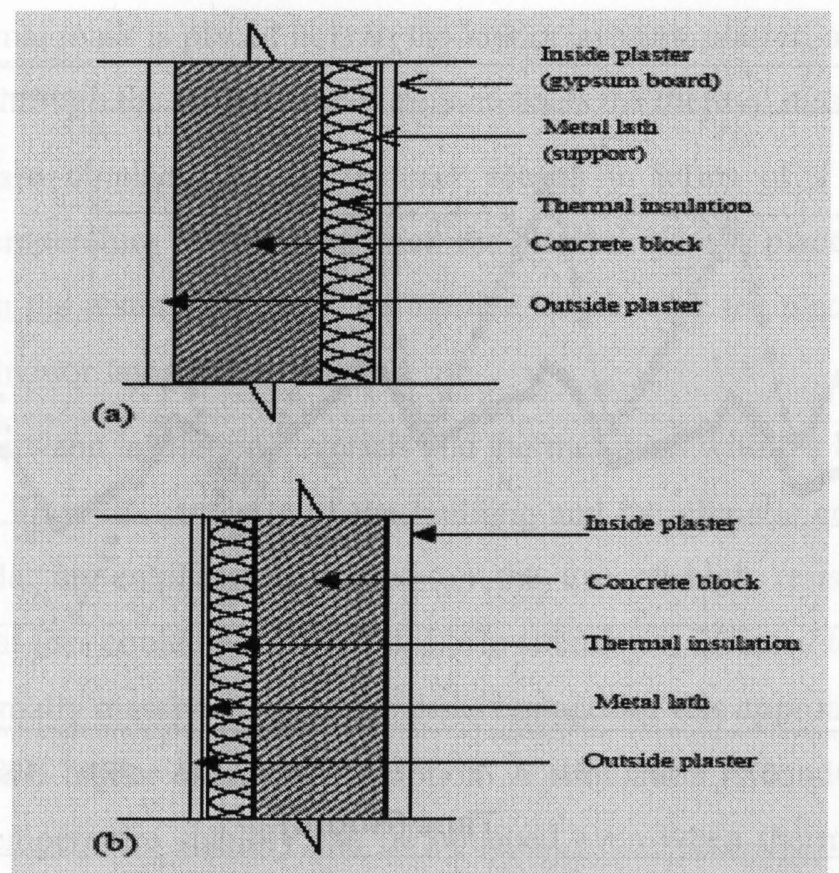

Figure 5.12: Possible Locations of thermal mass within the building envelope (Al-Homoud, 2005)

Figures 5.13 and 5.14 show the temperature profile of the 3rd floor as a result of this analysis. The location of the thermal mass within the building envelope would be denoted by the variable, $x$, where $x$ represents the thickness of the building envelope at the point where the thermal mass is placed. The variable $x$ can be defined as:

$$
0 m \leq x \leq 0.384 m
$$

Where the total thickness of the wall layers is $0.384 \mathrm{~m}$ and $x$ has a value of $0 \mathrm{~m}$ at the indoor wall surface. Figure 5.13 shows the temperature profile for a typical winter week in Toronto when the 4 inch concrete slab is placed within the building envelope at different locations.

Figure 5.14 shows the temperature profile for a typical summer week in Toronto when the 4-inch concrete slab is placed within the building envelope at different locations. It was found that for the winter season only, the location where the concrete slab was attached had a large impact on the indoor temperatures. Best results were obtained when the thermal mass was placed right next to the gypsum board, which forms the interior wall in the house. 


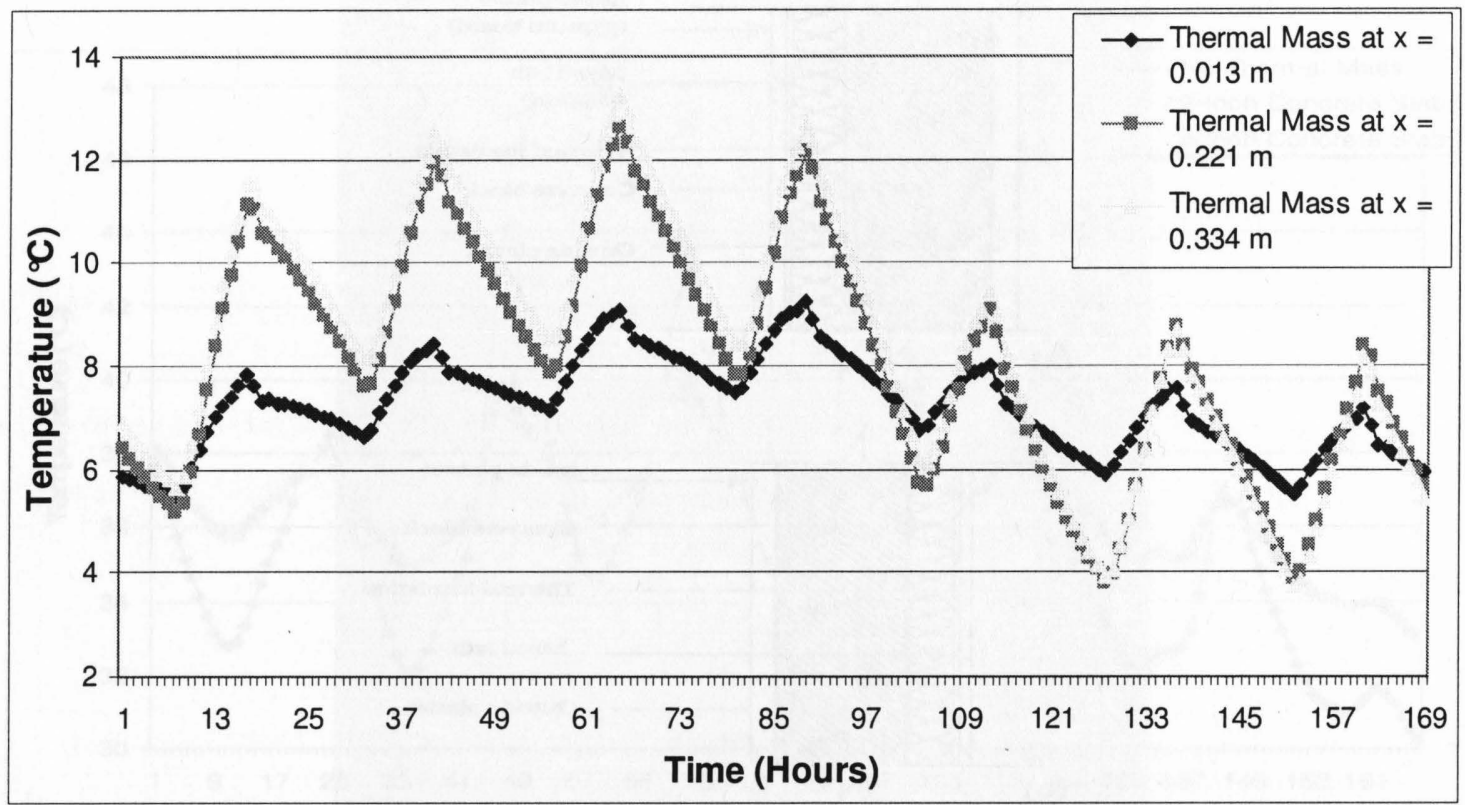

Figure 5.13: Thermal mass placed at different locations within the building envelope for a typical winter week in Toronto.

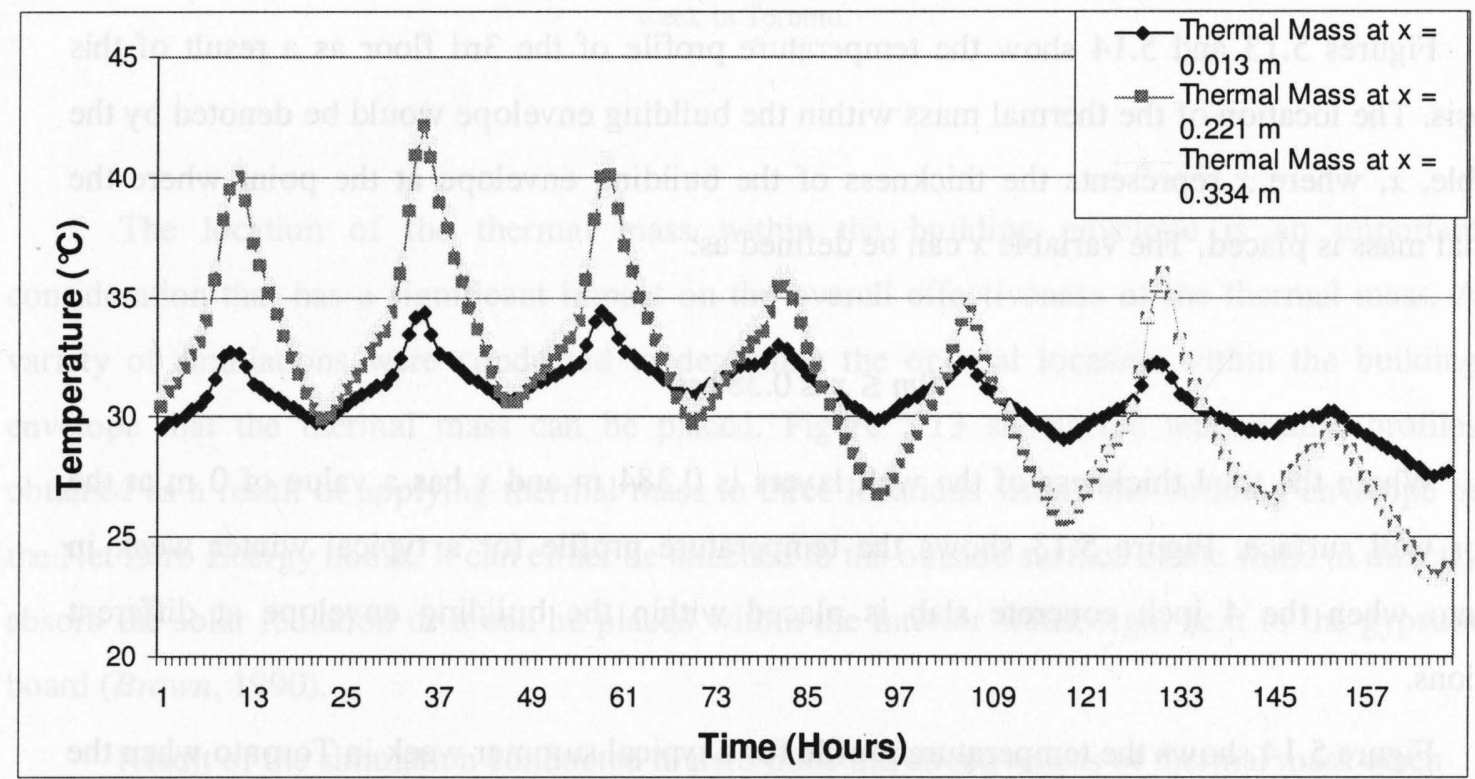

Figure 5.14: Thermal mass placed at different locations within the building envelope for a typical summer week in Toronto.

The effectiveness of this configuration depends on the fact that heat transfer with the surroundings has to pass through the thick layers of insulation thus slowing down the flow. Furthermore, for the cases involving thermal mass placed after the insulation and next to the outside plaster, similar results are obtained. This is because of the fact that in both cases, any heat gain/loss from the outside flows through the thermal mass before passing through the insulation. 
However, when the thermal mass is placed next to the indoor gypsum plaster, any heat flow/gain from the outside passes through the insulation before it contacts the thermal mass.

Similar results are obtained for the summer season in terms of a reduction in the amplitude of the daily temperature fluctuations when the thermal mass is placed in contact with the inside wall. Based on the results, the most appropriate location for the placement of thermal mass is right next to the indoor layer in the building.

The interaction between insulation materials and thermal mass within a building envelope is complex and depends upon the structure of the building and the climatic conditions. In cold climates such as Canada, an emphasis is placed on the use of high resistance, low mass insulation, so that the heat loss could be minimized. Little attention is directed towards the use of making the building thermally massive. One of the disadvantages of this approach is wide indoor temperature fluctuation and higher energy consumption. A simulation is conducted to illustrate the fact that excellent temperature stability can be obtained even when thermal mass replaces some of the insulation in a house. Figure 5.15 shows the yearly indoor temperature profile of the Mezzanine floor in the Net Zero Energy house, with the polyisocyanurate foam replaced with a 4- inch concrete slab. It is clear from the figure that replacing the polyisocyanurate foam with the concrete slab reduces the temperature peaks during the summer and winter seasons, while at the same time providing a superior insulation effect. It is interesting to note that even though the Uvalue of the modified building envelope (with thermal mass) increases to $0.198 \mathrm{~W} / \mathrm{m}^{2} \mathrm{~K}$ from $0.093 \mathrm{~W} / \mathrm{m}^{2} \mathrm{~K}$, no negative impact in noted in the temperature profiles.

Results from Figure 5.15 emphasize the importance of including thermal mass as a component of every building envelope so that a proper balance can be achieved between the indoor temperature and its fluctuations during the various seasons.

Although the removal of a portion of insulation decreases the overall resistance value, the thermal diffusivity of the building envelope is increased. With less insulation, any solar gains incident on the exterior walls, move through the various building layers faster to charge the thermal mass and store heat faster. By replacing a portion of the insulation with thermal mass, significant costs savings and occupant comfort can be achieved.

The thickness of the thermal mass within the building envelope is a critical parameter. Although an extremely thick concrete slab would prove to be very effective as a thermal mass, it might not conform to the structural requirement of the buildings. Thus it is essential that a compromise between the amounts of thermal mass used and architectural specifications. 


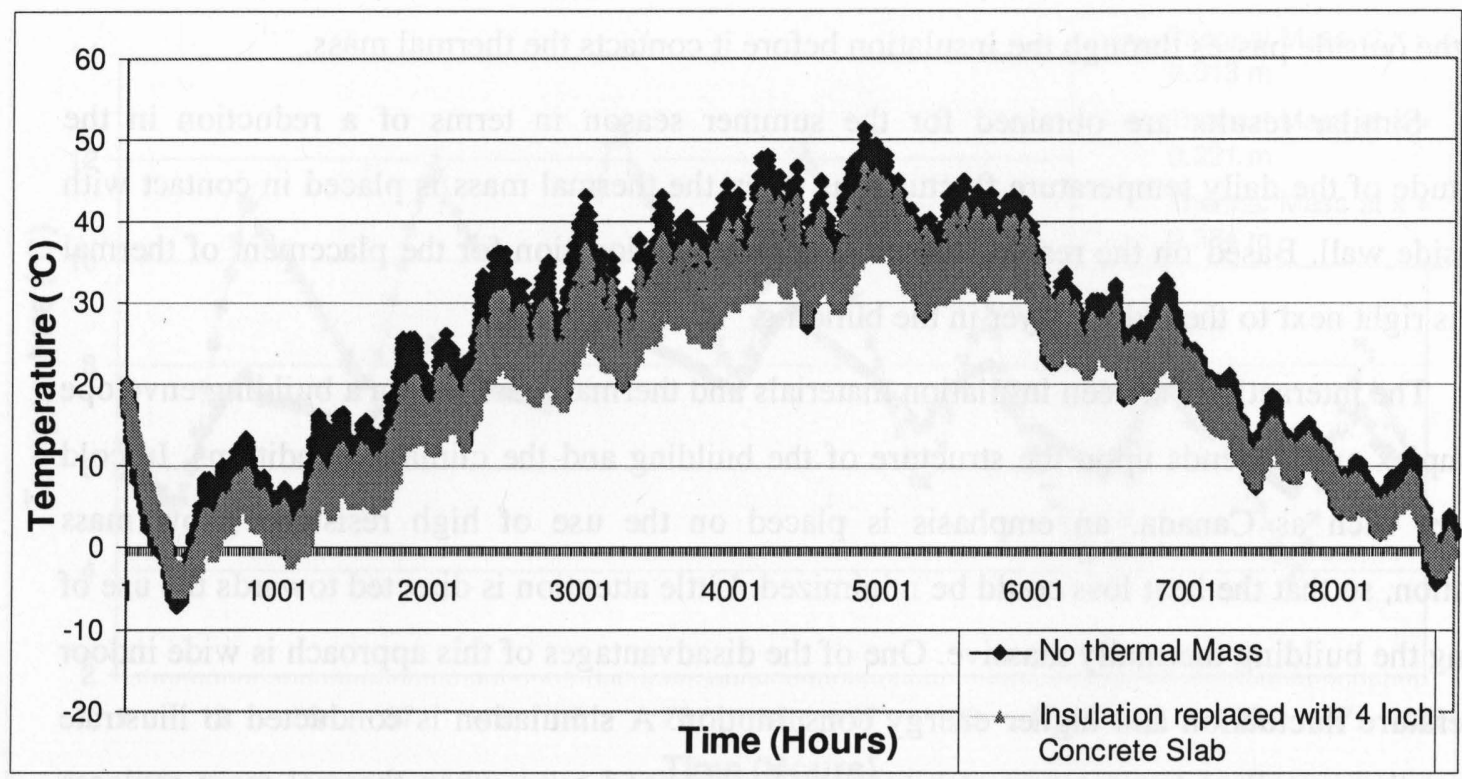

Figure 5.15: Yearly temperature profile showing the impact of replacing the polyisocyanurate insulation with a 4inch concrete slab.

Simulations were conducted for the winter and summer months with added thermal mass in the form of concrete slab of thickness 2,4 and 6 inches respectively. The use of any concrete slabs thicker than 6 inches was found to be not practical and thus was not included in the results. It was found from the analysis conducted that the 4-inch concrete slab provided the best return in terms of temperature reduction and dimensions during both the winter and summer seasons. There seems to be little difference in performance between the 4 and 6-inch concrete slab. It is also obvious that increasing the thickness of the slab generates diminishing returns in terms of the temperature reduction potential.

Figures 5.16 and 5.17 detail the results of the simulation. Figure 5.16 illustrates the temperature profile of the 3rd floor when the thermal mass in form of a concrete slab is varied in thickness from 2 in to 6 in. These simulations are run for a typical winter week in Toronto.

Figure 5.17 illustrates the temperature profile of the 3rd floor when the thermal mass in form of a concrete slab is varied in thickness from 2 in to 6 in. These simulations are run for a typical summer week in Toronto. Figure 5.18 presents a comparison of the peak heating and cooling loads as a result of using concrete slab and 20\% Micronal PCM. It can be observed that there is significant reduction in the peak heating load as compared to peak cooling load. Further increases in the thickness of the concrete slab yields only a marginal decrease in the heating and cooling loads. 


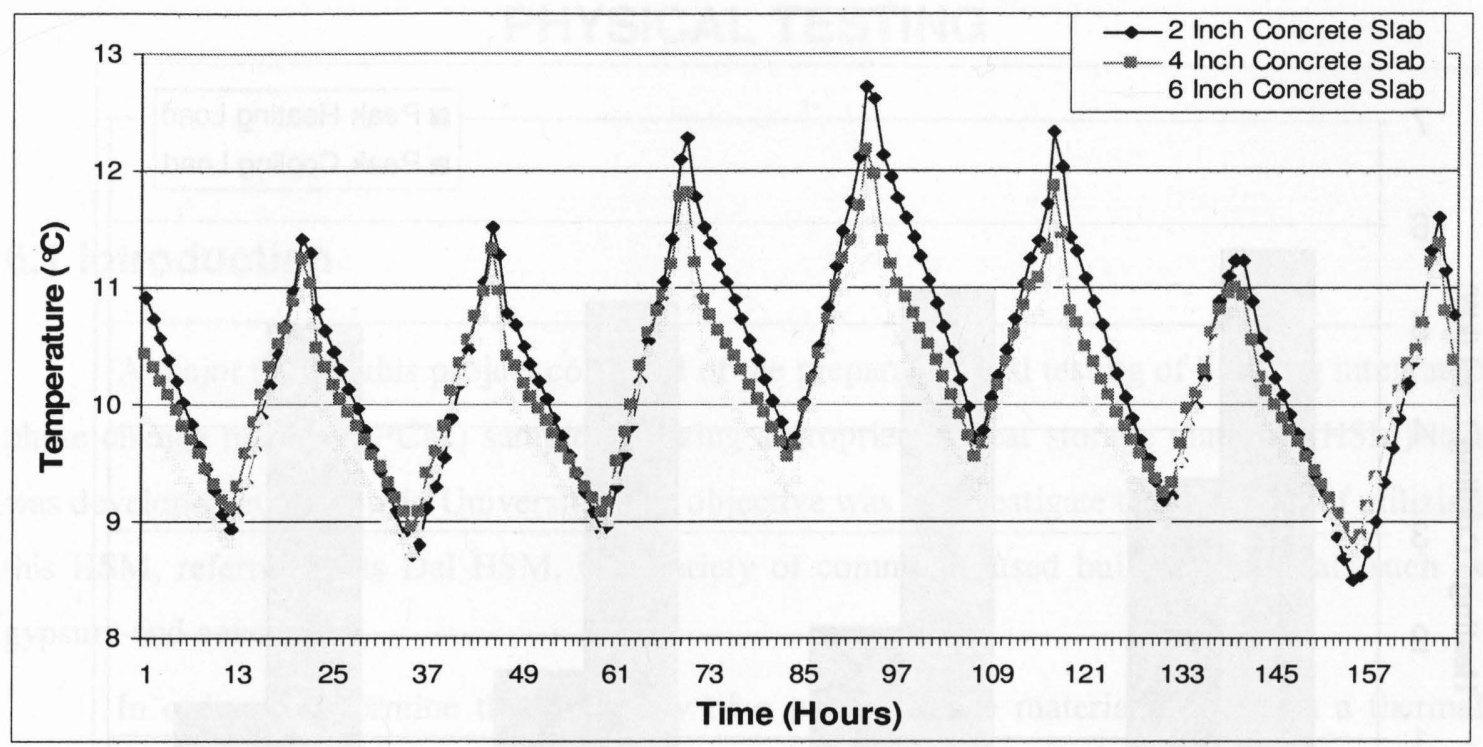

Figure 5.16: Effect of varying the thermal mass of the Net Zero Energy house for a typical winter week in Toronto.

The greater reduction in the peak heating load in contrast to the peak cooling load can be explained by considering that on a typical winter day, solar gains into the building constitute an additional source of heating for the building. This excess solar gain is readily stored by the thermal mass during the afternoon and released during the later part of the evening, when the heating requirements of the building increase.

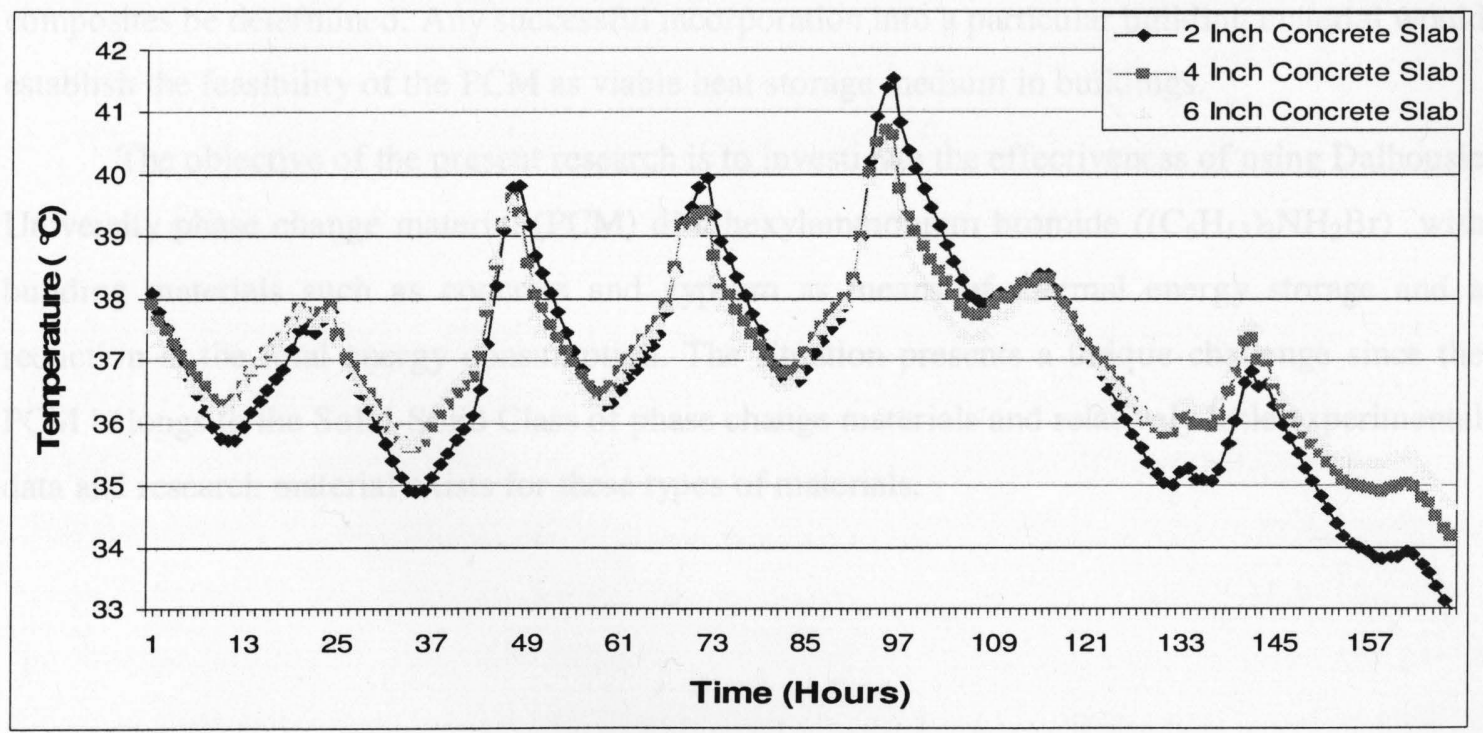

Figure 5.17: Effect of varying the thermal mass of the Net Zero Energy house for a typical summer week in Toronto. 


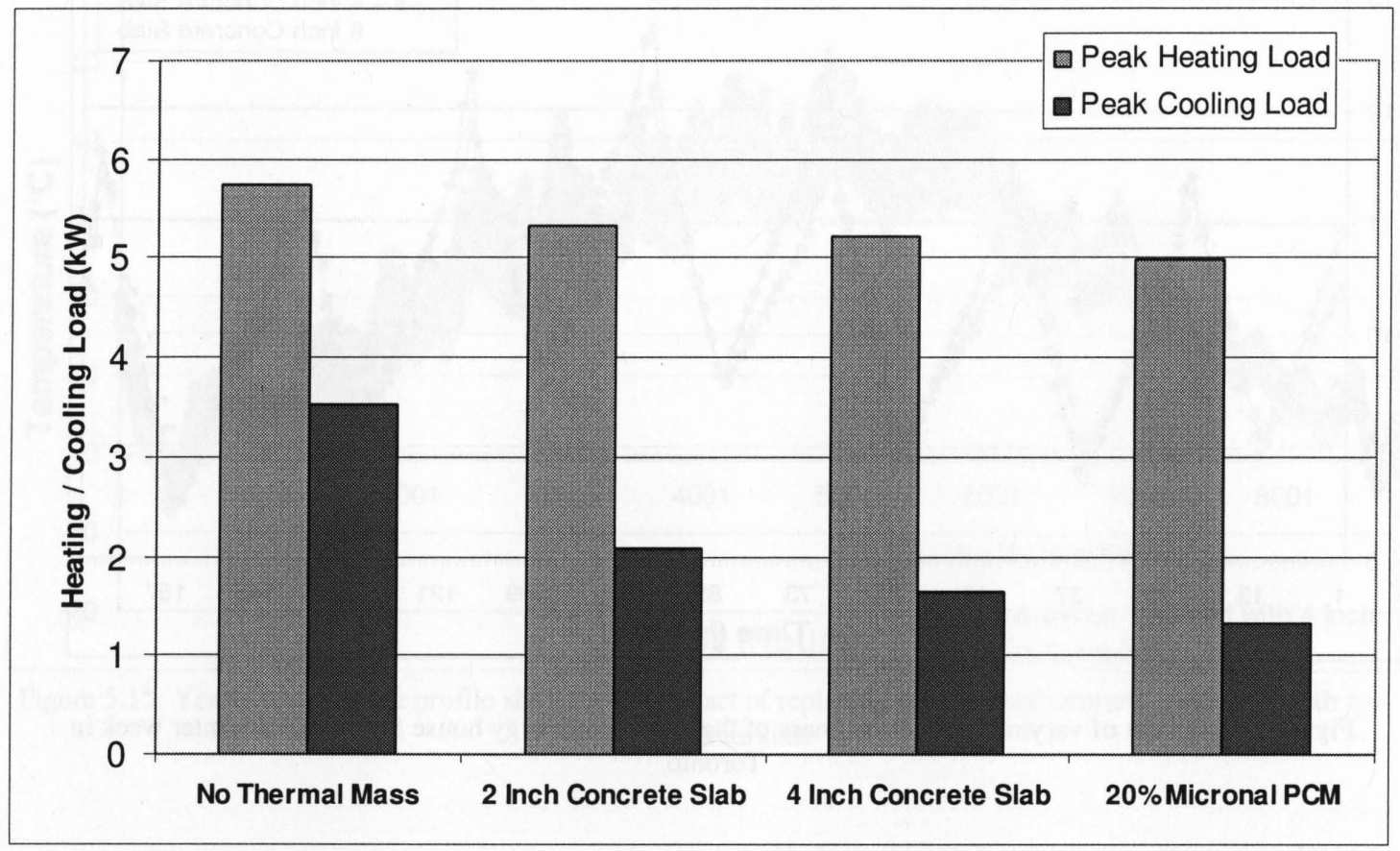

Figure 5.18: Peak heating and cooling load of the Net Zero Energy house using a variety of thermal mass. 


\section{CHAPTER 6: SAMPLE MANUFACTURING METHODS AND PHYSICAL TESTING}

\subsection{Introduction}

A major part of this project consisted of the preparation and testing of building integrated phase change material (PCM) samples utilizing a proprietary heat storage material (HSM) that was developed at Dalhousie University. The objective was to investigate the potential of utilizing this HSM, referred to as Dal HSM, in a variety of commonly used building materials such as gypsum and concrete.

In order to determine the suitability of a phase change material for use as a thermal storage medium, it is essential that the fundamental thermal and physical characteristics such as thermal conductivity, specific heat capacity and compressive strength be measured. For the most commonly used materials that have also found applications as phase change materials, extensive experimental data is available and therefore very little experimentation of the pure sample is required. However for a wide variety of novel phase change materials such as Dal HSM that are developed in a research environment, repetitive testing is required to establish the fundamental properties. Once a particular phase change material has been found to be useful as a heat storage medium, the next process is the incorporation of the PCM into other materials such as building materials. Once again, it is imperative that the thermal and physical characteristics of these PCM composites be determined. Any successful incorporation into a particular building material would establish the feasibility of the PCM as viable heat storage medium in buildings.

The objective of the present research is to investigate the effectiveness of using Dalhousie University phase change material (PCM) di-n-hexylammonium bromide $\left(\left(\mathrm{C}_{6} \mathrm{H}_{13}\right)_{2} \mathrm{NH}_{2} \mathrm{Br}\right)$ with building materials such as concrete and gypsum as means of thermal energy storage and a reduction in the total energy consumption. The situation presents a unique challenge since the PCM belongs to the Solid-Solid Class of phase change materials and relatively little experimental data and research material exists for these types of materials. 


\subsection{Dal HSM Material Properties}

Dal HSM belongs to the Solid-Solid class of phase change materials, which remain in the solid state upon phase transition. The material is available in the form of coarse particles, which can be grounded into a very fine powder, to assist with integration of the PCM into any building material. It possesses excellent solid-solid phase change characteristics in the temperature range of $25 \mathrm{~K}$ and $350 \mathrm{~K}$ (Van Oort et al., 1988). The adiabatic calorimetry experiments have shown that the phase transition of this PCM occurs at $297.7 \mathrm{~K}$ with a molar heat of transition of 16000 $\mathrm{J} / \mathrm{mol}$. Figure 6.1 shows Dal HSM in powder form in a container ready to be used for sample preparation.

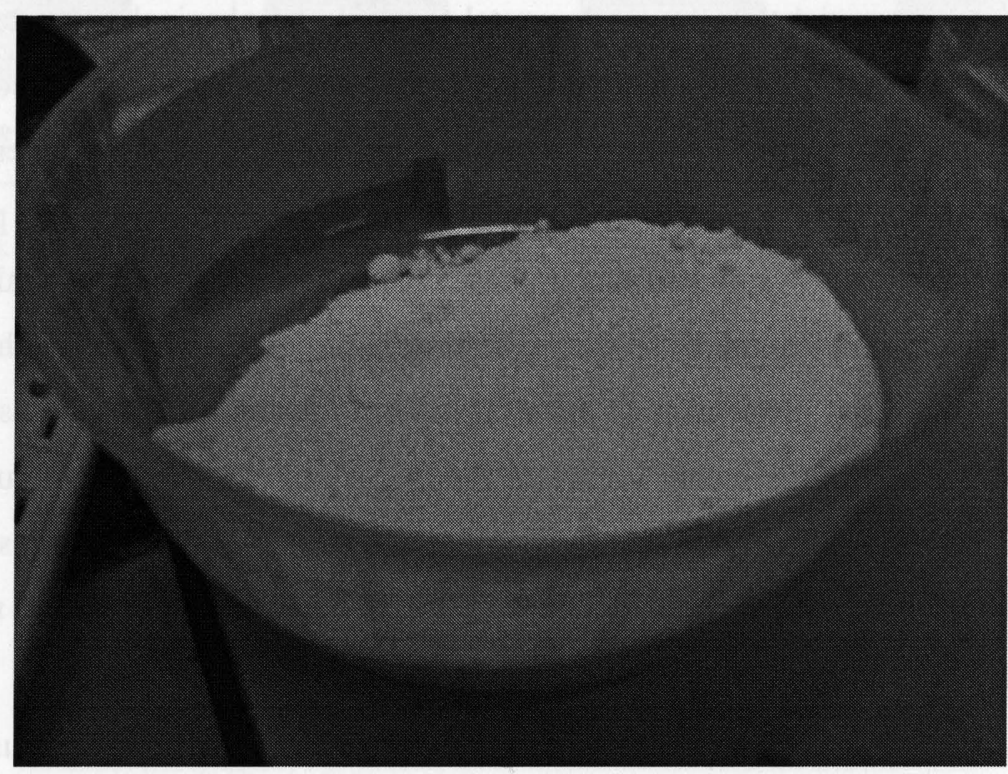

Figure 6.1: Dal HSM in powdered form

The high entropy in the solid-solid phase transition indicates solid state alkyl-chain melting. It is through the melting of these chains in the solid state that the material is able to absorb energy without actually changing state from solid to liquid (Van Oort and White., 1988). Some of the fundamental material properties of the PCM used for the simulation are tabulated below in Table 6.1. 
Table 6.1: Selected Material properties of the Dal HSM

\begin{tabular}{|c|c|}
\hline Property & Value \\
\hline Density $(\rho) \mathrm{kg} \cdot \mathrm{m}^{-3}$ & 800 \\
\hline Thermal conductivity $(k) \mathrm{W} \cdot \mathrm{m}^{-1} \mathrm{~K}^{-1}$ & 0.3 \\
\hline Specific heat $\left(C_{p}\right) \mathrm{kJ} \cdot \mathrm{kg}^{-1} \mathrm{~K}^{-1}$ & 1.6 \\
\hline $\begin{array}{l}\text { Onset phase change temperature upon } \\
\text { heating/cooling }\left(T_{\mathrm{O}}\right)^{\circ} \mathrm{C} \mathrm{C}\end{array}$ & $20 / 22$ \\
\hline $\begin{array}{l}\text { End phase change temperature upon } \\
\text { heating/cooling }\left(T_{\mathrm{e}}\right)^{\circ} \mathrm{C}\end{array}$ & $20 /$ \\
\hline \multicolumn{2}{|c|}{ Latent heat of transition on heating $(L), \mathrm{kJ}^{\prime} \mathrm{kg}^{-1}, \quad 80$} \\
\hline \multicolumn{2}{|c|}{ Latent heat of transition on cooling $(L), \mathrm{kJ} \cdot \mathrm{kg}^{-1}, \quad 80$} \\
\hline
\end{tabular}

\subsection{Experimental Strategy}

A detailed strategy was developed for the development of experimental procedures for this project. Listed below are the steps followed during the investigation:

- Design and development of moulds for the casting of PCM-integrated samples.

- Development of procedures relating to the appropriate quantities of materials used in the slurry.

- Detailed step-by-step manufacturing procedures for different building materials.

- Physical testing of cast samples to investigate characteristics such as compressive and bending strength.

\subsubsection{Mould Design and Development}

The incorporation of Solid-Solid phase change materials into building materials requires the preparation of slurry containing the PCM, which can be poured easily into a mould and cured to achieve a solid sample. This is in contrast to a Solid-Liquid PCM which can be easily integrated into a solid sample, when it is in the liquid phase. The liquid can easily permeate through the voids and crevices within the solid sample representing the building material, through the process of diffusion. Since a Solid-Solid phase change material achieves phase transition without changing phase to a liquid, casting is the only alternative that could be used to 
thoroughly mix the PCM powder with a particular building material. Eight wood/plastics moulds of different dimensions are designed to cast samples. The square moulds were made of hardwood with three side walls glued on the base and one removable along the grooves. The samples were cast in a range of sizes with surface area of $2 \times 2$ inch or $4 \times 4$ inch and ranging in thickness from 0.5 inch -2 inch. Figure 6.2 shows a $4 \times 4$ inch plastic mould with the easily removable walls screwed to the base.

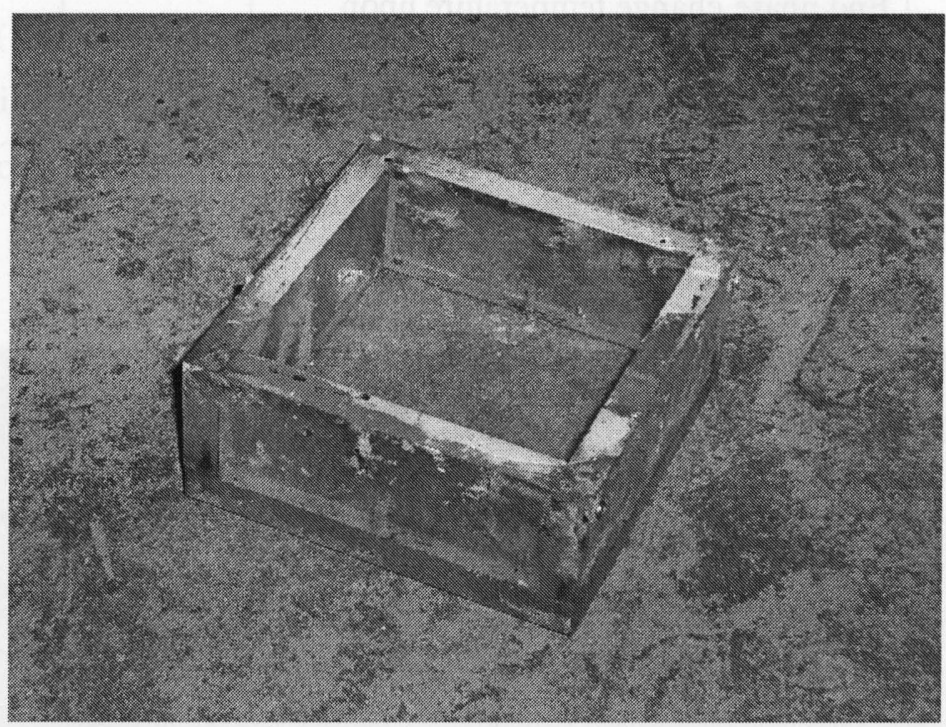

Figure 6.2: A 4 x 4 inch plastic mould for casting samples.

The selection of wood and plastic as the material for the mould was based on the ease with which the walls of the mould could be assembled and removed. The surface finish was also a consideration as the final sample would need to be relatively flat and smooth so that the appropriate testing could be done on the finished sample. Taking this into account, polished wood or plastic were found to be ideal materials for the mould. Metals such as Aluminum and Steel were also considered but were disregarded because of the difficulty in machining and attaching the walls to the base of the mould. The mould was designed to resemble a box with the top surface open, with the four walls resting on the base, so that the slurry can be easily poured into the mould.

\subsubsection{Material Quantities}

The determination of the relative quantities of each of the materials in ample was done so that a uniform procedure could be followed for each sample with a particular concentration of 
PCM within it. A total of five different types of samples are prepared for the gypsum-PCM combination. These include 0\% PCM, 5\% PCM, 10\% PCM, 20\% PCM, and 30\% PCM concentrations respectively. Table 6.2 presents the relative amounts of each material used in the in a sample of a particular concentration. The PCM-concrete samples are also prepared with the same concentrations as gypsum.

Table 6.2: Relative materials quantities for the PCM-gypsum combination

\begin{tabular}{|l|l|l|l|l|l|}
\hline Material & $\begin{array}{l}\text { Pure Sample } \\
(0 \% \mathrm{PCM})\end{array}$ & $\begin{array}{l}5 \% \text { PCM in } \\
\text { Gypsum }\end{array}$ & $\begin{array}{l}10 \% \text { PCM in } \\
\text { Gypsum }\end{array}$ & $\begin{array}{l}\text { 20\% PCM } \\
\text { in Gypsum }\end{array}$ & $\begin{array}{l}30 \% \text { PCM in } \\
\text { Gypsum }\end{array}$ \\
\hline $\begin{array}{l}\text { White Cement } \\
\text { (Gypsum Powder) }\end{array}$ & $500 \mathrm{~g}$ & $475 \mathrm{~g}$ & $450 \mathrm{~g}$ & $400 \mathrm{~g}$ & $350 \mathrm{~g}$ \\
\hline Water (45\%) & $225 \mathrm{~g}$ & $225 \mathrm{~g}$ & $225 \mathrm{~g}$ & $225 \mathrm{~g}$ & $225 \mathrm{~g}$ \\
\hline Dal PCM & $0 \mathrm{~g}$ & $25 \mathrm{~g}$ & $50 \mathrm{~g}$ & $100 \mathrm{~g}$ & $150 \mathrm{~g}$ \\
\hline Total weight & $725 \mathrm{~g}$ & $725 \mathrm{~g}$ & $725 \mathrm{~g}$ & $725 \mathrm{~g}$ & $725 \mathrm{~g}$ \\
\hline
\end{tabular}

Table 6.3 presents the components of the concrete-PCM combination.

Table 6.3: Relative materials quantities for the PCM-cement combination

\begin{tabular}{|l|l|l|l|l|l|}
\hline Material & $\begin{array}{l}\text { Pure Sample } \\
(0 \% \mathrm{PCM})\end{array}$ & $\begin{array}{l}5 \% \mathrm{PCM} \text { in } \\
\text { Cement }\end{array}$ & $\begin{array}{l}10 \% \mathrm{PCM} \text { in } \\
\text { Cement }\end{array}$ & $\begin{array}{l}\text { 20\% PCM } \\
\text { in Cement }\end{array}$ & $\begin{array}{l}30 \% \text { PCM in } \\
\text { Cement }\end{array}$ \\
\hline $\begin{array}{l}\text { Portland Cement } \\
\text { (Ready to use) }\end{array}$ & $800 \mathrm{~g}$ & $760 \mathrm{~g}$ & $720 \mathrm{~g}$ & $640 \mathrm{~g}$ & $560 \mathrm{~g}$ \\
\hline $\begin{array}{l}\text { Water (percentage } \\
\text { depends upon the } \\
\text { PCM } \\
\text { concentration }\end{array}$ & $280 \mathrm{~g}$ & $260 \mathrm{~g}$ & $230 \mathrm{~g}$ & $220 \mathrm{~g}$ & $200 \mathrm{~g}$ \\
\hline Dal PCM & $0 \mathrm{~g}$ & $40 \mathrm{~g}$ & $80 \mathrm{~g}$ & $160 \mathrm{~g}$ & $240 \mathrm{~g}$ \\
\hline Total weight & $1080 \mathrm{~g}$ & $1060 \mathrm{~g}$ & $1030 \mathrm{~g}$ & $1020 \mathrm{~g}$ & $1000 \mathrm{~g}$ \\
\hline
\end{tabular}

As can be observed from Table 6.3, the percentage of water used in the overall sample varies as function of the PCM concentration, with higher PCM concentrations having a lower overall water ratio. This scheme was used as a result of the problems observed during the preparation of the samples, whereby the PCM would mix with the water and emerge as a thin 
film on top of the mixed slurry. This would lead to wastage of PCM and an overestimation of the overall concentration of PCM within the sample.

\subsection{Sample Manufacturing Methods}

Detailed step-by-step procedures were developed for the preparation of both PCMgypsum and PCM-concrete sample. Each set of successive experimentation conformed closely to these procedures so that a consistent sample was produced every time.

\subsubsection{Manufacturing Objectives and Strategies}

Before any analysis of PCM thermal performance could be begun, investigating the effectiveness of the integration of phase change materials within building materials must be conducted. It is also essential that rigorous standards and procedures be developed for the preparation of samples of either gypsum or concrete with varying quantities of PCM. Some of the control strategies that would be investigated include:

1. The mixing procedure used for integrating PCM into the respective building material. It has been discovered that, direct incorporation is the most appropriate means for ensuring the PCM powder is uniformly mixed into the sample.

2. The quantity of water used would be carefully controlled to ensure that the finished samples have a relatively constant moisture ratio. Due to the high specific heat capacity of water, considerable experimental inaccuracies can be introduced into the thermal analysis if this variable is not controlled.

3. The particle size of the PCM before it is mixed with the building materials will also be determined. In this, the use of very fine powdered PCM would be compared to the use of macroscopic particles of PCM.

4. It is known that there are differences in the drying time for different building materials. This information will be used to determine the optimum time during which the addition of the PCM would be done. Gypsum is a fast drying material that solidifies completely after water is added, within 15 minutes. It could take 
almost 12 hours for pure concrete to harden and up to 28 days to cure and reach the appropriate strength.

5. In order to ensure that a sample with uniformly distributed phase change material is produced, it is essential that the mixture be thoroughly mixed to ensure than any excess material not used for the sample, has the same quantity of PCM as the material used for the sample.

6. Research has shown the use of laminated PCM as being more effective in terms of heat storage than uniformly mixed PCM. An attempt would be made to develop some manufacturing procedures that would produce a sample having a layer of laminated PCM either on the front or the back surface.

7. The effects of any chemical interaction between the PCM and the various building materials being used would also be investigated.

8. The thermal conductivity of the sample has exhibited a reduction as a result of the addition of the PCM to the sample. This problem could be resolved during the manufacturing phase by introducing metal particles such as aluminum meshes.

The overall objective of the development of manufacturing procedures is to produce a final product that could be compared to the commercially available building fabrics such as concrete block and gypsum wallboard. By comparing a PCM integrated sample, with a product available in the market, important conclusion about the overall effectiveness of the heat storage characteristics could be made.

\subsection{Manufacturing Procedure of PCM/Concrete samples}

A total of three different methods have been used for the preparation of $\mathrm{PCM} /$ concrete composites. Concrete is basically composed of aggregates and paste. The aggregates are composed of sand, gravel or crushed stone, whereas the paste component consists of cement, water and air. Aggregates are further classified into two categories: fine and coarse, with the former ranging in particle sizes up to $10 \mathrm{~mm}$ and the latter up to $150 \mathrm{~mm}$. The combination of cement and water generates a chemical reaction known as hydration which causes the mixture to harden (Komsatka et al., 2002). In order to produce a concrete sample possessing acceptable tensile strength, there are some very strict guidelines relating to the proportion of the mix and the 
appropriate drying time. It takes a total of 28 days for the concrete to fully cure. During this stage, moisture levels are carefully controlled to prevent the sample from developing cracks. Humidity levels must be maintained at levels at or above $80 \%$, so that curing could progress smoothly. The presence of coarse aggregates requires a sample to have moderate thickness so that the cement can bind effectively to the aggregates. In current study, coarse aggregates will not be used in order to simplify the model by minimizing the uncertain parameters. The mixture of cement, PCM and water would be poured into the mould and cured in the moist curing room after solidification. Since the moisture content of the sample has a significant effect on the thermal properties, a heat treatment in an oven is required to maintain the moisture content to an acceptable level.

The methods, that were used for casting the composite with the 5, 10, 20, 30\% PCM (weight ratio), are detailed below.

\subsubsection{Method \# 1: Mixing the dry cement and PCM powder together:}

The steps followed for this method are described below:

- The PCM is cut into small pieces and blended into a fine powder so that it can be easily mixed with the cement.

- Depending on the PCM concentration of the sample required, water equal to 30$35 \%$ of the total weight of the sample (cement+PCM) is used.

- The cement powder and the PCM powder are then mixed together without the addition of any water.

- The dry powder mix is then uniformly mixed.

- This dry mix is then placed in a container and water (with fabric softener) is poured into it slowly while mixing.

- After all the water has been poured into the container, the mixture is shaken and mixed thoroughly with the mechanical mixer to ensure it has the appropriate consistency.

- The mixing is continued for another 5-10 minutes depending on the consistency of the mixture and is stopped when the mixture appears to be of a viscosity where it flows without a lot of difficulty but not readily. 
- The inside surfaces of the castings moulds made up of plastic are then coated with a layer of oil, so that removing the cast samples is easy.

- The slurry is then poured into the mould and the mould is shaken to ensure there are no empty voids or water bubbles.

- The poured slurry is then covered with a plastic bag and allowed to dry for 24 hours.

- After 24 hours, the samples are then removed from the moulds and placed in a curing room for a total of 28 days. The curing room is designed to provide a moist environment through the injection of water spray to ensure that the samples dry without any cracking.

\section{Method \# 1: Problems}

One noticeable problem is that exudation of PCM was found covered over the composite after some time in the curing room, indicating a possible PCM loss. The Differential Scanning Calorimetry also suggested possible chemical change of the PCM property.

\subsubsection{Method \# 2: Mixing the PCM with water before combining with cement:}

The steps in the preparation of the samples are described below:

- The PCM is cut into small pieces and blended into a fine powder so that it can be easily mixed with the cement.

- Depending on the PCM concentration of the sample required, water equal to 30$35 \%$ of the total weight of the sample (cement+PCM) is used.

- The water and the PCM are mixed together using a mechanical drill.

- The mixing is completed when the mixture (PCM+water) becomes slurry. This process takes a total of about five minutes.

- The total amount of cement required is measured and the powder is poured in another container.

- In order to ease the mixing process, approximately $20 \%$ of the cement powder is put into another container, to be added to the mixture later. 
- The PCM/water slurry is then added to the remaining $80 \%$ cement powder.

- Initially the mixture appears dry, but continued shaking and mixing with a mechanical drill improves the consistency.

- The mixing is continued for at least 5 minutes or until a little water appears in the mixture.

- The remaining $20 \%$ of the cement powder is then poured into the mixture and the mixing is continued.

- The mixing is continued for another 5-10 minutes depending on the consistency of the mixture and is stopped when the mixture appears to be of a viscosity where it flows without a lot of difficulty but not readily.

- The inside surfaces of the castings moulds made up of plastic are then coated with a layer of oil, so that removing the cast samples is easy.

- The slurry is then poured into the mould and the mould is shaken to ensure there are no empty voids or water bubbles.

- The poured slurry is then covered with a plastic bag and allowed to dry for 24 hours.

- After 24 hours, the samples are then removed from the moulds and placed in a curing room for a total of 28 days. The curing room is designed to provide a moist environment through the injection of water spray to ensure that the samples dry without any cracking.

\section{Method \# 2: Problems}

One problem which is observed using this approach is after the PCM slurry is added to the cement power and the mixture is thoroughly mixed, a layer of water appears on the top of the mixture surface. Continued mixing of the mixture results in the release of more water which accumulates at the top surface. One possible explanation for this is due to the incomplete cement hydration process. This occurs because when the PCM/water slurry is mixed with the cement powder, there is very little liquid which can react with the cement, as most of it has been dissolved in the PCM/cement slurry. When the mixture is mechanically mixed, the dissolved water is released but it fails to completely react with the cement. 


\subsubsection{Method \# 3: Preparing the cement mixture before adding the PCM powder:}

This method has been used to ensure that one of the major problems arising from Method\# 2, which involves the release of water as the mixture is mixed, could be solved. The cement is thoroughly mixed with the water to produce slurry. This ensures that the hydration reaction between the cement and water is complete. The steps used in this method are described below:

- The PCM is cut into small pieces and blended into a fine powder so that it can be easily mixed with the cement.

- Depending on the PCM concentration of the sample required, water equal to $25 \%$ of the total weight of the only the dry cement is used. This is different from Method \# 2 where the total mass of water is based on the overall weight of the cement and PCM.

- The water is then poured into the cement powder and mixed thoroughly to produce slurry. The mixing process is continued for at least 5 minutes

- After the mixture has been thoroughly mixed, PCM powder is added to it.

- The mixing is continued for another 5-10 minutes depending on the consistency of the mixture and is stopped when the mixture appears to be of a viscosity where it flows without a lot of difficulty but not readily.

- The inside surfaces of the castings moulds made up of plastic are then coated with a layer of oil, so that removing the cast samples is easy.

- The slurry is then poured into the mould and the mould is shaken to ensure there are no empty voids or water bubbles.

- The poured slurry is then covered with a plastic bag and allowed to dry for 24 hours.

- After 24 hours, the samples are then removed from the moulds and placed in a curing room for a total of 28 days. The curing room is designed to provide a moist environment through the injection of water spray to ensure that the samples dry without any cracking. 
Table 6.4: Different PCM-Cement composite manufacturing methods

\begin{tabular}{|c|c|c|c|}
\hline Factor & Method \#1 & Method \#2 & Method \#3 \\
\hline Procedure & $($ Cement $+P C M) \stackrel{\text { water }+F S}{\longrightarrow}$ Composite & Cement $\stackrel{(\text { water }+P C M)}{\longrightarrow}$ Composite & Cement $\stackrel{\text { water }}{\longrightarrow}$ Slurry $\stackrel{P C M}{\longrightarrow}$ Composite \\
\hline $\begin{array}{l}\text { Water ratio } \\
\text { (wt } \%)\end{array}$ & $\begin{array}{l}\text { 30-35\% of overall mass } \\
\text { (cement + PCM) }\end{array}$ & $\begin{array}{l}25-30 \% \text { of overall mass } \\
\text { (cement + PCM) }\end{array}$ & $35 \%$ of cement mass \\
\hline $\begin{array}{c}\text { PCM } \\
\text { concentration }\end{array}$ & $5 \%, 10 \%, 20 \%, 30 \%$ & $5 \%, 10 \%, 20 \%, 30 \%$ & $5 \%, 10 \%, 20 \%, 30 \%$ \\
\hline & $\begin{array}{l}\text { Water ratio was adjusted } \\
\text { based on the PCM } \\
\text { concentration. Less water } \\
\text { was used for higher } \\
\text { concentration composite. } \\
\text { Fabric softener was used as } \\
\text { additive. }\end{array}$ & $\begin{array}{l}\text { Both new and old PCM } \\
\text { powder was used. PCM } \\
\text { slurry was prepared } \\
\text { before pouring into } \\
\text { cement powder. }\end{array}$ & $\begin{array}{l}\text { Water ratio was strictly } \\
\text { controlled based on the mass } \\
\text { of cement. PCM was added } \\
\text { into the cement slurry and then } \\
\text { blended. }\end{array}$ \\
\hline Observations & $\begin{array}{l}\text { Problems: noticeable PCM } \\
\text { exudation over the composite } \\
\text { surface during curing period. } \\
\text { DSC indicates possible } \\
\text { chemical change of the PCM } \\
\text { and nearly none PCM was } \\
\text { detected. }\end{array}$ & $\begin{array}{l}\text { Problems: initial mixing } \\
\text { was very difficult } \\
\text { because cement could not } \\
\text { get direct contact with } \\
\text { water for reaction. } \\
\text { However, with } \\
\text { continuous blending of } \\
\text { the mixture, the mass } \\
\text { becomes increasingly } \\
\text { moist and eventually } \\
\text { water comes out. This } \\
\text { might possibly carry out } \\
\text { some PCM in the excess } \\
\text { water. }\end{array}$ & $\begin{array}{l}\text { No apparent problems were } \\
\text { found for this method. } \\
\text { However, further DSC should } \\
\text { be carried out to verify this. }\end{array}$ \\
\hline
\end{tabular}

\subsection{Manufacturing Procedure of PCM/Gypsum samples}

In contrast to the manufacturing procedure for PCM-concrete, the gypsum-PCM combination is relatively easy to manufacture due to its simpler chemical structure as compared to Portland cement. Furthermore, the quick drying nature of gypsum slurry and lack of any curing requirement makes it a particularly attractive building material to combine with a phase change material. The procedure is described as below:

- The PCM is cut into small pieces and blended into a fine powder so that it can be easily mixed with the gypsum powder. 
- Depending on the PCM concentration of the sample required, water equal to $45 \%$ of the total weight of the only the dry gypsum cement is used. Compared to the Portland cement, the water ratio requirement is significantly higher.

- The PCM powder, gypsum powder and water is weighed depending on the desired concentration.

- The PCM powder and the gypsum powder are thoroughly mixed together, without the addition of any water.

- The water is then poured into the already mixed PCM-Gypsum powder and mixed thoroughly to produce slurry. The mixing process is continued for at least 5 minutes using a mechanical mixer.

- The mixing is continued for another 5-10 minutes depending on the consistency of the mixture and is stopped when the mixture appears to be of a viscosity where it flows without a lot of difficulty but not readily. Care is taken to ensure that the slurry does not dry as gypsum is a fast drying material.

- The inside surfaces of the castings moulds made up of plastic are then coated with a layer of oil, so that removing the cast samples is easy.

- The slurry is then poured into the mould and the mould is shaken to ensure there are no empty voids or water bubbles.

- The poured slurry is then left uncovered at the room temperature and allowed to dry for 24 hours.

- After 24 hours, the samples are then removed from the moulds and depending on the moisture content are placed in an oven for a period of 24 hours at a temperature of $60^{\circ} \mathrm{C}$ Further drying may be required but normally, the samples are ready to be used.

Figure 6.3 shows the cast PCM-gypsum sample after being removed from the mould. The sample would be left to dry. At this stage, the sample has completely solidified but retains some moisture close to the edges. 


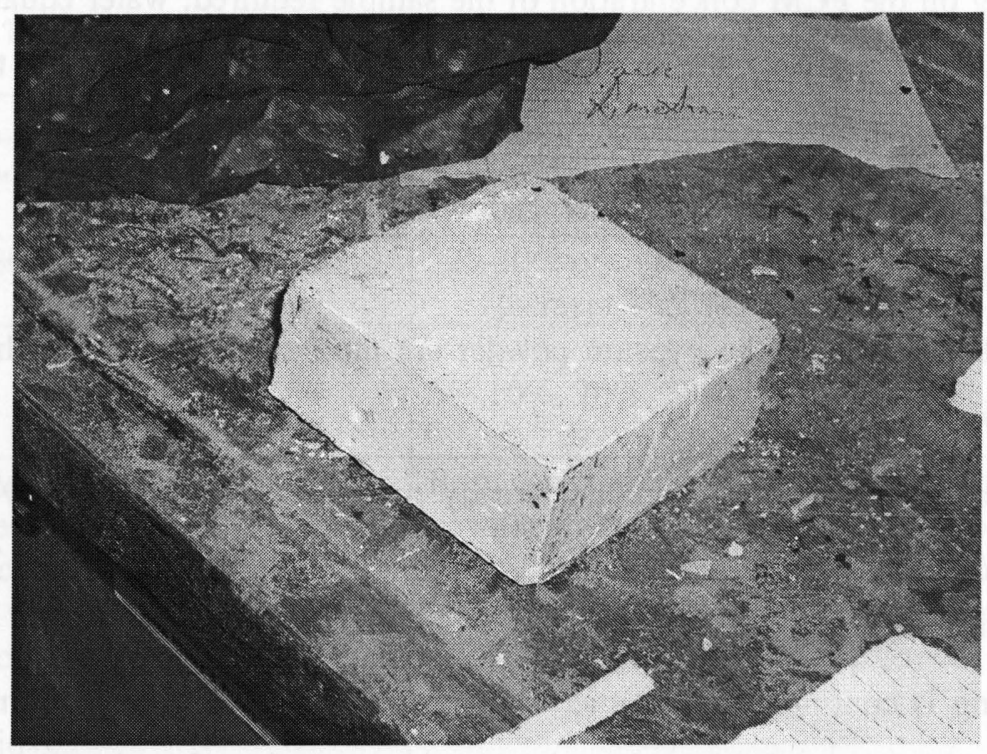

Figure 6.3: Cast PCM-Gypsum sample removed from the mould

\subsection{Physical Testing of PCM-Integrated Gypsum Samples}

The success of the integration of phase change materials into commonly used building materials can be measured using a variety of methods. Chief amongst these methods include a whole range of thermal and physical testing procedures that the prepared samples could be subjected to. The conduct of thermal testing can be used to validate the performance of PCM as a medium of heat storage. While the thermal testing of PCM-integrated samples is beyond the scope of this thesis, the use of physical testing could be utilized to establish another important characteristic of the success of PCM integration into building materials. This factor is related to the physical integrity of samples incorporated with phase change materials. It is essential that any effort to produce a viable heat storage product for use in buildings must exhibit not only superior thermal characteristics but should also conform to all structural requirements relating to physical strength and integrity.

The gypsum-PCM samples that would be prepared would be subjected to two critical tests examining their physical characteristics. These tests include the compressive strength test and flexural strength. The compressive strength tests would compare the impact of increasing the concentration of PCM on the overall strength of the sample. The importance of compressive strength as a physical characteristic depends on the manner in which PCM-integrated materials are utilized within a building. While in hot climates, where the insulation requirements are minimal, the PCM-gypsum or PCM-concrete blocks form part of the structural support of the 
building, in colder regions the PCM could be easily integrated into a gypsum board on the inside of the building and fully supported by a wooden frame. Bending or flexural strength would also be an important characteristic if the overall thickness of the sample is varied. In this case, a mould with a different thickness would need to be prepared.

All of the tests relating to the physical characteristics would conform to the published standards developed by the American Society for testing of Materials.

\subsubsection{Compressive Testing of Gypsum-PCM samples}

The compressive testing of Gypsum-PCM samples is done to ensure that the strength of the samples does not degrade excessively as a result of incorporating phase change materials. Samples composed of $5 \%, 10 \%, 20 \%$ and $30 \%$ PCM are tested to failure and the strength is compared to a pure gypsum sample. Compressive strength is one of the most important performance measures that is of interest to designers and engineers. The selection of a particular material and its application is dictated by its strength and resilience. Compressive strength is defined as the total stress that a material can sustain in compression until it yields to failure. Equation 6.1 shows how it is related to the applied axial force (Callister, 2003).

$$
\sigma_{c}=\frac{F_{a p p}}{A_{o}}
$$

Where $F_{a p p}$ is the applied axial force and $A_{o}$ is the original cross sectional area of the specimen. The specimen is subjected to the axial force until cracks emerge. At this point the total force is reduced. As the structural integrity of the specimen deteriorates with further applied force, less compressive force is need to deform the sample. At the point of failure, the equipment uses the maximum force for the calculation of compressive strength.

The tests are performed in conformance to the ASTM C-472-99, Standard Test Methods for Physical Testing of Gypsum, Gypsum Plasters and Gypsum Concrete (ASTM,2004). Appendix B presents the experimental data obtained as a result of the testing. According to this standard, the samples must consist of 2 -inch cubic blocks of gypsum and the test could be conducted either a hydraulic or screw type machine. The facilities at the Civil Engineering Lab at Ryerson University are utilized for the tests. This lab is equipped with the screw type machine for the testing of compressive strength. Figure 6.4 shows the compressive testing machine at the civil engineering lab at Ryerson University. Appendix C illustrates the detailed procedure followed for performing compressive testing. 


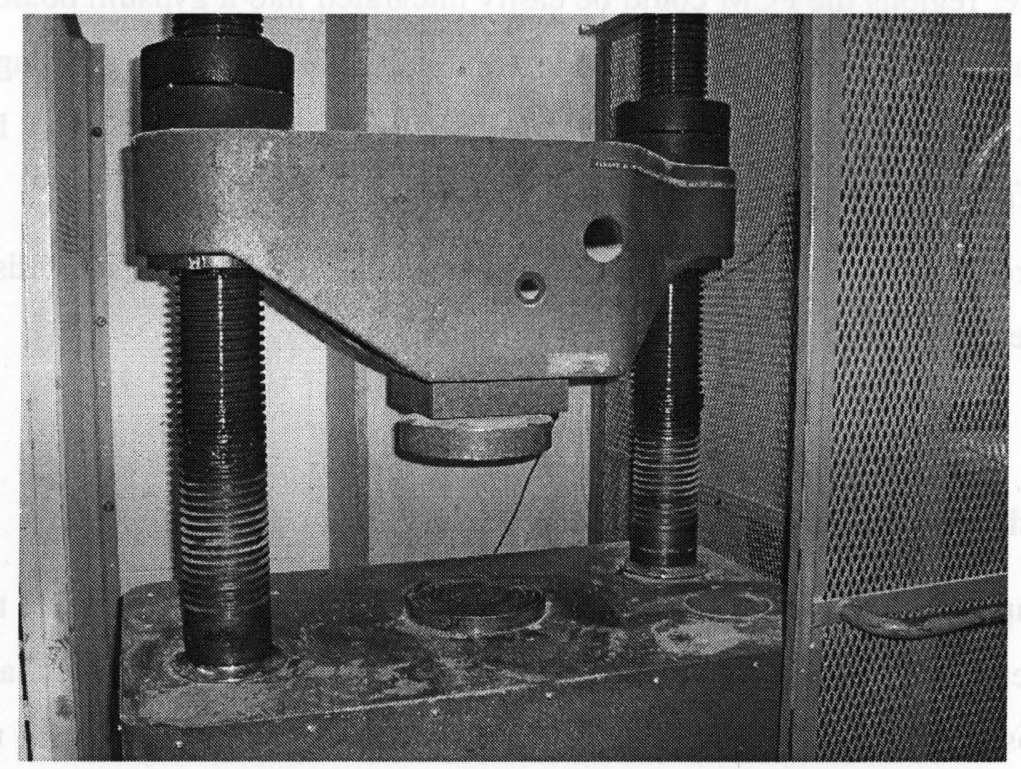

Figure 6.4: Compressive strength testing apparatus at Ryerson University

The sample was carefully placed on the base of the compressive testing apparatus ensuring that is properly centered. The load was applied gradually to ensure that there was no possibility of impact loading. The application of the load was continued until the specimen failed. The mechanism of failure commenced with the development of a crack, which was observed to propagate with further application of load. The crack propagation continued until the complete compressive failure of specimen occurred. At this point, the length of the crack was observed to encompass the entire thickness of the specimen. The peak load that is applied to the specimen is automatically stored by the apparatus and displayed at the conclusion of the test. The value of compressive strength could be calculated manually from the peak load and the area of the specimen or could be automatically obtained from the apparatus if the relevant specimen dimensions have been entered at the beginning of the test.

Compressive strength testing was performed on PCM-gypsum composite samples with the following concentration; $0 \%, 5 \%, 10 \%, 20 \%$ and $30 \%$. For each concentration, a total of 4 specimens were tested to ensure the consistency of the results. The results for the tests are presented in Figure 6.5 below.

Analyzing the results of the compressive strength testing, it is obvious that there is a significant reduction in the compressive strength of the specimen as the concentration is increased. After the almost $50 \%$ drop in the strength, as the concentration is increased from $0 \%$ to $5 \%$, there is a very little drop in the strength as the concentration is increased up to $10 \%$. 
Further increase in the concentration results in a drop in the compressive strength, but the decrease is not as steep as that encountered at lower concentrations.

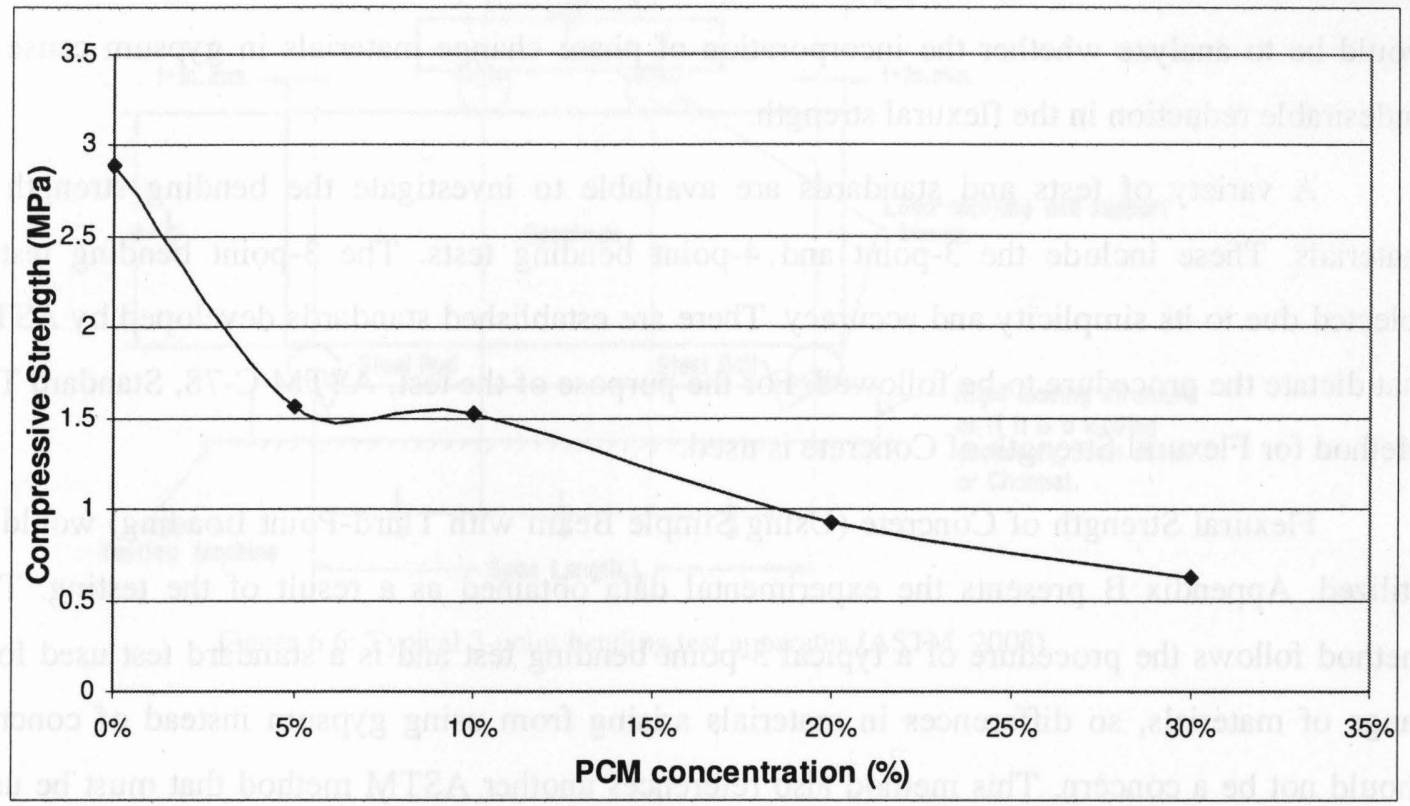

Figure 6.5: Compressive strength of PCM-gypsum composite specimens as a result of varying the PCM concentration.

The decline in the compressive strength as a result of incorporating phase change materials would be a concern if the most common loading experienced by the material was compressive. However, since the PCM-gypsum composite material would not be utilized as a structural component of any building, the compressive strength is not a critical parameter. An investigation of the bending strength would be a more appropriate parameter to analyze since most of the failures with gypsum boards occur during the handling process when the boards can be snapped or bent.

\subsubsection{Flexural Strength Testing of Gypsum-PCM samples}

Bending is another common mode of failure that can occur during handling and transportation of gypsum products and thus is an important physical characteristic that must be measured. Flexural strength is the ability of a material to resist deformation under an applied load. The flexural stress that a material is subjected to is a function of the bending moment (due to the applied force) and the shape of the cross-section of the sample. The material fails when the applied stress exceeds the bending strength of the material. 
The objective of this investigation would be to analyze the impact of increasing the PCM concentration on the modulus of rupture, commonly referred to as flexural strength. The focus would be to analyze whether the incorporation of phase change materials in gypsum cause an undesirable reduction in the flexural strength.

A variety of tests and standards are available to investigate the bending strength of materials. These include the 3-point and 4-point bending tests. The 3-point bending test is selected due to its simplicity and accuracy. There are established standards developed by ASTM that dictate the procedure to be followed. For the purpose of the test, ASTM C-78, Standard Test Method for Flexural Strength of Concrete is used.

Flexural Strength of Concrete (Using Simple Beam with Third-Point Loading) would be utilized. Appendix B presents the experimental data obtained as a result of the testing. This method follows the procedure of a typical 3-point bending test and is a standard test used for a range of materials, so differences in materials arising from using gypsum instead of concrete should not be a concern. This method also references another ASTM method that must be used for the preparation of samples that conform to this procedure. This method is the ASTM C31, 2009, Standard Practice for Making and Curing Concrete Test Specimens in the Field. This method relates to the preparation of beam samples for the purpose of flexural strength test. Based on this method, the length of the beam must be 2 inches greater than three times the depth of the beam. Furthermore, the ratio of depth to width must not exceed 1.5. A recommended dimension of the beam is a cross-section of 6 in x 6 in and a total length of 20 inches. Modifications can be made to this as long as the ratio of length to depth of 3 times is maintained. Due to constraints in the availability of materials, a mould would be prepared for a beam that measures $2 \times 2$ inches in cross section, with a length of 8 inches. The mould would be made of wood to ensure the smoothness of the cast sample surface that would be subjected to the load during the test.

A typical 3-point bending test is performed normally using a rigid bed apparatus capable of fully supporting the beam. The load applying and support blocks are positioned below the specimen at two equidistant points, close to the edge of the beam and at the top surface of the specimen, oriented at the middle of the specimen. Figure 6.6 shows the schematic of a 3-point bending test apparatus. 


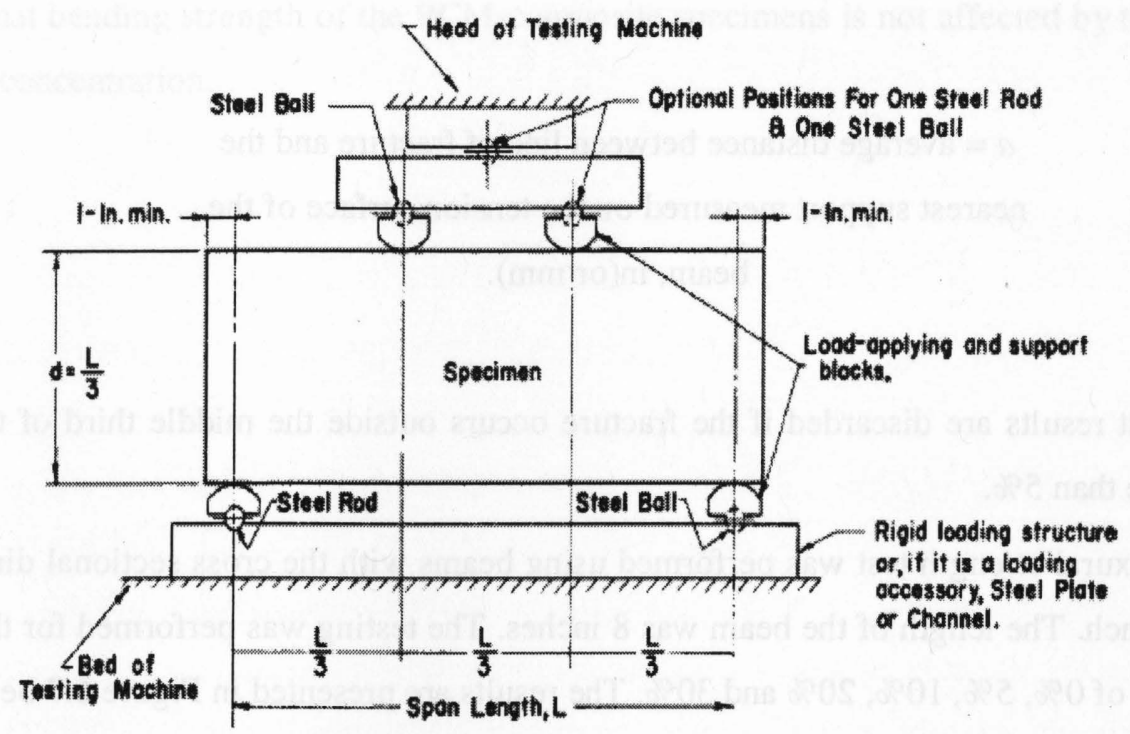

Figure 6.6: Typical 3-point bending test apparatus (ASTM, 2008)

One important criterion that must be carefully controlled during the test is the loading rate, which must be kept between 0.86 and $1.21 \mathrm{MPa} / \mathrm{min}$. The calculation of modulus of rupture is only possible after the specimen has fractured, since the location of the fracture affects the equation to use for that situation (ASTM, 2008). Equation 6.2 below relates the modulus of rupture to the applied load and the dimension of the beam for the situation where the fracture occurs in the middle third of the span length:

$$
R=\frac{F_{a p p} L}{b d^{2}}
$$

Where:

$R=$ modulus of rupture, $\mathrm{psi}$ or $\mathrm{MPa}$,

$F_{a p p}=$ maximum applied load indicated by the testing machine, lbf, or N,

$L=$ span length, in or $\mathrm{mm}$,

$b=$ average width of specimen, in or $\mathrm{mm}$, at the fracture,

$d=$ average depth of specimen, in or $\mathrm{mm}$, at the fracture.

If the fracture is initiated outside the middle third of the span length by $5 \%$ or less then Equation 6.3 is used as shown below.

$$
R=\frac{3 F_{a p p} a}{b d^{2}}
$$


Where:

$a=$ average distance between line of fracture and the nearest support measured on the tension surface of the beam, in(or $\mathrm{mm})$.

The test results are discarded if the fracture occurs outside the middle third of the span length by more than $5 \%$.

The flexural strength test was performed using beams with the cross sectional dimension of 2 inch $x 2$ inch. The length of the beam was 8 inches. The testing was performed for the PCM concentrations of $0 \%, 5 \%, 10 \%, 20 \%$ and $30 \%$. The results are presented in Figure 6.7 below.

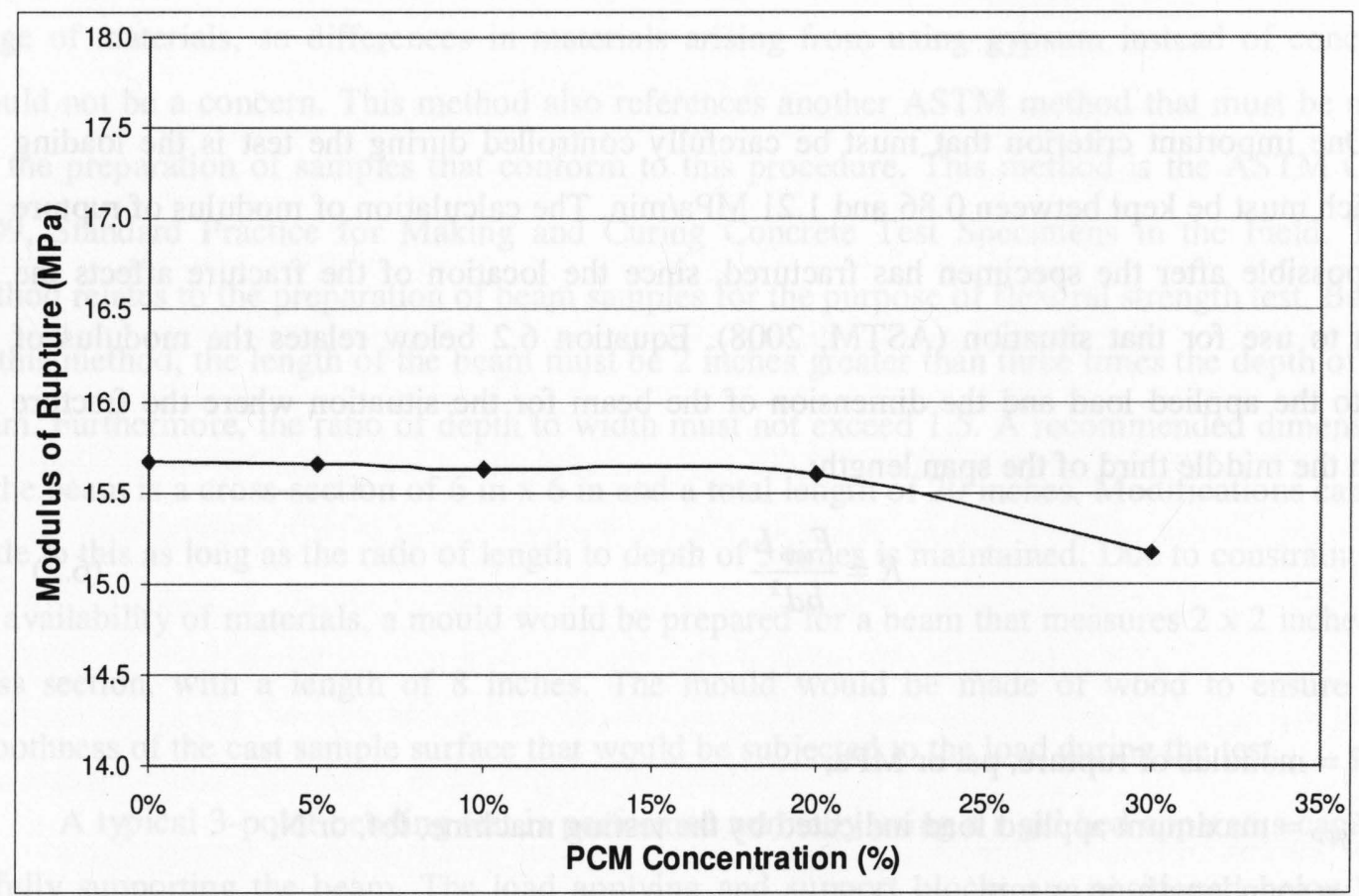

Figure 6.7: Modulus of rupture of PCM-gypsum composite specimens as a function of PCM concentration

Based on the results, it can be observed that there is a negligible decrease in the modulus of rupture as the concentration of PCM is increased up to $20 \%$. There is a slight decrease of less than $5 \%$ as the PCM concentration is increased to $30 \%$. Based on these results, it can be 
concluded that bending strength of the PCM-composite specimens is not affected by the changes in the PCM concentration. 


\section{CHAPTER 7: CONCLUSIONS AND RECOMMENDATIONS}

\subsection{Conclusions}

The current interest in the arena of energy efficient buildings has unveiled a variety of technical solutions and led to the development of alternative materials and technologies. One of these solutions involves the use of building incorporated thermal mass and phase change materials, which have been demonstrated to contribute to the improvement in the occupant comfort and energy savings. Tremendous inefficiencies exist in Canada's building sector, which can be addressed by approaches similar to what this research proposes. Considering the fact that buildings constitute such a large portion of Canada's overall energy consumption, the use of PCM in buildings holds significant potential in reducing the overall energy consumption and the associated green house gases.

The objective of this research project is the development of fundamental understanding of the technical and economic feasibility of incorporating phase change materials (PCM) into building materials. The incorporation of phase change materials in concrete and gypsum was investigated, and it was found that gypsum provided the most suitable medium for integrating Dal HSM. The strength was found to decrease as the concentration of PCM increased, but this fact is not a major concern since thermal mass within a building does not contribute to its structural integrity.

The impact of using thermal mass on the occupant comfort was also investigated by considering the total number of hours where the temperature exceeded the heating set point of $21^{\circ} \mathrm{C}$. Simulations conducted for the $3^{\text {rd }}$ floor of the Toronto Net Zero Energy house revealed that the total number of hours where the temperature exceeded $21^{\circ} \mathrm{C}$ was reduced from 1603 hours to 998 hours when 20\% Micronal PCM was used. Furthermore, the daily temperature fluctuations are significantly reduced through the use of PCM, thus contributing significantly to the comfort of the occupants. In addition to the reduction in the temperature peaks and fluctutations, there is also a shift in when the peak temperature occurs and the duration that it lasts for. Based on the simulations, it observed that the temperature peaks at $25^{\circ} \mathrm{C}$ and remains at this level for 4-5 hours. This is contrasted with a peak temperature that lasts at most 1-2 hours when a 2-inch concrete slab is used. 
The energy consumption was also of interest, and it was found that there was a $15 \%$ reduction in the overall energy consumption as a result of using 20\% Micronal PCM. The performance of other types of thermal mass was also determined to contribute to energy savings. The performance of $20 \%$ Micronal PCM is comparable to that of a 4 inch concrete slab. The performance of the Dal HSM was found to be inferior to Micronal PCM especially when the cooling loads are taken into consideration. As can be expected, due to the slightly lower latent heat capacity, the $30 \%$ Dal-HSM performs comparably with Micronal $20 \%$ for the heating season. However, the Dal-HSM does not have much effect on cooling. The total cooling load is $10 \%$ higher when $30 \%$ Dal HSM is used as compared to the 20\% Micronal PCM. This is attributable to the lower latent heat capacity, phase transition below the cooling set point and a smaller density of the material. Since the cooling set point is higher than the phase transition temperature of Dal HSM, any thermal energy stored by the PCM does not have an opportunity to be released.

The location of thermal mass within the building envelope was also found to be an important criterion. It was found that for the winter season only, the location where the concrete slab was attached had a large impact on the indoor temperatures. Best results were obtained when the thermal mass was placed right next to the gypsum board, which forms the interior wall in the house.

Detailed sensitivity analyses examining the fundamental characteristics were also conducted and it was found that during the heating season, as the phase change temperature is lower than the heating set point, the PCM would have a minimal effect on the heating/cooling consumption of the house, as the heating equipment would be activated as soon as the indoor temperature reaches the set point. Thus, during the winter season, the phase change material must have a phase transition temperature higher than the heating set point. However, during the summer season the situation is reversed and the phase change temperature must be below the cooling set point.

The effect of PCM melting point on the energy performance was also investigated, and it was found that, as the melting temperature is increased from $20^{\circ} \mathrm{C}$, the heating and cooling load is reduced. This trend continues until the minimum heating load is achieved at $23^{\circ} \mathrm{C}$ and the minimum cooling load occurs at $24^{\circ} \mathrm{C}$. The heating and cooling loads gradually increase as the melting point is increased further. At $26^{\circ} \mathrm{C}$, which is the cooling set point, the effectiveness of PCM is negligible, since the phase change occurs at as soon as the cooling equipment is activated. Since the temperature is not allowed to rise above $26^{\circ} \mathrm{C}$, there is no opportunity for the 
phase change material to store any thermal energy. The same trend is noted for the case where the PCM melting temperature is $20^{\circ} \mathrm{C}$. In this case, since the heating set point of $21^{\circ} \mathrm{C}$ is higher than the PCM melting point, there is no opportunity for the phase change process to occur. The impact of varying the latent heat capacity of PCM on the energy performance was also investigated, and it was found that an increase in the latent heat capacity of the PCM contributes to a reduction in the annual heating and cooling loads. Furthermore, the impact on the cooling load is much more significant in contrast to the heating load, as can be seen by the steeper slope of the cooling load in reference to the increase in the latent heat capacity. It is clear that the performance of a particular phase change material during the summer season improves as the latent heat capacity is increased.

This study has endeavoured to establish the feasibility of utilizing thermal mass and phase change materials in a cold climate, typical to Canada. The use of phase change materials has been demonstrated to contribute to occupant comfort and energy savings. The current focus and public interest in energy conservation and sustainability, has generated a myriad of ideas and solutions to conserve and produce energy from renewable sources. Some of these solutions are capital intensive and require extensive modifications in our existing infrastructure and lifestyle. While these solutions would become feasible in the near future, at present simple considerations such as improved building envelope insulation and thermal mass would contribute greatly to preventing heat loss from a building. The use of phase change materials in the form of gypsum wallboard can also be integrated easily within the building envelope, as it is currently done with the commonly used gypsum board.

The impact of the energy savings potential of a typical building as a result of utilizing thermal mass might appear to be miniscule on an individual basis but when considered from a larger perspective of energy demand and grid generation capacity, the potential is unlimited. The reduction and shifting of peak loads, which the use of thermal mass can effectively enable, has long lasting implications in reducing the need for power generation plants that are designed specifically for meeting the peak loads.

\subsection{Recommendations}

Extensive research has been conducted investigating the use of phase change materials in buildings. While this provides a wide body of knowledge to base any new investigations upon, 
some of the relevant studies are beyond the scope of this thesis, but would be extremely useful starting points for any future enquiry. Some aspects of these studies are as follows:

- Since most of the simulations of the impact of using phase change materials and thermal mass were conducted for Toronto, which has a climate typically characterized by cold winters and warm summers, it would be of significant interest to expand the examination and scope to include a diverse range of cities encompassing climates from hot to moderate. This would allow the determination of climate as factor in the performance of PCMs.

- The incorporation of PCM, within building materials was investigated for the case of gypsum and concrete. However, due to its complex chemical structure, the integration within concrete was not found to be successful. Any future studies should consider the impact of additives within the concrete mixture to better absorb the PCM

- The addition of materials with high thermal conductivities should also be investigated as a means to enhance the heat transfer of the PCM.

- The optimum location of thermal mass within the building envelope was found to be on the inside surface of the wall next to the wallboard. This effect could be investigated for different climates.

- Detailed optimization studies can also be conducted on the melting temperature range, enthalpy and concentration.

- In highly insulated building where over heating can be a problem during the spring and autumn seasons, the use of thermal mass must be combined with smart adaptive shading control to prevent unnecessary solar gains. Furthermore, an outlet must be provided for the release of stored heat by the thermal mass. This could involve free cooling at night by keeping the windows open.

- The heating set point must be kept lower than the PCM phase transition temperature for the winter season.

- The cooling set point should be set higher than the PCM phase transition temperature for the summer season.

- The use PCM has been shown to be technically feasible; however detailed studies examining the economic impact of PCM in buildings must be conducted. Other 
metrics that can be investigated include peak load reduction potential on a larger scale and prospective greenhouse gases mitigation.

- The interaction of phase change materials and thermal mass with a variety of systems including HVAC equipment, shading and glazing area must be investigated to identify factors which influence the energy consumption and comfort parameters.

- The influence of using phase change materials on the compressive and flexural strength must be investigated to understand the inherent failure mechanisms and determine why compressive strength is more adversely affected as a result of incorporating PCMs than the flexural strength. 


\section{APPENDIX A: SAMPLE TRNSYS TRANSFER FUNCTION METHOD CALCULATION}




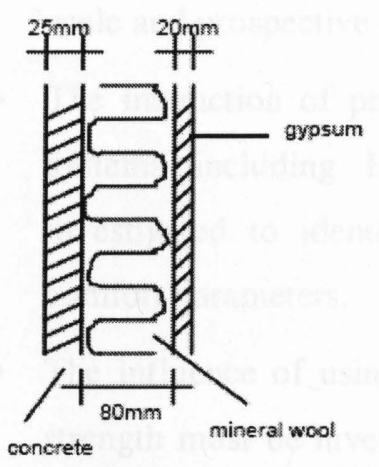

real wall

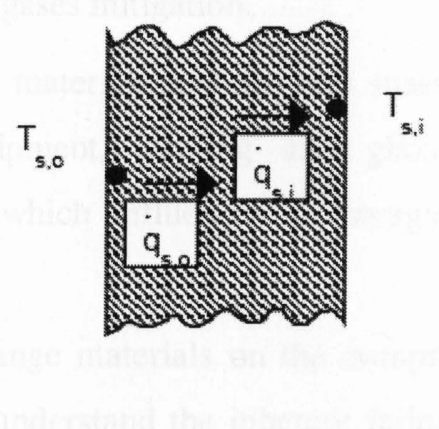

black box model

Figure 5-Real Wall and Black Box Model of the wall.

The wall example consists of three layers with concrete, mineral wool and gypsum from outside to inside.

\begin{tabular}{|l||l|l|l|l|}
\hline Material data & $\begin{array}{l}\text { Thickness } \\
{[\mathrm{m}]}\end{array}$ & $\begin{array}{l}\text { conductivity } \\
{[\mathrm{kJ} / \mathrm{h} \cdot \mathrm{m} \cdot \mathrm{K}]}\end{array}$ & $\begin{array}{l}\text { capacity } \\
{[\mathrm{kJ} / \mathrm{kg} \cdot \mathrm{K}]}\end{array}$ & $\begin{array}{l}\text { density } \\
{[\mathrm{kg} / \mathrm{m} 3]}\end{array}$ \\
\hline \hline Concrete & 0.025 & 7.56 & 1.0 & 2400 \\
\hline Mineral Wool & 0.08 & 0.144 & 1.0 & 40 \\
\hline Gypsum & 0.02 & 2.52 & 1.0 & 1400 \\
\hline
\end{tabular}

Using the transfer function method, the TRNBUILD-program calculates the transfer function coefficients, listed below for the example wall. 
THERMAL CONDUCTANCE, $\mathrm{U}=1.76429 \mathrm{~kJ} / \mathrm{h} \mathrm{m} 2 \mathrm{~K} ; \mathrm{k}-\mathrm{Wert}=0.45239 \mathrm{~W} / \mathrm{m} 2 \mathrm{~K}$

TRANSFERFUNCTION COEFFICIENTS

K

A

$\begin{array}{lr}0 & 3.0402072 \mathrm{E} \div 01 \\ 1 & -2.8791436 \mathrm{E}+01 \\ 2 & 1.4382785 \mathrm{E}-01 \\ 3 & -1.0589132 \mathrm{E}-06 \\ \text { SUM } & 1.7544627 \mathrm{E}+00\end{array}$
B

8.6597596E-01

8.7958309E-01

8.9032318E-03

4.0042651E-07

$1.7544627 \mathrm{E}+00$
C

$6.2473097 \mathrm{E}+01 \quad 1.0000000 \mathrm{E}+00$

$-6.1044043 \mathrm{E}+01-5.5725114 \mathrm{E}-03$

3.2541274E-01

$-4.7183532 \mathrm{E}-06$

$1.7544627 \mathrm{E}+00$

1.0083948E-07

9.9442759E-01

\section{Figure 6 - Transfer Function Equation-System (Mitalas)}

For the test wall, the coefficient table looks like that above. In addition to the transfer function coefficients, the listing contains a calculation of the heat conduction value $U$ of the wall construction and the total heat transfer coefficient $\mathrm{k}$ considering a constant combined (convective+radiative) heat transfer $\left(\alpha_{1}, \alpha_{0}\right)$ for the inside and outside surface. Note: these combined heat transfer coefficients are not used during the simulation. For the calculation of the $\mathrm{k}$-values stated in the information file (*.INF), the following combined heat transfer coefficients are used:

$$
\frac{1}{\alpha_{i}}=0.13 \frac{1}{\frac{W}{m^{2} K}} ; \quad \frac{1}{\alpha_{0}}=0.04 \frac{1}{\frac{W}{m^{2} K}}
$$

A dynamic simulation considering the thermal mass of a wall element does not use these values explicitly, but is describing the thermal resistance implicit in transient heat flows into and out of the wall surfaces. The latest validation report for the transfer function method and the whole TYPE 56 building model was prepared by Peter Voit \#[7] using detailed measurements from the CEC research program PASSYS. 
APPENDIX B: EXPERIMENTAL DATA FROM PHYSICAL TESTING 
The experimental data for the physical testing performed on the gypsum-PCM samples is presented below. The two different types of tests performed were concerned with determining the flexural and compressive strength.

\section{Compressive Strength (MPa)}

\begin{tabular}{|l|l|l|l|l|l|}
\hline Specimen \# & 0\% PCM & 5\% PCM & 10\% PCM & 20\% PCM & 30\% PCM \\
\hline 1 & $2.73 \mathrm{MPa}$ & $1.52 \mathrm{MPa}$ & $1.66 \mathrm{MPa}$ & $1.02 \mathrm{MPa}$ & $0.616 \mathrm{MPa}$ \\
\hline 2 & $3.03 \mathrm{MPa}$ & $1.60 \mathrm{MPa}$ & $1.44 \mathrm{MPa}$ & $0.95 \mathrm{MPa}$ & $0.637 \mathrm{MPa}$ \\
\hline 3 & $2.95 \mathrm{MPa}$ & $1.49 \mathrm{MPa}$ & $1.51 \mathrm{MPa}$ & $0.91 \mathrm{MPa}$ & $0.694 \mathrm{MPa}$ \\
\hline 4 & $2.86 \mathrm{MPa}$ & $1.61 \mathrm{MPa}$ & $1.46 \mathrm{MPa}$ & $0.83 \mathrm{MPa}$ & $0.572 \mathrm{MPa}$ \\
\hline
\end{tabular}

\section{Flexural Strength (MPa)}

\begin{tabular}{|l|r|r|r|r|r|}
\hline PCM Concentration & 0\% PCM & 5\% PCM & 10\%PCM & 20\%PCM & 30\%PCM \\
\hline Modulus of Rupture & 15.664 & 15.656 & 15.627 & 15.607 & 15.168 \\
(MPa) & $\mathrm{MPa}$ & $\mathrm{MPa}$ & $\mathrm{MPa}$ & $\mathrm{MPa}$ & $\mathrm{MPa}$ \\
\hline
\end{tabular}


APPENDIX C: COMPRESSIVE TESTING MACHINE PROCEDURE 


\section{INSTRUCTIONS FOR OPERATING THE COMPRESSION TEST MACHINE}

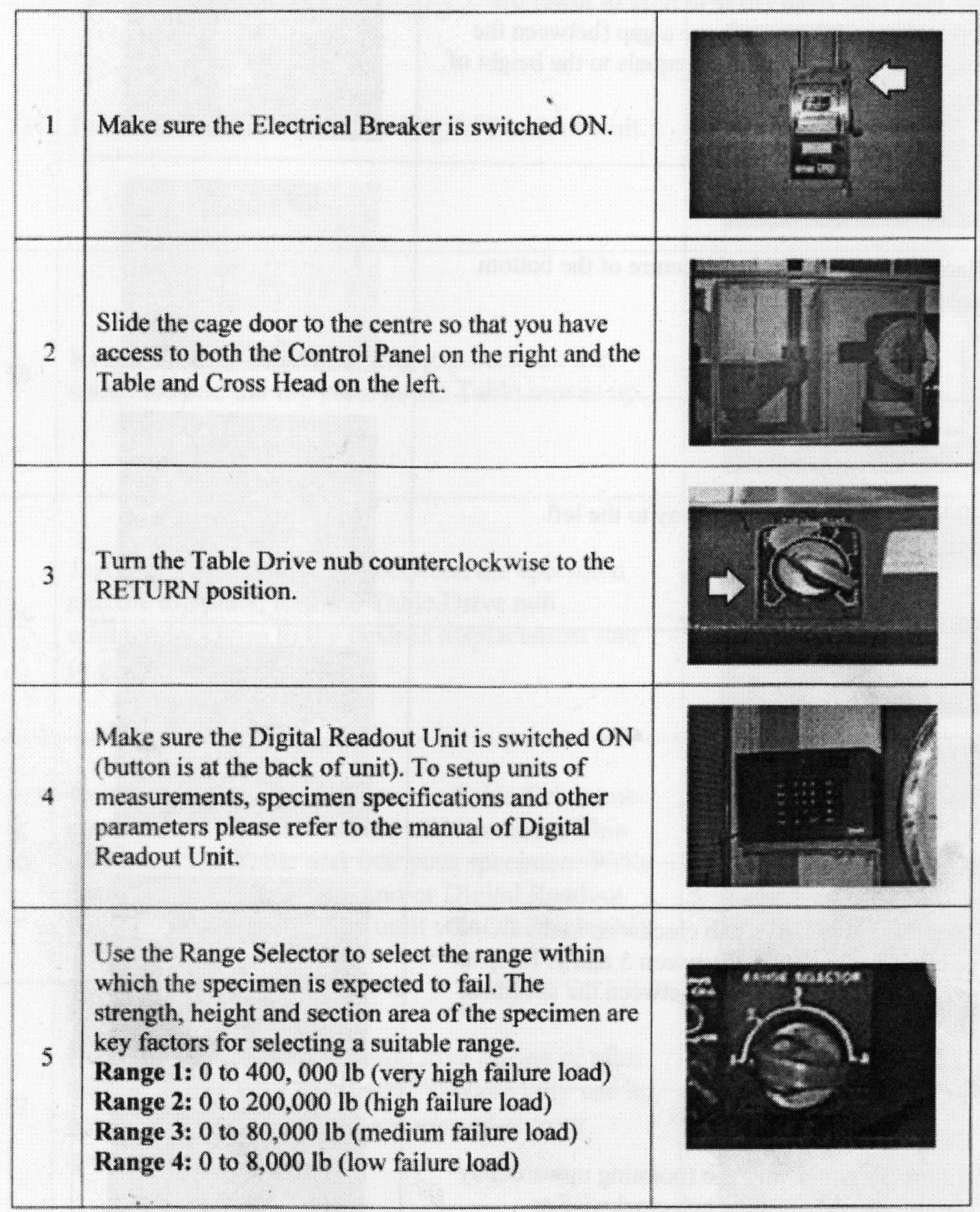




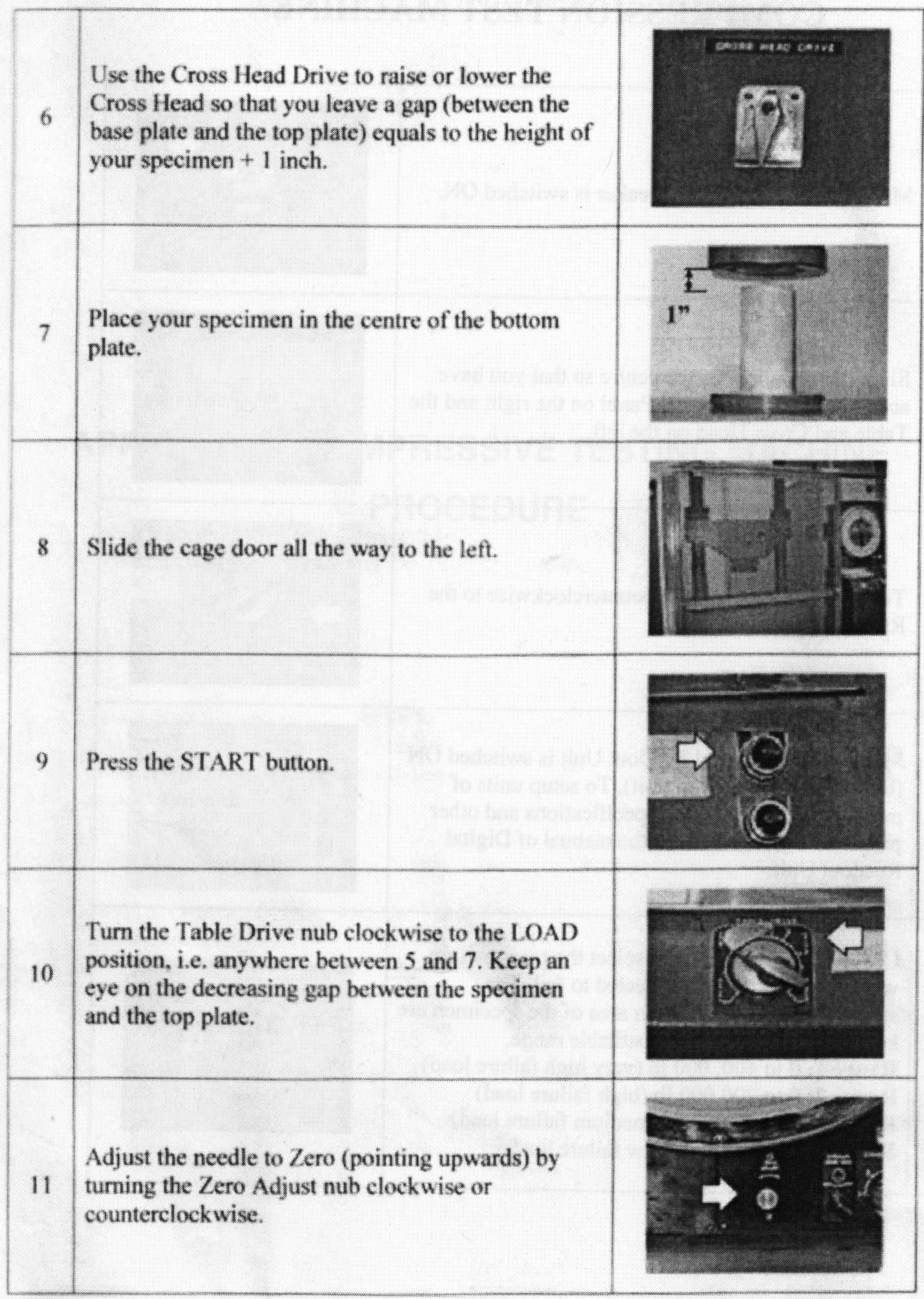




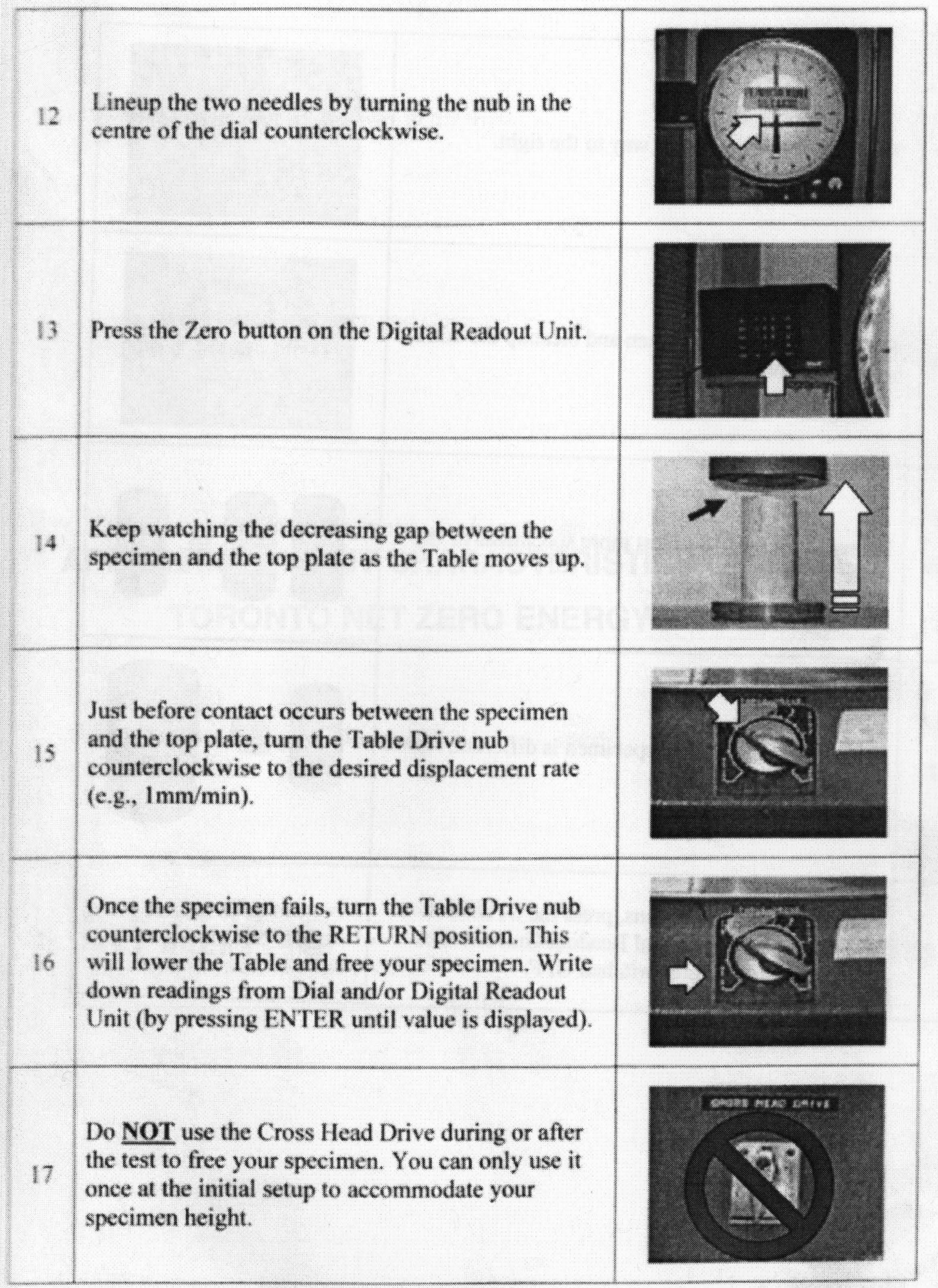







APPENDIX D: INPUT CHARACTERISTICS OF THE SUI TORONTO NET ZERO ENERGY MODEL 


\section{NZEHH Project Characteristics}

- The development in a new build of 3 townhouse units

- The site area is 0.0402 Hectares $\left(402 \mathrm{~m}^{2}\right)$

- The site is in an urban location in downtown Toronto

- The lot is serviced

- There are 3 housing units on the site

- The housing units are townhouses with flexi living space that can allow for an separate apartment

- Each of the three units can have from 2 to 4 bedrooms depending on configuration

- The ownership will be simple condominium structure

\section{NZEHH Unit Characteristics for a typical unit}

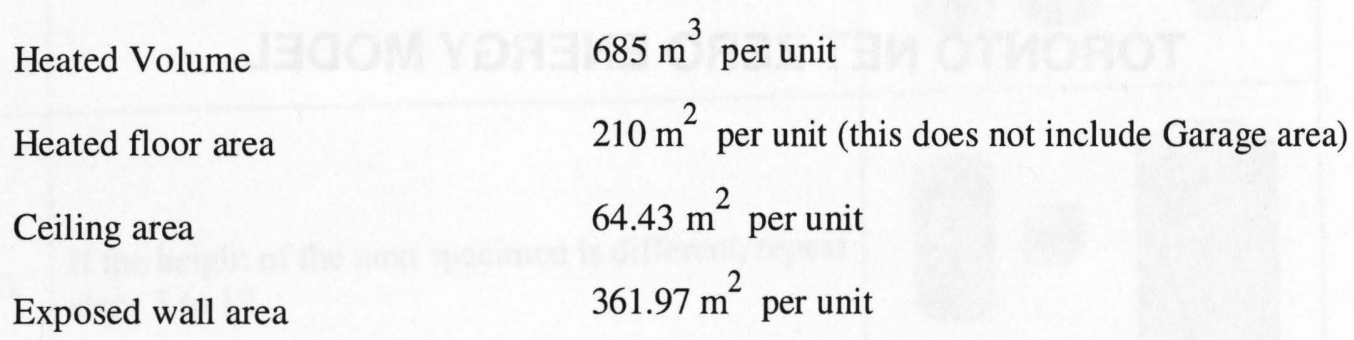

Glazing area (normalized the window areas in NW,NE,SW,SE directions using sin45)
North $23.2 \mathrm{~m}^{2}$
South $33.6 \mathrm{~m}^{2}$
East $26.48 \mathrm{~m}^{2}$
West $30.34 \mathrm{~m}^{2}$

South glazing to floor ratio $16 \% \quad(33.6 / 210 \times 100 \%)$

Air tightness $\quad 0.5 \mathrm{ACH} @ 50 \mathrm{~Pa}$

Thermal characteristics (nominal)

Roof RSI

$13.6 \mathrm{~m}^{2} \mathrm{~K} / \mathrm{W}$

Above grade wall RSI

$10.8 \mathrm{~m}^{2} \mathrm{~K} / \mathrm{W}$

Below grade wall RSI

$10.8 \mathrm{~m}^{2} \mathrm{~K} / \mathrm{W}$

Window RSI

$0.71 \mathrm{~m}^{2} \mathrm{~K} / \mathrm{W}$

Exposed floor RSI

$12.0 \mathrm{~m}^{2} \mathrm{~K} / \mathrm{W}$

Below grade slab RSI

$3.6 \mathrm{~m}^{2} \mathrm{~K} / \mathrm{W}$ 
Zone Characteristics and PCM quantities:

\begin{tabular}{|l|l|l|l|l|}
\hline $\begin{array}{l}\text { Part of the } \\
\text { house }\end{array}$ & $\begin{array}{l}\text { Total Floor } \\
\left.\text { Area } \mathbf{( m}^{\mathbf{2}}\right)\end{array}$ & $\begin{array}{l}\text { Total Wall } \\
\text { Surface } \\
\text { Area }\left(\mathbf{m}^{\mathbf{2}}\right)\end{array}$ & $\begin{array}{l}\text { Total Zone } \\
\text { Volume } \\
\left(\mathbf{m}^{\mathbf{3}}\right)\end{array}$ & $\begin{array}{l}\text { Total Mass } \\
\text { of PCM } \\
\text { used } \mathbf{( k g}) \\
\text { Assuming } \\
\mathbf{2 0 \%} \text { PCM }\end{array}$ \\
\hline Garage & 9.71 & 41.43 & 26.22 & $\begin{array}{l}\text { No PCM } \\
\text { used }\end{array}$ \\
\hline $1^{\text {st }}$ Floor & 86.87 & 138.21 & 173.5 & 349.67 \\
\hline $2^{\text {nd }}$ Floor & 58.70 & 103.54 & 172.45 & 261.96 \\
\hline $\begin{array}{l}\text { Mezzanine } \\
\text { Floor }\end{array}$ & 26.24 & 98.44 & 118.93 & 249.05 \\
\hline $3^{\text {rd }}$ Floor & 95.32 & 187.31 & 267 & 473.89 \\
\hline
\end{tabular}

\section{Energy Sources}

- A ECONAR GeoSource $2000 \mathrm{GW} / 360 / 361$ ground source heat pump for heating and cooling

- Thermodymanics SB64-9PV Solar DHW system for hot water energy delivered yearly is $1.41 \mathrm{MWh} / \mathrm{yr}$.

- Sharp NT-185U1 Photo-voltaic modules for electricity with the array tilted at $20^{\circ}$ and at an azimuth of $37^{\circ}$ West of South, the annual energy production of the system is 6.6 $\mathrm{MWh} / \mathrm{yr}$.

- Mechanical ventilation rate $65 \mathrm{~L} / \mathrm{s}$

\section{Renewable energy systems}

- PV Array $-44 \mathrm{~m}^{2}$ of Sharp NT-185U1 modules (14.2\% efficiency)

- Solar Domestic Hot Water $-6 \mathrm{~m}^{2}$ Thermodymanics SB64-9PV

- Ground source heat pump - Enconar GeoSource $2000 \mathrm{GW} / 360 / 361$ with a $8.42 \mathrm{~kW}$ capacity and 4.23 COP Heating efficiency. and 4.92 COP Cooling efficiency

- PV Array $-44 \mathrm{~m}^{2}$ of Sharp NT-185U1 modules (14.2\% efficiency)

- HRV - Vanee HRV 2000HEHigh Efficiency Heat Recovery Ventilator which is a 200 CFM - HRV Unit. 
Health, Resources, Environmental Impact and Affordability

\section{Water Statistics}

- Annual potable water use $=10,000$ Litres (ignoring benefits of grey water recycling system which may save $25 \%-30 \%$ if implemented).

- Annual grey water use $=3,000$ Litres if implemented

\section{Appliances}

\begin{tabular}{|l|l|l|l|}
\hline Type of Appliance & $\begin{array}{l}\text { Default Energy } \\
\text { Consumption } \\
\text { for base design } \\
\text { (kWh/year) }\end{array}$ & Appliance Model & $\begin{array}{l}\text { Specific Energy } \\
\text { Consumption } \\
\text { (kWh/year) }\end{array}$ \\
\hline Refrigerator & 537 & GE Monogram 48" & 592 \\
\hline Stove & 758 & Frigidaire BFEF323C* & 438 \\
\hline Clothes Washer & 802 & Whirlpool WFW8500SR & 152 \\
\hline Freezer & 573 & See refrigerator & 0 \\
\hline Dishwasher & 615 & Asko D3531 & 194 \\
\hline Total & $\mathbf{3 , 2 8 5}$ & & $\mathbf{1 , 3 7 6}$ \\
\hline
\end{tabular}

External uses are $4 \mathrm{kWh} /$ day by default $(1,460 \mathrm{kWh} / \mathrm{y})$, of which a good part is the clothes dryer, the rest being external and garage lighting, garage door openers, and well pumps. In our case, external uses are very limited because of the urban environment and the absence of outdoor space (e.g. yard). They can be estimated as:

Lighting: 6 hours times $30 \mathrm{~W}$ (for CFLs, possibly with motion sensor) $=180 \mathrm{Wh}$; Garage door opener: 6 times 15 seconds times $1 / 2 \mathrm{hp}=9 \mathrm{Wh}$;

Standby losses of the garage door opener are between 1.6 and $10.8 \mathrm{~W}$ with an average of $4 \mathrm{~W}$, leading to a daily use of $94 \mathrm{Wh} /$ day.

Other uses (power tools, etc.) $=$ estimated at $100 \mathrm{Wh} /$ day.

Dryer: Total annual energy consumption of $537 \mathrm{kWh} / \mathrm{yr}$ or $1.47 \mathrm{kWh} /$ day 


\section{APPENDIX E: CLIMATE CHARACTERISTICS OF TORONTO,ON}




\section{Toronto Site and Climate Characteristics}

Altitude $\quad 113 \mathrm{~m}$

Latitude $\quad 43^{\circ} 40^{`} \mathrm{~N}$

Longitude $79^{\circ} 24^{`} \mathrm{~W}$

Average daily insolation

Horizontal:

$1.30 \mathrm{kWh} / \mathrm{m}^{2}$

Vertical:

$0.99 \mathrm{kWh} / \mathrm{m}^{2}$

Clearness Index $(\mathrm{Kt})$ :

$\sim 0.46$

Average annual precipitation:

$834 \mathrm{~mm}$

Average annual wind speed:

$4.0 \mathrm{~m} / \mathrm{s}$

ASHRAE Design Temperatures (ASHRAE Handbook, 2005)

99\% heating dry bulb:

$-16.7^{\circ} \mathrm{C} \quad$ (January)

$1 \%$ cooling dry bulb:

$28.9^{\circ} \mathrm{C}$

(July)

\section{Degree-days}

Heating degree days (base $\left.18^{\circ} \mathrm{C}\right)=3570$

Cooling degree days (base $\left.18^{\circ} \mathrm{C}\right)=359$

Typical winter day (Feb $\mathbf{1}^{\text {st }}$ ) ambient temperature profile for Toronto

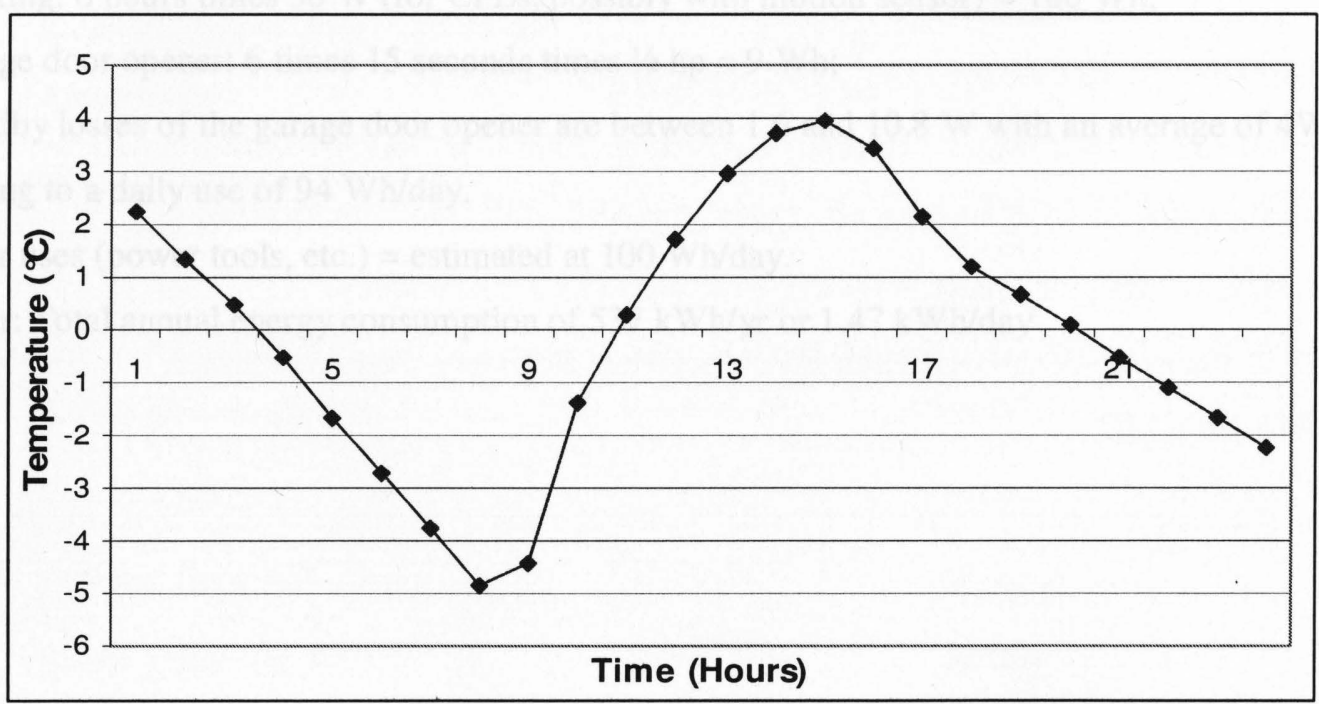


Typical winter week (Feb $1^{\text {st }}-\mathrm{Feb} 7^{\text {th }}$ ) ambient temperature profile for Toronto

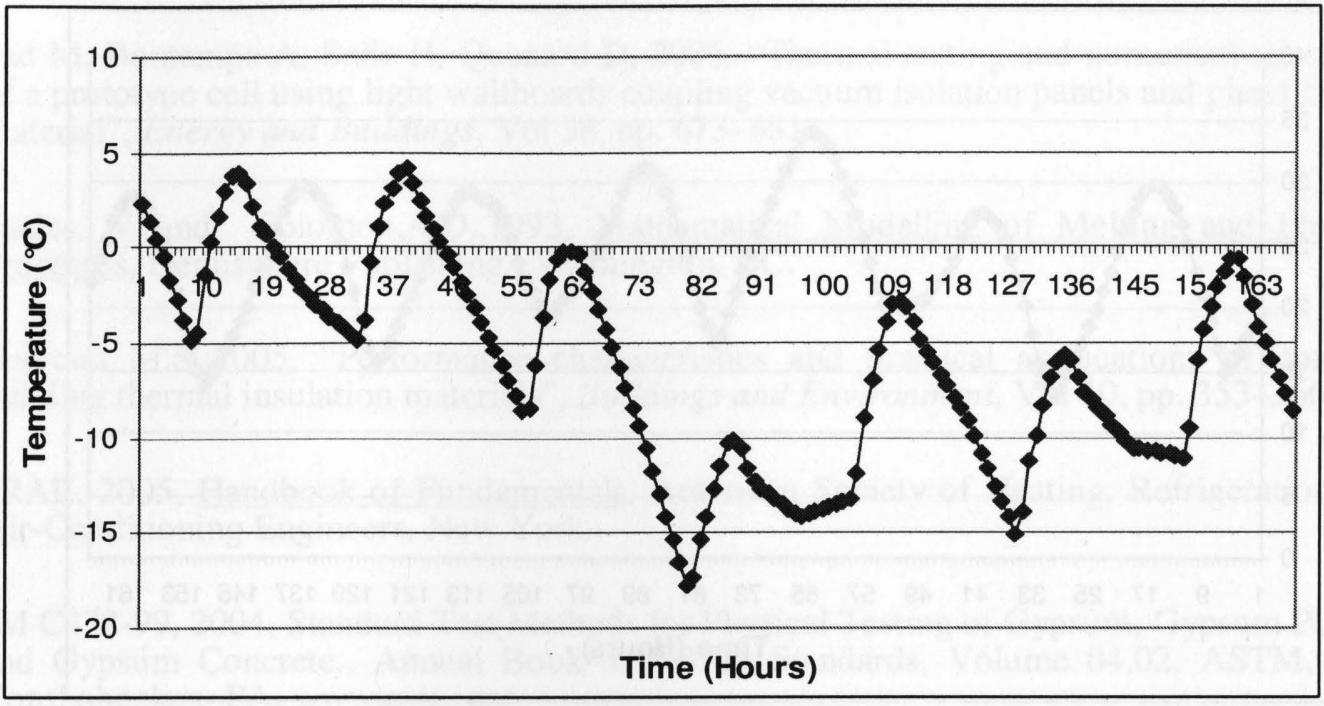

Typical summer day $\left(\mathrm{Jul} 15^{\text {th }}\right)$ ambient temperature profile for Toronto

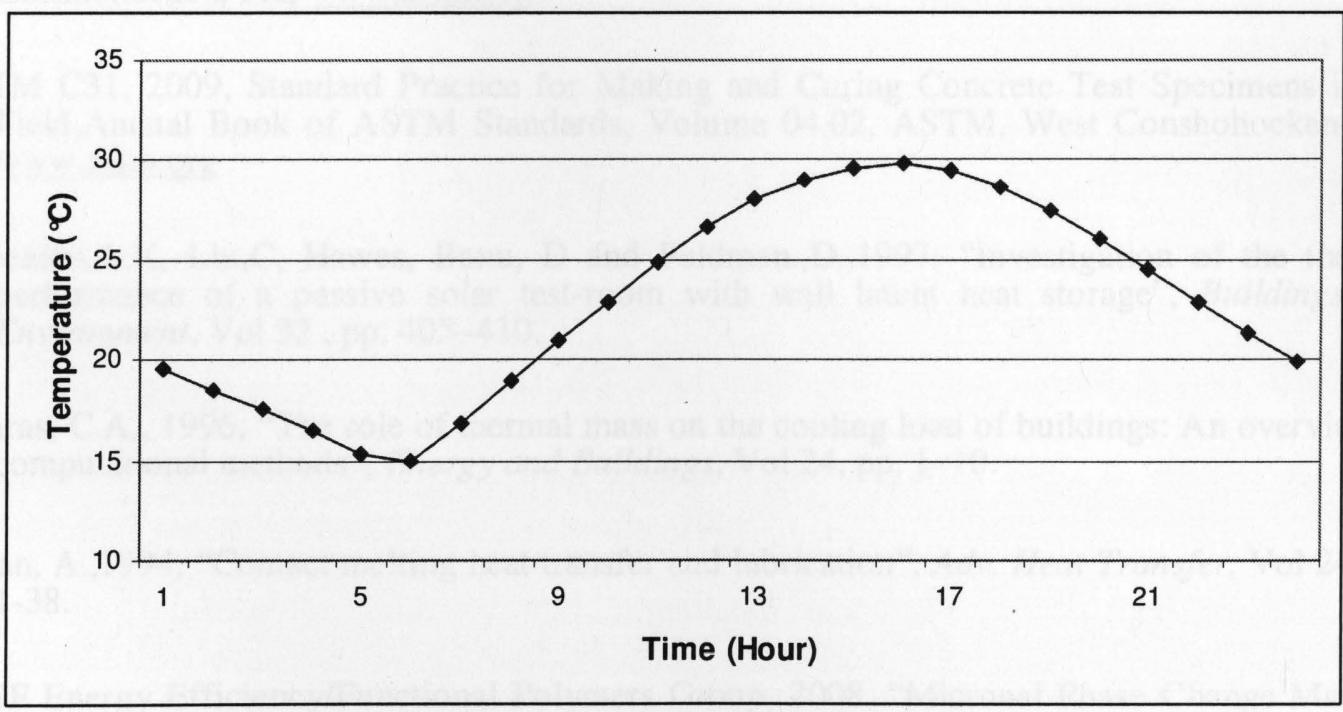


Typical summer week (Jul $15^{\text {th }}-\mathrm{Jul} 21^{\text {st }}$ ) ambient temperature profile for Toronto

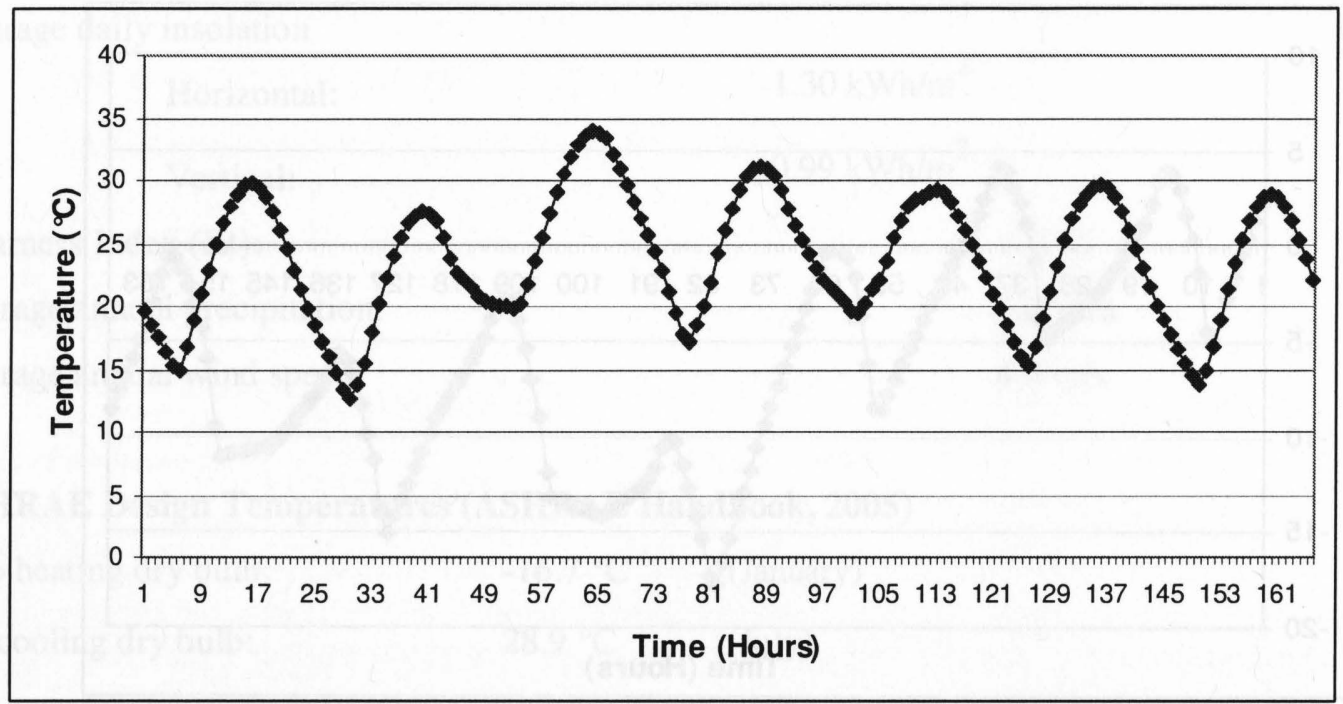




\section{REFERENCES}

Abhat, A.,1981, "Short Term Thermal Energy Storage”, Energy and Buildings, Vol.3, pp.49 76.

Ahmad M, Bontemps A, Salle H, Quenard D, 2006, "Thermal testing and numerical simulation of a prototype cell using light wallboards coupling vacuum isolation panels and phase change material", Energy and Buildings, Vol 38, pp. 673-681.

Alexiades, V and Solomon,A.D.,1993, Mathematical Modelling of Melting and Freezing Processes, Hemisphere Publishing, Washington, DC.

Al-Homoud M.S.,2005, "Performance characteristics and practical applications of common building thermal insulation materials", Buildings and Environment, Vol 40, pp. 353-366.

ASHRAE, 2005, Handbook of Fundamentals, American Society of Heating, Refrigeration, and Air-Conditioning Engineers, New York..

ASTM C472-99, 2004, Standard Test Methods for Physical Testing of Gypsum, Gypsum Plasters and Gypsum Concrete., Annual Book of ASTM Standards, Volume 04.02, ASTM, West Conshohocken, PA, www.astm.org.

ASTM C78, 2008, Standard Test Method for Flexural Strength of Concrete (Using Simple Beam with Third-Point Loading), Annual Book of ASTM Standards, Volume 04.02, ASTM, West Conshohocken, PA, www.astm.org

ASTM C31, 2009, Standard Practice for Making and Curing Concrete Test Specimens in the Field,Annual Book of ASTM Standards, Volume 04.02, ASTM, West Conshohocken, PA, www.astm.org

Athienitis,A.K, Liu,C, Hawes, Banu, D and Feldman.,D.,1997, "Investigation of the thermal performance of a passive solar test-room with wall latent heat storage", Buildings and Environment, Vol 32 , pp. 405-410.

Balaras, C.A., 1996, "The role of thermal mass on the cooling load of buildings: An overview of computational methods", Energy and Buildings, Vol 24, pp. 1-10.

Bejan, A.,1994, "Contact melting heat transfer and lubrication”, Adv. Heat Transfer, Vol 24, pp. $1-38$.

BASF Energy Efficiency/Functional Polymers Group, 2008, "Micronal Phase Change Material (PCM)",<http://www.micronal.de/portal/basf/ien/dt.jsp?setCursor=1_290823>.

Bonacina, C, Comini, G, Fasano,A and Primicerio, M.,1973, "Numerical solution of phasechange problems", Int. J. Heat Mass Transfer, Vol 16, pp. 1825-1832. 
Boresi, A.P, Schmidt, R. J. and Sidebottom, O. M., 1993, Advanced Mechanics of Materials, Wiley Publishing.

Brown M., 1990, "Optimization of thermal mass in commercial building applications", ASME J. Sol. Energy Eng., Vol 112, pp.273-279.

Buddhit, D, Sawhney, R.L, Sehgal, P.N and Bansal, N.K., 1987, "A simplification of the differential thermal analysis method to determine the latent heat of fusion of phase change materials", J. Phys. D: Appl. Phys, Vol 20, pp.1601-1605.

Callister W.D. Jr., 2003, Materials Science \& Engineering an Introduction, $6^{\text {th }}$ Edition, John Wiley \& Sons. U.S.A

Costa, M, Buddhi, D and Olivia, A.,1998 "Numerical simulation of latent heat thermal energy storage system with enhanced heat conduction", Energy Convers. Mgmt. Vol 39, pp. 319330.

Darkwa, K and Kim, J.,2005, "Dynamics of energy storage in phase change drywall systems", International Journal of energy research, Vol 29, pp 335-343.

Darkwa, K, O'Callaghan,P.W and D. Tetlow., 2006, "Phase-change drywalls in a passive-solar building", Applied Energy, Vol 83, pp. 425-435.

Darkwa, K and P.W. O'Callaghan, 2006, "Simulation of phase change drywalls in a passive solar building", Applied Thermal Eng., Vol 26, pp. 853-858.

Department of Chemistry, Colby College, 2008, "Differential Scanning Calorimetry", http://www.colby.edu/chemistry/PChem/notes/DSCalor.pdf.

Doshi, N., Furman, M., Rudman, R.,1973, "Formation of plastic crystal phase in several pentaerythritol derivatives"., Acta Crystallographica. Section B, Structural Science, Vol 29, pp 143-144.

Drake J.B., 1987, "A study of the optimal transition temperature of PCM wallboard for solar energy storage", Oak Ridge National Laboratory report ORNL/TM-10210 available from National Technical Information Service, Springfield, VA, USA.

Environment Canada Weather Office, 2009, Statistics on Climate Averages and Normals, $<$ http://www.weatheroffice.com>.

Feldman, D., D. Banu.,1991, "Obtaining An Energy Storing Building material by direct incorporation of an organic hase change material in gypsum wallboard", Solar Energy Materials, Vol 22 pp. 231-242.

Fifield, F. W.; Kealey, D., 2000, Principles and Practice of Analytical Chemistry, Oxford, Malden, Mass. Blackwell Science publishing.

Floridesa, G.A., Tassoub, S.A., Kalogirou, S.A and Wrobelb, L.C., 2002, "Measures used to lower building energy consumption and their cost effectiveness", Applied Energy, Vol 73, pp. 299-328. 
Fuestel, H and Stetiu C, 1997., "Thermal Performance of Phase-Change Wallboard for Residential Cooling”. Center for Building Science News, p.6, Fall 1997.

Gao, W, Lin, W, Lin, T, Xia, C.,2007, "An experimental study on the heat storage performances of polyalcohols NPG,TAM,PE and AMPD and their mixtures as solid-solid phase change materials", International Journal of Green Energy, Vol 4, pp.301-311.

Gregory K, Moghtaderi B, Sugo H and Page A., 2008, "Effect of thermal mass on the thermal performance of various Australian residential constructions systems", Energy and Buildings, Vol 40, pp. 459-465.

Groulx, D and Lacroix, M., 2007, "Study of the effect of convection on close contact melting of high Prandtl number substances", Int. J. Thermal Sci, Vol 46, pp 213-220.

Hasan, A, Sayigh, A.,1994, "Some Fatty Acids as Phase-Change thermal energy storage materials", Renewable energy, Vol 4, pp.69-76.

Hasnain, S.M.,1998, "Review on sustainable thermal storage technologies, Part I: Heat storage materials and techniques”, Energy Conversion Management, Vol 39, 1127-1138.

Hawes, D.W, Feldman D and Banu D, 1993, "Latent heat storage in building materials", Energy and Buildings, Vol 20 pp.77-86.

Hawes, D.W , Banu, D and Feldman, D, 1989, "Latent heat storage in concrete ", Solar Energy Materials, Vol 19, pp.335-348.

Hawes, D.W. , Banu, D and Feldman, D., 1990, "Latent heat storage in concrete II" ,Solar Energy Materials, Vol 21, pp. 61-80.

He, B , Setterwall, F., 2002, "Technical grade paraffin waxes as phase change materials for cool thermal storage and cool storage systems capital cost estimation", Energy Conversion and Management, Vol 43, pp.1709-1723.

Heim, D., 2005, "Two Solution Methods of Heat Transfer with Phase Change within whole Building Dynamic simulation", Ninth International IBPSA Conference proceedings, Aug $15^{\text {th }}-18^{\text {th }}, 2005$, Montreal, Canada.

Hittle, D.C., 2002, "Phase Change Materials in Floor Tiles for Thermal Energy Storage", Technical report, Colorado State University, 2002.

Ibanez , M, Lazaro A, Zalba B and Cabeza L.F., 2005, "An approach to the simulation of PCM in building applications using TRNSYS”, Applied Thermal Engineering, Vol 25, pp.17961807.

Jokisalo J, Lamberg P and.Siren K., 1999, "Suitability of Building Construction Materials in Short-term Energy Storage, Part 2: Thermal Simulation of Phase Change Materials in Concrete Products", Helsinki University of Technology, HVAC-laboratory, Report B64, 1999. 
Kalogirou S.A, Florides G., Tassoub S., 2002, "Energy analysis of buildings employing thermal mass in Cyprus", Renewable Energy, Vol 27, pp.353-368.

Kalousck, M and Hirs, J., 2002, "Simulation of the summer indoor thermal comfort by using wallboard with phase change material", Eurosun Conference, Bologna, Italy, Jun 2002.

Kaygusuz, K., 1995, "Experimental and Theoretical Investigation of Latent Heat Storage for Water Based Solar Heating systems", Energy Conversion Management, Vol 36, pp.315-323.

Kedl R.J, Stovall T.K., 1989, "Activities in support of the wax-impregnated wallboard concept" US Department of energy thermal energy storage researches activity review, New Orleans, LA, USA.

Khudhair, A,Farid, M.A., 2004, "A review on energy conservation in building applications with thermal storage by latent heat using phase change materials", Energy conservation and Management, Vol 45, pp.263-275.

Klein S.A., Beckman W.A., Mitchel J.W., Duffie J.A., Duffie N.A and Freeman T.L., 1998, "TRNSYS manual", University of Wisconsin.

Kosmatka, S, Kerhoff, B, Panarese, W, McLeod, N and Mcgrath, R., 2002, Design and Control of Concrete Mixtures, $17^{\text {th }}$ Canadian Edition, Cement Association of Canada.

Lamberg, P, Lehtiniemi, R and Henell, A.M., 2004, "Numerical and experimental investigation of melting and freezing processes in phase change material storage", Int. J. Thermal Sci, Vol 43 , pp. $277-287$.

Lamberg P, 2003, "Mathematical Modelling and Experimental Investigation of Melting and Solidification in a Finned Phase Change Material Storage" Technical Report, Helsinki University of Technology. Department of Mechanical Engineering.

Mehling, $\mathrm{H}$ and Cabeza, L.F., 2008, Heat and cold storage with PCM: An up to date introduction into basics and applications, Springer Press, Berlin.

McQuiston, F, Parker D, Spitler, J., 2004, Heating, Ventilating and Air Conditioning Analysis and Design, 6th ed, John Wiley and Sons Inc.

Murrill, E , Breed, L. W., 1970, "Solid--solid phase transitions determination by differential scanning calorimetry : Part II. Octahedral substances", Thermochimica Acta, Volume 1, Issue 4, Pages 409-414.

Nakano,E, Hirotsu, K., Shimada, A.,1969, "Crystal structures of pentaglycerol and neopentylglycol”, Bulletin of the Chemical Society of Japan, Vol 42, pp.3367-3367.

National Resources Council of Canada, 2007, “Twin Research Houses”, http://www.cchtcctr.gc.ca/twinhouses e.html.

Neeper, D. 1990, "Benefits of Wallboard Impregnated With Phase-Change Material for Residential Heating and Cooling", subcontract report to Solar Energy Research Institute, . 
NSERC Solar Buildings Research Network (SBRN), 2008, "Objectives", $<$ http://www.solarbuildings.ca>.

Ogoli D.M., 2003, "Predicting indoor temperatures in closed buildings with high thermal mass", Energy and Buildings, Vol 35, pp.851-862.

Ontario energy Board, 2008, "Time of use pricing for smart meters", $<$ http://www.oeb.gov.on.ca/html/en/consumers/energyoptions/fs timeofuse.htm>.

Peippo K., Kauranen P., Lund P., 1991, "A Multicomponent PCM Wall Optimized for Passive Solar Heating", Energy and Buildings, Vol 17, pp 259-270 .

Ruud M.D., Mitchell J.W.,Klein S.A., 1990, "Use of building thermal mass to offset cooling loads", ASHRAE Trans., Vol 96, pp.820-828.

Saito, A, Hong, H and Hirokane, O., 1992, "Heat transfer enhancement in the direct contact melting process”, Int. J. Heat Mass Transfer, Vol 35, pp. 295-305.

Schossig, P, Henning, H.M, Haussmann, T. Fraunhofer-Institute for Solar Energy Systems ISE, "Microencapsulated Phase Change Materials integrated into construction materials", Solar Energy Materials and Solar cells, Vol 89, pp.297-306.

Shapiro, M., D. Feldman, D. Hawes, D. Banu., 1987, "P.C.M. Thermal Storage In Drywall Using Organic Phase-Change Material", Passive Solar Journal, Vol 4, pp.419-438.

Shapiro,M.M, Feldman D, Hawes D, Banu D., 1987, "PCM thermal storage in wallboard" Proceedings of the 12th passive solar conference, Portland,OR, 1987, p. 48-58.

Sharma, A, Tyagi, V, Chen, C.R, Buddhi, D., 2009, "Review on thermal energy storage with phase change materials and applications, Renewable and Sustainable Energy Reviews, Vol 13, pp.318-345.

Sharma, S, Kitano, H and Sagara, K., 2004, "Phase Change Materials for Low Temperature Solar Thermal Applications", Res. Fac. Eng. Mie Univ., Vol. 29, pp. 31-64.

Shaw M.R., Treadaway K.W.and Willis S.T., 1994, "Effective use of building mass", Renewable Energy, Vol 5, pp.1028-1038.

Simmonds P.,1991, "The utilisation and optimisation of building's thermal inertia in minimising the overall energy use", ASHRAE Trans, Vol 97, pp.1031-42.

Stoval, T. and Tomlinson, J., 1991, "Potential Benefits of Including latent Storage in common wallboard", Proceedings of the $26^{\text {th }}$ Intersociety Energy Conversion Engineering Conference, Boston,1991.

Sustainable Urbanism Initiative Toronto.,2006,"Net Zero Energy House Report" $<$ http://www.sui-toronto.com>.

TRNSYS and Solar Energy Laboratory, 2004, University of Wisconsin-Madison, "TRNSYS User Manual" Version 16.0. 
Trp,A., 2005, “An experimental and numerical investigation of heat transfer during technical grade paraffin melting and solidification in a shell-and-tube latent thermal energy storage unit", Solar Energy, Volume 79, pp.648-660.

Tyagi, V, and Buddhi.D.,2005, "PCM thermal storage in buildings: A state of art", Renewable and Sustainable Energy Reviews, Vol 11, pp.1146-66.

Van Oort, M.J.M, White, M.A., 1988, "Polymorphism in Dialkylammonium Chlorides. An Adiabatic Calorimetric Study", Berichte der Bunsen-Gessellschaft fur physikalische Chemie, Vol 92, pp.168-176.

Voller, V and Cross, M., 1981, "Accurate Solutions of moving boundary problems using the enthalpy method", Int. J. Heat Mass Transfer Vol 24, pp.545-556.

Wirtz, A, Zheng, N and Chandra, D., 1999, "Thermal Management using dry phase change materials", Proc. Fifteenth IEEE Semiconductor Thermal Measurement and Management Symposium,1999, San Diego, CA.

Yoo,H, Hong, H and Kim,C.J.,1998, "Effect of transverse convection and solid-liquid density difference on the steady close-contact melting", Int. J. Heat Fluid Flow, Vol 19, pp.368-373.

Zalba, B, Ma Marına, J, Cabeza ,L.F, and Mehling, H., 2003, "Review on thermal energy storage with phase change materials: Heat Transfer analysis and applications", Applied Thermal Engineering, Vol 23 pp.251-83.

Zhang, D, Fung, A.S, Siddiqui, O., 2007, "Numerical Studies of Integrated Concrete with a Solid-Solid Phase Change Material", Proceedings of the $2^{\text {nd }}$ Annual Solar Building Network conference, Calgary, AB, 2007. 
